Maestría en Manejo Integral de Cuencas Hidrográficas.

Tesis de Post-grado.

\title{
Efecto de la restauración agro-hidrológica sobre el escurrimiento superficial en la Sierra de Pillahuinco.
}

Autor: Rodríguez Vagaría, Alfonso Martín

Expediente $N^{o}$ 200-2871/07

Directora: Dra Gaspari, Fernanda J.

Codirector: Dr. Kruse, Eduardo E. 


\section{INDICE}

RESUMEN

INTRODUCCIÓN

ANTECEDENTES DE LA CUENCA DEL ARROYO PILLAHUINCO GRANDE ..... 4

HIPÓTESIS DE TRABAJO

OBJETIVO GENERAL

OBJETIVOS ESPECÍFICOS

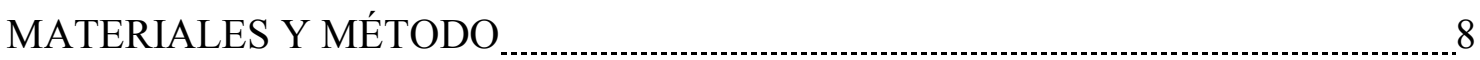

1. Delimitación del área de estudio

2. Caracterización del área serrana de la cuenca del Arroyo Pillahuinco Grande $\ldots 10$

2.1. Caracterización morfométrica

2.1.1. Parámetros de forma

2.1.2. Parámetros de relieve

2.1.3. Parámetros relativos a la red hidrográfica

2.2. Caracterización climática.

2.2.1. Precipitación.

2.2.2. Temperatura.

2.2.3. Balance hidrológico medio mensual

2.2.4. Clasificación climática.

2.2.5. Análisis de Precipitaciones.

2.2.6. Ajuste de precipitaciones máximas diarias a la ley de Gumbel.

2.2.7. Test de bondad de ajuste

2.2.8. Determinación del Período de retorno

2.2.9. Selección de tormentas

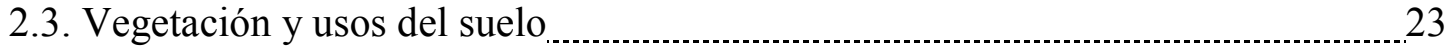

2.4. Suelos

3. Cartografía temática digital de la condición actual $\quad 24$

3.1. Cartografía de primer orden

3.1.1. Drenaje

3.1.2. Cuenca y subcuencas

3.1.3. Vegetación y usos del suelo.

3.1.4. Suelos

3.2. Cartografía de segundo orden 26

3.2.1. Rangos de pendiente

3.2.2. Orientación de laderas

3.2.3. Grupos hidrológicos

3.3. Cartografía de tercer orden 25

3.3.1. Número de curva

4. Descripción del método de transformación de lluvia-escorrentía. _.......................... 26

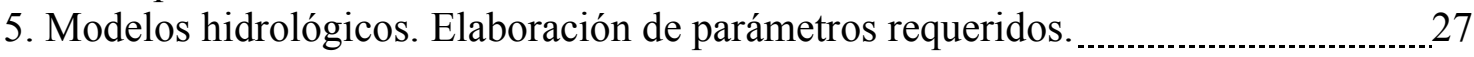

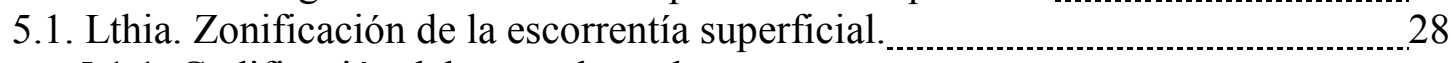

5.1.1. Codificación del mapa de suelos.

5.1.2. Codificación del mapa de vegetación y usos del suelo.

5.1.3. Adaptación de los valores de NC.

5.2. Hec Hms. Generación de hidrogramas. 
5.2.1 Modelo de Cuenca.

5.2.2. Modelo Meteorológico.

5.2.3. Especificaciones de Control.

6. Medidas de restauración agro-hidrológica

7. Análisis comparativo de la respuesta del escurrimiento superficial de la

condición actual y restaurada 34

RESULTADOS 35

1. Delimitación del área de estudio $\quad 35$

2. Caracterización del área serrana de la cuenca del Arroyo Pillahuinco Grande _.......... 39

2.1. Caracterización morfométrica

2.1.1. Parámetros de forma

2.1.2. Parámetros de relieve

2.1.3. Parámetros relativos a la red hidrográfica

2.2. Caracterización climática.

2.3. Vegetación y usos del suelo2.2.1. Precipitación.

2.2.2. Temperatura.

2.2.3. Balance hidrológico medio mensual

2.2.4. Clasificación climática.

2.2.5. Análisis de Precipitaciones.

2.2.6. Ajuste de precipitaciones máximas diarias a la ley de Gumbel.

2.2.7. Test de bondad de ajuste

2.2.8. Determinación del Período de retorno

2.2.9. Selección de tormentas

2.4. Suelos 60

3. Cartografía temática digital de la condición actual $\quad 62$

3.1. Cartografía de primer orden

3.1.1. Drenaje

3.1.2. Cuenca y subcuencas

3.1.3. Vegetación y usos del suelo.

3.1.4. Suelos

3.2. Cartografía de segundo orden 66

3.2.1. Rangos de pendiente

3.2.2. Orientación de laderas

3.2.3. Grupos hidrológicos

3.3. Cartografía de tercer orden

3.3.1. Número de curva

4. Modelos hidrológicos. Elaboración de parámetros requeridos. 72

4.1. Lthia. Zonificación de la escorrentía superficial.

4.1.1. Codificación del mapa de suelos.

4.1.2. Codificación del mapa de vegetación y usos del suelo.

4.1.3. Adaptación de los valores de NC.

4.2. Hec Hms. Generación de hidrogramas.

4.2.1 Modelo de Cuenca.

4.2.2. Modelo Meteorológico.

4.2.3. Especificaciones de Control.

4.3. Zonificación de la escorrentía superficial.

4.4. Generación de hidrogramas. 84

5. Medidas de restauración agro-hidrológica $\ldots$

5.1. Caracterización de las propuestas. 86 
5.2. Cartografía

5.2.1. Mapa de vegetación y usos del suelo propuesto.

5.2.2. Mapa de Número de curva propuesto.

5.3. Elaboración de parámetros requeridos por los modelos. 94

5.3.1. Modelo Lthia.

5.3.2. Modelo Hec Hms.

5.4. Zonificación de la escorrentía superficial. $\ldots \ldots$

5.5. Generación de hidrogramas.

6. Análisis comparativo de la respuesta del escurrimiento superficial de la condición actual y restaurada. 102

CONCLUSIONES

DEDICATORIA

AGRADECIMIENTOS

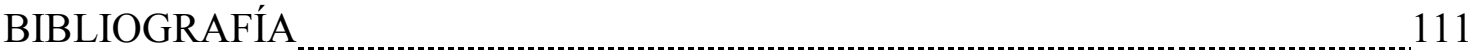

ANEXO 1: TABLAS 


\section{RESUMEN}

La cuenca hidrográfica según FAO/RLAC (1998), es una unidad territorial formada por un río con sus afluentes y por un área colectora de las aguas. En la cuenca están contenidos los recursos naturales básicos para las múltiples actividades humanas, como agua, suelo, vegetación y fauna. Todos mantienen una continua y particular interacción entre ellos y con los aprovechamientos y desarrollos productivos del hombre. El manejo inadecuado de los recursos naturales origina problemas que afectan seriamente la capacidad productiva de los sistemas agropecuarios y finalmente repercuten a mediano y largo plazo en la calidad de vida de los habitantes. Desde un punto de vista hidrográfico, el área de estudio, corresponde a la cabecera de la cuenca del Arroyo Pillahuinco Grande perteneciente al partido de Coronel Pringles, provincia de Buenos Aires. Esta área, posee gran influencia sobre los caudales que circulan por el cauce, ya que las características particulares de sus suelos, vegetación y topografía, ligados al uso del territorio determinan que gran parte de la precipitación pluvial se transforme en escorrentía. Los recursos que dispone el hombre para paliar la degradación ambiental, se encuentran en la ingeniería agro-hidrológica y medioambiental a través de los proyectos de restauración agro-hidrológica de las cuencas. Con la aplicación de medidas de control del agua superficial en el área serrana de la cuenca del Arroyo Pillahuinco Grande, se estaría aumentando el recurso hídrico disponible para los cultivos en épocas deficitarias, los caudales punta disminuirían y con ello el riesgo de inundación en la ciudad. La hipótesis del trabajo plantea que las prácticas de restauración agro-hidrológicas propuestas constituyen un método integral en el control del escurrimiento superficial. Para ello se propuso el objetivo general de determinar el efecto de la restauración agro-hidrológica sobre el escurrimiento superficial en el área serrana de la Cuenca del Arroyo Pillahuinco Grande. Teniendo como objetivos particulares: caracterizar ambientalmente el área serrana de la cuenca del Arroyo Pillahuinco Grande, elaborar una base de datos cartográfica temática digital para su potencial disponibilidad pública, modelizar la respuesta hidrológica del área serrana de la cuenca del Arroyo Pillahuinco Grande ante diferentes eventos de precipitación para la condición actual, proponer medidas de restauración agro-hidrológica coherentes con el tipo de producción actual tendientes a disminuir la escorrentía superficial, ajustar las medidas propuestas ante diferentes eventos de precipitación para la condición restaurada y comparar la respuesta del escurrimiento superficial según la condición actual y restaurada del área ante diferentes 
eventos de precipitación. Para abordar los objetivos se utilizaron diversas metodologías, basadas en el uso de información antecedente, toma de datos a campo y el procesamiento de los mismos a través de Sistemas de Información geográfica (SIG) y los modelos hidrológicos Lthia Gis NPS y Hec Hms, ambos basados en el método de transformación precipitación-escorrentía del Número de Curva elaborada por el Soil Conservation Service de los Estados Unidos. Los modelos permitieron establecer el funcionamiento hidrológico de la cuenca y sus subcuencas, obteniendo la zonificación espacial de la lámina de escorrentía, los hidrogramas caudales pico y volumen total de escorrentía para la condición actual y para las medidas propuestas, ante diferentes eventos de precipitación. La utilización de SIG permitió establecer medidas de restauración agro-hidrológica haciendo una evaluación multicriterio de las condiciones presentes en la cuenca. La comparación de los hidrogramas para la condición actual y restaurada ante los eventos de precipitación demuestra una marcada influencia de la morfometría sobre los volúmenes escurridos y los caudales picos. Una mayor disminución de los valores de lámina escurrida podría lograrse convirtiendo el pastizal serrano en bosques protectores, lo que trae aparejado, por un lado, una reducción del área con producción ganadera a niveles que pueden no poseer sustentabilidad económica y por otro, la disminución de la biodiversidad natural del ambiente. 


\section{INTRODUCCIÓN}

El manejo inadecuado de los recursos naturales origina problemas que afectan seriamente la capacidad productiva de los sistemas agropecuarios y finalmente repercuten a mediano y largo plazo en la calidad de vida de los habitantes.

La experiencia de gran cantidad de personas en todo el mundo, que desde hace años ha trabajado en encontrar soluciones a estos inconvenientes, ha demostrado que el enfoque más preciso para comprender y resolver dichas dificultades es tomando como unidad de gestión el "sistema cuenca" (García Nájera, 1962; Mintegui Aguirre y López Unzú, 1990).

La cuenca hidrográfica es una unidad territorial formada por un río con sus afluentes y por un área colectora de las aguas. En la cuenca están contenidos los recursos naturales básicos para las múltiples actividades humanas, como agua, suelo, vegetación y fauna. Todos mantienen una continua y particular interacción entre ellos y con los aprovechamientos y desarrollos productivos del hombre (FAO/RLAC, 1998).

El hombre, con sus acciones en el marco de una cuenca, puede provocar perturbaciones como erosión hídrica, pérdida de suelo y de su fertilidad y capacidad de producción, desertificación, contaminación, alteración del régimen hidrológico (agudización de sequías e inundaciones), cambios en la microflora y fauna de los suelos y aguas, variación en el nivel freático y reducción de la capacidad de regulación y almacenamiento de agua.

Desde un punto de vista hidrográfico, el área de estudio, corresponde a la cabecera de la cuenca del Arroyo Pillahuinco Grande perteneciente al partido de Coronel Pringles, provincia de Buenos Aires. Esta área, posee gran influencia sobre los caudales que circulan por el cauce, ya que sus características particulares de suelos, vegetación y topografía ligados al uso del territorio determinan que gran parte de la precipitación pluvial se transforme en escorrentía. Como resultado de ello, se producen grandes volúmenes de escorrentía, asociados a bajos tiempo de concentración que originan caudales pico de gran magnitud. La consecuencia directa se traduce principalmente, en el corto plazo, a través de inundaciones en la parte media y baja de la cuenca. En el largo plazo, por la disminución del potencial productivo tanto de la cabecera, por erosión hídrica superficial, como de las partes bajas donde se generan desbordes del cauce y se depositan los sedimentos.

Durante las últimas décadas el Partido de Coronel Pringles ha sufrido inundaciones por excesos hídricos provocando diferentes perjuicios según el área afectada. Como consecuencia de ello se han realizado obras de saneamiento en el cauce con el fin de conducir y evacuar rápidamente el agua de escorrentía.

Esta modalidad de saneamiento y/o canalización es una práctica habitual en toda la región pampeana, comprende el dragado de canales, ríos y arroyos y la construcción de canales que desvían los cursos de agua, de canales que drenan el agua de áreas anegables y una red de canales secundarios y prediales construidos por propietarios con el fin de evacuar el agua de terrenos inundables hacia la red de drenaje artificial o natural existente. 
En relación a este tipo de prácticas, F. Ameghino en 1884, escribe en su libro "Las secas y las inundaciones en la provincia de Buenos Aires":

"Aunque el entusiasmo es contagioso, no se me ha comunicado; he permanecido frio y pensativo, reflexionando sobre las ventajas y desventajas que reportarían los canales de desagüe y me he confirmado mas en mi opinión que si ellos no son el complemento de obras más eficaces y de mayor consideración, reportarán probablemente más perjuicios que beneficios".

Los recursos que dispone el hombre para paliar la degradación ambiental se encuentran en la ingeniería agro-hidrológica y medioambiental a través de los proyectos de restauración agro-hidrológica de las cuencas. El término agro-hidrológico puede interpretarse como un vocablo aglutinador de todas las acciones a realizar, ya que abordar tanto las actuaciones de carácter forestal como las prácticas agrícolas habituales en las superficies vertientes de la cuenca, así como las medidas adecuadas en los cauces de evacuación de los flujos de avenida y las obras auxiliares (Mintegui Aguirre y López Unzú, 1990).

La restauración agro-hidrológica trata de englobar en un plan unificado de acción, la problemática común a suelos, agua y vegetación de las cuencas conduciendo a un auténtico proceso de ordenación.

Los objetivos generales de la ordenación agro-hidrológica de una cuenca hidrográfica y de su posterior restauración hidrológico-forestal se centran en el uso racional de los recursos que dispone, fundamentalmente el suelo y el agua. De todos modos, es frecuente desglosarlos en los siguientes (Mintegui Aguirre y Robredo Sánchez, 1994):

- La retención del suelo mediante el control de la erosión, tratando al mismo tiempo de aprovechar este recurso.

- La regulación de las avenidas y del transporte de materiales provocado por las mismas, así como la sedimentación de estos últimos en las áreas dominadas.

- La provisión hídrica.

Estos objetivos se dividen para su estudio en dos grandes grupos: por un lado, los relacionados con los problemas generados por los eventos torrenciales en la cuenca; por otro, los referentes a la utilización agronómica de la misma y el aprovechamiento racional de los recursos hídricos y las potencialidades vegetativas en las diferentes zonas de la cuenca (Mintegui Aguirre y Robredo Sánchez, 1994).

Las actuaciones en la cuenca hidrográfica pueden sintetizarse en dos líneas, totalmente compatibles y en cierta medida, complementarias. Estas son, la utilización racional de las áreas de cultivo, que cubren las zonas de menores pendientes y suelos más fértiles, y el establecimiento de una cubierta vegetal protectora adecuada en el resto del territorio. Esta puede adquirir distintas formas tales como praderas, landas, áreas de matorral o monte bajo y finalmente zonas de bosque, bien sean de repoblación o naturales (Mintegui Aguirre y López Unzú, 1990). 
En Argentina, se destaca la necesidad de desarrollar procedimientos de evaluación de proyectos de manejo de cuencas hidrográficas, a partir de enfoques de mayor integridad que contemplen los diversos recursos involucrados y los aspectos técnicos, sociales, de impacto ambiental, gerenciales y económico-financieros, que puedan ser desarrollados a pequeña escala. En términos generales, el avance en la definición e implementación de acciones de manejo de cuencas se ve demorado por la insuficiencia de fondos operativos y de inversión. Gran parte de los proyectos de cuencas se encuentran a nivel de diagnóstico y prefactibilidad, lo que define que pocos son ejecutados y consecuentemente realizadas las evaluaciones técnicas, ambientales y económicas, así como los análisis del grado de adopción de prácticas que proponen (Casaza, 2003).

Las prácticas de restauración agro-hidrológica poseen una fuerte vinculación con la conservación y recuperación de suelos. Bajo este ámbito, cualquier proyecto desarrollado en la Provincia de Buenos Aires, se enmarca en el Decreto Ley 9867/82 (Gobierno de la Provincia de Buenos Aires, 1982) el cual dispone:

ARTICULO 1:Declárase de interés general la acción privada y pública tendiente a la conservación y recuperación de la capacidad productiva de los suelos.

ARTICULO 2: El Estado nacional y las provincias que se adhieran al régimen de la presente ley fomentarán la acción privada destinada a la consecución de los fines mencionados en el art. $1^{\circ}$.

ARTICULO 3: A los efectos indicados en los artículos. $1^{\circ}$ y $2^{\circ}$, las respectivas autoridades de aplicación podrán declarar distrito de conservación de suelos toda zona donde sea necesario o conveniente emprender programas de conservación o recuperación de suelos y siempre que se cuente con técnicas de comprobada adaptación y eficiencia para la región o regiones similares. Dicha declaración podrá igualmente ser dispuesta a pedido de productores de la zona.

ARTICULO 4: En los distritos de conservación de suelos se propiciará la constitución de consorcios de conservación, integrados voluntariamente por productores agrarios cuyas explotaciones se encuentren dentro del distrito, quienes podrán acogerse a los beneficios previstos en esta ley y sus disposiciones reglamentarias.

Con la aplicación de medidas de control del agua superficial en el área serrana de la cuenca del Arroyo Pillahuinco Grande, se estaría aumentando el recurso hídrico disponible para los cultivos en épocas deficitarias, los caudales punta disminuirían y con ello el riesgo de inundación en la ciudad.

La región se caracteriza por presentar un relieve con variados rangos de pendiente, que genera condiciones puntuales sobre las cuales se debe evaluar la mejor solución para controlar la escorrentía superficial sin afectar de manera significativa el tipo de producción y los hábitos del productor.

La restauración agro-hidrológica en el área serrana busca atenuar los efectos negativos provocados por las características particulares del área, haciendo un uso racional de los recursos disponibles en la cuenca. 


\section{ANTECEDENTES DE LA CUENCA DEL ARROYO PILLAHUINCO GRANDE}

La cuenca del Arroyo Pillahuinco Grande, se encuentra ubicada en el sistema serrano de Ventania, en el sudoeste de la Provincia de Buenos Aires, Partido de Coronel Pringles (Figura 1), abarcando una superficie de 109.350 has.

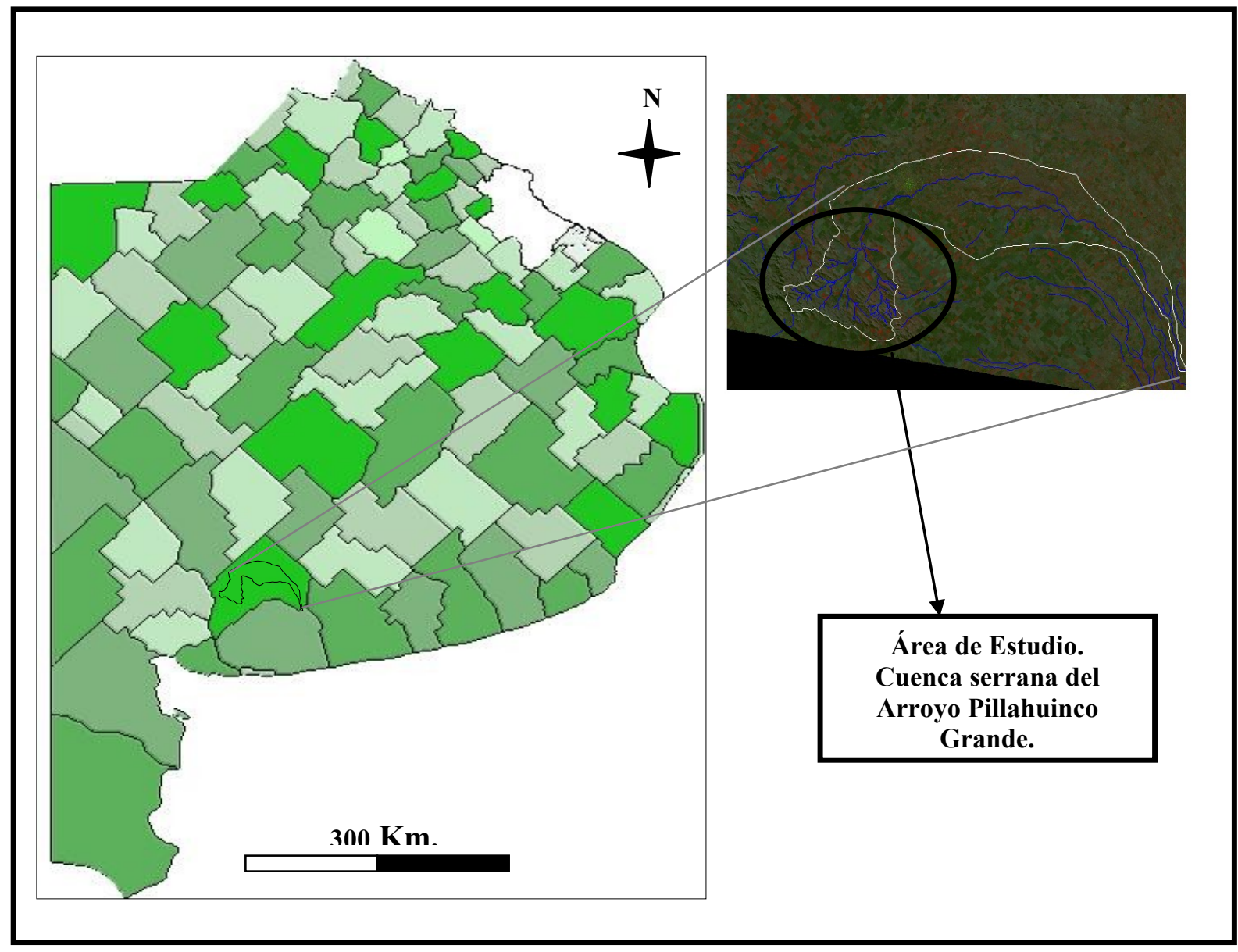

Figura 1: Mapa de ubicación del área de estudio. Provincia de Buenos Aires.

La zona en estudio, fitogeográficamente, se encuentra en la Región Neotropical, Dominio Chaqueño, Provincia Pampeana, Distrito Pampeano Austral, según "La fitogeografía de la Republica Argentina", Cabrera (1994).

La fisonomía vegetal dominante en la región es el pastizal. Las especies predominantes son: Stipa, Piptochaetium, Festuca y Briza, en algunos lugares arbustos y algunos árboles dispersos. Los arbustos son principalmente: Eupatorium buniifolium y Discaria lonjispina, sobre suelos someros o pedregosos y sólo escasos manchones pequeños de la xerófita Geoffroea decorticans en suelos arenosos - finos (Frangi y Bottino, 1994).

La geomorfología caracterizada por el clima, el relieve, la estructura y composición del material geológico originario y la vegetación son los factores que, en sus variaciones regionales, determinan la resultante de esta fuerza dinámica que origina la edafogénesis de los suelos de la región. 
La identificación de los suelos, su distribución areal y las variaciones locales observadas han hecho vincularlos con el medio en el cual se encuentran. Es por ello que al hablar de la geomorfología ha realizado una descripción por sectores, según sus tipos de paisaje y características de los elementos que las componen. Siendo el suelo parte integrante y funcional del paisaje en que se encuentra, se demuestra como las variaciones geomorfológicas influyen en la constitución de los suelos. Por lo cual se ajustó la clasificación edafológica a los ambientes geomorfológicos que la circunscriben y su denominación edafológica. (Spinelli Zinni, 1970). Se divide la región en 4 ambientes geoedafológicos: Grupo I. Ambiente serrano, presenta un suelo Argiudol típico (Brunizem somero, con B2t y con discontinuidad litológica). Grupo II. Ambiente intraserrano, con Argiudol típico (Brunizem moderadamente profundo con discontinuidad litológica y B2t levemente textural). Grupo III. Ambiente periserrano con Argiudol típico (Brunizem con B2 levemente textural) y Grupo IV, Ambiente de llanura (llanura septentrional, llanura de derrames y llanura sudoriental). Presenta suelos Hapludol éntico (Brunizen regosólico), Argiudol típico (Brunizem moderadamente profundo con B2 levemente textural), Argiudol típico (Brunizem moderadamente profundo con B2 fuertemente textural y con discontinuidad litológica), Argiudol típico (Brunizem rankeriformel) y Argiudol típico (Brunizem con B2 levemente textural con discontinuidad litológica) (Spinelli Zinni, 1970) (Figura 2).

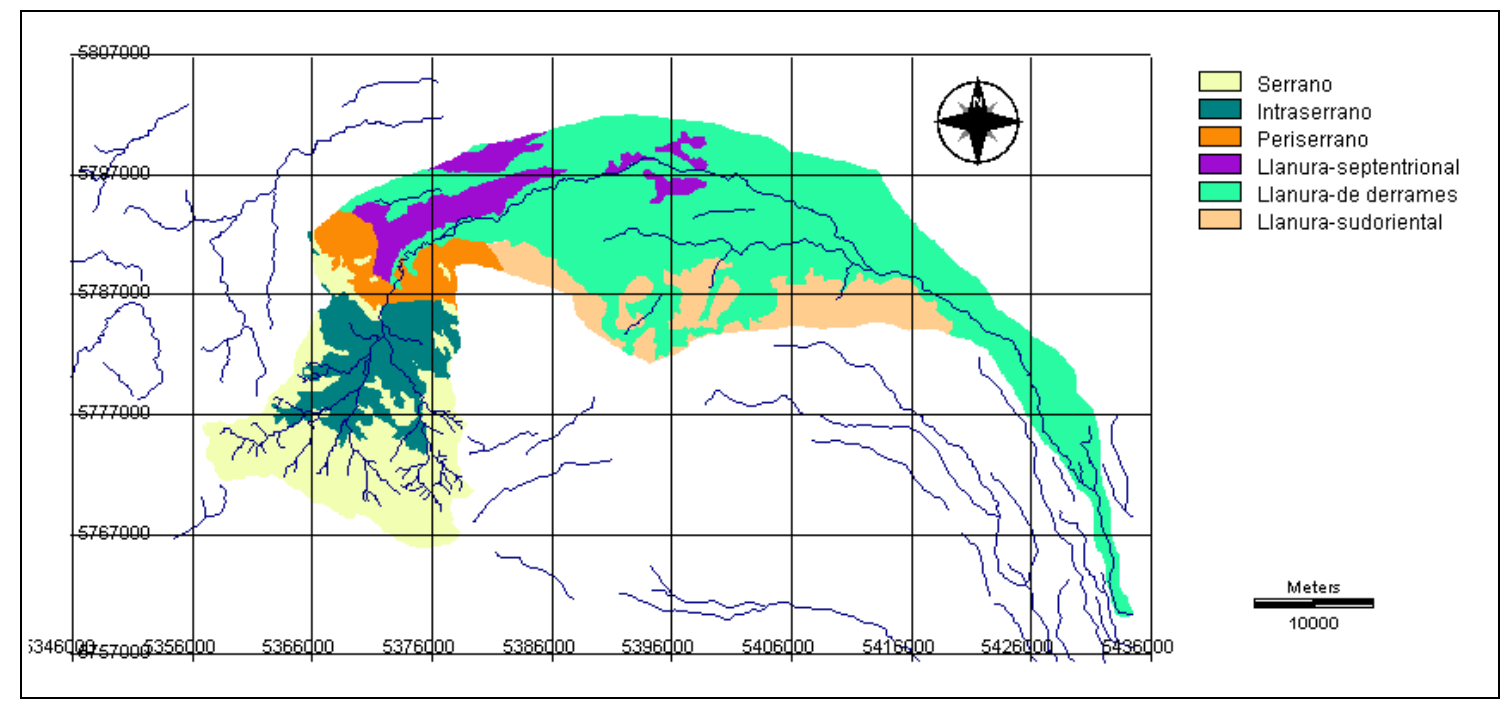

Figura 2: Mapa de Ambientes geomorfológicos.

Históricamente el crecimiento del Partido de Coronel Pringles estuvo relacionado con la producción agrícola-ganadera, siendo los cultivos principales: trigo, soja, cebada, girasol, sorgo y maíz; en cuanto a la ganadería, la región se caracteriza por invernada o cría (Gaspari y Rodríguez Vagaría, 2006).

La aptitud para la explotación agrícola-ganadera sustentable en la cuenca se encuentra ligada a la tecnología existente en la región y a las prácticas conservacionistas que se implementen para el control de la erosión superficial. De ésta manera se evitarán procesos erosivos tendientes a disminuir el potencial productivo de la cuenca.

La zonificación ambiental permite atenuar los procesos erosivos de la cuenca evitando el uso indebido de los recursos naturales. Se identificaron tres zonas con diferentes características ambientales y usos posibles: 1) Ganadería sobre pastizal 
natural, zona cercana a las divisorias de aguas, y debido a las condiciones topográficas (pendientes superiores al $10 \%$ y edáficas (suelos con afloramiento de roca), la agricultura es impracticable. Por lo tanto se recomienda zona apta para la ganadería. 2) Agricultura con medidas conservacionistas: La zona ocupa toda la cuenca media y el sector sur de la cuenca baja, los suelos son profundos y fértiles con algún afloramiento rocoso. Se sugiere que se realicen prácticas conservacionistas como el cultivo en curvas de nivel y/o, en fajas. 3) Ganadería y agricultura sobre suelos inundables: En esta zona se presentan suelos con escasa fertilidad, poca pendiente y con problemas de salinidad, generada por las sucesivas de inundaciones a que están expuestos. Las actividades que se recomiendan son la ganadería o la agricultura, tratando de no realizar laboreos excesivos que dejen suelo desnudo que puedan ser arrastrados y favorecer el proceso erosivo (Gaspari y Rodríguez Vagaría, 2006)

La problemática ambiental actual en la cuenca del Arroyo Pillahuinco Grande, según Gaspari et al (2007), se establece a partir de los siguientes criterios:

1) La acción directa de todo tipo de erosión hídrica de origen torrencial (escurrimiento encausado, en manto superficial y subsuperficial) en alta cuenca y/o sus cabeceras.

2) El impacto medioambiental negativo de las inundaciones en la cuenca media y baja, cuyos sectores afectados son:

a) En forma directa o corto plazo:

a1) Sector social urbano, periurbano y rural con perjuicios sobre bienes muebles e inmuebles;

a2) Sector productivo urbano, periurbano y rural con perdida de capital productivo inmueble (infraestructura como galpones, pozos, bebidas, alambrados, tanques) y perdida de capital productivo mueble (maquinarias como tractores, aperos, bombas, motores, electrificadores, fumigadores y animales, forraje, cosechas)

b) En forma indirecta o largo plazo:

Perdida del capital productivo suelo y agua:

b1) reducción por perdida del horizonte productivo superficial agrícola del suelo (Ap);

b2) modificación del perfil subsuperficial y profundo (síntomas de exceso hídrico en el perfil) por parámetros físicos (textura, granulometría, estructura, porosidad); parámetros químicos (aerobiosis, concreciones, pigmentaciones y otras manifestaciones y procesos químicos característicos del caso); parámetros biológicos y físiológicos (como ser sanidad del suelo);

b3) afectación directa sobre la calidad y cantidad de agua disponible. 


\section{HIPÓTESIS DE TRABAJO}

Las prácticas de restauración agro-hidrológicas propuestas constituyen un método integral en el control del escurrimiento superficial.

\section{OBJETIVO GENERAL}

Determinar el efecto de la restauración agro-hidrológica sobre el escurrimiento superficial en el área serrana de la Cuenca del Arroyo Pillahuinco Grande.

\section{OBJETIVOS ESPECÍFICOS}

- Caracterizar ambientalmente el área serrana de la cuenca del Arroyo Pillahuinco Grande.

- Elaborar una base de datos cartográfica temática digital para su potencial disponibilidad pública.

- Modelizar la respuesta hidrológica del área serrana de la cuenca del Arroyo Pillahuinco Grande ante diferentes eventos de precipitación para la condición actual.

- Proponer medidas de restauración agro-hidrológica coherentes con el tipo de producción actual tendientes a disminuir la escorrentía superficial.

- Ajustar las medidas propuestas ante diferentes eventos de precipitación para la condición restaurada.

- Comparar la respuesta del escurrimiento superficial según la condición actual y restaurada del área ante diferentes eventos de precipitación. 


\section{MATERIALES Y MÉTODO}

El efecto de la restauración agro-hidrológica sobre el escurrimiento superficial debe ser abordado sobre la base del concepto de cuenca hidrográfica y será analizado como objeto de estudio.

\section{Delimitación del área de estudio.}

El estudio de los movimientos del agua superficial debe ser abordado tomando como unidad a la cuenca hidrográfica y sus subunidades, las subcuencas. El primer paso fue definir la cuenca hidrográfica y sus respectivas subcuencas en el área serrana del Arroyo Pillahuinco Grande mediante el uso de Sistemas de Información geográfica (S.I.G).

Durante las últimas décadas el avance de los S.I.G dieron como resultado una serie de herramientas vinculadas a la rama de hidrología, entre ellas se encuentran los modelos delimitación automática de límites de cuencas hidrográficas a partir de la representación topográfica digital del terreno denominado Modelo de Elevación Digital (MED).

La delimitación de la cuenca se realizó a través de la extensión Swat 2000 bajo entorno ArcView, esta extensión posee una herramienta denominada Watershed delineation que crea una interfase para la delimitación automática del perímetro de una cuenca y sus subcuencas para un área de interés.

El proceso requiere como dato de entrada un MED del área de interés, a partir del cual realiza automáticamente la delimitación. Si se dispone de la red de ríos en formato vectorial, puede ser provista para mejorar el proceso de segmentación hidrológica y definir los bordes de las subcuencas. Este proceso se denomina quemado de ríos (Di Luzio, 2002).

El primer proceso que realiza la interfase consiste en remover las zonas sin drenaje del MED, para ello asigna valores nuevos a dichos píxeles de forma tal que la escorrentía pueda desplazarse hacia el píxel vecino (Figura 3).

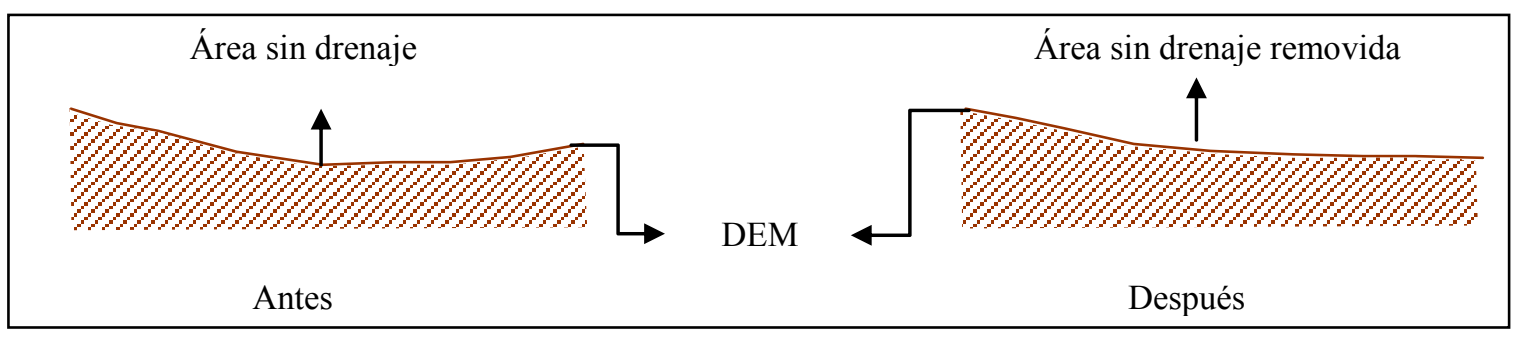

Figura 3: Remoción de áreas sin drenaje 
En un segundo proceso se realiza el quemado de ríos, el cual consiste en disminuir la elevación de los píxeles forzando de esta manera la circulación de la escorrentía a través de la red de drenaje (Figura 4).

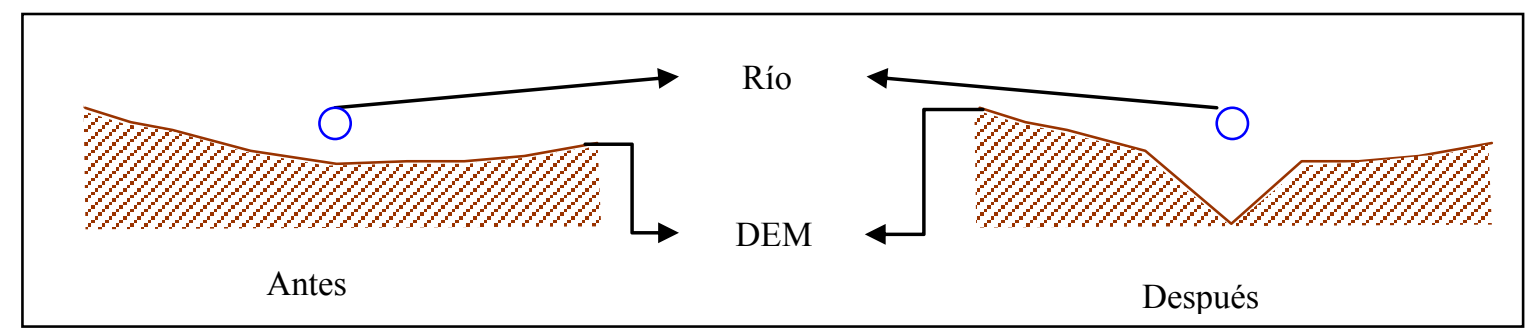

Figura 4: Quemado de ríos.

Por último la delimitación de la cuenca y las subcuencas es generada a partir de puntos de cierre, los cuales pueden ser definidos manualmente.

El proceso genera como resultado final archivos vectoriales de la cuenca, subcuencas y red de drenaje y un documento de texto en formato tabular con reportes topográficos para la caracterización morfométrica de la cuenca y subcuencas.

El MED utilizado para la delimitación de la cuenca y subcuencas fue el SRTM_24_20_4_2 en formato ascii, con link disponible bajo entorno Google Earth (C). Este fichero fue convertido al formato requerido por Swat 2000 y recortado al área de estudio. La red de drenaje utilizada para generar el quemado de ríos fue creada por digitalización en pantalla a partir de una composición de las bandas 1, 2 y 3 correspondientes a la escena 226/86 de Enero de 2007, obtenidas por el satélite Landsat 5, apoyado con imágenes disponibles en Google Earth (C). Se obtuvo de esta manera un archivo vectorial, el cual fue convertido al formato requerido por Swat 2000.

En febrero del 2000 la NASA, la Agencia Nacional de Inteligencia Geo-Espacial (NGA), y las Agencias Espaciales de Alemania y de Italia lanzaron la Misión Shuttle Radar Topography Mission (SRTM) Esta misión produjo el MED de más alta resolución de la superficie terrestre. Este MED fue producido a una resolución de 1 arco-segundo (aproximadamente $30 \mathrm{~m}$ en el Ecuador) para casi todo el globo terráqueo, entre las latitudes 60 grados norte y 56 grados sur (Farr, 2007) con un error de altitud vertical medio de 6,2 m (nivel de confianza de 90\%) y un error de geoubicación de $9 \mathrm{~m}$ para Suramérica (Rodríguez et al, 2006; Mathew Cushing, 2008).

La distribución de estos datos se rige por el Memorando de Entendimiento de NASA/NGA, y, en pocas palabras, expone que para aquellas áreas que caigan fuera del territorio de los Estados Unidos los datos se pueden distribuir públicamente a una resolución reducida igual a, o mayor que 3 arco-segundos (aproximadamente $90 \mathrm{~m}$ en el ecuador).

El SRTM utilizó una técnica llamada interferometría para recoger los datos topográficos En pocas palabras, la interferometría recoge dos imágenes de la misma 
ubicación en distintas posiciones de ventaja. Cuando se comparan las dos imágenes se aprecia una ligera diferencia en los valores de las mismas y a partir de esa diferencia se puede calcular la topografía de la superficie terrestre (NASA, 2005; Mathew Cushing, 2008).

Las imágenes recogidas de la interferometría no son "fotografías" típicas de la superficie terrestre ya que estas imágenes fueron producidas por dos sistemas radar de apertura sintética: banda-C (SIR-C) y banda-X (X-SAR) (Farr, 2007; Mathew Cushing, 2008).

Para el continente Sudamericano el conjunto de datos SRTM tiene un error horizontal promedio de 9,0 $\mathrm{m}$ y un error vertical absoluto (altura) promedio de $6,2 \mathrm{~m}$ (Rodríguez, 2006; Mathew Cushing, 2008). América del Sur ha visto una mejoría de 10 veces (tanto en resolución espacial como en exactitud vertical) con la aparición del MED de 90 m comparado al último MED continental, el GTOPO30 del USGS (Gesch, 1999; Mathew Cushing, 2008)

\section{Caracterización del área serrana de la cuenca del Arroyo Pillahuinco Grande.}

\subsection{Caracterización morfométrica.}

El análisis de las características morfológicas y funcionales de una cuenca hidrográfica se realiza a través de la determinación de parámetros de forma, de relieve y relativos a la red hidrográfica. Estos parámetros son indicadores destinados a determinar la influencia de la forma de la cuenca en el movimiento y captación del agua de lluvia.

Los parámetros de una cuenca desempeñan un papel fundamental en el estudio y comportamiento en los componentes del ciclo hidrológico, asimismo, algunos parámetros son requeridos como datos de entrada en la mayoría de los modelos hidrológicos para el análisis de las características morfológicas y funcionales (Gaspari et $a l, 2009)$. A continuación se describen los parámetros calculados.

\subsubsection{Parámetros de forma.}

\subsubsection{Perímetro $(\mathrm{P})$.}

Es la medición de la línea envolvente de la cuenca hidrográfica, por la divisoria de aguas. Su unidad de medida es kilómetro.

\subsubsection{Longitud axial (La).}

Es la distancia existente entre la desembocadura y el punto más lejano de la cuenca. Su unidad de medida es kilómetro. 


\subsubsection{3. Área (A).}

Es la superficie encerrada por la divisoria de aguas. Su unidad de medida es kilómetro cuadrado.

\subsubsection{Ancho promedio (Ap).}

Es la relación entre la superficie de la cuenca con su longitud axial. Su unidad de medida es kilómetro.

$$
\mathrm{Ap}=\mathrm{A} \cdot \mathrm{La}-1
$$

Fórmula 1: Ancho promedio de una cuenca (Ap).

Ap: Ancho promedio de una cuenca $(\mathrm{km})$;

A: Área $(\mathrm{km} 2)$;

La: $\quad$ Longitud axial $(\mathrm{km})$.

\subsubsection{Factor de forma (IF).}

Este factor regula la concentración del escurrimiento superficial. Resulta importante en lo referente a las crecientes de los cursos de agua. Una cuenca alargada, con un colector de mayor longitud que la totalidad de los tributarios, estará sujeta a crecientes de menor magnitud. Una cuenca de forma triangular, con dos vértices en las cabeceras, afluentes de similar longitud y sincronismo en la llegada, provocará crecidas más significativas. Es un factor adimensional, que además expresa la tendencia de la cuenca hacia las crecidas. Así, las cuencas con factor de forma bajos, son menos propensas a tener crecidas intensas, que una de igual tamaño con un factor de forma mayor.

Cuando IF es similar a 1, se esta ante una cuenca de forma redondeada, y en los casos en que IF es menor a 1, se caracteriza por ser una cuenca alargada.

$$
\mathrm{IF}=\mathrm{Ap} \cdot \mathrm{La}-1
$$

Fórmula 2: Factor de forma (IF).

Siendo Ap: el ancho promedio de la cuenca $(\mathrm{km})$ y La: la longitud axial o longitud del río hasta su punto más alto $(\mathrm{km})$.

\subsubsection{Coeficiente de compacidad de Gravelius (Kc).}

El contorno define la forma y la superficie que abarca la cuenca vertiente. Es evidente que la forma tendrá influencia sobre los escurrimientos y sobre la marcha del hidrograma resultante de una precipitación dada. El tiempo de concentración también depende de la forma (López Cadenas de Llano y Mintegui Aguirre, 1987). 
El coeficiente de compacidad de Gravelius, es un índice adimensional que permite relacionar el perímetro de la cuenca con el perímetro de un círculo de área equivalente al de la cuenca, y de esta manera representar esta característica (Gaspari, 2002).

Para tratar de explicar cuantitativamente la forma de la cuenca se ha propuesto su comparación con una cuenca ideal de forma circular, con sus tributarios dispuestos radialmente y que desembocan en el punto central y está expresado por el coeficiente de compacidad.

Si A es la superficie de la cuenca y $\mathrm{P}$ el perímetro, Kc su coeficiente de compacidad se establece por medio de la siguiente Fórmula:

$$
\mathrm{Kc}=\frac{\mathrm{P}}{(2 \square \sqrt{\square},}=\frac{0,28 \square}{\sqrt{\mathrm{A}})}
$$

Fórmula 3: Coeficiente de Gravellius (Kc).

P: $\quad$ Perímetro de la cuenca $(\mathrm{km})$;

A: $\quad$ Área de la cuenca $(\mathrm{km} 2)$;

$\pi: \quad 3,1416$.

El coeficiente de compacidad está relacionado estrechamente con el tiempo de concentración, que es el tiempo que tarda una gota de lluvia en moverse desde la parte más lejana de la cuenca hasta la salida. En este momento ocurre la máxima concentración de agua, puesto que están llegando las gotas de lluvia de todos los puntos de la cuenca.

Según el valor que tome este coeficiente, la cuenca tendrá diferente forma:

$$
\begin{aligned}
& \mathrm{Kc}=1,00 \rightarrow \text { cuenca redonda; } \\
& \mathrm{Kc}=1,25 \rightarrow \text { cuenca oval redonda; } \\
& \mathrm{Kc}=1,50 \rightarrow \text { cuenca oblonga; } \\
& \mathrm{Kc}=1,75 \rightarrow \text { cuenca rectangular oblonga. }
\end{aligned}
$$

Su valor será mayor que la unidad y crecerá con la irregularidad de la forma de la cuenca. A medida que su Kc tiende a 1, es decir cuando tiende a ser redonda, la peligrosidad de la cuenca a las crecidas es mayor, porque las distancias relativas de los puntos de la divisoria con respecto a uno central, no presenta diferencias mayores y el tiempo de concentración se hace menor, por lo tanto mayor será la posibilidad de que las ondas de crecidas sean continuas. 


\subsubsection{Parámetros de relieve.}

\subsubsection{Curva hipsométrica.}

Es la distribución del área de acuerdo a su elevación. La curva hipsométrica permite obtener la relación hipsométrica $(\mathrm{Rh})$, la cual es obtenida a partir del análisis altitudinal correspondiente al límite de la cuenca, el cual es reclasificado de acuerdo con el tamaño del intervalo asignado previamente (de preferencia el valor debe de ser igual a la equidistancia). Para cada clase se obtiene su área, lo cual permite realizar los cálculos de la curva hipsométrica, es decir generar la curva de frecuencia que representa distribución areal según cota altimétrica. Se expresa a través de una curva de un doble eje de coordenadas donde la ordenada es la cota de altura (m.s.n.m.) y la abscisa es el área por encima de una cota dada $\left(\%-\mathrm{km}^{2}\right)$.

La generación de la curva hipsométrica en un área fue sugerida por Langbein (1947), para proporcionar información sintetizada sobre la altitud de la cuenca, que representa gráficamente la distribución de la cuenca vertiente por tramos de altura.

\subsubsection{Curva hipsométrica adimensional.}

Se utiliza para la comparación de cuencas con distinto desnivel, cuyo gráfico se expresa en dos ejes donde la ordenada es la Altura relativa $(\mathrm{h} / \mathrm{H})$ y la abscisa es Área relativa (a/A), donde $\mathrm{h}$ : Intervalo entre curvas de nivel $(\mathrm{m}), \mathrm{H}$ : Desnivel total de la cuenca (m), A: Superficie total de la cuenca (ha) y a: Área entre curvas de nivel (ha).

Normalmente su forma es sigmoidal, cóncava hacia arriba en la parte superior y convexa en la parte baja; el grado de sinuosidad es muy variable, lo mismo que la pendiente en el punto de inflexión.

El Gráfico 1 muestra tres curvas hipsométricas correspondientes a cuencas que tienen potenciales evolutivos distintos. La curva superior (curva A) refleja una cuenca con un gran potencial erosivo; la curva intermedia (curva B) es característica de una cuenca en equilibrio; y la curva inferior (curva C) es típica de una cuenca sedimentaria.

Cuando las curvas hipsométricas presentan variaciones, ya sea por apartarse de las teóricas o por presentar más de un punto de inflexión, ello puede relacionarse con controles tectónicos o litológicos. El valor del área relativa que yace bajo la curva (integral hipsométrica) es indicativo del estado de desarrollo de la cuenca; valores superiores al $60 \%$ indican desequilibrio manifiesto en el funcionamiento de la cuenca (juventud), valores rondando el $47 \%$ representan equilibrio o madurez, e inferiores a $30 \%$ implican fase de senectud (Strahler, 1952, 1957; Racca, 2007). 


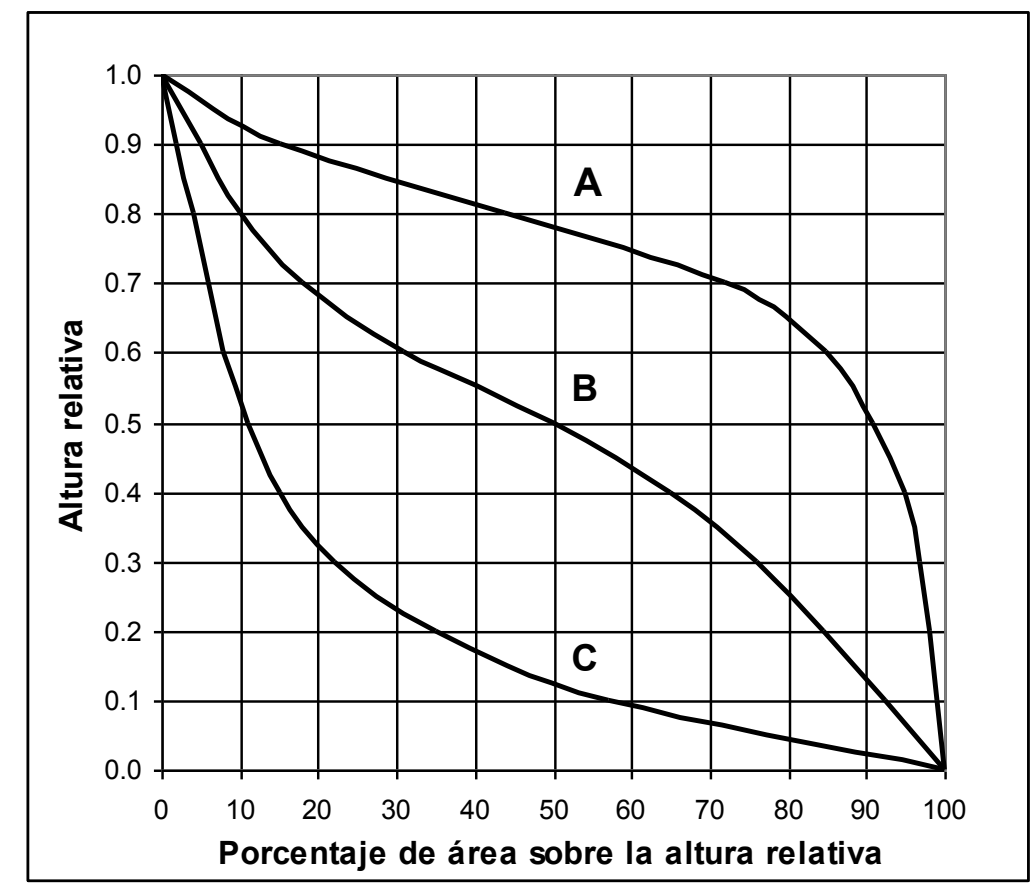

Grafico 1: curvas hipsométricas correspondientes a cuencas que tienen potenciales evolutivos distintos.

\subsubsection{Parámetros relativos a la red hidrográfica.}

\subsubsection{Densidad de drenaje (Dd).}

La densidad de drenaje está definida para cada cuenca como la relación entre la suma de las longitudes de todos los cursos de agua que drenan en la cuenca con respecto al área de la misma (López Cadenas de Llano y Mintegui Aguirre, 1987; López Cadenas de Llano, 1998). Cabe recordar que se denomina red hidrográfica al drenaje natural, permanente o temporal, por el que fluyen las aguas de los escurrimientos superficiales.

Se considera que la densidad de drenaje caracteriza cuantitativamente la red hidrográfica de la cuenca. Además define el grado de relación entre el tipo de red y la clase de material predominante, los cuales permiten el escurrimiento (Henaos, 1988; López Cadenas de Llano, 1998; Gaspari, 2002).

La densidad de drenaje fue establecida por Horton según la Fórmula 4.

$$
\mathrm{Dd}=\frac{\mathrm{Ln}}{\mathrm{A}}
$$

Fórmula 4: Densidad de drenaje (Dd, en $\mathrm{km} \cdot \mathrm{km}^{-2}$ )

Ln: Sumatoria de las longitudes de todos los cursos de agua que drenan por la cuenca $(\mathrm{km})$;

A: Área total de la cuenca $(\mathrm{km} 2)$. 
En un principio, y sin tener en cuenta otros factores del medio físico de la cuenca, cuanto mayor sea la densidad del drenaje, más rápida será la respuesta de la cuenca frente a una tormenta, evacuando el agua en menos tiempo. Es decir: al ser la densidad de drenaje alta, una gota deberá recorrer una longitud de ladera pequeña, realizando la mayor parte del recorrido a lo largo de los cauces, donde la velocidad del escurrimiento es mayor; por lo tanto los hidrogramas en principio tendrán un tiempo de concentración corto.

\subsubsection{Pendiente media del cauce (J).}

La pendiente media del cauce se deduce a partir del desnivel topográfico sobre el cauce principal y la longitud del mismo (López Cadenas de Llano y Mintegui Aguirre, 1987; López Cadenas de Llano, 1998; Gaspari, 2002). Se expresa en porcentaje, según la Fórmula 5.

$$
\mathbf{J}=\left[\left(\frac{\text { H máx - Hmín }}{\mathrm{L}}\right)\right] \square
$$

Fórmula 5: Pendiente media del cauce (J, en \%).

H máx.: Cota máxima sobre el curso de agua (m);

H mín.: Cota mínima sobre el curso de agua (m);

L: Longitud del río más largo (m).

\subsection{Caracterización climática.}

\subsubsection{Precipitación.}

Para la caracterización de las precipitaciones en la cuenca se utilizaron los registros pluviométricos diarios de la serie de datos desde 1911 hasta 2006 inclusive. Se obtuvo la precipitación media anual y las precipitaciones medias mensuales.

\subsubsection{Temperatura.}

La región en estudio presenta carencia en el registro de datos termométricos, debido a ellos se utilizaron los datos de temperatura media mensual de la estación meteorológica más cercana, correspondiente a la estación Coronel Suarez Aero del Servicio meteorológico Nacional.

\subsubsection{Balance hidrológico medio mensual.}

El cálculo del balance hidrológico mensual requiere como variables de entrada la precipitación media mensual (PP) y la evapotranspiración potencial media mensual (ETP). Para el cálculo de la Evapotranspiración potencial se utilizó el método de 
Thornthwaite (1948). El cálculo de la ETP expresada en $\mathrm{mm} / \mathrm{mes}$ se determina a partir de la fórmula 6 (Sánchez San Román, 2006)

$$
E T P=16 \square \begin{gathered}
17\lceil N\rceil\left\lceil 1 \cap T s 7^{a}\right. \\
\lfloor 12\rfloor\lfloor 3 U\rfloor\lfloor\quad I\rfloor
\end{gathered}
$$

Formula 6: Evapotranspiración potencial ETP (mm/mes)

Donde:

$\mathrm{I}=$ Duración del día en horas

$\mathrm{N}=$ Número de días en el mes

$\mathrm{Ta}=$ Temperatura media mensual del aire expresada en ${ }^{\circ} \mathrm{C}$

$\mathrm{a}=6,75$

Donde

$$
I=\sum_{1}^{12} i \quad \text { e } \quad \mathrm{i}=\left[\frac{T a}{5}\right]^{1,514}
$$

La duración del día se calculó con la función DDIAF56 del módulo Agroclima de INTA (Abbate, P.E. 2004) para Microsoft Excel, la cual posee como valores de entrada el día juliano y la latitud del área de estudio.

Las variables calculadas en el balance hidrológico fueron:

- Evapotranspiración real (ETR):

El procedimiento de cálculo de la ETR se realizó a partir de la relación PP-ETP, utilizando una reserva máxima como valor de referencia de $100 \mathrm{~mm}$ (Thornthwaite, 1948). El cálculo de la ETR se efectúa aplicando las Formula 7 u 8 según condición 1 ó 2 respectivamente.

Condición 1: $\mathrm{PP}_{\mathrm{j}}-\mathrm{ETP}_{\mathrm{j}} \geq 0$

Formula 7: $\mathrm{ETR}_{\mathrm{j}}=\mathrm{ETP}_{\mathrm{j}}$.

Condición 2: $\mathrm{PP}_{\mathrm{j}}-\mathrm{ETP}_{\mathrm{j}}<0$

Formula 8: $\mathrm{ETR}_{\mathrm{j}}=\left[\mathrm{ETP}_{\mathrm{j}} /\left(\right.\right.$ Reserva máxima $\left.\left.+\mathrm{ETP}_{\mathrm{j}}\right)\right] \bullet\left(\right.$ Almacenaje $\left._{\mathrm{j}-1}+\mathrm{PP}_{\mathrm{j}}\right)$ 
- Almacenaje (A):

Para el cálculo del almacenaje se procedió a iniciar el ciclo del balance cuando la reserva del suelo se encuentra en capacidad máxima. La determinación de la lámina almacenada en el perfil se realiza a través de la Fórmula 9 ó 10 según condición 3 ó 4 respectivamente.

Condición 3: Almacenaje $\mathrm{j}_{\mathrm{j}-1}+\mathrm{PP}_{\mathrm{j}}-\mathrm{ETR}_{\mathrm{j}} \geq$ Reserva máxima.

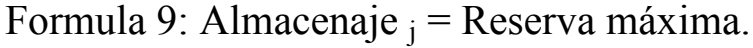

Condición 4: Almacenaje $\mathrm{j}_{\mathrm{j}-1}+\mathrm{PP}_{\mathrm{j}}-\mathrm{ETR}_{\mathrm{j}}<$ Reserva máxima. Fórmula 10: Almacenaje ${ }_{\mathrm{j}}=$ Almacenaje $_{\mathrm{j}-1}+\mathrm{PP}_{\mathrm{j}}-\mathrm{ETR}_{\mathrm{j}}$

- Variación del almacenaje $(\Delta \mathrm{A})$ :

Este valor se calcula a través de la Fórmula 11

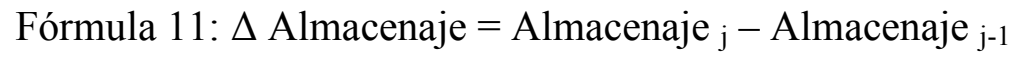

- Déficit de saturación (DS):

El déficit de saturación representa la lámina de agua necesaria para que el suelo se encuentre a reserva máxima. Su cálculo se realiza a través de la Fórmula 12:

Fórmula 12: DS = Reserva máxima - Almacenaje $_{\mathrm{j}}$

- $\operatorname{Exceso(E):~}$

Los excesos se generan cuando el almacenamiento es máximo y la precipitación es mayor a la evapotranspiración. Su determinación se realiza aplicando la Fórmula 13 ó 14 según condición 5 ó 6 respectivamente.

Condición 5: Almacenaje ${ }_{\mathrm{j}}=$ Reserva máxima.

Formula 13: $\mathrm{E}=\mathrm{PP}_{\mathrm{j}}-\mathrm{ETR}_{\mathrm{j}}+\Delta \mathrm{Alm}_{\mathrm{j}}$.

Condición 6: Almacenaje $\mathrm{j} \leq$ Reserva máxima.

Formula 14: $\mathrm{E}=0$ 
- Déficit (D):

El déficit es la lámina de agua que falta para satisfacer la evapotranspiración potencial.

Su modo de cálculo se efectúa aplicando la Fórmula 15 ó 16 según condición 7 ó 8 respectivamente.

$$
\begin{aligned}
& \text { Condición 7: } \mathrm{PP}_{\mathrm{j}}-\mathrm{ETP}_{\mathrm{j}}<0 . \\
& \text { Formula 15: } \mathrm{D}=\mathrm{ETP}_{\mathrm{j}}-\mathrm{PP}_{\mathrm{j}} \\
& \text { Condición 8: } \mathrm{PP}_{\mathrm{j}}-\mathrm{ETP}_{\mathrm{j}} \geq 0 . \\
& \text { Formula 16: } \mathrm{D}=0
\end{aligned}
$$

\subsubsection{Clasificación climática.}

Se utilizó el modelo de clasificación climática de Thornthwaite (1948), el cual se basa en la evapotranspiración potencial y el índice hídrico, que cuantifican la eficiencia térmica y la eficiencia pluvial del medio analizado.

Esta clasificación se realizó a partir del balance hidrológico, explicado en el punto 2.2.3. La misma está simbolizada por cuatro dígitos o índices climáticos que en su conjunto expresan las características climáticas del lugar. A continuación se describen dichos índices tomados de Urdaneta (2003).

- Índice hídrico (Im).

El primer dígito de la clasificación de Thornthwaite expresa el grado de humedad de un lugar. Una vez calculado el índice según la Fórmula 17, se ingresa a la Tabla 1 del Anexo 1 con el valor y se determina el tipo de clima y símbolo que corresponde al medio caracterizado.

$$
\operatorname{Im}=(100 \bullet \mathrm{E}-60 \bullet \mathrm{D}) / \mathrm{ETP}
$$

Fórmula 17: Indíce hídrico.(Im).

Donde:

$\mathrm{E}=$ exceso de humedad en el año

$\mathrm{D}=$ deficiencia de humedad en el año

$\mathrm{ETP}=$ evapotranspiración potencial anual. 
- Índice de Variación estacional de la humedad (VEA).

Se representa por una letra minúscula que indica como es la variación estacional de la humedad en el lugar que se está clasificando. Si dicho lugar presenta un clima húmedo (A, B ó C2) se emplea la Fórmula 18 de índice de aridez (Ia) puesto que interesa caracterizar la magnitud y distribución de los períodos secos en el lugar estudiado. Por el contrario si el lugar tiene un clima seco (C1, D ó E), se utiliza la Fórmula 19 que permite calcular el índice de humedad (Ih) para saber cómo está distribuida la posible humedad que exista en el lugar y qué importancia tiene esa estación húmeda.

\author{
Índice de aridez $(\mathrm{Ia})=100 \bullet \mathrm{D} / \mathrm{ETP}$ \\ Fórmula 18: Índice de Aridez. (Ia) \\ Índice de humedad $(\mathrm{Ih})=100 \bullet \mathrm{E} / \mathrm{ETP}$ \\ Fórmula 19: Índice de humedad.(Ih)
}

Una vez calculado el índice según corresponda se ingresa a la Tabla 2 o Tabla 3 del Anexo 1 con el valor y se determina su símbolo.

- Tipos de clima según el índice de eficiencia térmica (IET).

El tercer dígito esta constituido por una letra mayúscula con apóstrofe que indica la eficiencia térmica del lugar considerado. Este se determina entrando directamente con el valor de la ETP anual en mm a la Tabla 4 del Anexo 1.

- Tipos de clima según la concentración de la eficiencia térmica (Cet) en verano.

El cuarto y último dígito de la Clasificación de Thornthwaite se expresa con una letra minúscula con apóstrofe e indica como es el régimen térmico durante el verano en relación al resto del año, o lo que es similar, cual es el nivel de concentración de las temperaturas altas durante esa época del año. Dicho índice se determina sumando los valores de ETP de los tres meses de verano y relacionándolos luego con la sumatoria de la ETP anual (Fórmula 20):

$$
\text { Cet }=(\text { ETP meses de verano } \bullet 100) / \text { ETP anual }
$$

Fórmula 20: Tipos de clima según la concentración de la eficiencia térmica en verano (Cet).

Una vez calculado el Cet se ingresa a la Tabla 5 del Anexo 1 y se obtiene el símbolo correspondiente. 


\subsubsection{Análisis de Precipitaciones.}

El análisis de las precipitaciones en la cuenca se realizó en base a los registros pluviométricos diarios de la serie de datos desde 1911 hasta 2006 inclusive.

Se ajustaron las tendencias de las precipitaciones anuales con el fin de determinar variaciones temporales tanto en cantidad de precipitación como en número de las mismas.

Se dividió la precipitación anual en función de su distribución mensual, considerando 2 períodos, uno húmedo, denominado cálido, el cual incluye los meses del intervalo Septiembre - Abril y otro, seco, denominado frío, que incluye los meses del intervalo Marzo - Octubre. Se ajustaron las tendencias de las precipitaciones en los períodos con el fin de determinar variaciones temporales tanto en cantidad de precipitación como en número de las mismas para relacionarlas con las tendencias a nivel anual.

\subsubsection{Ajuste de precipitaciones máximas diarias a la ley de Gumbel.}

Los procesos hidrológicos evolucionan en el espacio y en el tiempo en una forma que es parcialmente predecible o determinístico y parcialmente aleatoria. Un proceso de este tipo se conoce con el nombre de proceso estocástico. En algunos casos, la variabilidad aleatoria del proceso es tan grande comparada con su variabilidad determinística, que se justifica que el hidrólogo trate el proceso como puramente aleatorio. De esta manera, el valor de una observación del proceso no está correlacionada con los valores de las observaciones adyacentes, y las propiedades estadísticas de todas las observaciones son iguales. Una variable aleatoria $\mathrm{X}$ puede ser descripta ó ajustada a una función de probabilidad conociéndose sus frecuencias de ocurrencia. (Chow et al, 1994).

Este tipo de tratamiento es apropiado para observaciones de eventos hidrológicos extremos, como crecientes o sequías, y para información hidrológica promediada a lo largo de tiempos grandes, como la precipitación anual. (Chow et al, 1994).

La distribución de Gumbel ofrece resultados óptimos en el estudio de frecuencias de valores extremos de variables meteorológicas. Los resultados obtenidos deben ser contrastados mediante un test de comprobación cuya aplicación pretende conseguir el mejor ajuste posible por aceptación o rechazo de ciertos valores de la serie observada (Miliarium Aureum, 2004).

Para la determinación de las máximas precipitaciones, se parte de la siguiente hipótesis: las precipitaciones son variables aleatorias e indefinidas, sujetas a una distribución estocástica determinada.

Sea la precipitación diaria una variable $X$, con probabilidad de ocurrencia $\mathrm{P}(\mathrm{x})$ se dice que esta posee una distribución Gumbel si se ajusta a la Fórmula 21: 


$$
\mathrm{P}(x)=e^{-e^{-\alpha(x-u)}}
$$

Donde:

Fórmula 21: Distribución Gumbel.

$e=$ base de los logaritmos neperianos.

$X=$ Precipitación diaria $\left(\mathrm{mm} \cdot 24 \mathrm{~h}^{-1}\right)$

$\alpha$ y $u=$ Parámetros de la distribución. Calculados según las Fórmulas 22 y 23 respectivamente.

$$
\alpha=\frac{\mathrm{S}_{n}}{\mathrm{~S}_{x}}
$$

Fórmula 22: Parámetro $\alpha$ de la distribución Gumbel.

$$
u=\bar{X}-\bar{Y}\left(\frac{\mathbf{S}_{x}}{\mathbf{S}_{n}}\right)
$$

Fórmula 23: Parámetro $u$ de la distribución Gumbel.

Siendo

$\bar{X}=$ Media de los valores diarios máximos anuales de precipitación $\left(\mathrm{X}_{\mathrm{i}}\right)$.

Calculado según la Formula 24.

$\mathbf{S}_{\mathrm{x}}=$ Desvío de los valores diarios máximos anuales de precipitación $\left(\mathrm{X}_{\mathrm{i}}\right)$.

Calculado según la Fórmula 25.

$\bar{Y}=$ Media de los valores del tamaño dependientes del tamaño de la muestra $\left(\mathrm{Y}_{\mathrm{i}}\right)$. Calculado según Fórmula 26.

$\mathbf{S}_{\mathrm{n}}=$ Desvío de los valores del tamaño dependientes del tamaño de la muestra $\left(\mathrm{Y}_{\mathrm{i}}\right)$. Calculado según Fórmula 27.

$\mathrm{Y}_{\mathrm{i}}=$ Valores de la variable $\mathrm{Y}$ según el número de orden de la muestra (n) Calculado según Fórmula 28.

$$
\bar{X}=\frac{\sum_{i=1}^{n} X_{i}}{n}
$$

Fórmula 24: Media de los valores diarios máximos anuales de precipitación $\left(\mathrm{X}_{\mathrm{i}}\right)$. $\mathrm{n}=$ número de precipitaciones máximas.

$$
S_{x}=\frac{\sum_{i=1}^{n}\left(X_{i}-\bar{X}\right)^{2}}{n-1}
$$

Fórmula 25: Desvío de los valores diarios máximos anuales de precipitación $\left(\mathrm{X}_{\mathrm{i}}\right)$. $\mathrm{n}=$ número de precipitaciones máximas. 


$$
\bar{Y}=\frac{\sum_{i=1}^{n} Y_{i}}{n}
$$

Fórmula 26: = Media de los valores dependientes del tamaño del tamaño de la muestra $\left(Y_{i}\right) \cdot n=$ Tamaño de la muestra.

$$
S_{n}=\frac{\sum_{i=1}^{n}\left(Y_{i}-\bar{Y}_{n}\right)^{2}}{n}
$$

Fórmula 27: Desvío de los valores dependientes del tamaño del tamaño de la muestra $\left(\mathrm{Y}_{\mathrm{i}}\right) \cdot \mathrm{n}=$ Tamaño de la muestra.

$$
Y_{i}=-\ln \left[\ln \left(\frac{n+1}{i}\right)\right]
$$

Fórmula 28: Valores de la variable Y según el número de orden del tamaño de la muestra. $\mathrm{N}=$ Tamaño de la muestra. $I=$ número de orden.

\subsubsection{Test de bondad de ajuste.}

La bondad de ajuste de una distribución de probabilidad puede probarse comparando los valores teóricos y muestrales de frecuencia relativa o de frecuencia acumulada (Chow, 1994)

El test de Kolmogorov-Smirnov es el más extendido cuando se desea comparar la distribución de probabilidad de eventos extremos. Se basa en la idea de comparar la función de distribución acumulada de los datos observados con la de una distribución a probar, midiendo la máxima distancia entre ambas curvas (D). Para ello se ordenan de menor a mayor los valores de probabilidad acumulada muestral $(\mathrm{Pm})$ y teórica $(\mathrm{Pt})$, luego se obtienen las diferencias para Xi....Xn. y se calcula el valor D según la Fórmula 29:

$$
D=\max |P m(x i)-P t(x i)|
$$

Fórmula 29: Distancia máxima entre curvas de distribución.(D)

Luego, asumiendo un valor de significancia, se contrasta con los valores críticos obtenidos según la tabla 6 del Anexo 1. Una vez determinado dicho valor se establece que si $\mathrm{D}<\mathrm{D}$ tabla, se acepta que el ajuste es adecuado, con el nivel de confiabilidad asumido. 


\subsubsection{Determinación del Período de retorno.}

Por definición un evento extremo, asociado a una variable aleatoria $\mathrm{X}$, se produce cuando en una observación $\mathrm{Xi}$, el valor de dicha variable es mayor o igual que un cierto valor Xt. El intervalo de recurrencia $\mathrm{R}$ es el tiempo transcurrido entre dos eventos consecutivos, es decir entre dos observaciones de la muestra con Xi mayor o igual Xt. El período de retorno ( $\mathrm{Tx}$ ) de un evento con $\mathrm{Xi} \geq \mathrm{Xt}$ es el intervalo de recurrencia promedio entre dos eventos, es decir el tiempo promedio entre observaciones con $\mathrm{Xi} \geq \mathrm{Xt}$. (López Cadenas de Llano, 1998)

A partir de los valores de probabilidad de precipitación puede calcularse el período de retorno para esa precipitación a partir de la Fórmula 30:

$$
T_{(x)}=\left(\frac{1}{1-P_{(x)}}\right)
$$

Fórmula 30: Período de retorno para una probabilidad de precipitación. $T_{(x)}$

Si se desea calcular la lámina de precipitación para un período de retorno determinado se aplica la fórmula 31:

$$
x=u-\frac{1}{\alpha} \ln \left[-\ln \left(\frac{T_{(x)}-1}{T_{(x)}}\right)\right]
$$

Fórmula 31: Lámina de precipitación para un período de retorno. $(x)$

\subsubsection{Selección de tormentas.}

El Centro de Información Meteorológica del Servicio Meteorológico Nacional, Comando Regiones Aéreas de la Fuerza Aérea Argentina, permitió el acceso a la información pluviográfica de la Estación Meteorológica en Coronel Pringles, Provincia de Buenos Aires, cuyo expediente de tramitación fué el $N^{\circ}$ 99.833. Se dispuso de fajas pluviográficas de la Estación Coronel Pringles Aero, correspondientes a 17 tormentas ocurridas durante el período 1956 al 2000.

Se procedió a su lectura y posterior digitalización analítica con intervalos cada 30 minutos. Una vez obtenidas las curvas de masa de lluvia, se determinaron los períodos de retorno, a través de la metodología citada con anterioridad. A partir de estos resultados se seleccionaron 3 tormentas para la aplicación de los modelos hidrológicos.

\subsection{Vegetación y usos del suelo.}

Se relevaron datos de vegetación y uso del suelo in situ con apoyo de imágenes satelitales y un sistema de posicionamiento global (GPS). Los datos fueron procesados y clasificados en categorías para la confección del mapa de vegetación y usos de suelo. 
La caracterización de vegetación y uso del suelo se baso en descripciones bibliográficas apoyada por toma de datos a campo y posterior interpretación de imágenes satelitales Landsat 5 e imágenes de alta resolución provistas por el servidor Google Earth.

\subsection{Suelos.}

Se utilizó la caracterización de suelos de la cuenca a escala 1: 50000, realizada por AICET-RCD, 2008.

\section{Cartografía temática digital de la condición actual.}

\subsection{Cartografía de primer orden.}

La cartografía digital de primer orden ó primaria se generó a partir de la digitalización de cartografía analógica y/o tratamiento de imágenes satelitales con sistemas de información geográfica. Los mapas obtenidos se detallan a continuación:

3.1.1. Drenaje. Obtenido según lo descripto en el apartado 1.

3.1.2. Cuenca y subcuencas. fueron obtenidos utilizando las técnicas descriptas en el apartado 1 .

3.1.3. Vegetación y usos del suelo. Para la obtención del mapa de vegetación y usos del suelo se utilizaron imágenes satelitales Landsat 5 escena 226/86 e imágenes de alta resolución provistas por el servidor Google Earth. La imagen fue georreferenciada tomando como base la cartografía de red de drenaje y límite de cuenca y subcuencas. Para ello se localizaron puntos de control, como ser las uniones de arroyos de la red de drenaje y los puntos más relevantes del límite de cuenca y subcuencas. Una vez georreferenciada la imagen, se procedió a la digitalización de polígonos de características uniformes, asignando por medio de la interpretación y el apoyo de la toma de datos a campo, las categorías de vegetación y uso del suelo.

3.1.4. Suelos. El mapa de suelos de la cuenca fue elaborado a partir de cartografía analógica a escala 1: 50000, realizada por AICET-RCD, 2008. La cartografía analógica disponible constaba de cuatro aerofotografías con sus unidades de suelo diferenciadas a través de polígonos. Las aerofotografías fueron convertidas en imágenes digitales y georreferenciadas tomando como base la cartografía de red de drenaje y límite de cuenca y subcuencas. Para ello se localizaron puntos de control, como ser las uniones de arroyos de la red de drenaje y los puntos más relevantes del límite de cuenca y subcuencas. Una vez georreferenciadas las aerofotografías se procedió a la digitalización de polígonos obteniendo el mapa digital de suelos. 


\subsection{Cartografía de segundo orden.}

La cartografía de segundo orden fue elaborada a partir de la cartografía primaria, para su confección se procedió de la siguiente manera:

3.2.1. Rangos de pendiente. El mapa de pendientes fue realizado en Idrisi Andes ${ }^{\circledR}$ a través del comando Slope. El mismo determina la pendiente del píxel a partir del MED, basado en la resolución del píxel y los valores más cercanos de los píxeles vecinos a su derecha, izquierda, arriba y abajo. El valor de la pendiente es calculada como un vector resultante de las pendientes en el sentido de los ejes x e y del píxel en cuestión, aplicando la fórmula 35 (Eastman, 2006).

$$
\operatorname{Pendiente}(m / m)=\sqrt{\left[\frac{P_{i z}-P_{d e}}{2 \square}\right]^{2}+\left[\frac{P_{s u}-P_{i n}}{\square}\right]^{2}}
$$

Fórmula 35: Valor de la pendiente para un píxel.

Donde:

$P_{i z}$ : Valor del píxel izquierdo del píxel en cuestión.

$P_{d e}$ : Valor del píxel derecho del píxel en cuestión.

$P_{s u}$ : Valor del píxel superior del píxel en cuestión.

$P_{i n}$ : Valor del píxel inferior del píxel en cuestión.

Res: Resolución del píxel.

El mapa de pendientes expresado como porcentaje surge de multiplicar el mapa obtenido anteriormente por 100 .

A partir de la reclasificación de valores de pendiente se obtiene como resultado final el mapa de rangos de pendiente.

3.2.2. Orientación de laderas. El mapa de orientación de laderas fue realizado en Idrisi Andes ${ }^{\circledR}$ a través del comando Aspect. El mismo determina la orientación de la ladera expresada en decimales de grado respecto del Norte. Para la obtención del mapa se procedió a reclasificar los valores a fin de expresarlos respecto de los puntos cardinales.

3.2.3. Grupos hidrológicos. El mapa de Grupos hidrológicos deriva de la reclasificación del mapa de suelos asignando un valor de grupo hidrológico a cada unidad edáfica. Las características de cada grupo son descriptas en el apartado 4.

\subsection{Cartografía de tercer orden.}

La cartografía de tercer orden fue elaborada a partir del procesamiento de cartografía de segundo orden. Para su confección se procedió de la siguiente manera:

3.3.1. Número de curva. El mapa de número de curva se genera como resultado de la intersección del mapa de Grupos hidrológicos y de vegetación y uso del suelo, posteriormente se realiza una reclasificación de las nuevas categorías a partir de valores 
tabulares. El proceso se genera automáticamente mediante el modelo Lthia descripto en el Apartado 5.1.

\section{Descripción del método de transformación de lluvia-escorrentía.}

La metodología del número de curva (NC) fue elaborada por el Soil Conservation Service (SCS) de los Estados Unidos, es un método empírico para el cálculo de la transformación de lluvia-escorrentía, que surgió de la observación del fenómeno hidrológico en distintos tipos de suelo en varios estados y para distintas condiciones de humedad antecedente. (Chow et al, 1994; López Cadenas de Llano, 1998; Mintegui Aguirre y López Unzu, 1990).

El método se basa en que las combinaciones suelo-vegetación de características semejantes, responderán de manera análoga bajo el efecto de una tormenta de intensidad variable. A mayor valor de Número de Curva, las condiciones de escurrimiento son más críticas, es decir, los valores de infiltración son menores (Gaspari et al, 2009).

Para ello se estableció una clasificación de los complejos hidrológicos a los que asignó una capacidad de infiltración (Chow et al, 1994; López Cadenas de Llano, 1998; Mintegui Aguirre y López Unzu, 1990).

Cada complejo se especifica por un tipo geomorfológico y de suelo. Se definen cuatro agrupaciones:

- Grupo A: Suelo con el potencial de escurrimiento mínimo. Incluye a las arenas profundas con poco limo y arcilla, así como a los loess muy permeables.

- Grupo B: Suelos en su mayor parte arenosos, menos profundos que los del grupo A, y loess menos profundos y menos compactos que los del grupo anterior.

- Grupo C: Suelos poco profundos con abundante cantidad de arcilla y coloides.

- Grupo D: Potencial de escurrimiento máximo. Suelos con elevado contenido de arcillas, poco profundos, con subhorizontes casi impermeables cerca de la superficie.

Conociendo el grupo hidrológico al que corresponden los diferentes suelos de la cuenca y teniendo en cuenta el uso del suelo, es decir la vegetación que sustentan, incluyendo el tratamiento cultural que reciben, se establecen los Números de Curva en las diferentes zonas de la cuenca (Gaspari y Senisterra, 2006).

La escorrentía (Q) se calcula a partir de la Fórmula 36.

$$
\mathrm{Q}=\frac{(\mathrm{P}-\mathrm{Io})^{2}}{\mathrm{P}+4 \square}=\frac{(\mathrm{P}-0,2 \square}{\square}
$$

Fórmula 36: Lámina de escorrentía Q (mm) según el método del NC del SCS.

Donde el valor de Io representa las pérdidas por intercepción, almacenamiento en superficie e infiltración, conocida también como abstracciones, antes de que se inicie el 
escurrimiento (Q). La retención máxima de $\mathrm{P}$ absorbida por la cuenca (retención potencial máxima) se denomina $\mathrm{S}$.

A partir de los resultados obtenidos a campo para muchas cuencas experimentales pequeñas, el S.C.S. desarrolló una ecuación empírica para determinar Io, según la Fórmula 37, a partir de la retención potencial máxima (S).

$$
\text { Io }=0,2 \square
$$

Fórmula 37: Determinación de las abstracciones iniciales (Io).

El valor de $\mathrm{S}$ se obtiene aplicando la Fórmula 38, obteniendo el valor del número de curva (NC) a partir de la Tabla 8 del Anexo 1 en función de la vegetación y Uso del Suelo y Grupo hidrológico.

$$
\mathrm{S}=254 \square\left(\begin{array}{ll}
1 \mathrm{nn} & 1 \\
(\mathrm{NC} & 1
\end{array}\right)
$$

Fórmula 38: Retención potencial máxima (S) según el método del NC del SCS.

La condición de humedad antecedente del suelo incide directamente sobre la cantidad de agua que puede infiltrar en el suelo, por lo cual es importante considerar este estado de saturación del suelo. El tipo de condición de humedad antecedente se establece según la Tabla 1.

Tabla 1: Determinación de la condición hidrológica antecedente en función de la lluvia y el estadío de crecimiento

\begin{tabular}{c|c|c}
\hline \multirow{2}{*}{$\begin{array}{c}\text { Clases de condiciones de } \\
\text { humedad antecedentes }\end{array}$} & \multicolumn{2}{|c}{ Lluvia total de los 5 días anteriores(milímetros) } \\
\cline { 2 - 3 } & $\begin{array}{c}\text { Estación sin desarrollo } \\
\text { vegetativo }\end{array}$ & $\begin{array}{c}\text { Estación de crecimiento } \\
\text { vegetativo }\end{array}$ \\
\hline I & menos de $12,7 \mathrm{~mm}$ & menos de $35,6 \mathrm{~mm}$ \\
II & 12,7 a $27,9 \mathrm{~mm}$ & 35,6 a $53,3 \mathrm{~mm}$ \\
III & Más de $27,9 \mathrm{~mm}$ & más de $53,3 \mathrm{~mm}$ \\
\hline
\end{tabular}

\section{Modelos hidrológicos. Elaboración de parámetros requeridos.}

La modelización de la respuesta hidrológica ante diferentes eventos de precipitación para la condición actual, se realizó mediante el modelo Long-Term Hydrologic Impact Assessment and Non Point Source Pollutant Model (Lthia) obteniendo la zonificación de la escorrentía superficial y con el modelo Hydrologic Engineering Center Hydrologic Modeling System (Hec Hms) se generaron los hidrogramas, caudal de punta y escorrentía total para diferentes eventos de precipitación para la cuenca y todas sus subcuencas.

A continuación se describen los parámetros requeridos para la ejecución de cada uno de los modelos. 


\subsection{Lthia. Zonificación de la escorrentía superficial.}

Lthia se ha desarrollado como una herramienta de análisis simple que ofrece estimaciones de los cambios en el escurrimiento, la recarga y las fuentes de contaminación no puntual resultantes del uso del suelo pasado o para los cambios propuestos. Expresa resultados a largo plazo el escurrimiento promedio anual según el uso del suelo, basado en datos reales de clima, mediante el uso de una base de datos climáticos multianual o una tormenta extrema (Engel et al, 2005).

Los resultados son destinados a proporcionar información sobre los impactos hidrológicos relativos al uso del suelo para diferentes escenarios Los resultados pueden ser utilizados para generar conciencia en la comunidad de los posibles problemas a largo plazo y para apoyar la planificación física con el fin de reducir al mínimo la perturbación en áreas críticas. (Engel et al, 2005).

La reciente preocupación sobre cuestiones en el cambio de uso de la tierra, incluida la falta de consideración sobre aspectos hidrológicos por el cambio de uso del suelo puede resultar en inundaciones, degradación del arroyo, la erosión y la pérdida de suministro de agua subterránea. Lthia es una herramienta ideal para colaborar en la evaluación de los efectos potenciales del cambio en el uso del suelo, e identificar la mejor ubicación de un uso particular a fin de contar con un mínimo impacto sobre el medio ambiente natural de la zona (Engel et al, 2005).

Lthia Gis es un modelo de procesamiento cartográfico geoespacial bajo entorno ArcView para el cálculo a nivel píxel de la lámina de escorrentía. Su empleo requiere de cartografía de suelos y vegetación y usos del suelo en formato vectorial codificadas de forma tal que luego del rasterizado, procesamiento y asignación a través de un archivo de valores (CN Table) se obtenga un mapa de número de curva a partir del cual se determina la lámina de escorrentía (Engel et al, 2005).

\subsubsection{Codificación del mapa de suelos.}

El mapa de suelos debe ser modificado agregando un campo con el nombre "Rcls_hsg" a la tabla de propiedades y asignando un valor de tipo "string" correspondiente al Grupo hidrológico de cada uno de los complejos de suelo. Luego del procesamiento se creará y asignará automáticamente un campo numérico con el nombre "Code" (Tabla 2)

Tabla 2: Tabla de codificación de G.H. del mapa de suelos requerido por Lthia.

\begin{tabular}{|c|c|c|}
\hline $\begin{array}{c}\text { Grupo } \\
\text { Hidrológico }\end{array}$ & $\begin{array}{c}\text { Valor asignado al } \\
\text { campo "Rcls_hsg" }\end{array}$ & $\begin{array}{c}\text { Valor asignado al } \\
\text { campo "Code" }\end{array}$ \\
\hline A & A & 1 \\
\hline B & B & 2 \\
\hline C & C & 3 \\
\hline D & D & 4 \\
\hline
\end{tabular}




\subsubsection{Codificación del mapa de vegetación y usos del suelo.}

El mapa de vegetación y usos del suelo debe ser modificado agregando un campo con el nombre "Rcls_land" a la tabla de propiedades y asignando un valor en función de las categorías requeridas por Lthia Gis. Luego del procesamiento se creará y asignará automáticamente un campo numérico con el nombre "Code" (Tabla 3)

Tabla 3: Tabla de codificación del mapa de vegetación y usos del suelo requerido por Lthia.

\begin{tabular}{|c|c|}
\hline $\begin{array}{c}\text { Valor asignado al } \\
\text { campo "Rcls_hsg" }\end{array}$ & $\begin{array}{c}\text { Valor asignado al } \\
\text { campo "Code" }\end{array}$ \\
\hline Water & 1000 \\
\hline Commercial & 2000 \\
\hline Agricultural & 3000 \\
\hline HD Residential & 4000 \\
\hline LD Residential & 5000 \\
\hline Pasture & 6000 \\
\hline Forest & 7000 \\
\hline Industrial & 8000 \\
\hline
\end{tabular}

\subsubsection{Adaptación de los valores de NC.}

Los valores de número de curva son asignados a partir de un archivo denominado CN_table. Este archivo puede ser adaptado de forma tal que un código de la Tabla 3 asigne valores de número de curva correspondientes a cualquier combinación vegetación y uso del suelo-grupo hidrológico, cambiando las especificadas en el archivo original.

\subsection{Hec Hms. Generación de hidrogramas.}

El centro de Ingeniería Hidrológica del Cuerpo de Ingenieros del Ejercito de los EEUU, diseñó el programa de computación Sistema de Modelamiento Hidrológico (HEC-HMS), este provee una variedad de opciones para simular procesos de precipitación - escurrimiento y también transito de caudales entre otros (US Army, 2000).

HEC-HMS es un modelo agregado debido a que el alcance espacial se limita a un punto, cada unidad (subcuenca) es tratada como un promedio ponderado de la superficie real. Según el tipo de respuesta es un modelo determinístico, teniendo como resultado un único valor para una combinación de variables determinada, también puede ser clasificado como un modelo de evento ya que calcula la variable respuesta para un suceso determinado en un momento dado.

E1 HEC-HMS comprende una interfaz gráfica para el usuario (GUI), componentes de análisis hidrológicos, capacidades para manejo y almacenamiento de datos, y 
facilidades para expresar los resultados mediante gráficas y reportes tabulados. La GUI provee los medios necesarios para especificar los componentes de la cuenca, para introducir los respectivos datos de estos componentes y para visualizar los resultados (US Army, 2000).

La ejecución de una simulación en el HEC-HMS, requiere las siguientes especificaciones:

- Modelo de Cuenca, contiene parámetros y datos conectados para elementos hidrológicos. Los tipos de elementos son: Subcuencas, tramos de transito, uniones, embalses, fuentes, derivaciones y sumidero.

- Modelo Meteorológico, consiste en datos meteorológicos e información requerida para procesarlos.

- Especificaciones de Control, con el cual se específica información de relación tiempo para efectuar la simulación.

\subsubsection{Modelo de Cuenca.}

Se requiere la selección y especificación de los siguientes parámetros:

\subsubsection{Subcuenca.}

Es el elemento donde se genera la escorrentía a partir de una precipitación determinada. Requiere los siguientes parámetros:

Conexión. Se define el elemento hacia el cual fluye el hidrograma de salida de la cuenca

- Área. Superficie de la subcuenca expresada en $\mathrm{Km}^{2}$

- Método de pérdidas. Se seleccionó el Método del Número de curva, asignando el NC ponderado en función de la superficie para cada una de las subcuencas a través de la Fórmula 38:

$$
N C_{\text {ponderado }}=\frac{\sum_{i=1}^{n} A_{i} \square}{\sum_{i=1}^{n} A_{i}}
$$

Fórmula 38: Ponderación areal del NC para un a subcuenca.

Donde:

$N C_{\text {ponderado: Número de curva para la subcuenca. }}$

$A_{i}$ : Área de ocupación del $N C_{i}$ en la subcuenca.

$N C_{i}$ : Números de curva presentes en la subcuenca. 
Método de transformación. Se utilizó el método de transformación del SCS desarrollado a partir de los datos observados recogidos en pequeñas cuencas agrícolas. El hidrograma general es escalado por el lapso de tiempo para producir el hidrograma unitario, donde el 37,5\% del volumen de escorrentía se produce antes del flujo máximo y la base de tiempo del hidrograma es cinco veces el retraso. Estudios realizados por el SCS encontraron que en general el tiempo de retraso se puede aproximar al tomar el $60 \%$ del tiempo de concentración (US Army, 2006). El tiempo de concentración fue calculado a través de la ecuación de retardo desarrollada por el SCS en 1973 (Chow, et al 1994) mediante la formula 39.

$$
T c=\frac{100 \square \cdots(5 / \mathrm{NC})-9]^{0.7}}{1900 \square}
$$

Fórmula 39: Tiempo de concentración (TC en minutos) según la Ecuación de retardo del SCS.

Donde:

$L$ es la longitud de la mayor trayectoria del flujo expresada en pies.

$N C$ número de curva de la cuenca

$S$ es la pendiente promedio de la cuenca expresado en porcentaje.

5.2.1.2. Tramos de tránsito. Corresponde al curso por donde circula el hidrograma. Requiere los siguientes parámetros:

- Conexión. Se define el elemento hacia el cual fluye el hidrograma de salida del tramo

Método de tránsito. Se utilizó el método Muskignum-Cunge eight point. La ejecución de este método utiliza como parámetros de entrada para cada uno de los cauces el largo total del tramo expresada en metros, la pendiente expresada en metro/metro, una sección transversal del cauce construida a partir de ocho puntos $(\mathrm{x} ; \mathrm{y})$ y los números de Manning del margen derecho, izquierdo y lecho (Figura 5).

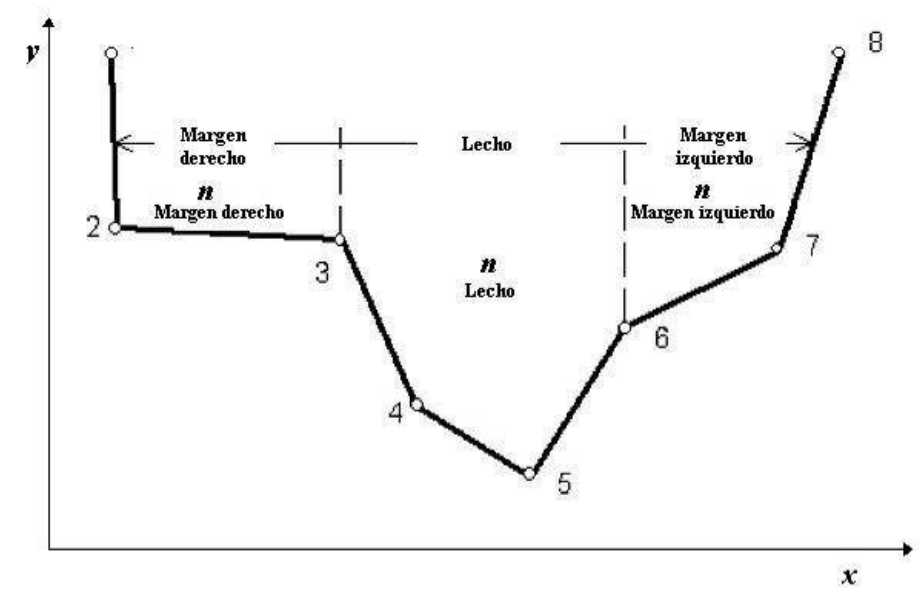

Figura 5: Formato para describir la geometría de canal con 8 puntos. Adaptado de Technical Reference Manual HEC HMS 3.1.0 
La ubicación de los perfiles transversales constó de dos etapas, la primera se realizó en gabinete mediante uso de S.I.G, utilizando como base el mapa de drenaje y el de subcuencas. Se identificaron y posicionaron espacialmente los puntos necesarios donde se realizar los perfiles. Una vez obtenidas las coordenadas, con el uso de GPS se situaron en el terreno, a continuación se procedió a medir la profundidad del lecho cada 1 metro (Fotografía 1) tomando como origen el comienzo de la planicie de inundación.

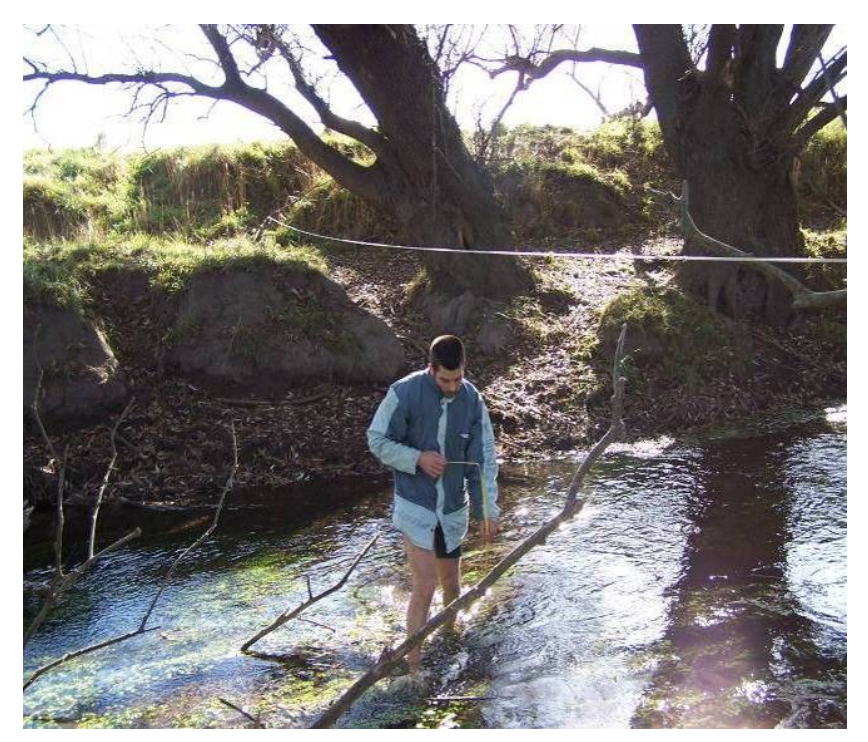

Fotografía 1: Procedimiento para la caracterización de perfiles transversales.

El tránsito de avenidas por canales normalmente corresponde a flujos completamente turbulentos, en esta situación la ecuación de Manning es la mas apropiada y sencilla para el cálculo de velocidades del flujo dentro de un canal abierto. Su expresión deriva de la ecuación de Chezy (Fórmula 32).

$$
\mathrm{V}=\frac{\mathrm{R}^{2 / 3} \square}{\eta}
$$

Fórmula 32: Velocidad del flujo en un canal abierto.(V)

\section{Donde}

$\mathrm{R}: \quad$ Radio hidráulico $(\mathrm{m})$.

S: $\quad$ Pendiente del canal $(\mathrm{m} \cdot \mathrm{m}-1)$.

$\eta$ : Coeficiente de Manning (adimensional).

Por ley de continuidad puede determinarse el caudal de avenida según la Fórmula 33.

$$
\mathrm{Q}=\mathrm{A} \bullet \mathrm{V}=\mathrm{A} \bullet \frac{\mathrm{R}^{2 / 3} \square}{\eta}
$$

Fórmula 33: Caudal (Q en $\left.\mathrm{m}^{3} / \mathrm{s}\right)$ para un canal abierto.

Siendo:

$$
\begin{array}{ll}
\mathrm{A}: & \text { Área }\left(\mathrm{m}^{2}\right) \\
\mathrm{V}: & \text { Velocidad }\left(\mathrm{m} \cdot \mathrm{s}^{-1}\right)
\end{array}
$$


El procedimiento general para estimar los valores del coeficiente de Manning se realiza a través de la selección de un valor de coeficiente base para un cauce recto, uniforme y suave, hecho de los materiales de interés y luego adicionar factores de corrección. El valor del coeficiente compuesto se calcula a través de la Fórmula 34 (Chow, 1982).

$$
\eta=\left(\mathrm{n}_{0}+\mathrm{n}_{1}+\mathrm{n}_{2}+\mathrm{n}_{3}+\mathrm{n}_{4}\right) \cdot \mathrm{n}_{5}
$$

Donde:

Fórmula 34: Valor del coeficiente compuesto de Manning

$\mathrm{n}_{0}=$ valor base para cauces rectos y uniformes.

$\mathrm{n}_{1}=$ valor adicional por la irregularidad en la sección recta.

$\mathrm{n}_{2}=$ valor adicional por variaciones en el cauce.

$\mathrm{n}_{3}=$ valor adicional por obstrucciones.

$\mathrm{n}_{4}=$ valor adicional por vegetación.

$\mathrm{n}_{5}=$ factor multiplicador por sinuosidad.

Los valores de $\mathrm{n}_{0}$ se determinaron a partir de la Tabla 7 , los valores $\mathrm{n}_{1}, \mathrm{n}_{2}, \mathrm{n}_{3}, \mathrm{n}_{4} \mathrm{y} \mathrm{n}_{5}$ a partir de la Tabla 8.

5.2.1.3. Unión. Constituye el punto de encuentro de dos o más elementos. Requiere el siguiente parámetro:

- Conexión. Se define el elemento hacia el cual fluye el hidrograma de salida de la unión

5.2.1.4. Sumidero. Representa la salida o punto de cierre de la cuenca.

\subsubsection{Modelo Meteorológico.}

Especificación del hidrograma: El modelo meteorológico fue elaborado a partir de fajas pluviográficas, uno para cada tipo de tormenta. Cada uno de los modelos meteorológicos se crea a partir de una curva de masa de lluvia con intervalos cada 30 minutos especificando el día y hora de comienzo de la precitación.

\subsubsection{Especificaciones de Control.}

En el se detallan el día y hora de inicio, a partir del cual se comenzarán a los cálculos y día y hora de finalización de los mismos. 


\section{Medidas de restauración agro-hidrológica.}

Del análisis de la respuesta hidrológica en la condición actual, la cartografía y la caracterización ambiental se asignaron medidas de restauración agro-hidrológicas coherentes con el tipo de producción actual, tendientes a disminuir la escorrentía total superficial y caudales pico.

La metodología empleada para la asignación de nuevos usos del suelo se basó en la combinación de tres variables espaciales: grupo hidrológico, rangos de pendiente y vegetación y usos del suelo actual.

Las medidas de restauración propuestas, se representaron cartográficamente (mapa de vegetación y usos del suelo) a fin de delimitar su ubicación geoespacial. El escenario propuesto modificó las condiciones hidrológicas, afectando los parámetros requeridos por los modelos. A fin de evaluar la respuesta hidrológica de las medidas propuestas con Lthia y HEC HMS se confeccionaron los parámetros necesarios. De esta manera, los resultados obtenidos para la condición restaurada pudieron ser comparados con la condición actual.

\section{Análisis comparativo de la respuesta del escurrimiento superficial de la condición actual y restaurada.}

El efecto de la restauración se comparó con la situación actual a través del análisis de lámina de escorrentía, hidrogramas, caudales pico y escorrentía total generados por los diferentes eventos de precipitación. 


\section{RESULTADOS}

\section{Delimitación del área de estudio.}

La delimitación de la cuenca serrana del Arroyo Pillahuinco Grande se realizó sobre una base cartográfica digital georreferenciada bajo el sistema de coordenadas GaussKruger Argentina, correspondiente a la Faja 5. El cuadrante donde se ubica el área de estudio tiene los siguientes límites expresados en metros: Min. X: 5353704.0; Max. X: 5383431.0; Min. Y: 5763580.5; Max. Y: 5794171.0. A partir de dicho cuadrante y tres bandas del satélite Landsat 5 se procedió a componer una imagen (Figura 6) con el fin de obtener por medio de digitalización en pantalla la red de drenaje de la cuenca (Figura 7).

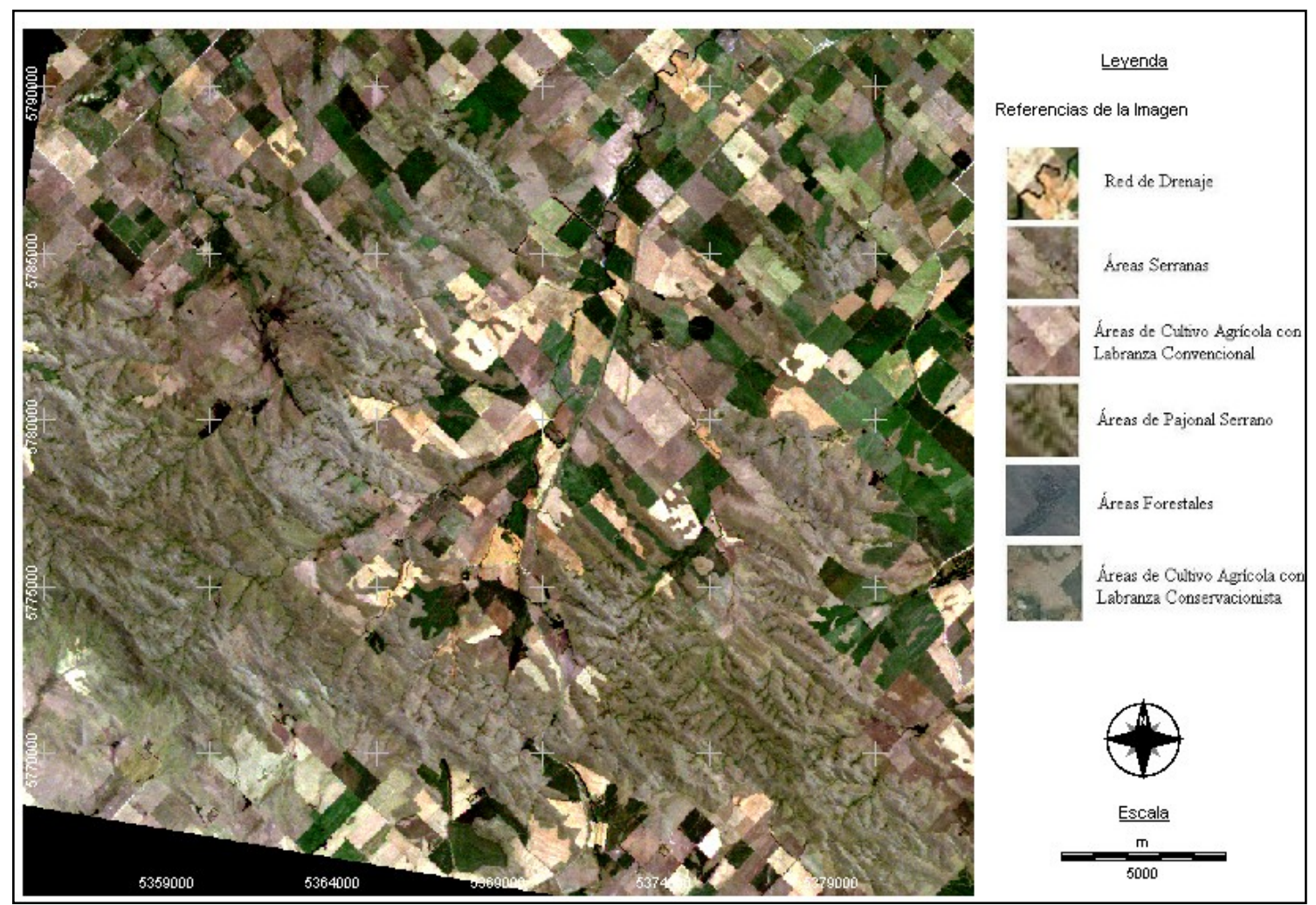

Figura 6: Composición de las bandas 1, 2 y 3 correspondientes a la escena 226/86 de Enero de 2007, obtenidas por el satélite Landsat 5 


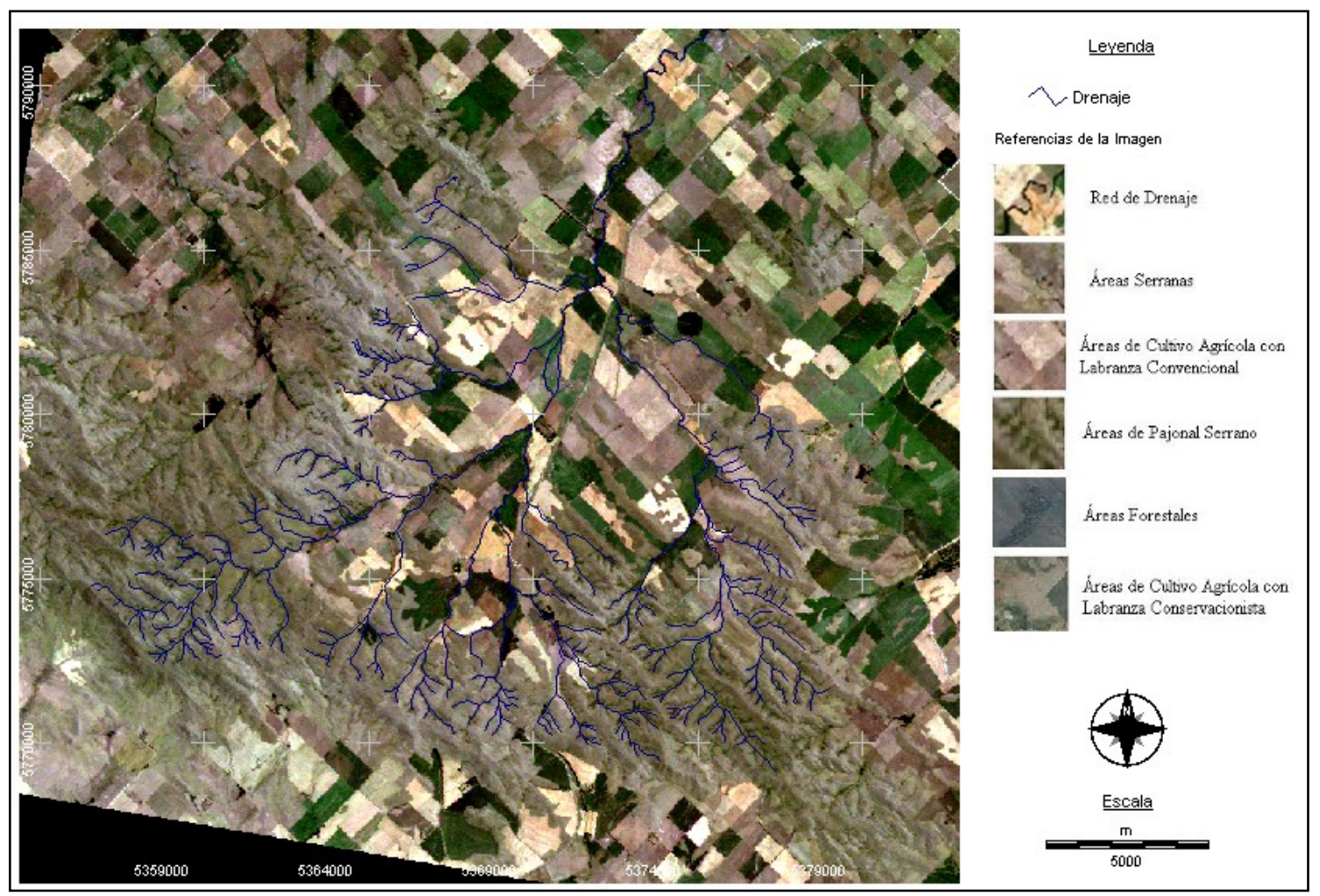

Figura 7: Red de drenaje de la cuenca obtenida por digitalización en pantalla.

Se procesó el srtm_24_20_4_2 para obtener un MED del área (Figura 8), una vez confeccionadas las dos capas temáticas y los puntos de cierre de las subcuencas (Figura 9), se delimitó la cuenca (Figura 10) y sus subcuencas automáticamente con el módulo Watershed delineation, obteniendo un total de 15 subcuencas (Figura 11). 


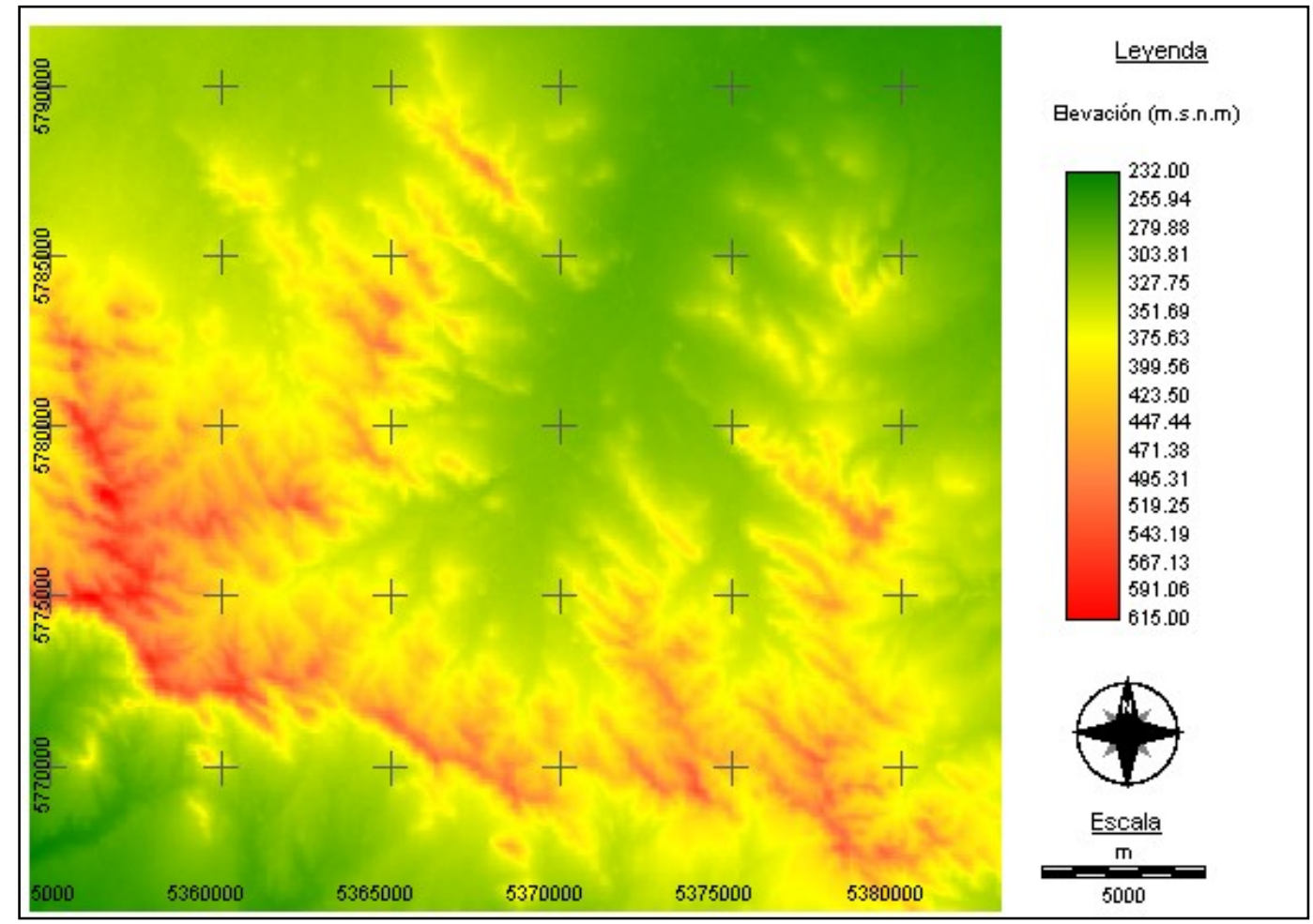

.Figura 8: MED obtenido por procesamiento del srtm_24_20_4_2

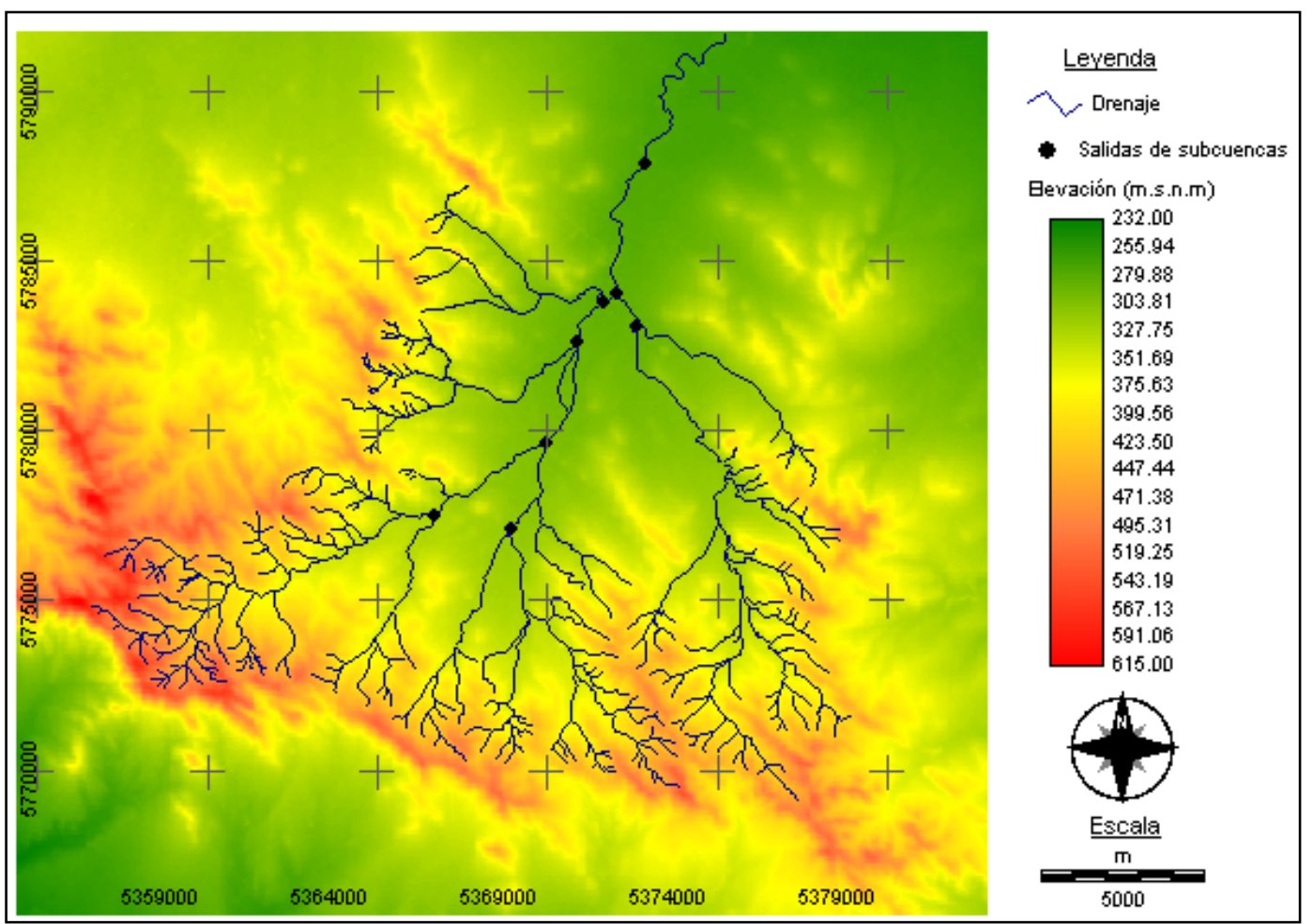

Figura 9: MED, Red de drenaje y puntos de cierre de subcuencas necesarios para la delimitación automática de cuenca y subcuencas por medio de Watershed delineation. 


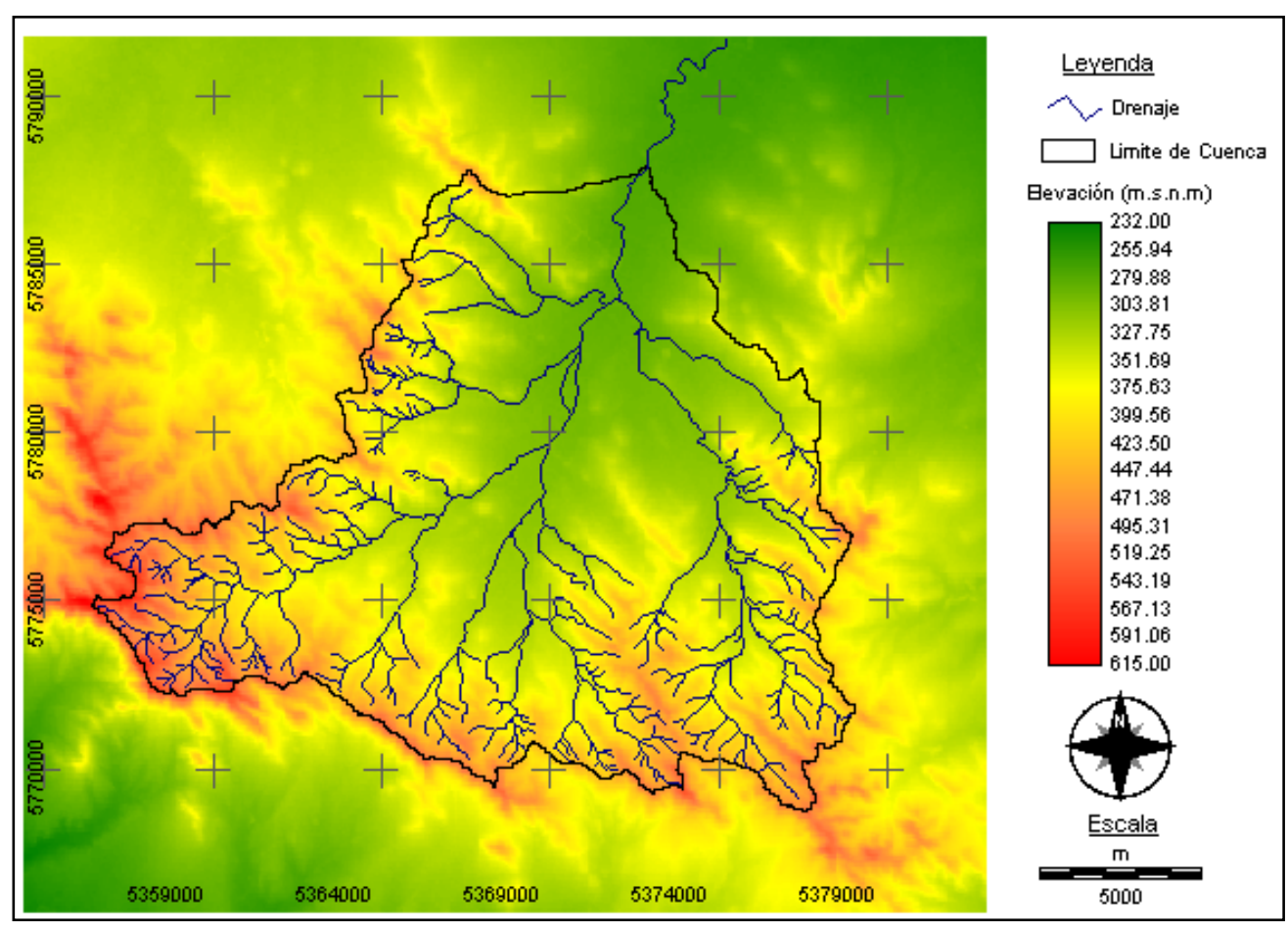

Figura 10: Cuenca del área serrana de Arroyo Pillahuinco Grande.

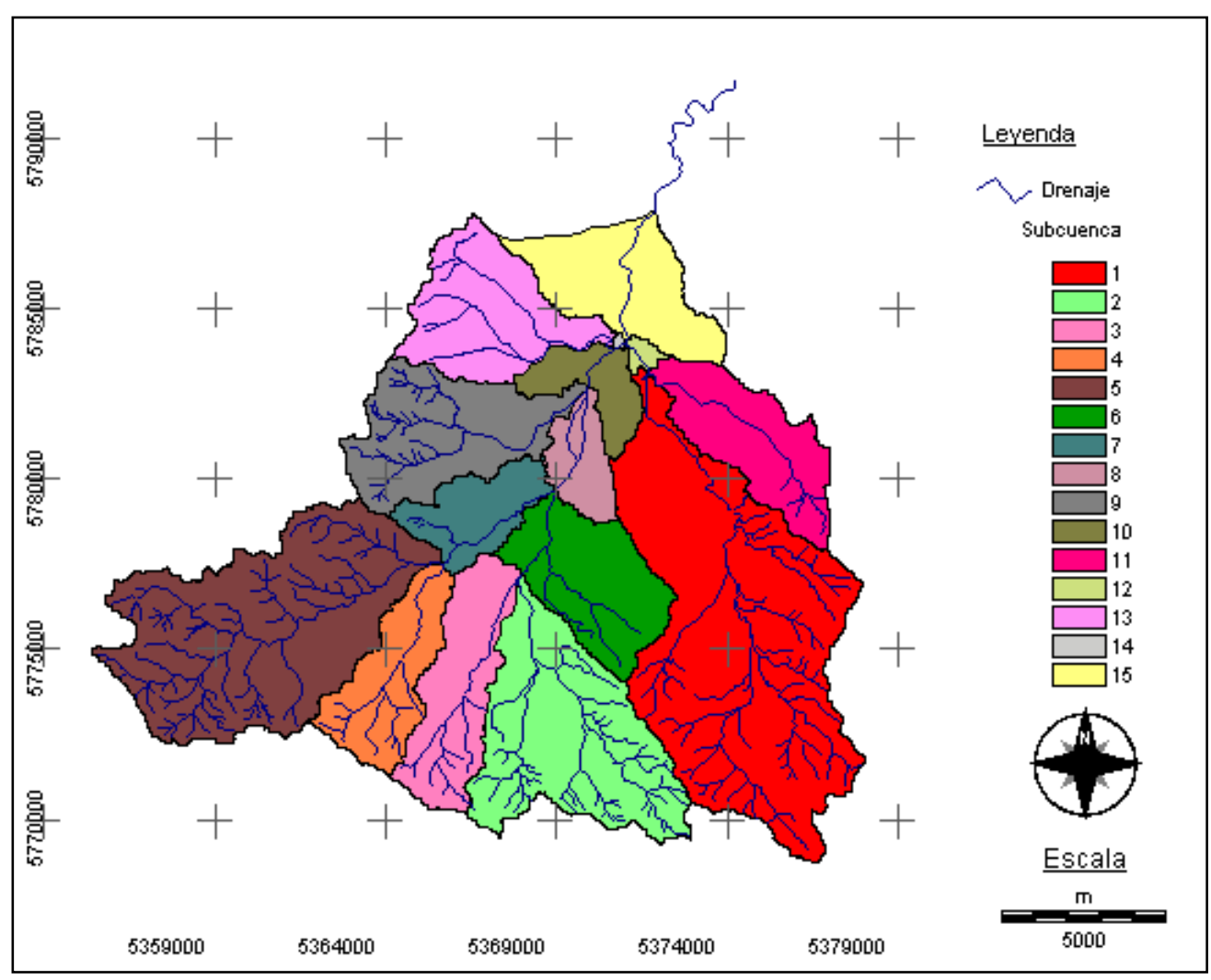

Figura 11: Subcuencas de la cuenca del área serrana de Arroyo Pillahuinco Grande. 


\section{Caracterización del área serrana de la cuenca del Arroyo Pillahuinco Grande.}

\subsection{Morfometría.}

\subsubsection{Parámetros de forma.}

En la Tabla 4 se presentan los valores obtenidos de perímetro, longitud axial, superficie, ancho promedio, factor de forma y coeficiente de compacidad correspondientes a los parámetros de forma para la cuenca y cada subcuenca. El Factor de forma indica en todos los casos que tanto la cuenca como las subcuencas poseen forma alargada, siendo rectangulares oblongas según el coeficiente de compacidad de Gravelius.

Tabla 4: Parámetros de forma para la cuenca y subcuencas

\begin{tabular}{|c|c|c|c|c|c|c|}
\hline \multirow{2}{*}{ Subcuenca } & \multicolumn{7}{|c|}{ Parámetros de forma } \\
\cline { 2 - 7 } & $\begin{array}{c}\text { Perímetro } \\
(\mathbf{m})\end{array}$ & $\begin{array}{c}\text { Longitud } \\
\text { Axial (Km.) }\end{array}$ & Área (Ha) & $\begin{array}{c}\text { Ancho } \\
\text { promedio } \\
\mathbf{( K m . )}\end{array}$ & $\begin{array}{c}\text { Factor de } \\
\text { forma }\end{array}$ & $\begin{array}{c}\text { Coef. de } \\
\text { compacidad }\end{array}$ \\
\hline 1 & 55128.1 & 15.19 & 5805.00 & 3.82 & 0.25 & 2.04 \\
\hline 2 & 35572.3 & 9.26 & 2753.64 & 2.97 & 0.32 & 1.91 \\
\hline 3 & 26394.1 & 7.35 & 1423.17 & 1.94 & 0.26 & 1.97 \\
\hline 4 & 23574.9 & 6.41 & 1173.69 & 1.83 & 0.29 & 1.94 \\
\hline 5 & 43251.4 & 10.62 & 4141.98 & 3.90 & 0.37 & 1.90 \\
\hline 6 & 23395.1 & 6.01 & 1491.66 & 2.48 & 0.41 & 1.71 \\
\hline 7 & 19736.1 & 4.96 & 823.32 & 1.66 & 0.33 & 1.94 \\
\hline 8 & 14276.8 & 4.03 & 541.17 & 1.34 & 0.33 & 1.73 \\
\hline 9 & 29274.2 & 7.47 & 1809.18 & 2.42 & 0.32 & 1.94 \\
\hline 10 & 17576.3 & 3.30 & 581.49 & 1.76 & 0.54 & 2.06 \\
\hline 11 & 24414.9 & 7.40 & 1391.67 & 1.88 & 0.25 & 1.85 \\
\hline 12 & 5698.9 & 1.43 & 83.07 & 0.58 & 0.41 & 1.76 \\
\hline 13 & 26334.8 & 6.52 & 1638.99 & 2.51 & 0.39 & 1.84 \\
\hline 14 & 2039.6 & 0.45 & 14.94 & 0.33 & 0.74 & 1.49 \\
\hline 15 & 24055.4 & 4.97 & 1459.62 & 2.94 & 0.59 & 1.78 \\
\hline Cuenca & 109957.5 & 21.37 & 25132.59 & 11.76 & 0.55 & 1.96 \\
\hline
\end{tabular}

\subsubsection{Parámetros de relieve.}

\subsubsection{Curva hipsométrica.}

El Gráfico 2 representa la proporción del área según las cotas altimétricas para cada subcuenca (curva hipsométrica). En ella puede observarse la variación entre curvas, expresando las diferencias, tanto de altitudes, como de relieve presentes en la cuenca. Estas diferencias tienen como consecuencia un funcionamiento hidrológico diferente para cada subcuenca. 

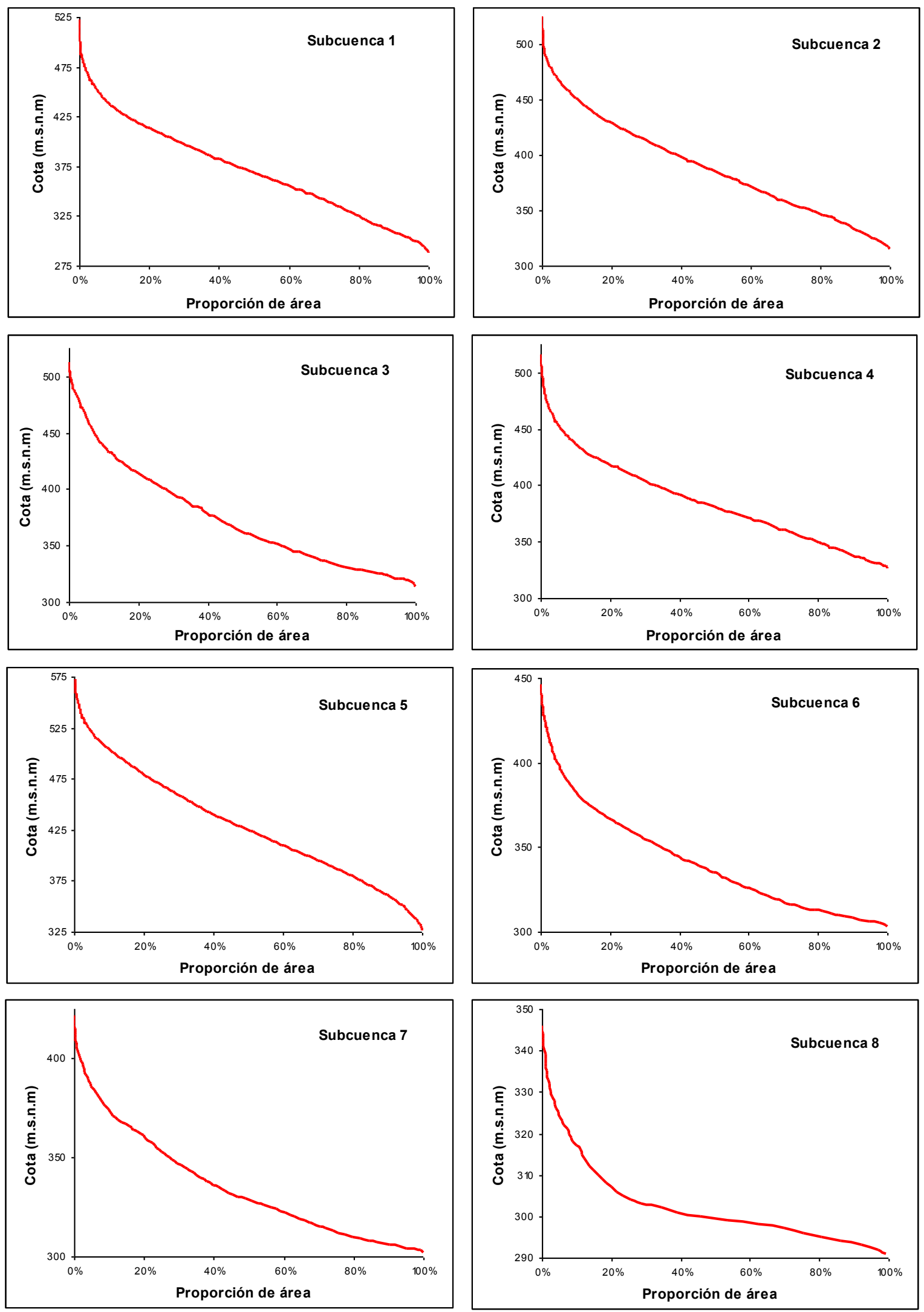

Gráfico 2: Curvas hipsómetricas de las subcuencas. 

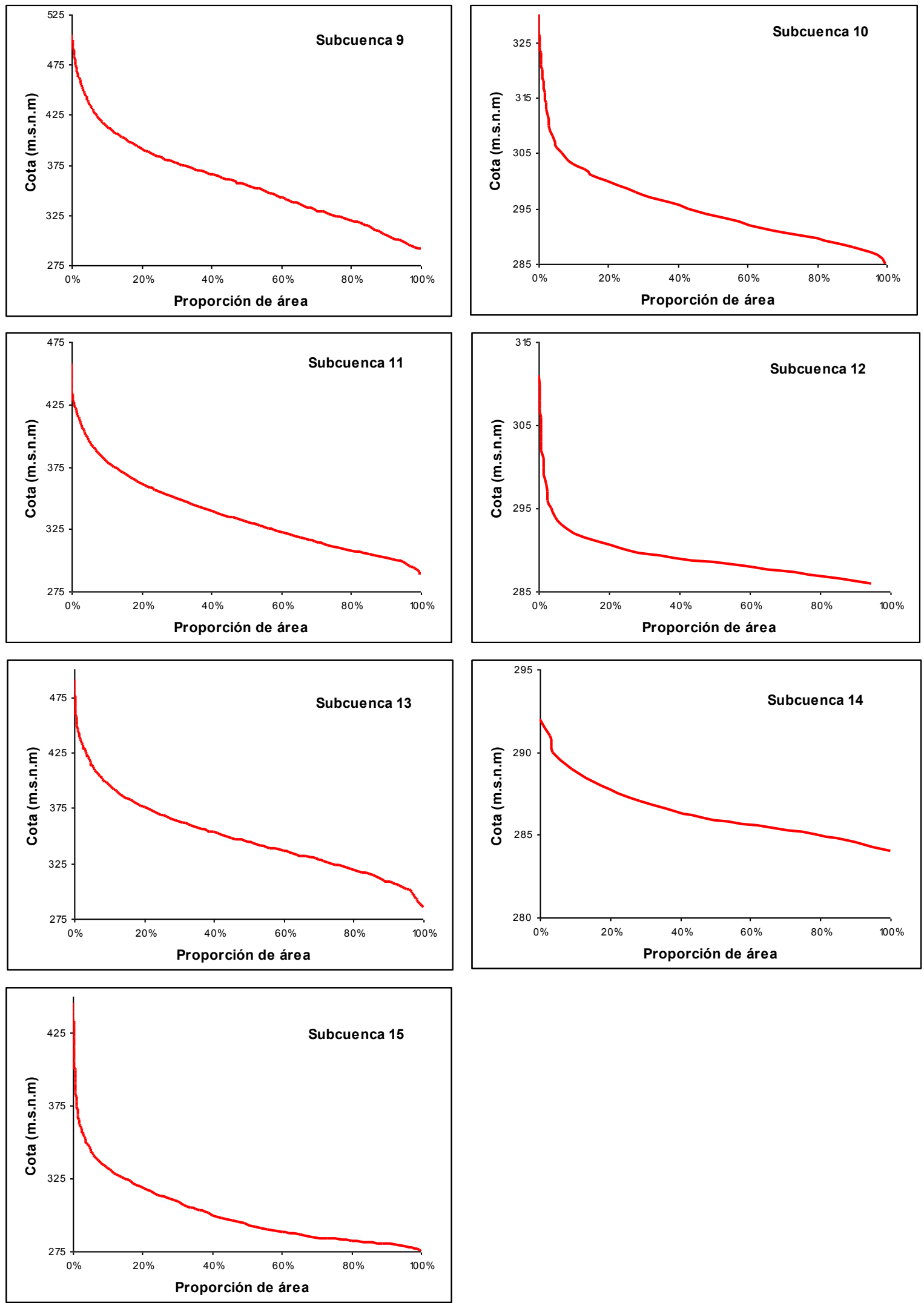

Gráfico 2 (continuación): Curvas hipsómetricas de las subcuencas. 
El Gráfico 3 ilustra la curva hipsométrica de la cuenca. Posee una altura máxima de $615 \mathrm{~m}$, una altura mínima de $276 \mathrm{~m}$ y una altura media (cota correspondiente al 50\% de proporción de área) de $360 \mathrm{~m}$. Su forma indica una distribución areal uniforme de cotas entre los 280 y $450 \mathrm{~m}$, lo que representa aproximadamente el $90 \%$ de la cuenca.

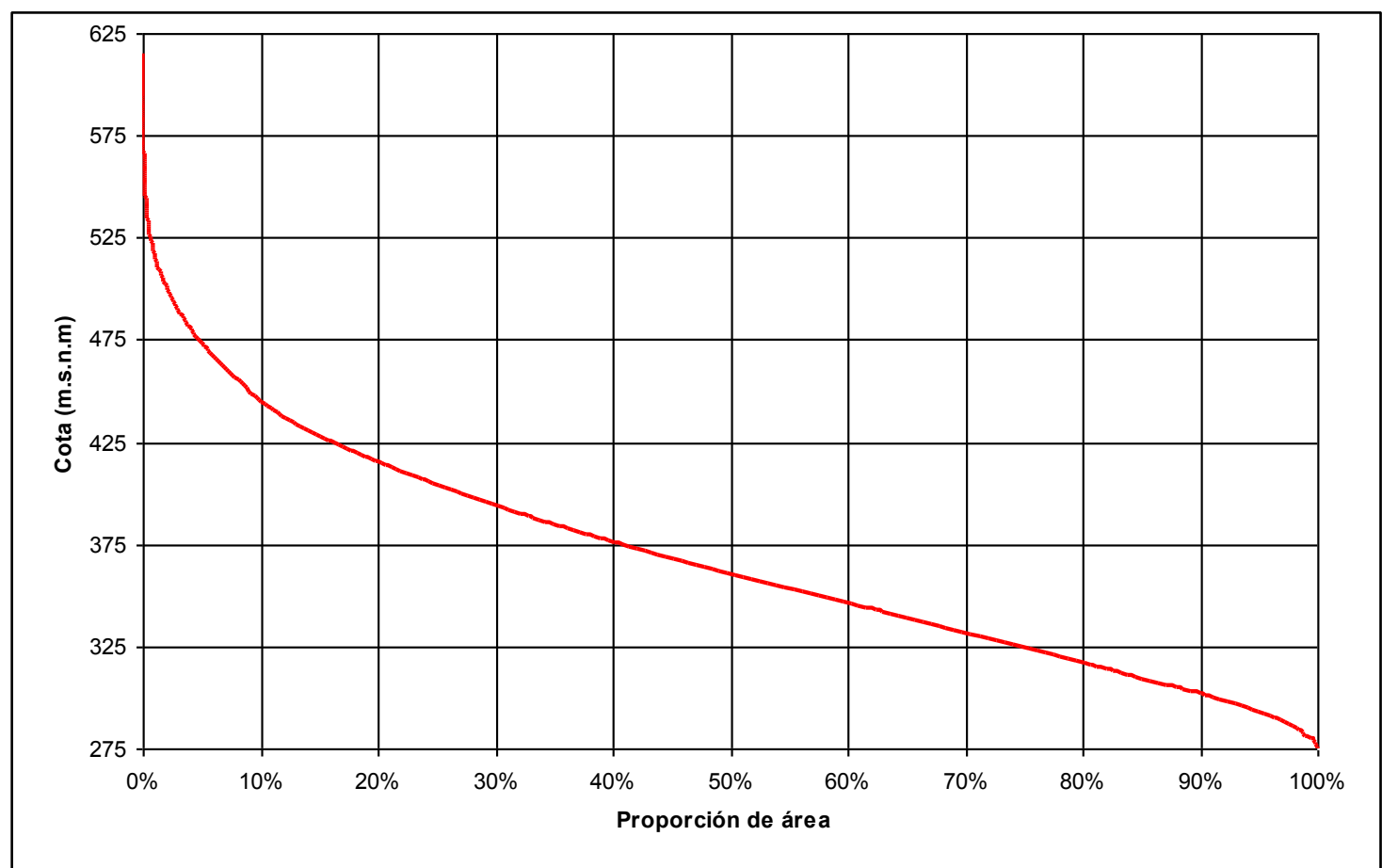

Gráfico 3: Curva hipsométrica de la cuenca.

\subsubsection{Curva hipsométrica adimensional.}

Para la comparación morfométrica de subcuencas a través de la curva de hipsométrica adimensional, se agruparon las mismas en tres categorías de 5 subcuencas cada una. La primera categoría (Gráfico 4) agrupa las subcuencas ubicadas en la cabecera, poseen curvas hipsométricas adimensionales similares, encontrándose en fase de equilibrio con tendencia a la madurez. La segunda (Gráfico 5) esta conformada por las subcuencas del área media, donde las subcuencas 8 y 10 se adaptan a la curva de madurez y las restantes poseen características similares a la primera. Por último, las subcuencas de la parte baja (Gráfico 6), se adaptan a la curva de madurez.

Las curvas hipsométricas adimensionales reflejan el funcionamiento de la subcuencas, donde las áreas poseen un potencial erosivo relativo menor, desde la cabecera de la cuenca hasta su desembocadura. 


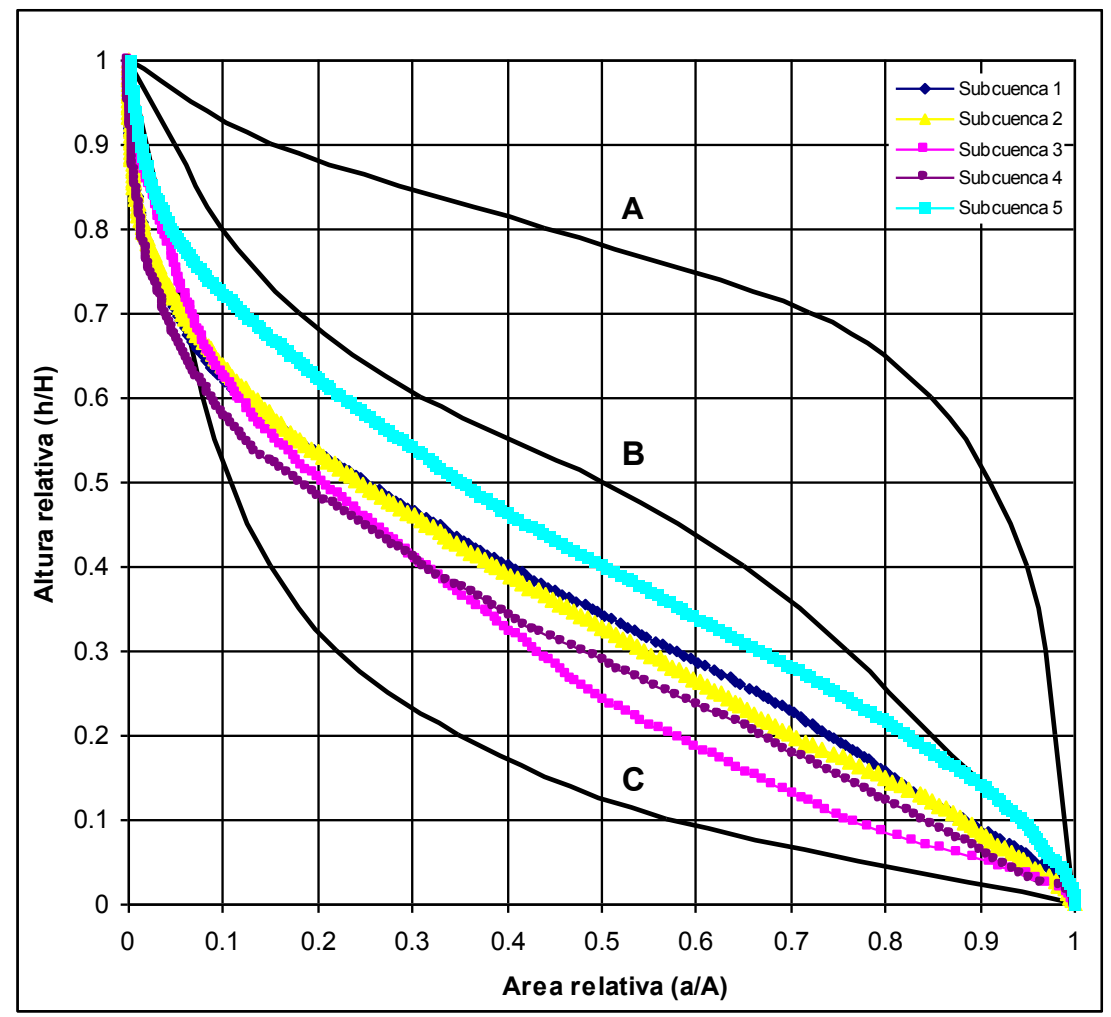

Gráfico 4: Curva hipsométrica adimensional de las subcuencas 1, 2, 3, 4 y 5.

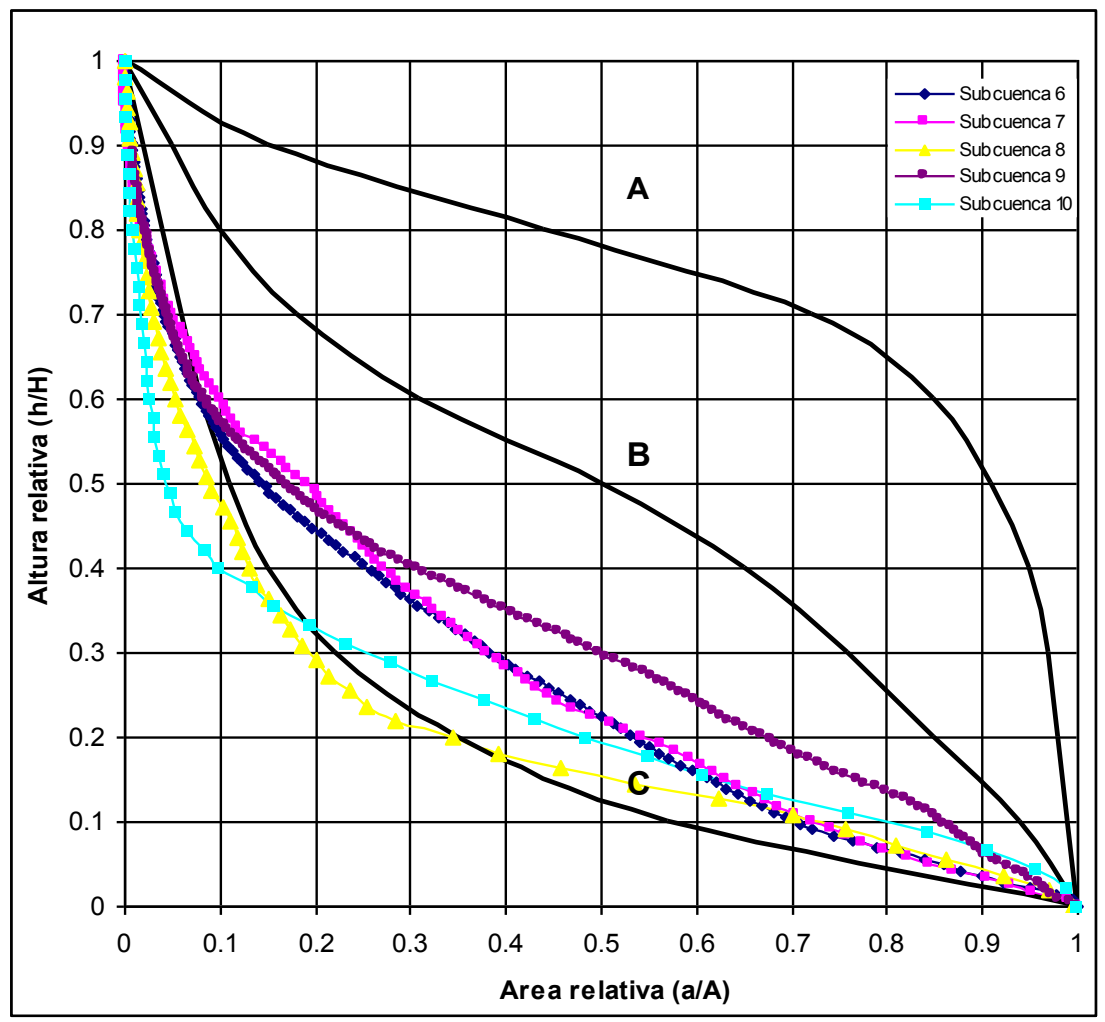

Gráfico 5: Curva hipsométrica adimensional de las subcuencas 6, 7, 8, 9 y 10. 


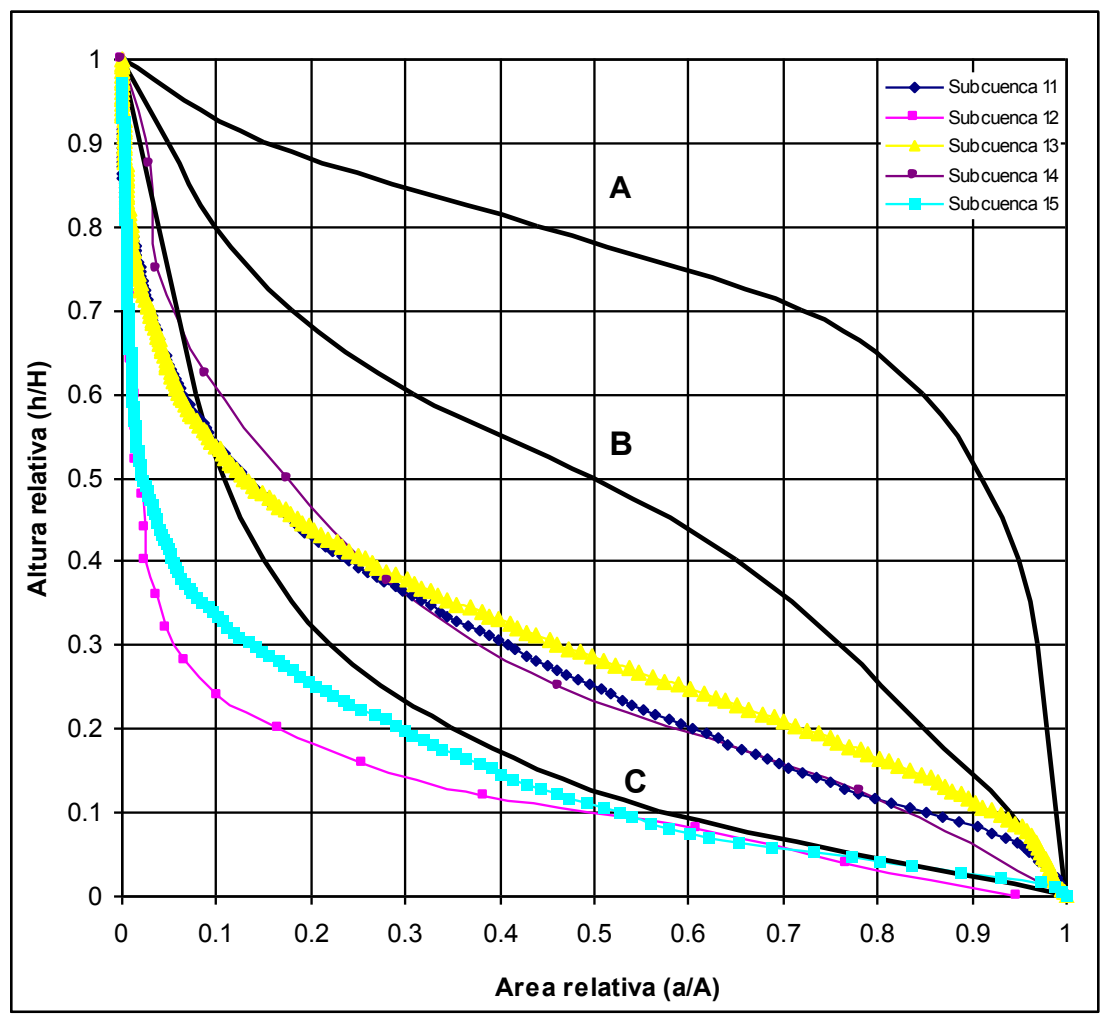

Gráfico 6: Curva hipsométrica adimensional de las subcuencas 11, 12, 13, 14 y 15.

La curva hipsométrica relativa de la cuenca (Gráfico 7) se encuentra entre las curvas B y C propuestas por Strahler (1952), encontrándose en fase de equilibrio con tendencia a la madurez.

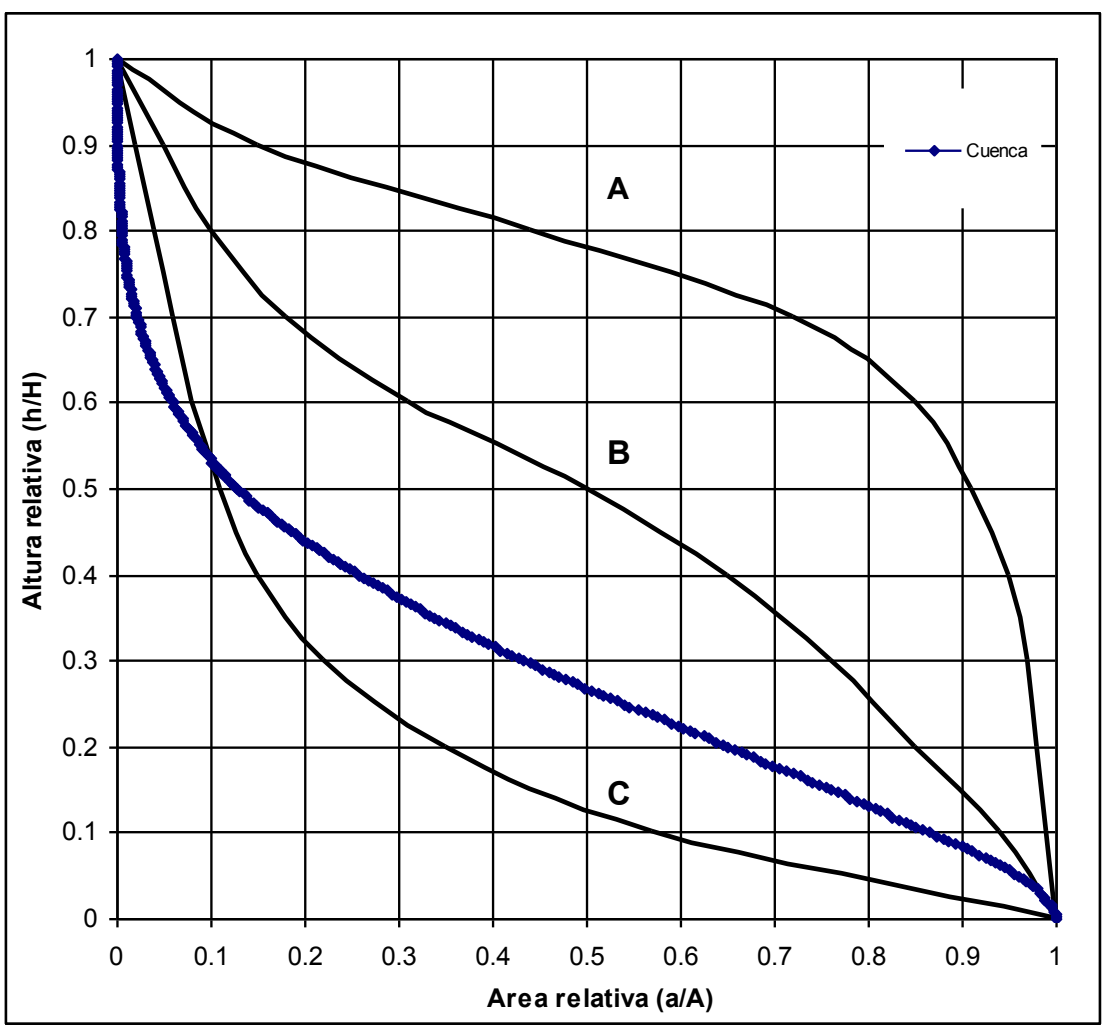

Gráfico 7: Curva hipsométrica relativa de la cuenca 
De manera similar a lo anteriormente expresado, el estado de desarrollo de cada subcuenca y de la cuenca puede visualizarse a través de la integral hipsométrica. El Gráfico 8, expresa la integral hipsométrica de cada subcuenca, indicando que las ubicadas en la parte media y baja poseen un estado de desarrollo mayor que las de la cabecera. Por otro lado, la cuenca tomada como unidad, se encuentra en un estadío avanzado de desarrollo.

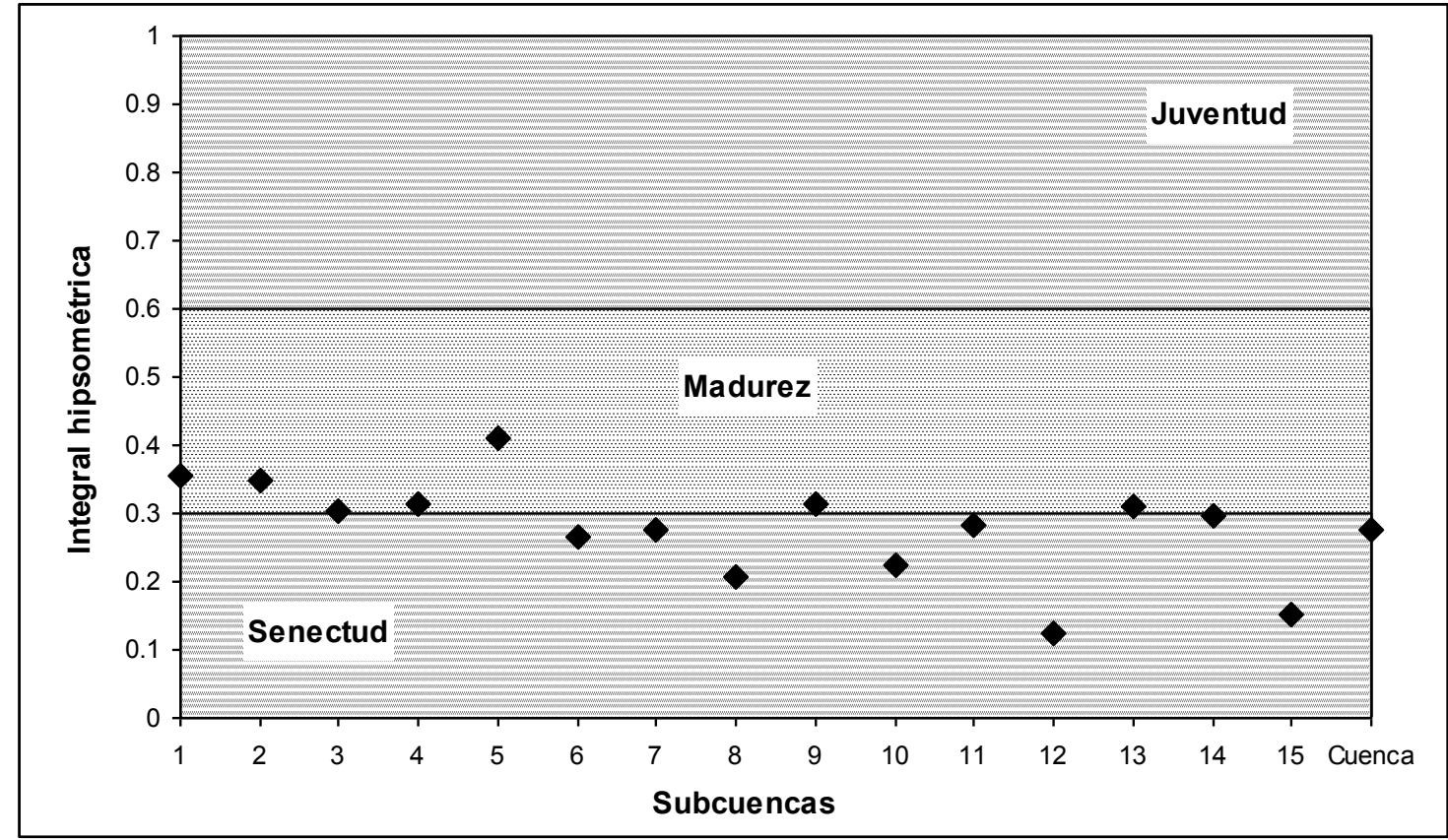

Gráfico 8: Valores de integral hipsométrica para subcuencas y cuenca.

\subsubsection{Parámetros relativos a la red de drenaje.}

Los valores de densidad de drenaje y pendiente media del cauce para cada subcuenca y la cuenca se exponen en la Tabla 5. Los valores mayores de densidad de drenaje corresponden a subcuencas con sectores serranos, donde la red de drenaje posee un mayor grado de bifurcación debido a las características litológicas. El valor elevado de la subcuenca 14 se debe a que es un área pequeña (interfluvio) por donde atraviesa el Arroyo Pillahuinco Grande. Las pendientes medias de los cauces variaron entre $1.64 \%$ para la subcuenca 5 y $0.23 \%$ para la subcuenca 15 . 
Tabla 5: valores de densidad de drenaje y pendiente media del cauce para cada subcuenca y cuenca.

\begin{tabular}{|c|c|c|}
\hline \multirow{2}{*}{ Subcuenca } & \multicolumn{2}{|c|}{ Parámetros relativos a la red de drenaje } \\
\hline & $\begin{array}{c}\text { Densidad de } \\
\text { drenaje }\left(\mathbf{k m} / \mathbf{k m}^{2}\right)\end{array}$ & $\begin{array}{c}\text { Pendiente media del } \\
\text { cauce }(\%)\end{array}$ \\
\hline 1 & 1.4 & 0.98 \\
\hline 2 & 1.8 & 1.27 \\
\hline 3 & 1.1 & 1.55 \\
\hline 4 & 1.3 & 1.32 \\
\hline 5 & 1.9 & 1.64 \\
\hline 6 & 0.8 & 0.46 \\
\hline 7 & 0.8 & 0.55 \\
\hline 8 & 1.0 & 0.35 \\
\hline 9 & 1.6 & 1.50 \\
\hline $\mathbf{1 0}$ & 0.3 & 0.27 \\
\hline 11 & 0.7 & 1.26 \\
\hline 12 & 1.5 & 0.21 \\
\hline 13 & 1.2 & 0.83 \\
\hline 14 & 3.0 & 0.29 \\
\hline 15 & 0.3 & 0.23 \\
\hline Cuenca & 1.3 & 0.91 \\
\hline
\end{tabular}




\subsection{Caracterización climática.}

\subsubsection{Precipitación.}

Los registros del período 1911-2006 arrojan una precipitación media anual de 770,4 mm. En el período Mayo - Agosto se registran los mínimos de precipitación y los máximos en el período Octubre - Abril (Gráfico 9).

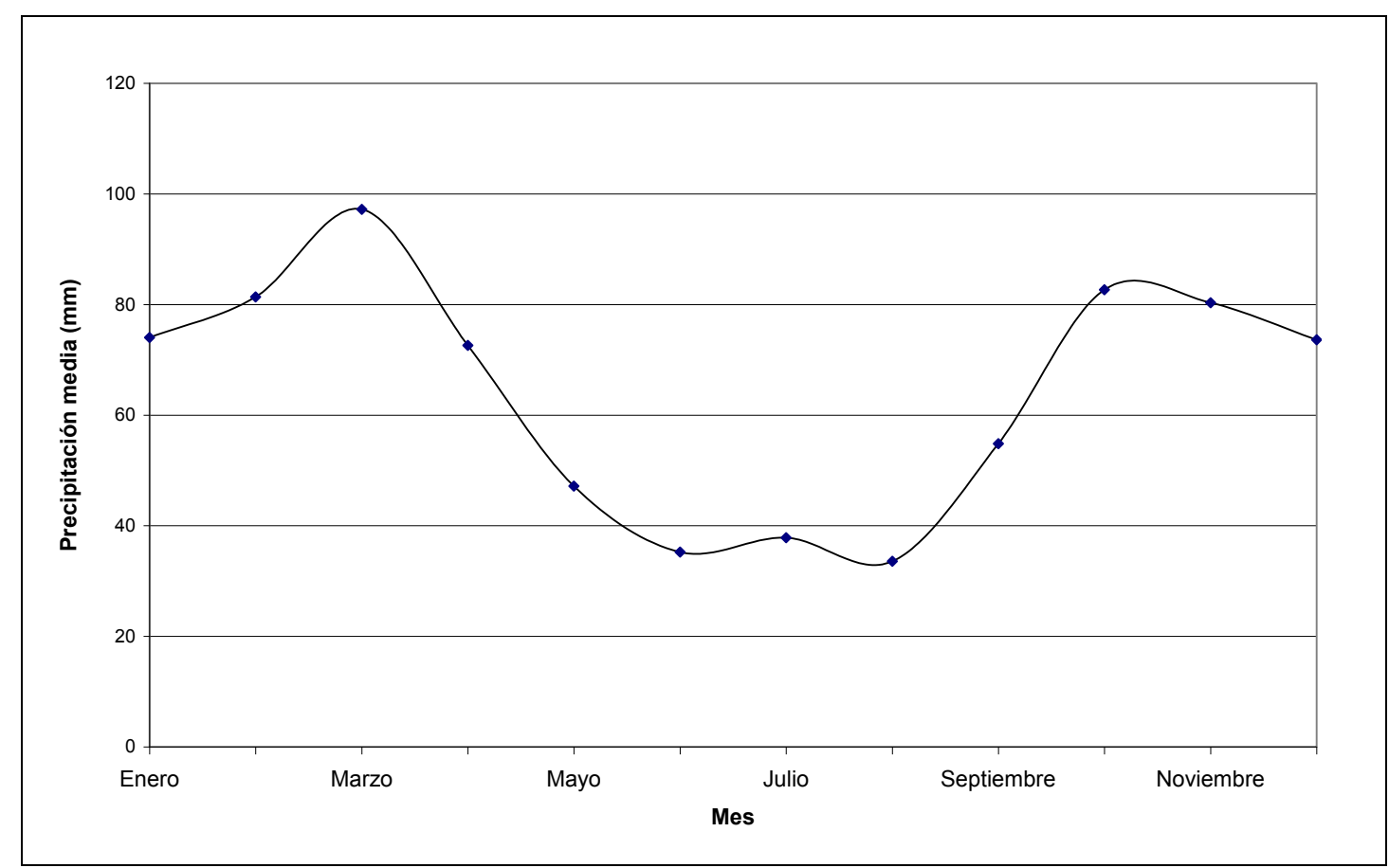

Grafico 9: Distribución media mensual de la precipitación.

\subsubsection{Temperatura.}

La temperatura media anual de la región es de $13.4^{\circ} \mathrm{C}$. La evolución de la temperatura media mensual se presenta en el Gráfico 10. La temperatura media mensual máxima es de $21.3^{\circ} \mathrm{C}$ correspondiente al mes de Enero y los valores mínimos se presentan en Julio con una media mensual de $6.0^{\circ} \mathrm{C}$. 


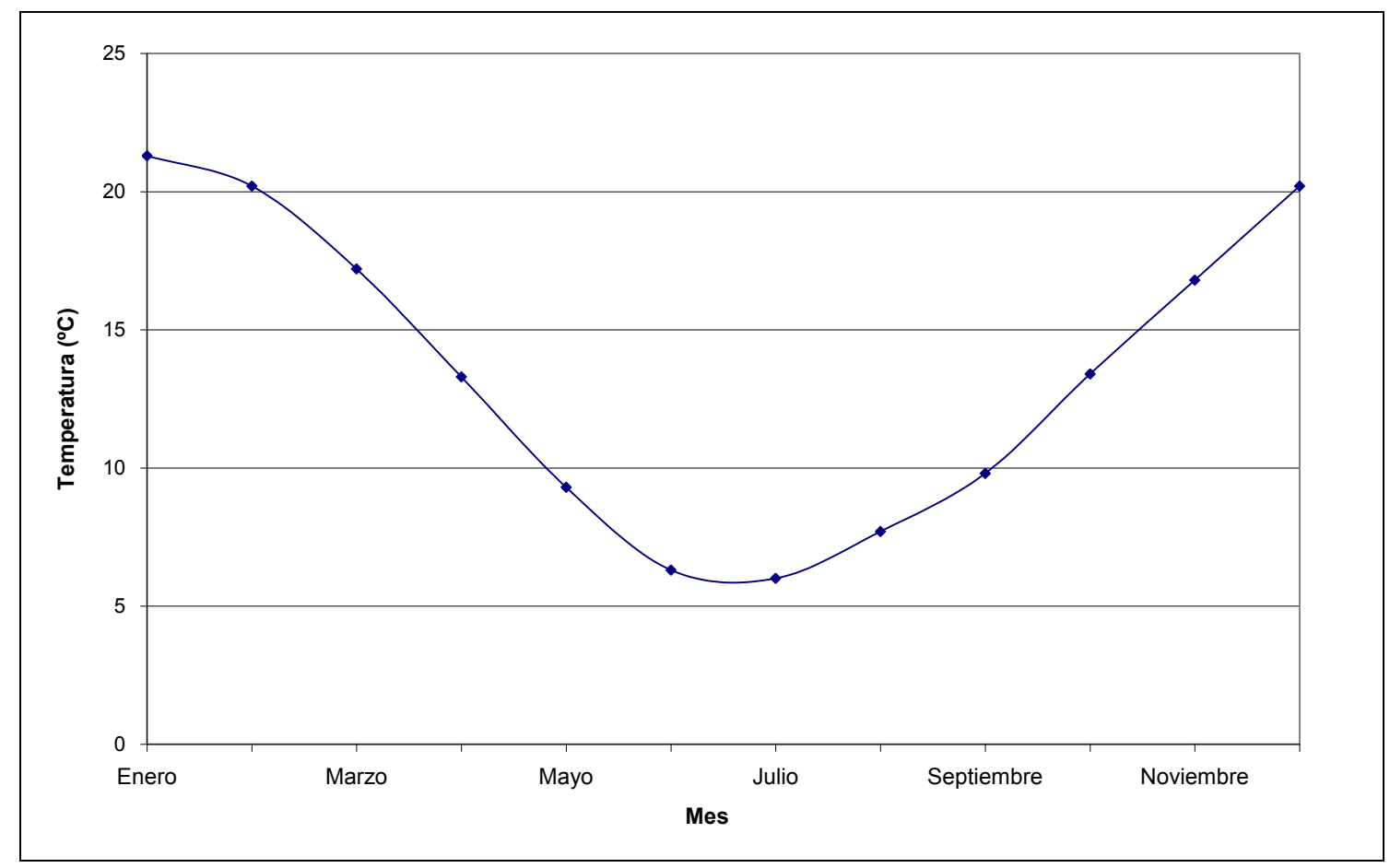

Gráfico 10: Evolución de la temperatura media mensual.

Las heladas se inician en el mes de Abril, finalizando en Noviembre, con un valor medio de 57.3 días con helada, siendo Julio el mes con mayor número de días con helada (25 días).

\subsubsection{Balance hidrológico.}

El balance hidrológico y la clasificación climática fueron calculados para el período 1911-2006. Los valores medios mensuales puede observarse en la tabla 6. La evolución mensual de la precipitación, la evapotranspiración potencial y la real se representan en el Gráfico 11. 


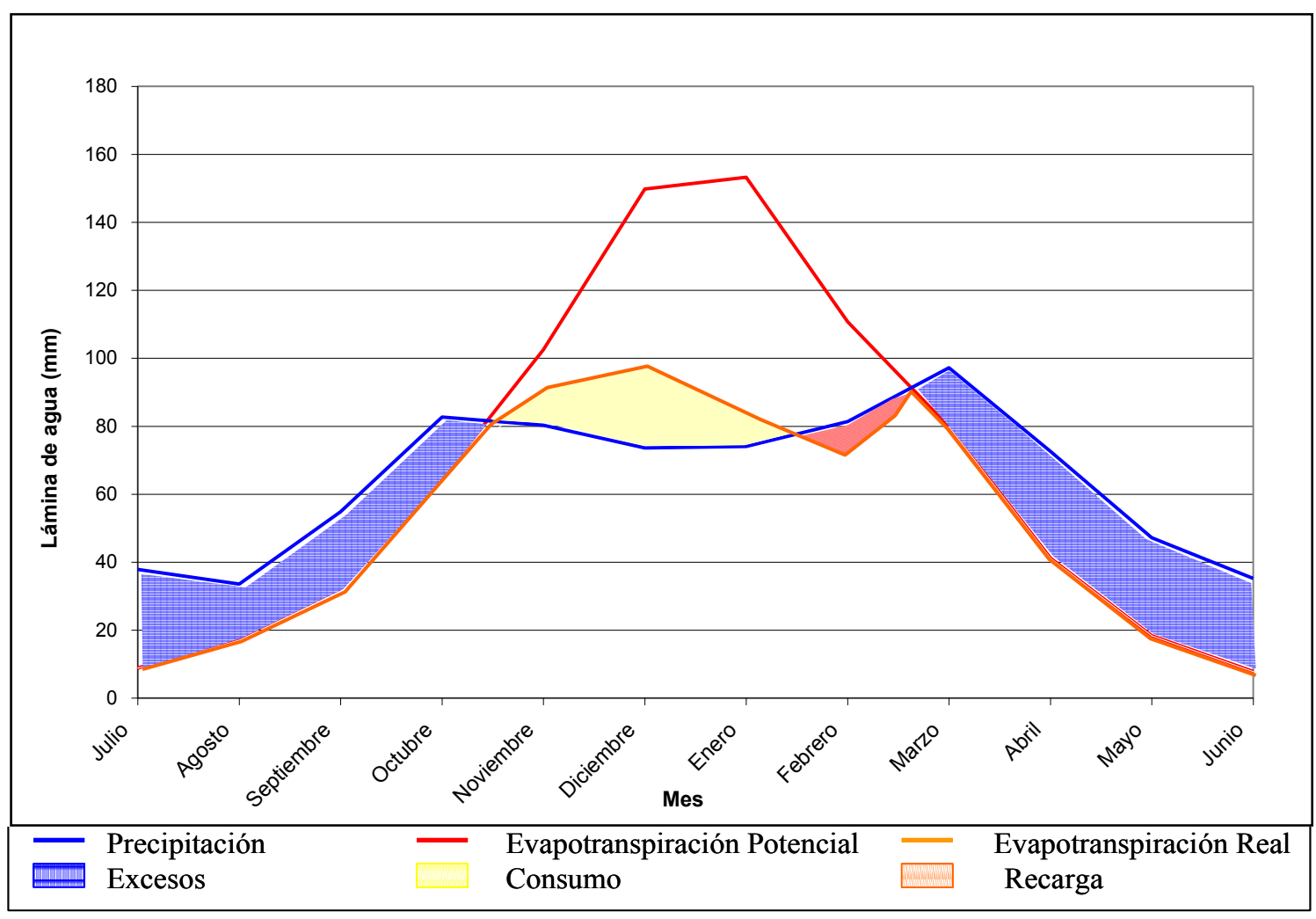

Gráfico 11: Evolución mensual de la precipitación, evapotranspiración potencial, evapotranspiración real, excesos, consumo y recarga del perfil para el período 19112006.

El análisis temporal del balance comienza en Julio donde el Almacenamiento es máximo. El período de excesos se extiende desde Abril a Octubre, a partir del cual las precipitaciones no cubren la evapotranspiración potencial, en consecuencia el almacenamiento del suelo desciende (representado por el consumo) hasta Enero. A partir de éste mes comienza la recarga del perfil terminando en Abril, momento en que el almacenamiento se completa hasta cerrar el ciclo (Tabla 6).

Tabla 6: Balance hidrológico medio mensual (1911-2006). PP, precipitación media mensual; ETP, evapotranspiración potencial; ETR, evapotranspiración real; A, almacenaje; $\Delta$ A, variación del almacenaje; DS, déficit de saturación; E, excesos; D, déficit.

\begin{tabular}{|c|c|c|c|c|c|c|c|c|c|c|c|c|c|}
\hline & Jul. & Ago. & Sep. & Oct. & Nov. & Dic. & Ene. & Feb. & Mar. & Abr. & May. & Jun. & Total \\
\hline PP & 38 & 34 & 55 & 83 & 80 & 74 & 74 & 81 & 97 & 73 & 47 & 35 & 770 \\
\hline ETP & 9 & 18 & 32 & 65 & 102 & 150 & 153 & 111 & 80 & 41 & 18 & 8 & 787 \\
\hline ETR & 9 & 18 & 32 & 65 & 91 & 98 & 84 & 72 & 80 & 41 & 18 & 8 & 616 \\
\hline A & 100 & 100 & 100 & 100 & 89 & 65 & 55 & 65 & 82 & 100 & 100 & 100 & \\
\hline$\Delta$ A & 0 & 0 & 0 & 0 & -11 & -24 & -10 & 10 & 17 & 18 & 0 & 0 & \\
\hline DS & 0 & 0 & 0 & 0 & 11 & 35 & 45 & 35 & 18 & 0 & 0 & 0 & \\
\hline E & 29 & 16 & 23 & 18 & 0 & 0 & 0 & 0 & 0 & 49 & 29 & 27 & 144 \\
\hline D & 0 & 0 & 0 & 0 & 22 & 76 & 79 & 29 & 0 & 0 & 0 & 0 & 191 \\
\hline
\end{tabular}




\subsubsection{Clasificación climática de Thornthwaite.}

A partir del balance medio mensual se realizó la clasificación climática para el período considerado (Tabla 7).La cuenca posee un tipo de clima subhúmedo húmedo, con moderada deficiencia en verano, una eficiencia térmica Mesotérmica templada fría y concentración de la eficiencia térmica en verano tipo b3'.

Tabla 7: Clasificación climática de Thornthwaite para el período 1911-2006.

\begin{tabular}{|c|c|c|c|}
\hline Índice & Símbolo & Tipo & valor \\
\hline Im. & C2 & Subhúmedo Húmedo & 8.46 \\
\hline Ia. & $\mathrm{S}$ & Moderada deficiencia en verano & 9.76 \\
\hline IET & B'2 & Mesotérmica templada fría & 787 \\
\hline Cet & b3' & - & 52.56 \\
\hline
\end{tabular}

\subsubsection{Análisis de precipitaciones.}

El análisis de las precipitaciones anuales del período comprendido desde el año 1911 hasta 2006 determina que la evolución lineal de las precipitaciones poseen una tendencia de aumento con una diferencia de aproximadamente $100 \mathrm{~mm}$. Puede observarse a través de una línea de tendencia polinómica, que los registros indican un período seco desde 1911 hasta 1955, seguido por uno húmedo desde 1956 hasta 1995, para finalmente ingresar en un período seco a partir de 1996 hasta la actualidad (Gráfico 12).

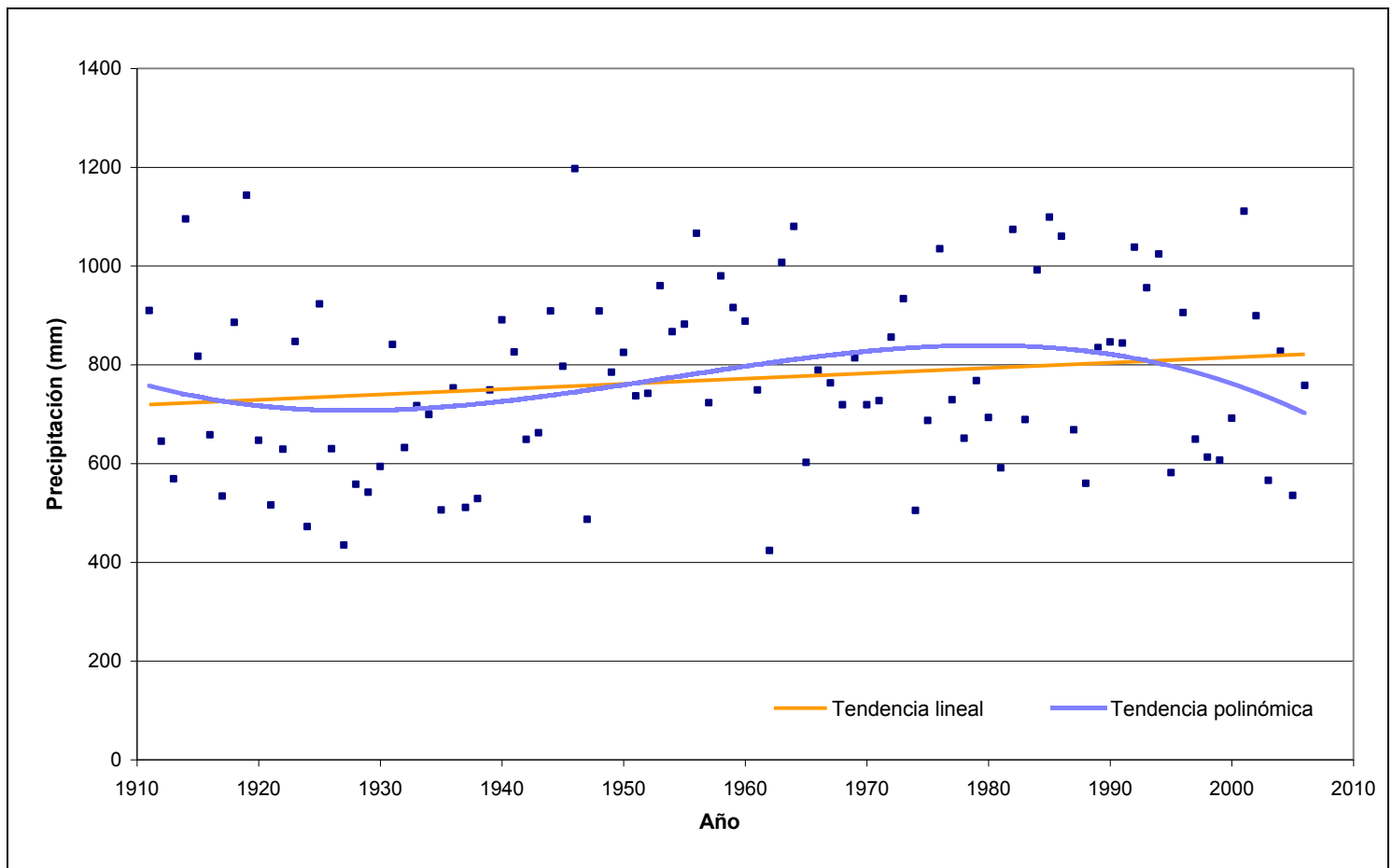

Grafico 12: Evolución y tendencia lineal y polinómica de las precipitaciones anuales. 
Para la determinación de la fuente del aumento de las precipitaciones anuales se dividió la precipitación anual en función de su distribución mensual, se consideraron 2 períodos uno húmedo, denominado cálido, el cual incluye los meses del intervalo Octubre - Marzo y otro, seco, denominado frío, que incluye los meses del intervalo Abril - Septiembre.

El período cálido posee una tendencia al aumento de las precipitaciones de aproximadamente $100 \mathrm{~mm}$. En cuanto al período frío, se observa que las precipitaciones tienden a mantenerse constantes (Gráfico 13). Según lo visto en la tendencia de las precipitaciones a nivel anual podría vincularse su aumento a la mayor pluviometría del período estival.

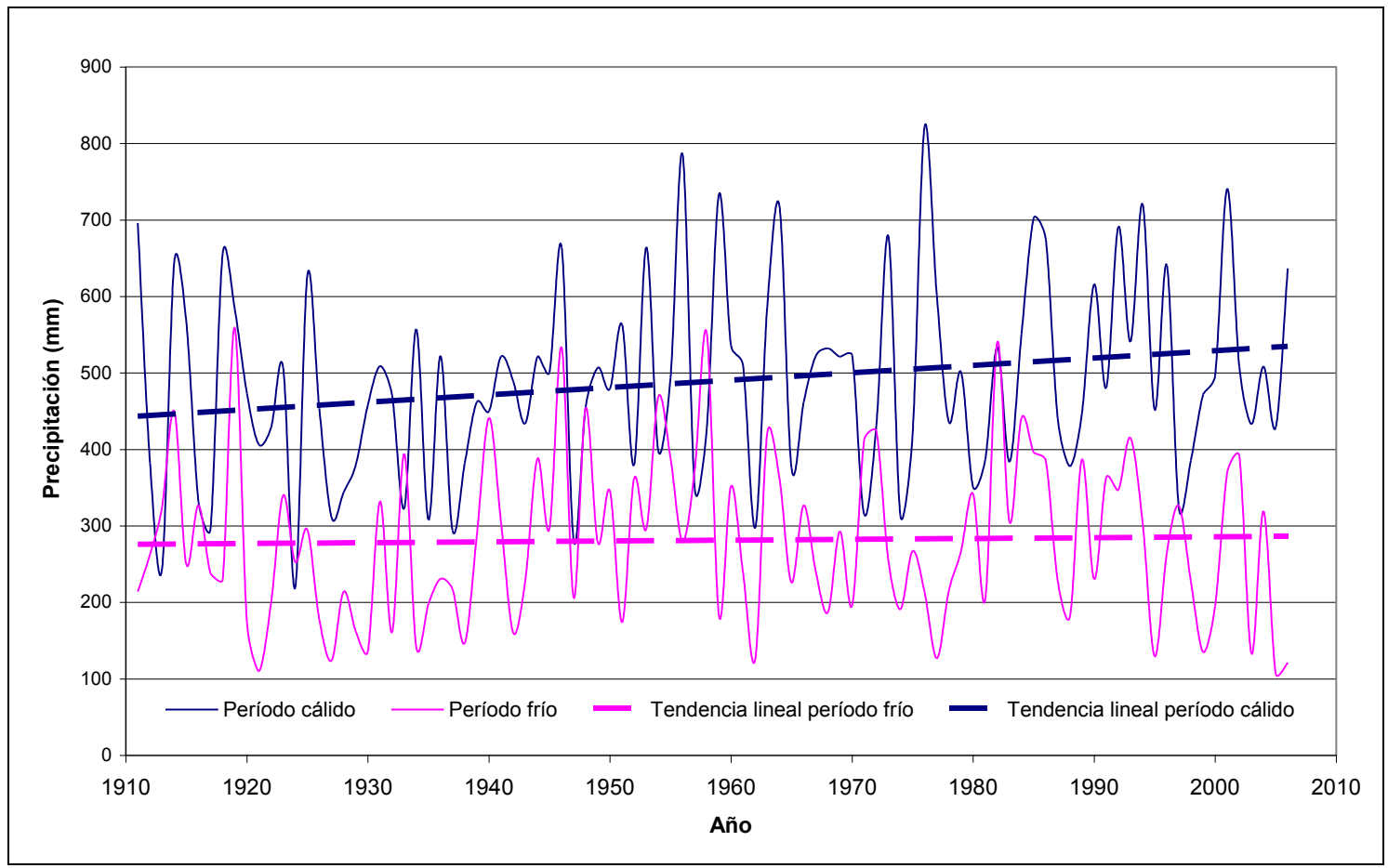

Grafico13: Evolución y tendencia lineal de las precipitaciones del periodo cálido y frío.

Se analizaron las tendencias del número de días con lluvia con el fin de determinar si la causa del aumento de las precipitaciones anuales podría ser atribuida a un mayor número de días con lluvia. El Gráfico 14 refleja que la tendencia de las precipitaciones es proporcional al aumento del número de días con lluvia. 


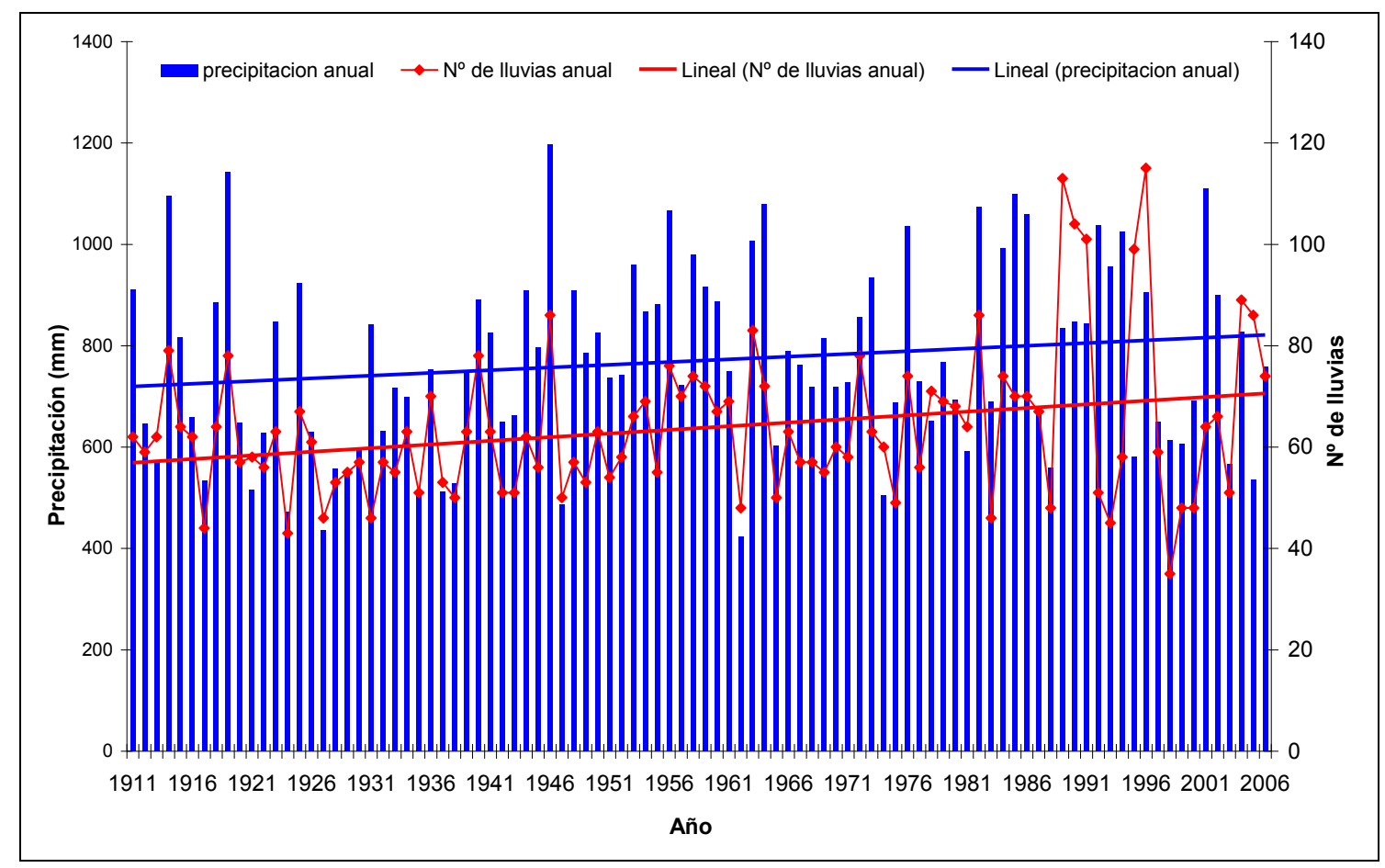

Grafico 14: Evolución y tendencia lineal de las precipitaciones y el número de precipitaciones anuales.

El mismo análisis se realizó para los períodos cálidos (Gráfico 15) y fríos (Gráfico 16). En el primero se observa, de manera similar que a nivel anual, una proporcionalidad entre el número de días con lluvia y la precipitación. En los períodos fríos, la tendencia de las precipitaciones se mantiene relativamente constante pero, como se manifiesta en el Gráfico 16 las tendencias en el número de días con lluvia es al aumento. 


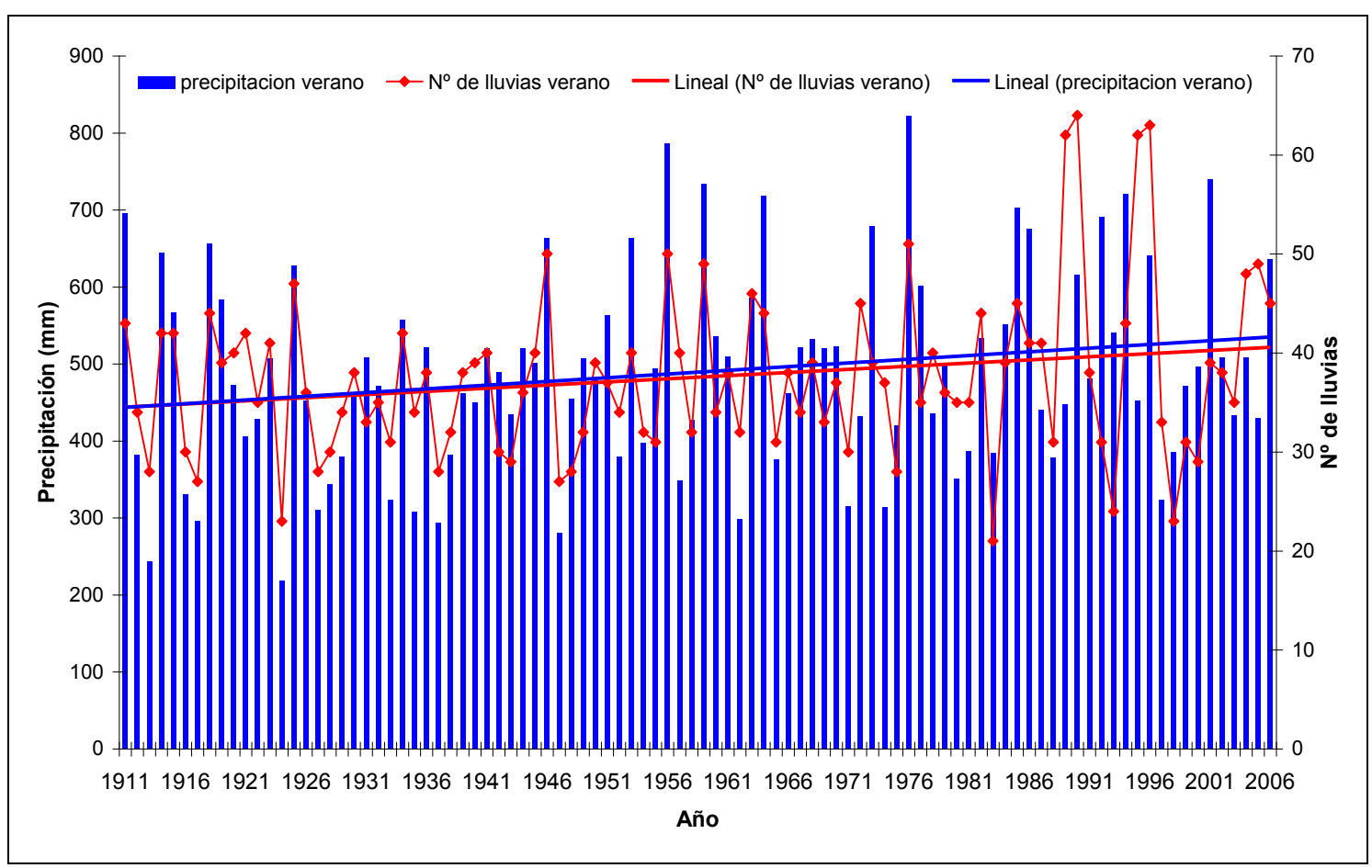

Gráfico 15: Evolución y tendencia lineal de las precipitaciones y el número de precipitaciones del periodo cálido.

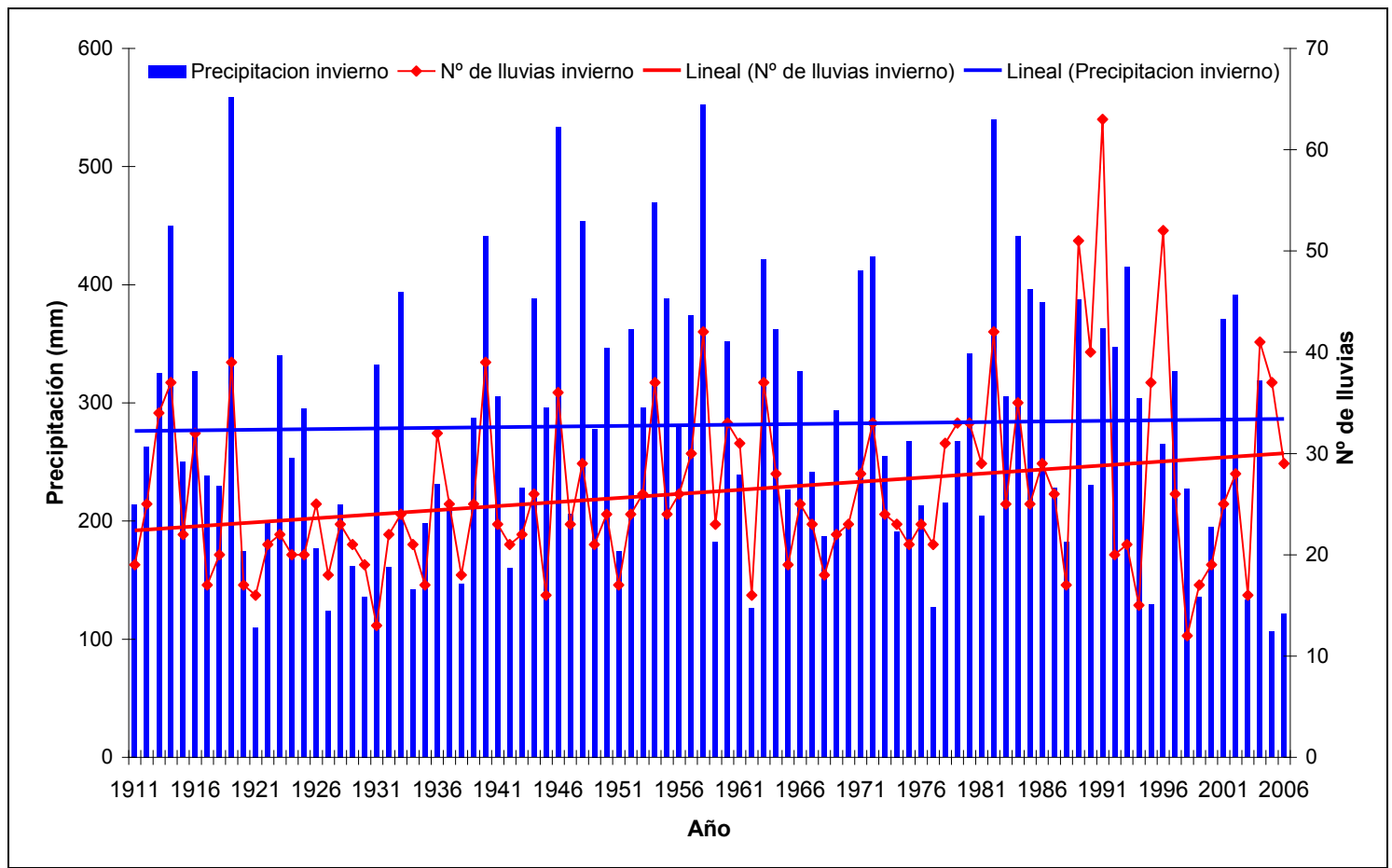

Gráfico 16: Evolución y tendencia lineal de las precipitaciones y el número de precipitaciones del periodo frío. 


\subsubsection{Ajuste de precipitaciones diarias máximas a ley de Gumbel.}

Se realizó el ajuste de las precipitaciones diarias máximas anuales del período 1911 2006, obteniendo los parámetros de la función de distribución de probabilidades acumuladas según la ley de Gumbel (Gráfico 17). La precipitación media máxima diaria $\left(\mathrm{P}_{0.5}\right)$ fue de $71.58 \mathrm{~mm}$ y un desvío Standard de $18.87 \mathrm{~mm}$.

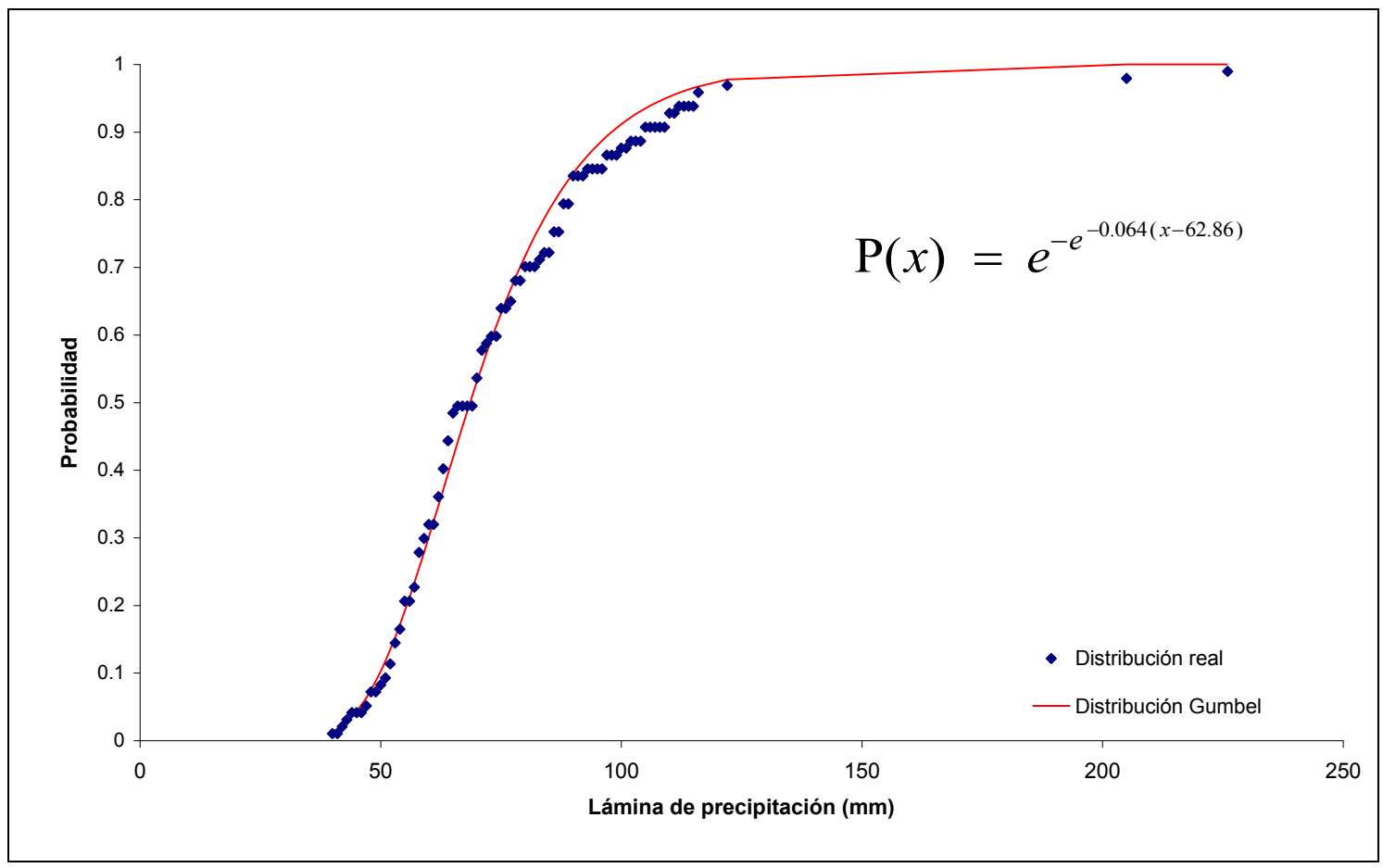

(Gráfico 17): Función de distribución de probabilidades acumuladas según la ley de Gumbel.

En la Tabla 8 se presentan los valores de los parámetros $\alpha$ y $u$ de la función Gumbel, la precipitación media máxima diaria $(\bar{X})$, media de los valores del tamaño de la muestra $(\bar{Y})$, desvío Standard de precipitación media máxima diaria $\left(S_{x}\right)$, desvío Standard de los valores del tamaño de la muestra $\left(S_{n}\right)$

Tabla 8: Valores de los parámetros $\alpha, u, \bar{X}, \bar{Y}, S_{x}, S_{n}$ obtenidos para el ajuste de la función Gumbel.

\begin{tabular}{|c|r|r|r|r|r|}
\hline$\alpha$ & $u$ & $\bar{X}$ & $\bar{Y}$ & $S_{x}$ & $S_{n}$ \\
\hline 0.064 & 62.85 & 71.58 & 0.56 & 18.87 & 1.20 \\
\hline
\end{tabular}




\subsubsection{Test de bondad de ajuste.}

Se realizó el test de Kolmogorov-Smirnov para comparar la función de distribución acumulada de los datos observados con la distribución Gumbel obtenida. El valor de distancia máxima entre curvas fue de 0.066 , por lo que su ajuste es adecuado para el nivel de confiabilidad 0.2. La Tabla 9, expresa el valor de distancia máxima obtenido y los valores tabulados para los niveles de confianza $0.01,0.05,0.1,0.15$ y 0.2 .

Tabla 9: Valor de distancia máxima obtenido y valores tabulados para los niveles de confianza $0.01,0.05,0.1,0.15$ y 0.2 .

\begin{tabular}{|c|c|c|}
\hline \multirow{6}{*}{ 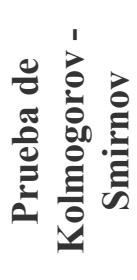 } & D supremo & 0.06634381 \\
\hline & D teórico 0.01 & 0.16636118 \\
\hline & D teórico 0.05 & 0.13880442 \\
\hline & D teórico 0.1 & 0.12451573 \\
\hline & D teórico 0.15 & 0.11635076 \\
\hline & D teórico 0.2 & 0.10920642 \\
\hline
\end{tabular}

\subsubsection{Determinación del Período de retorno.}

A partir de los valores de probabilidad obtenidos mediante el ajuste a la ecuación de distribución Gumbel, se determinó la lámina de precipitación para diferentes períodos de retorno. La lámina promedio esperable para un año es de $37.4 \mathrm{~mm}$.

Tabla 10: Lámina de precipitación para diferentes períodos de retorno.

\begin{tabular}{|c|c|}
\hline $\begin{array}{c}\text { Período de } \\
\text { retorno (años) }\end{array}$ & $\begin{array}{c}\text { Lámina de } \\
\text { precipitación } \\
\text { (mm) }\end{array}$ \\
\hline 1 & 37.4 \\
\hline 2 & 68.6 \\
\hline 3 & 76.9 \\
\hline 4 & 82.3 \\
\hline 5 & 86.3 \\
\hline 10 & 98.0 \\
\hline 15 & 104.6 \\
\hline 20 & 109.2 \\
\hline 25 & 112.8 \\
\hline 30 & 115.7 \\
\hline 50 & 123.8 \\
\hline 100 & 134.7 \\
\hline 125 & 138.1 \\
\hline 150 & 141.0 \\
\hline 200 & 145.5 \\
\hline 250 & 149.0 \\
\hline
\end{tabular}




\subsubsection{Selección de tormentas.}

Se procedió la lectura y posterior digitalización analítica con intervalos cada 30 minutos de fajas pluviográficas de la Estación Coronel Pringles Aero, correspondientes a 17 tormentas. Se determinaron los períodos de retorno en función de la lámina total precipitada (Tabla 11).

Tabla 11: Lámina total y período de retorno de 17 fajas pluviográficas.

\begin{tabular}{|c|c|c|}
\hline Tormenta & $\begin{array}{c}\text { Lámina de } \\
\text { precipitación } \\
\text { total (mm) }\end{array}$ & $\begin{array}{c}\text { Período de } \\
\text { retorno (años) }\end{array}$ \\
\hline $03 / 01 / 1963$ & 14.5 & 1.0 \\
\hline $07 / 12 / 1961$ & 20 & 1.0 \\
\hline $02 / 01 / 1961$ & 23.4 & 1.0 \\
\hline $18 / 01 / 1956$ & 24.1 & 1.0 \\
\hline $30 / 09 / 2000$ & 24.5 & 1.0 \\
\hline $02 / 02 / 1963$ & 27 & 1.0 \\
\hline $21 / 12 / 1962$ & 27 & 1.0 \\
\hline $13 / 12 / 1959$ & 27.2 & 1.0 \\
\hline $26 / 12 / 1994$ & 29 & 1.0 \\
\hline $10 / 03 / 1956$ & 33.8 & 1.0 \\
\hline $12 / 04 / 1961$ & 37 & 1.0 \\
\hline $15 \mathrm{~g}$ & 37.1 & 1.0 \\
\hline $30 / 10 / 1993$ & 41 & 1.0 \\
\hline $14 / 10 / 1961$ & 46.5 & 1.1 \\
\hline $15 / 02 / 1994$ & 49 & 1.1 \\
\hline $06 / 05 / 94 \mathrm{G}$ & 72 & 2.3 \\
\hline $10 / 11 / 1993$ & 89 & 5.9 \\
\hline
\end{tabular}

A partir de los valores de período de retorno de cada evento, se seleccionaron 3 tormentas para la aplicación de los modelos hidrológicos. En la Tabla 12 se presentan las curvas de masa de lluvia cada 30 minutos para las 3 tormentas junto a su período de retorno. 
Tabla 12: Curva de masa de lluvia cada 30 minutos y período de retorno para las 3 tormentas seleccionadas.

\begin{tabular}{|c|c|c|c|}
\hline \multirow{2}{*}{ Tiempo (hs) } & \multicolumn{3}{|c|}{ Período de retorno } \\
\hline & 5.9 años & 2.3 años & 1 año \\
\hline 0 & 0 & 0 & 0 \\
\hline 0.5 & 2.2 & 1 & 0.5 \\
\hline 1 & 7.9 & 10.5 & 1 \\
\hline 1.5 & 7.9 & 13.5 & 3 \\
\hline 2 & 7.9 & 18 & 14.5 \\
\hline 2.5 & 16 & 25 & 25 \\
\hline 3 & 16 & 29.1 & 30.5 \\
\hline 3.5 & 16.3 & 32.2 & 31.5 \\
\hline 4 & 17 & 41 & 37.1 \\
\hline 4.5 & 18 & 56 & \\
\hline 5 & 18.8 & 68.5 & \\
\hline 5.5 & 21 & 70 & \\
\hline 6 & 23.7 & 72 & \\
\hline 6.5 & 24.5 & & \\
\hline 7 & 24.5 & & \\
\hline 7.5 & 25.3 & & \\
\hline 8 & 25.7 & & \\
\hline 8.5 & 27.5 & & \\
\hline 9 & 28.5 & & \\
\hline 9.5 & 30.5 & & \\
\hline 10 & 32.3 & & \\
\hline 10.5 & 35 & & \\
\hline 11 & 37 & & \\
\hline 11.5 & 40.5 & & \\
\hline 12 & 45 & & \\
\hline 12.5 & 51.5 & & \\
\hline 13 & 60.2 & & \\
\hline 13.5 & 65 & & \\
\hline 14 & 72.8 & & \\
\hline 14.5 & 83 & & \\
\hline 15 & 87 & & \\
\hline 15.5 & 89 & & \\
\hline
\end{tabular}

\subsection{Vegetación y usos del suelo.}

Se realizó la recolección de datos de cobertura vegetal en 25 puntos, identificados y georreferenciados previamente en una imagen satelital del área (Figura 12). Se identificaron especies forestales, cultivos anuales y verdeos con labranza convencional o en curvas de nivel, pajonales y pastizales naturales. Las especies forestales identificadas fueron: Acacia blanca, Eucaliptos, Sauces y Pinos. Dentro de los cultivos y verdeos se encontraron: Maíz, Girasol, Soja, Trigo y Avena. 
El pastizal serrano se ve representado por ejemplares mayoritarios de los géneros Stipa, Piptochaetium, Festuca y Briza. El pajonal serrano se compone exclusivamente por Paja colorada, ubicado en barrancas bajas, muy húmedas, de los bordes de cursos de agua serranos, a veces formando una franja marginal estrecha, paralela al cauce. En otros casos ocupa superficies extensas, sobre suelos en general profundos, húmedos ligados a vertientes en concavidades y pendientes serranas suaves (3 a 11\%), y abanicos aluviales (Frangi y Bottino, 1994).

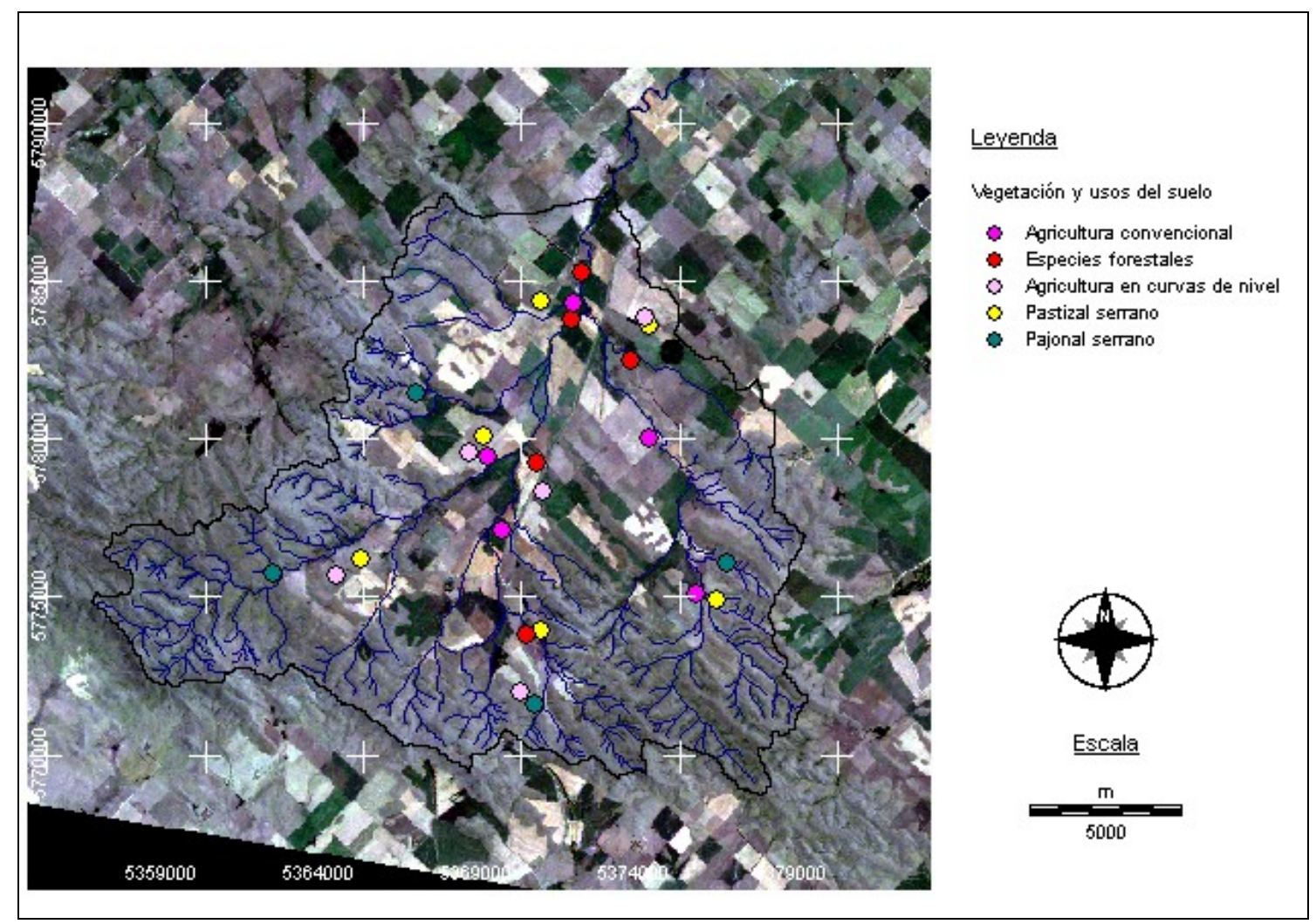

Figura 12: Distribución de puntos de muestreo de cobertura vegetal.

En función de los datos relevados se confeccionaron 5 clases de vegetación y usos del suelo diferentes adaptadas a las categorías utilizadas en la generación del NC (Tabla 9; Anexo 1). A continuación se expone la descripción de cada categoría:

- Bosques B (B.B): Incluye áreas con especies forestales, principalmente formando motes de reparo o cortinas rompe viento (Fotografía 2).

- Cultivos alineados R B (C.R.B): Conformado por cultivos anuales de grano fino y grueso o verdeos de verano e invierno con labranza convencional o en siembra directa (Fotografía 3).

- Cultivos alineados C B (C.C.B): representados por cultivos anuales de grano fino y grueso o verdeos de verano e invierno con labranza en curvas de nivel (Fotografía 4).

- Matorral, mezcla matorral y maleza Cubierta $>75 \%$ (M.C $>75 \%$ ): Incluye las especies del pajonal serrano (Fotografía 5).

- Prados permanentes (P.P): Constituida por las especies del pastizal serrano (Fotografía 5). 


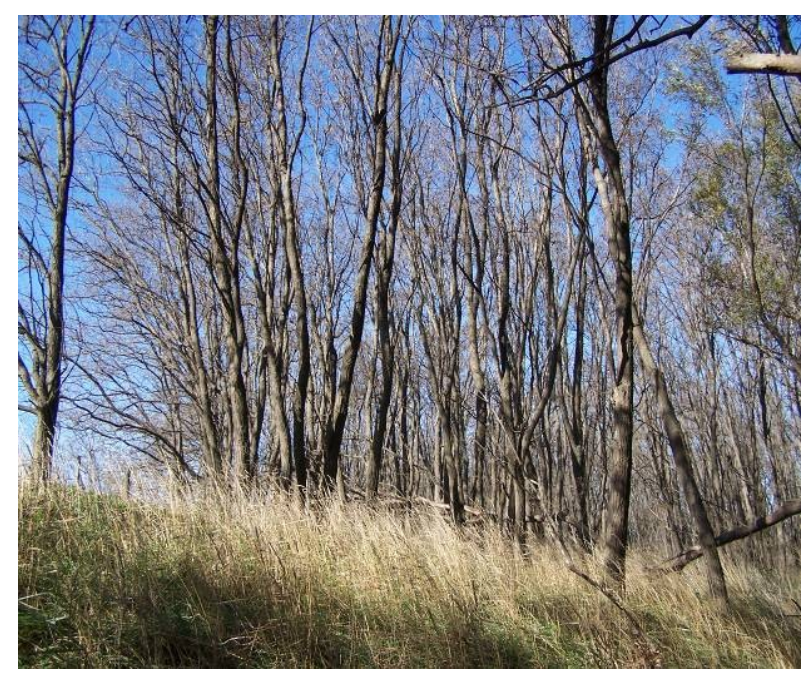

Fotografía 2: Monte de acacia blanca (Bosques B).

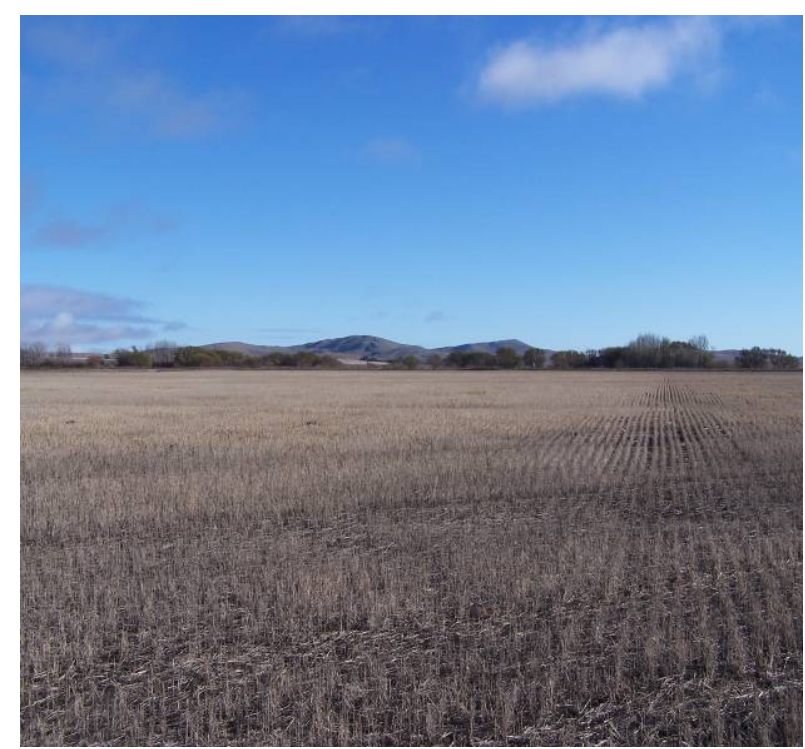

Fotografía 3: Rastrojo de Trigo con labranza convencional (Cultivos alineados R B).

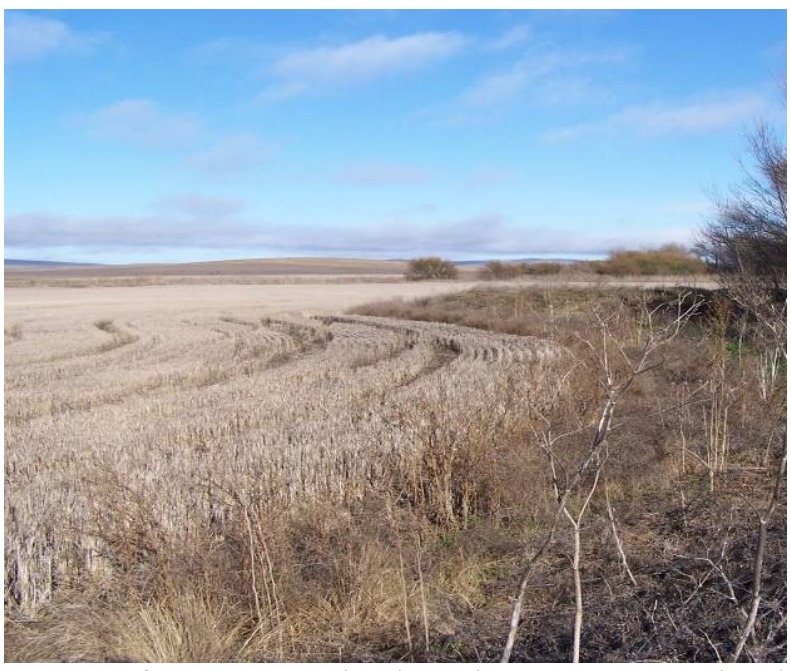

Fotografía 4: Rastrojo de Trigo en curvas de nivel (Cultivos alineados C B). 


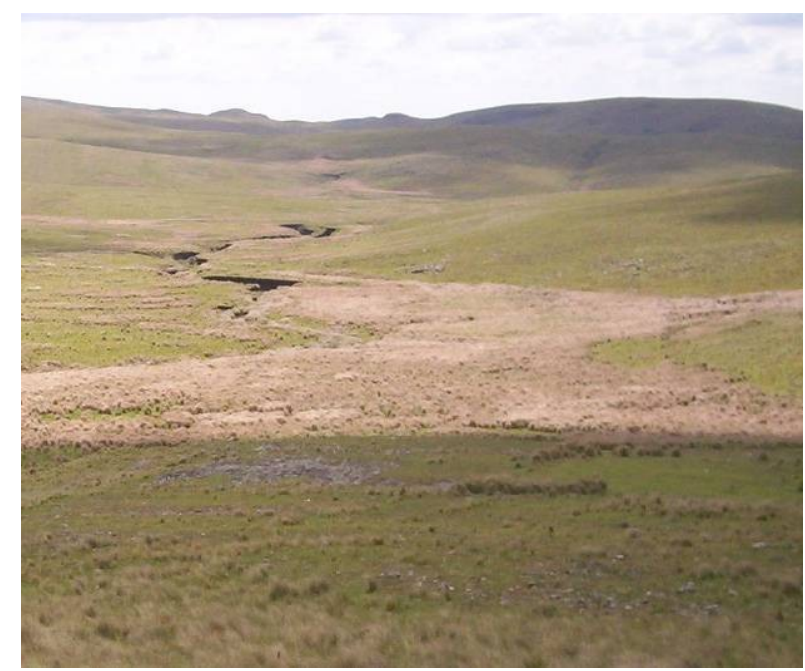

Fotografía 5: Pajonal serrano. (Matorral, mezcla matorral y maleza Cubierta $>75 \%$ ).

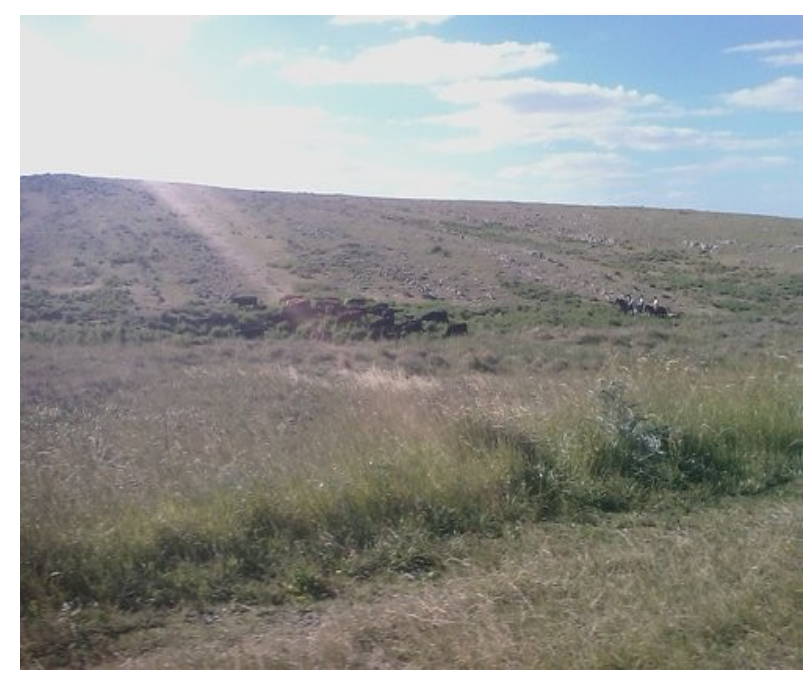

Fotografía 6: Pastizal serrano (Prados permanentes).

\subsection{Suelos.}

Los suelos encontrados en el área serrana sobre los diversos tipos de rocas están vinculados en primer término, con la ausencia o presencia de loess recubriendo las formaciones rocosas consolidadas. En los pocos casos en que el loess no existe, la roca aflorante constituye un litosol; en cambio cuando se halla presente los suelos resultantes dependen del espesor de la cobertura loéssica (Spinelli Zinni, 1970).

A continuación se presentan las características físicas principales y porcentajes de composición de las series que conforman los 11 complejos de suelo presentes en la cuenca, con una escala de 1:50000 según AICET-RCD, 2008 (Tabla 13). En términos generales las series poseen una textura que varía entre franco a franco arcillosa, con permeabilidades desde moderadas a lentas. 
Tabla 13: Caracterización de los complejos de suelos.

\begin{tabular}{|c|c|c|c|c|c|c|c|}
\hline \multirow{2}{*}{$\begin{array}{l}\text { Complejo } \\
\text { de suelos }\end{array}$} & \multirow{2}{*}{$\begin{array}{c}\text { Nombre de la } \\
\text { Serie }\end{array}$} & \multirow{2}{*}{$\begin{array}{c}\text { Porcentaje } \\
\text { de } \\
\text { composición }\end{array}$} & \multirow{2}{*}{ Textura } & \multicolumn{3}{|c|}{$\begin{array}{l}\text { Porcentaje de } \\
\text { partículas }\end{array}$} & \multirow{2}{*}{ Permeabilidad } \\
\hline & & & & Arcilla & Limo & Arena & \\
\hline AoPoG & $\begin{array}{c}\text { Arroyo } \\
\text { Pillahuinco } \\
\text { Grande }\end{array}$ & 100 & Franco & 15.6 & 51 & 33.4 & Moderada \\
\hline \multirow{3}{*}{ EG2 } & Semillero Buck & 50 & $\begin{array}{c}\text { Franco a franco } \\
\text { arcillosa }\end{array}$ & 25.7 & 31.5 & 42.8 & Moderada \\
\hline & Claudio Molina & 30 & Franco arcillosa & 33.6 & 44.9 & 21.5 & $\begin{array}{c}\text { Moderadamente } \\
\text { lenta }\end{array}$ \\
\hline & El Gavilán & 20 & $\begin{array}{c}\text { Franco arcillo } \\
\text { limoso }\end{array}$ & 37.4 & 47.6 & 15 & Lenta \\
\hline \multirow{3}{*}{$\mathrm{Ph} 5$} & Pillahuincó & 40 & Franco arcillosa & 40 & 31.1 & 28.9 & Lenta \\
\hline & San Gabriel & 45 & $\begin{array}{c}\text { Franco a franco } \\
\text { arcillosa }\end{array}$ & 20.6 & 44 & 35.4 & Lenta \\
\hline & Tres Arroyos & 15 & $\begin{array}{c}\text { Franco a franco } \\
\text { arcillosa }\end{array}$ & 25.9 & 26.9 & 47.2 & $\begin{array}{c}\text { Moderadamente } \\
\text { lenta }\end{array}$ \\
\hline $\mathrm{Ph} 2$ & Pillahuincó & 100 & Franco arcillosa & 40 & 31.1 & 28.9 & Lenta \\
\hline \multirow[t]{2}{*}{ TA6 } & Tres Arroyos & 90 & $\begin{array}{c}\text { Franco a franco } \\
\text { arcillosa }\end{array}$ & 25.9 & 26.9 & 47.2 & $\begin{array}{c}\text { Moderadamente } \\
\text { lenta }\end{array}$ \\
\hline & Pillahuincó & 10 & Franco arcillosa & 40 & 31.1 & 28.9 & Lenta \\
\hline $\mathrm{R}$ & Roca & 100 & $\mathrm{x}$ & $\mathrm{x}$ & $\mathrm{x}$ & $\mathrm{x}$ & $\mathrm{x}$ \\
\hline R1 & $\begin{array}{c}\text { Roca con } \\
\text { vegetación } \\
\text { natural } \\
\end{array}$ & 100 & $\mathrm{x}$ & $\mathrm{x}$ & $\mathrm{x}$ & $\mathrm{x}$ & $\mathrm{x}$ \\
\hline \multirow{2}{*}{ RG1 } & \begin{tabular}{|c|}
$\begin{array}{c}\text { Afloramiento de } \\
\text { tosca }\end{array}$ \\
\end{tabular} & 40 & $\mathrm{x}$ & $\mathrm{x}$ & $\mathrm{x}$ & $\mathrm{x}$ & $\mathrm{x}$ \\
\hline & Rancho Grande. & 60 & Franco arcillosa & 29.6 & 28.4 & 42 & $\begin{array}{c}\text { Moderadamente } \\
\text { lenta }\end{array}$ \\
\hline \multirow{3}{*}{ TA10 } & Tres Arroyos & 80 & $\begin{array}{c}\text { Franco a franco } \\
\text { arcillosa }\end{array}$ & 25.9 & 26.9 & 47.2 & $\begin{array}{c}\text { Moderadamente } \\
\text { lenta }\end{array}$ \\
\hline & Semillero Buck & 10 & $\begin{array}{c}\text { Franco a franco } \\
\text { arcillosa }\end{array}$ & 25.7 & 31.5 & 42.8 & Moderada \\
\hline & Pillahuincó & 10 & Franco arcillosa & 40 & 31.1 & 28.9 & Lenta \\
\hline \multirow[t]{2}{*}{ TA12 } & Tres Arroyos & 80 & $\begin{array}{c}\text { Franco a franco } \\
\text { arcillosa }\end{array}$ & 25.9 & 26.9 & 47.2 & $\begin{array}{c}\text { Moderadamente } \\
\text { lenta }\end{array}$ \\
\hline & Laprida & 20 & Franco & 25.1 & 41.5 & 33.4 & Moderada \\
\hline \multirow{3}{*}{ TA59 } & Tres Arroyos & 50 & $\begin{array}{c}\text { Franco a franco } \\
\text { arcillosa }\end{array}$ & 25.9 & 26.9 & 47.2 & $\begin{array}{c}\text { Moderadamente } \\
\text { lenta }\end{array}$ \\
\hline & La Loma & 20 & Franca & 25 & 32.7 & 42.3 & Moderada \\
\hline & Laprida & 30 & Franco & 25.1 & 41.5 & 33.4 & Moderada \\
\hline
\end{tabular}




\section{Cartografía temática digital de la condición actual.}

\subsection{Cartografía de primer orden.}

Los Mapas de Red de drenaje y la delimitación espacial de Cuenca y subcuencas se presentan en el apartado 1, Figuras 7, 10 y 11 respectivamente, según la metodología presentada en los apartados 3.1.1. y 3.1.2 de Materiales y Métodos.

\subsubsection{Mapa de vegetación y usos del suelo.}

La vegetación y uso del suelo predominante se encuentra constituida por prados permanentes abarcando el $54 \%$ de la cuenca; los Cultivos alineados bajo labranza convencional o siembra directa en buenas condiciones hidrológicas constituyen la segunda categoría de importancia con un $36 \%$ de ocupación; los Cultivos alineados bajo labranza conservacionista son una práctica poco difundida constituyendo el $6 \%$ de la superficie total; el Matorral, mezcla matorral y maleza cubierta $>75 \%$ ocupa el $3 \%$ del área total de la cuenca; los Bosques en buenas condiciones representan solo el $1 \%$ de la cobertura presente en la cuenca (Figura 13, Gráfico 18).

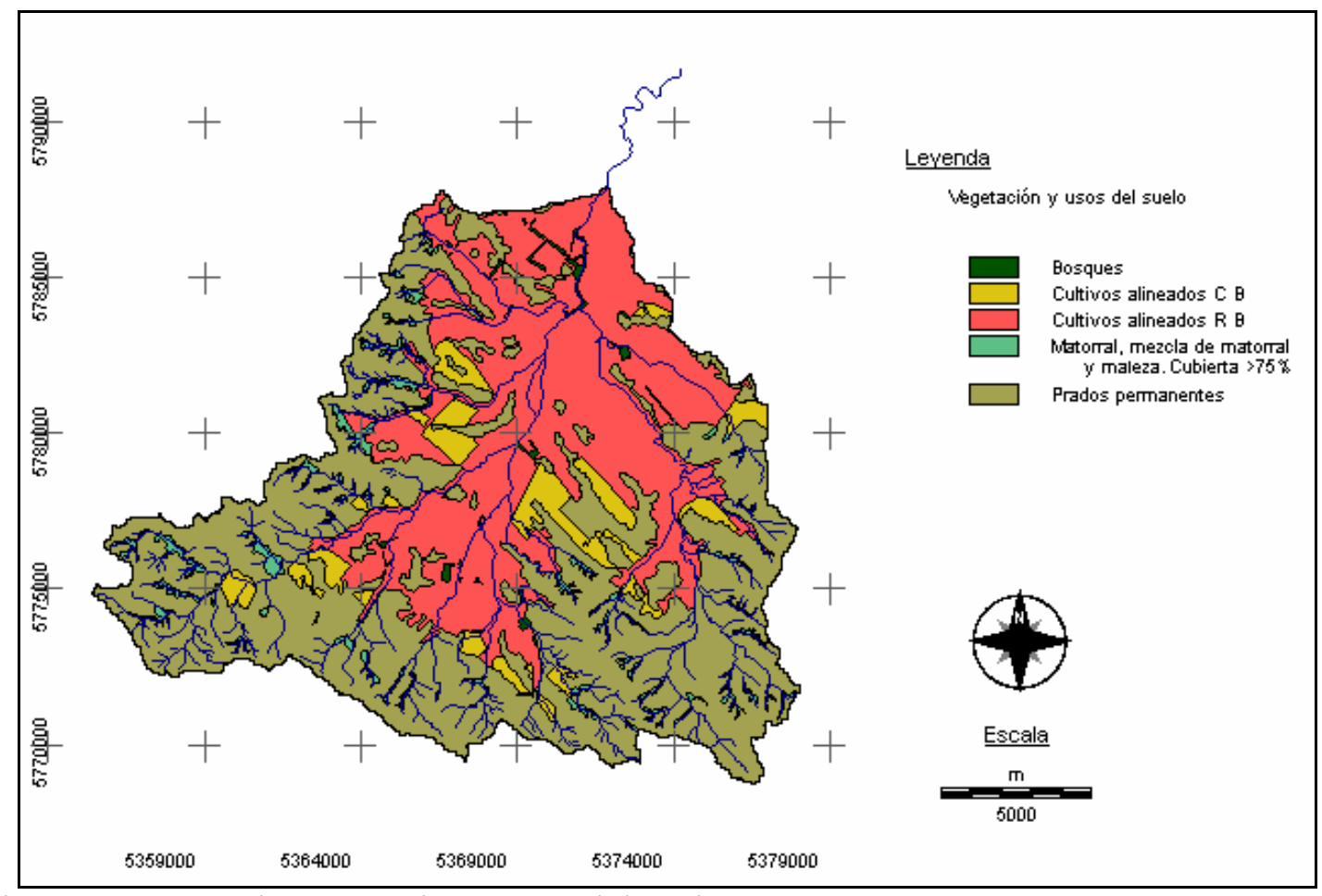

Figura 13: Mapa de Vegetación y usos del suelo. 


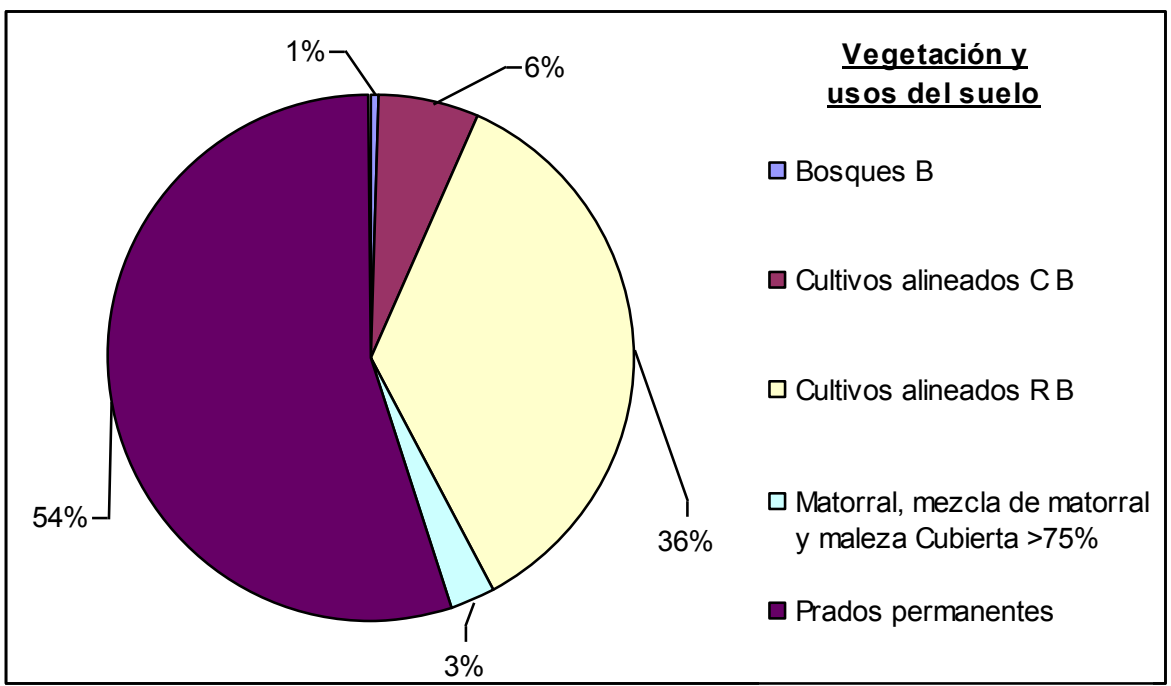

Gráfico 18: Representación de la ocupación porcentual de vegetación y usos del suelo en la cuenca.

Para un nivel de mayor detalle se realizó un análisis por subcuenca de los porcentajes de ocupación territorial de vegetación y usos del suelo. En el Gráfico 19 se presentan los valores obtenidos. Las subcuencas altas poseen un predominio de prados permanentes, siendo los cultivos agrícolas los que poseen mayor preponderancia en las subcuencas medias y bajas.

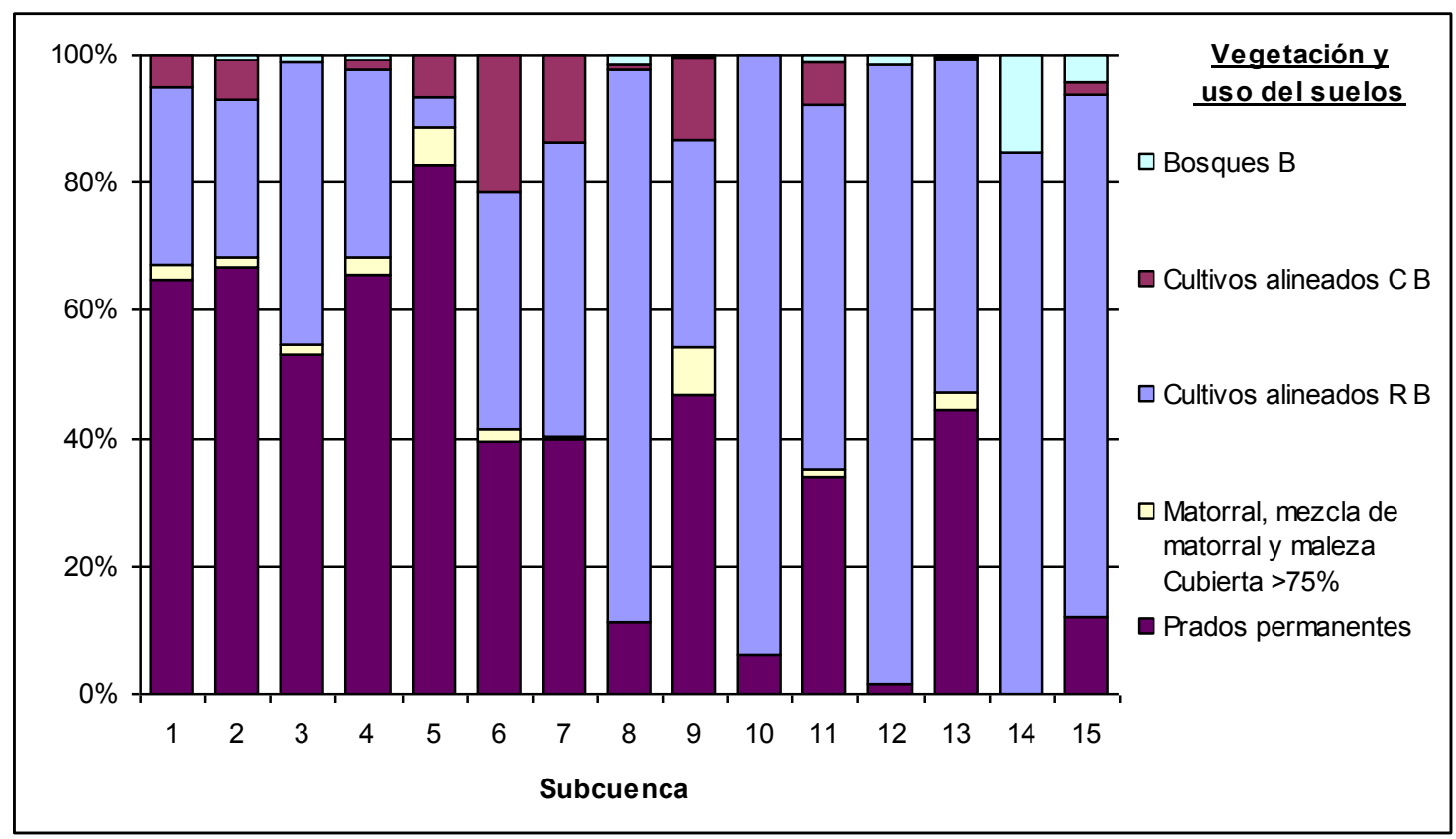

Gráfico 19: Ocupación territorial de vegetación y usos del suelo por subcuenca.

\subsubsection{Mapa de suelos.}

En la Figura14 se presenta la distribución espacial de los 11 complejos de suelos presentes en la cuenca, el Gráfico 20 describe la proporción de ocupación de cada uno. 
El complejo de suelos $\mathrm{R}$ posee predominancia en la cuenca con un $41 \%$ de superficie extendiéndose sobre el paisaje serrano, el 59\% restante se encuentra distribuido entre 10 complejos de suelo siendo TA59 el segundo complejo de mayor ocupación con un $12 \%$ desarrollado en lomas con pendientes cortas y medias, con gradientes de 1 a 3\%, seguido por TA10 con un $11 \%$ ubicado en paisajes de pendientes largas. El complejo AoPoG posee un 9\% de ocupación con distribución sobre los márgenes de la red de drenaje encausados. El complejo PH5 abarca planicies extendidas con tosca representando el 9\% de la superficie. Los complejos RG1 y R1 constituyen los suelos desarrollados sobre afloramientos rocosos con vegetación natural y cordones alargados con tosca superficial respectivamente, presentando un 7 y $6 \%$ de ocupación. Los complejos con menor extensión territorial están representados por TA12 con un 2\% situado en pasajes de lomas con gradiente de 1 a 3\% y con tosca en superficie en algunos sectores. Con un 1\% de la superficie cada uno se presentan EG2, en vías de avenamiento sin cauce marcado en áreas de lomas, $\mathrm{PH} 2$, en afloramientos rocosos con vegetación natural y TAG, en planicies suavemente onduladas.

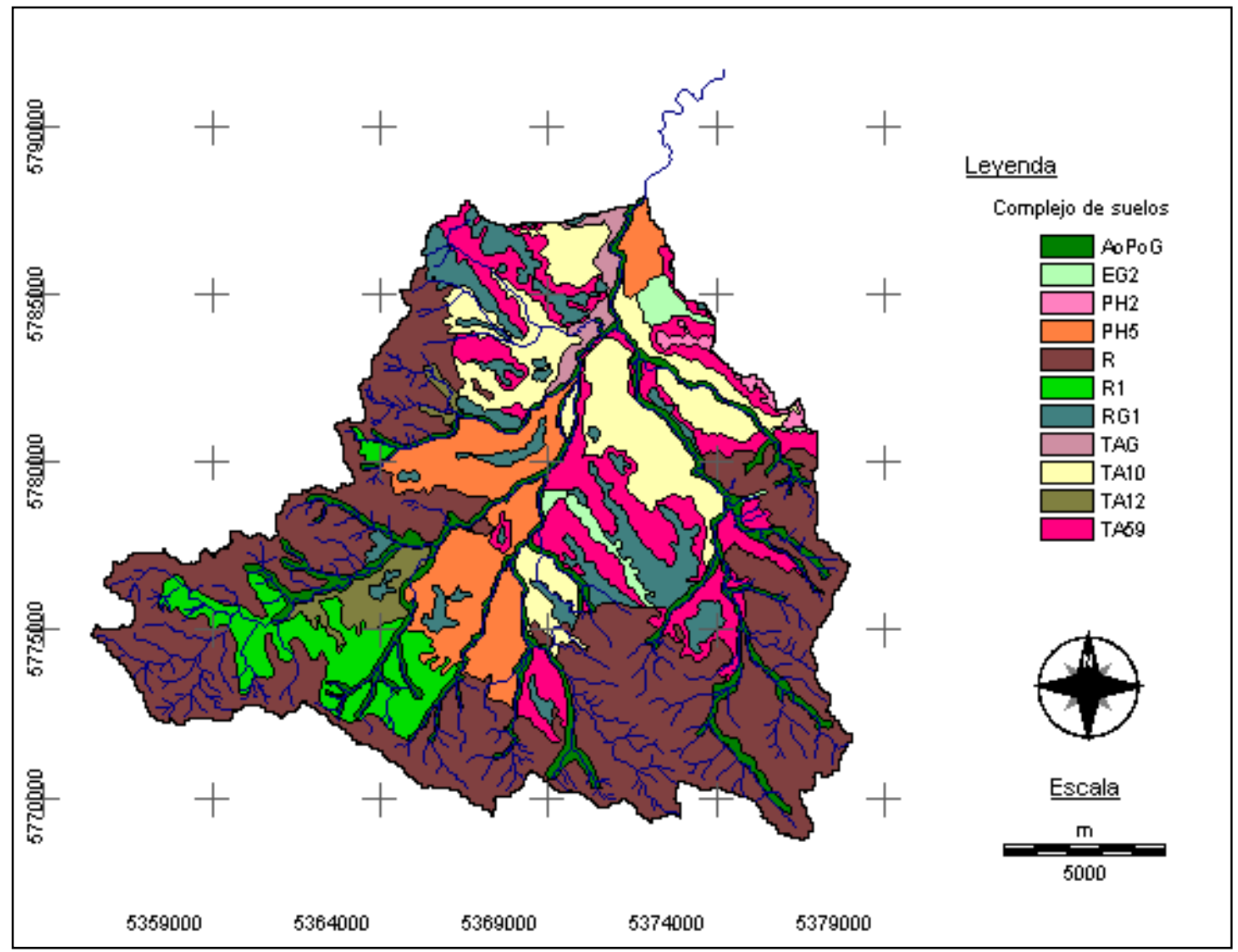

Figura 14: Mapa de complejos de suelos. 


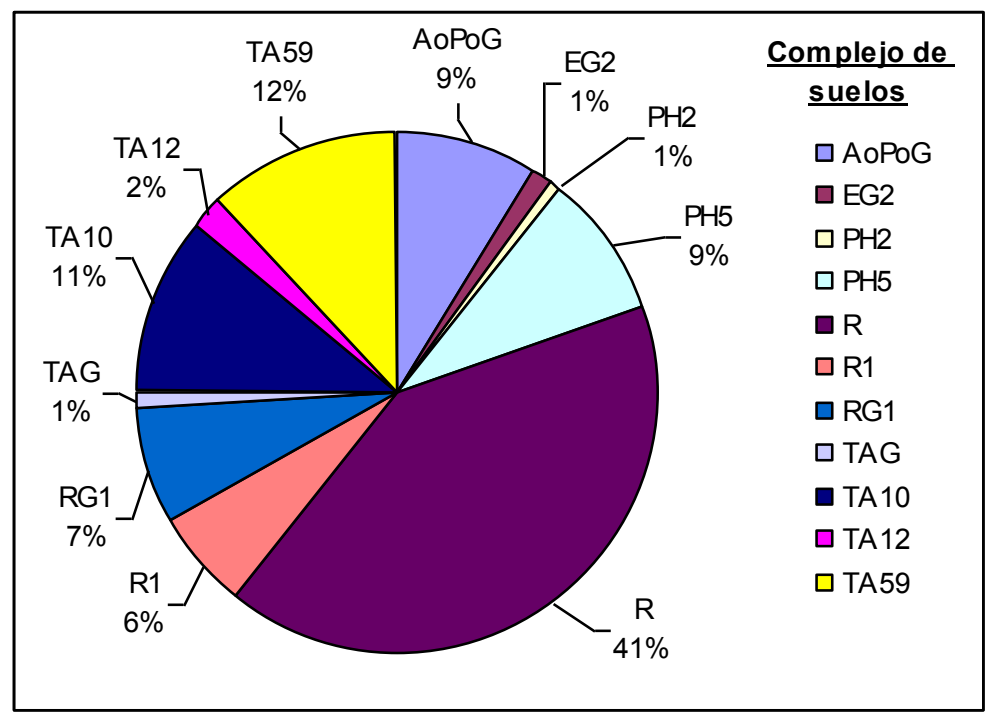

Gráfico 20: Representación de la ocupación porcentual de complejos de suelo en la cuenca.

Los complejos de suelo y su grado de ocupación a nivel subcuenca se exponen en el Grafico 21. Existe una variada composición tanto en complejos de suelo como en ocupación en cada subcuenca. Se destaca el complejo AoPoG por presentarse en todas las subcuencas y el complejo $\mathrm{R}$ por estar restringido a las cabeceras de las subcuencas que poseen paisaje serrano.

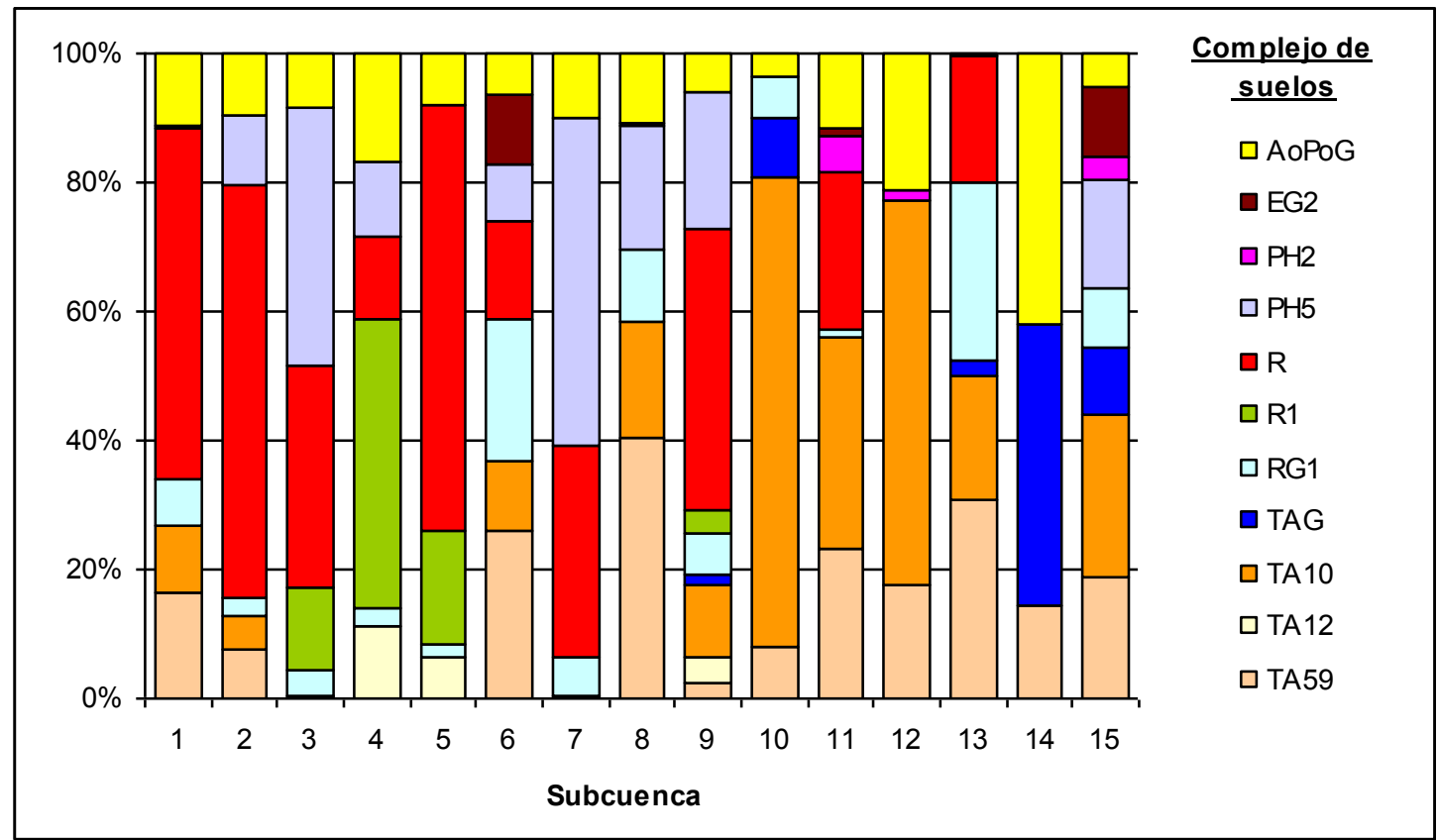

Gráfico 21: Ocupación territorial de complejos de suelo por subcuenca. 


\subsection{Cartografía de segundo orden.}

\subsubsection{Rangos de pendiente.}

Se definieron 6 rangos de pendiente (Figura 15). La cuenca presenta un predomino de pendientes comprendidas en el rango de 5 a $15 \%$ ocupando el $50.5 \%$ de la superficie. La segunda categoría de importancia desde el punto de vista de su extensión superficial esta constituida por el rango 0.5 a $3 \%$ con un $23.1 \%$ de ocupación, seguida por el rango 3 a $5 \%$ con un $15.3 \%$ y el rango 15 a $30 \%$ con un $10.7 \%$. Las categorías de menor importancia se encuentran en los rangos de 0 a $0.5 \%$ y de pendientes mayores a $30 \%$, representando solo el $0.2 \%$ del área de la cuenca cada uno.

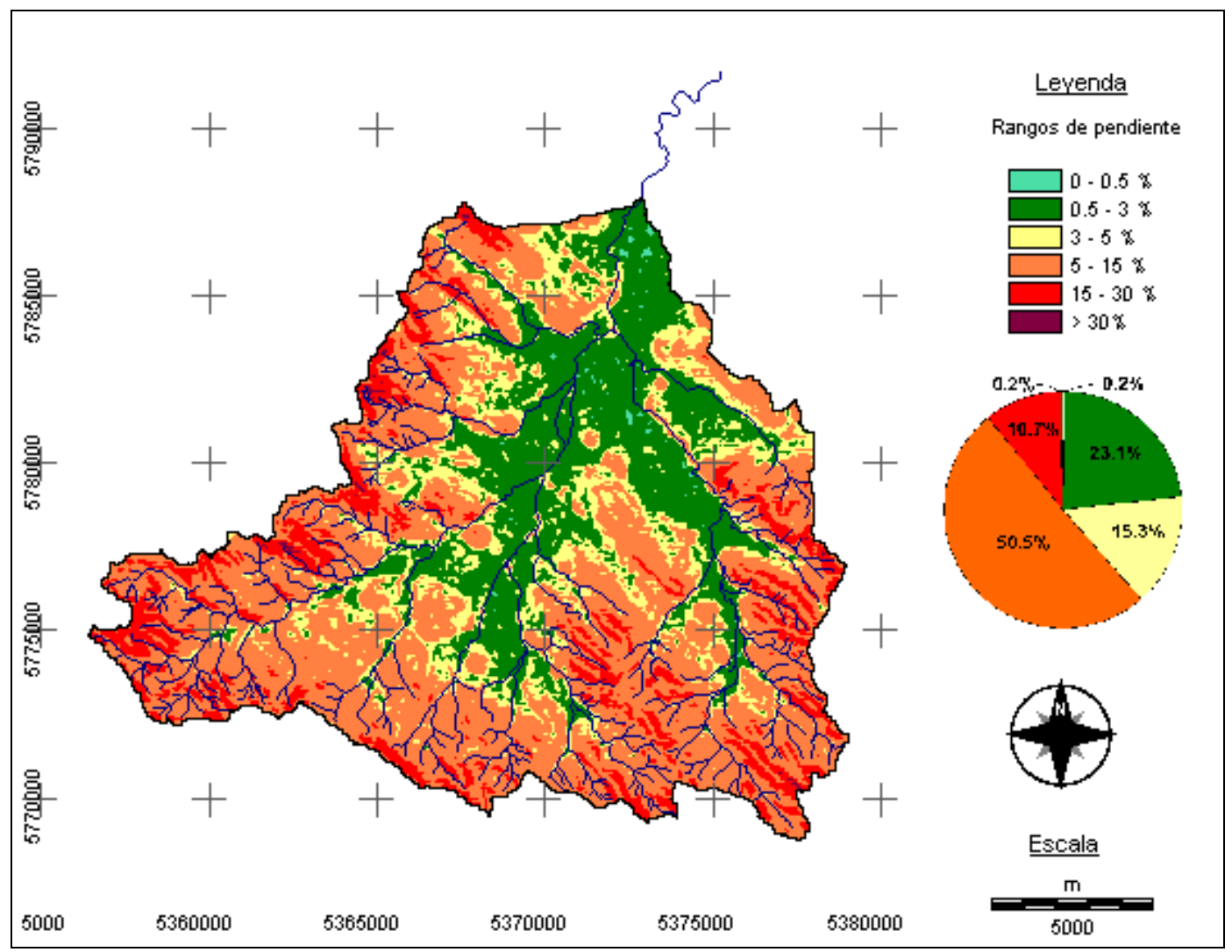

Figura 15: Mapa de rangos de pendientes.

El Gráfico 22 representa los porcentajes de ocupación de los rangos de pendiente a nivel subcuenca. En él se destacan el rango de pendiente de 5 a $15 \%$, distribuido principalmente en cuencas con cabeceras en paisajes serranos y el rango 0.5 a $3 \%$ en las subcuencas medias y bajas. 


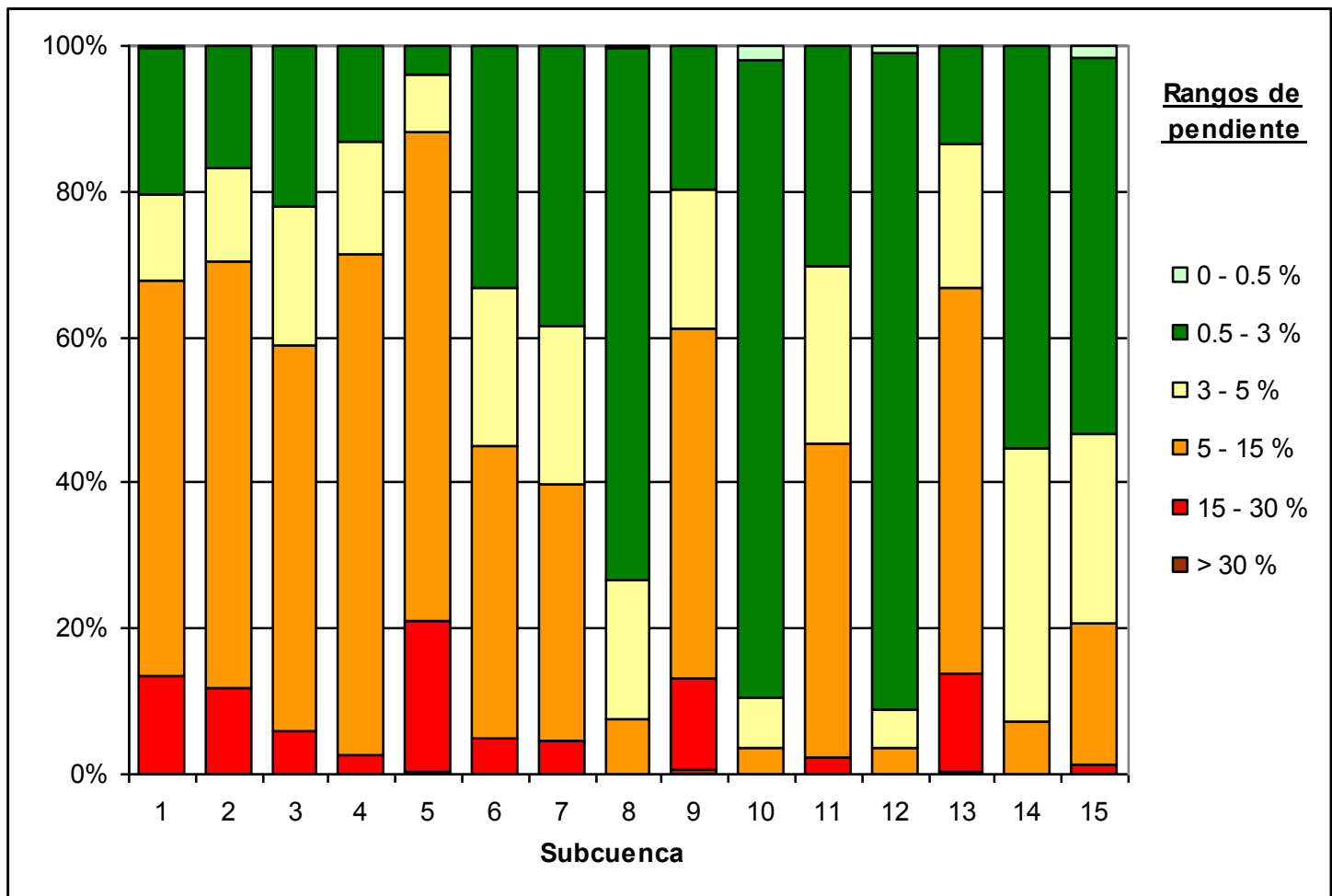

Gráfico 22: Porcentajes de ocupación de los rangos de pendiente a nivel de subcuenca.

\subsubsection{Orientación de laderas.}

La Figura 16 muestra el mapa de orientación de laderas respecto de los 4 puntos cardinales. La orientación preponderante es Norte, cubriendo un $36 \%$ de la cuenca, las orientaciones restantes se encuentran distribuidas uniformemente, con un $22 \%$ hacia el Oeste, un $20 \%$ hacia el Sur y un $20 \%$ hacia el Este. Las áreas con orientación cenital fueron clasificadas en la categoría Sin orientación, representando sólo un $2 \%$ de la superficie total de la cuenca. 


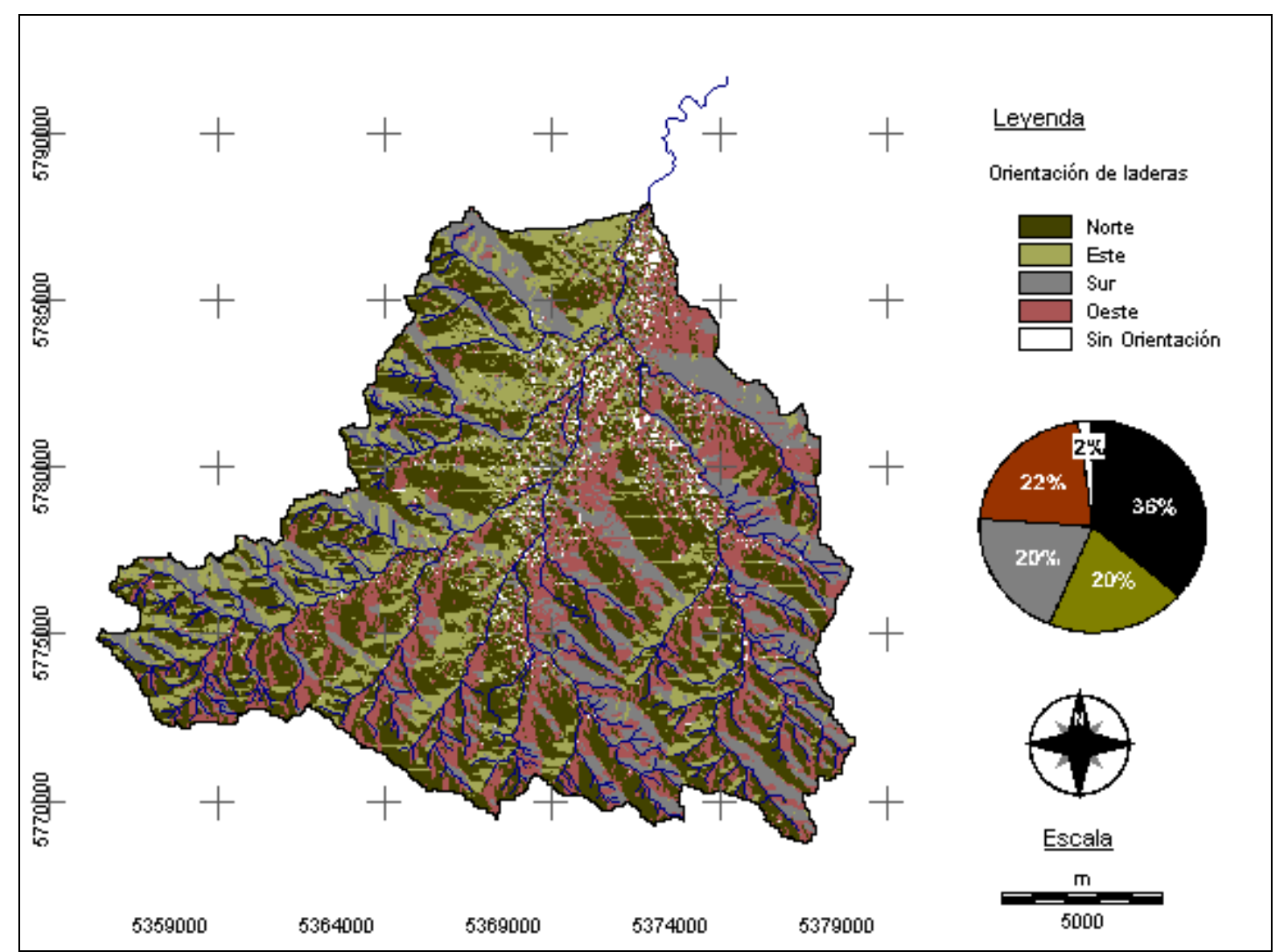

Figura 16: Mapa de orientación de laderas.

En el Gráfico 23 se presenta la orientación de laderas para cada subcuenca.

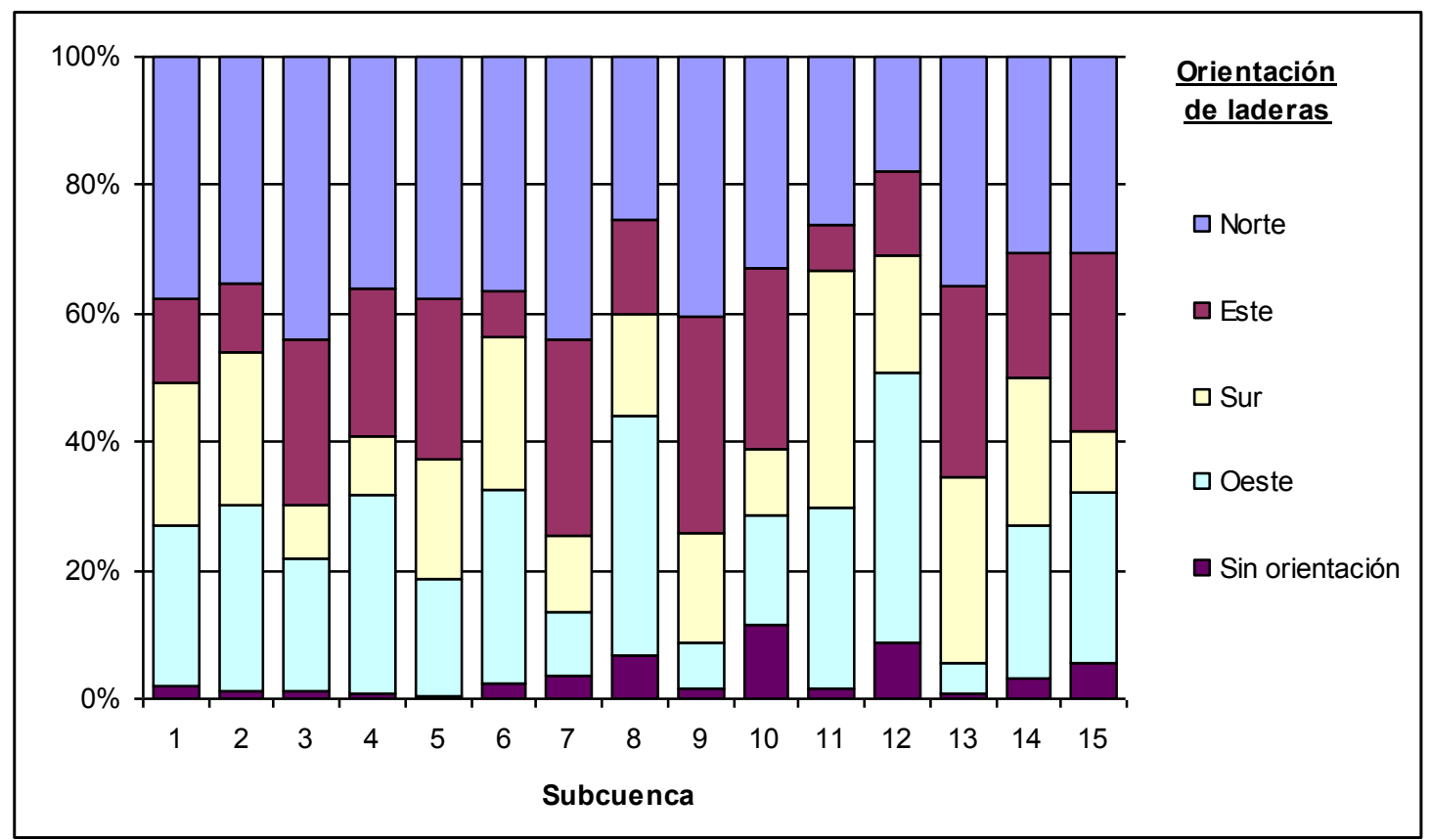

Gráfico 23: Orientación de laderas a nivel de subcuenca. 


\subsubsection{Grupos hidrológicos.}

Los grupos hidrológicos fueron asignados a cada complejo de suelos en función de los parámetros de textura, permeabilidad y porcentaje de composición de cada serie de suelos (Tabla 13). Las categoría de grupo hidrológico establecida para cada complejo de suelos (Tabla 14), fueron 2, correspondientes a los grupos B y C.

Tabla 14: Grupos hidrológicos correspondientes a cada complejo de suelos.

\begin{tabular}{|c|c|}
\hline Complejo suelos & $\begin{array}{c}\text { Grupo } \\
\text { Hidrológico }\end{array}$ \\
\hline AoPoG & B \\
\hline EG2 & B \\
\hline Ph5 & C \\
\hline Ph2 & C \\
\hline TA6 & B \\
\hline R & C \\
\hline R1 & C \\
\hline RG1 & C \\
\hline TA10 & B \\
\hline TA12 & B \\
\hline TA59 & B \\
\hline
\end{tabular}

La reclasificación del mapa de complejos de suelos según los grupos hidrológicos asignados (Tabla 14) representa el mapa de distribución espacial de grupos hidrológicos en la cuenca (Figura 17). El grupo B constituye el 36\% de la superficie, siendo el 64\% restante correspondiente al grupo $\mathrm{C}$. 


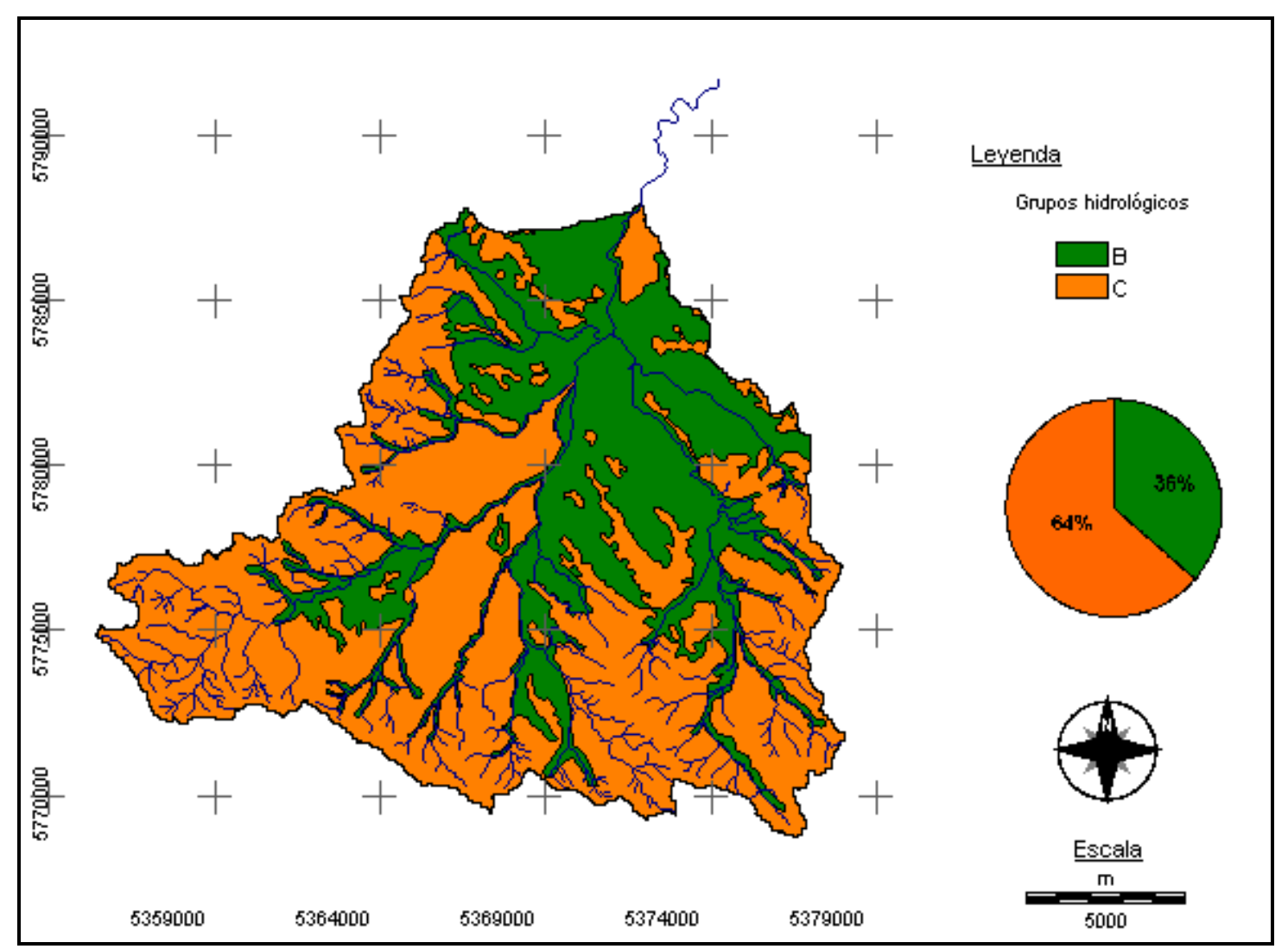

Figura 17: mapa de grupos hidrológicos.

La proporción de área de los grupos hidrológicos a nivel subcuenca se presentan en el Gráfico 24. El grupo B se distribuye en todas las subcuencas, teniendo mayor preponderancia en las subcuencas bajas, por el contrario, el grupo C, si bien presente en todas las subcuencas, exceptuando la subcuenca 14, predomina en las subcuencas que constituyen la cabecera de la cuenca.

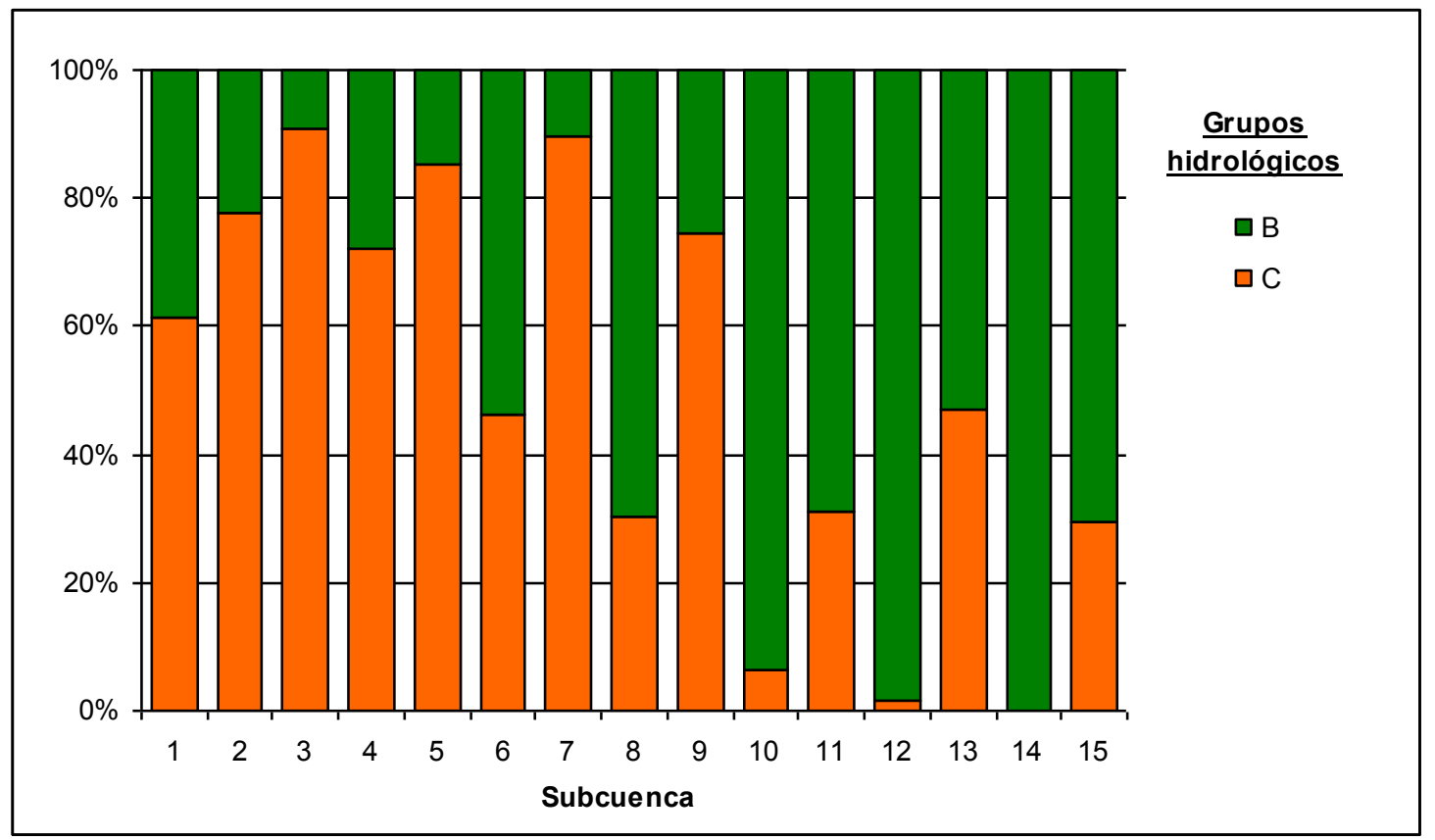

Gráfico 24: Grado de ocupación de grupos hidrológicos a nivel subcuenca. 


\subsection{Cartografía de tercer orden.}

\subsubsection{Número de curva.}

El mapa de número de curva de la cuenca (Figura 18) fue obtenido automáticamente a través del procesamiento de los mapas de Suelos y de Vegetación y usos del suelo con el modelo Lthia. La combinación de ambas capas generó $10 \mathrm{NC}$ diferentes con un valor mínimo de 48 y un máximo de 85 . Los valores con mayor grado de ocupación fueron de 71 y 78 con un 51.3 y $27.4 \%$ respectivamente, seguidos por 85 con un $8.1 \%$.

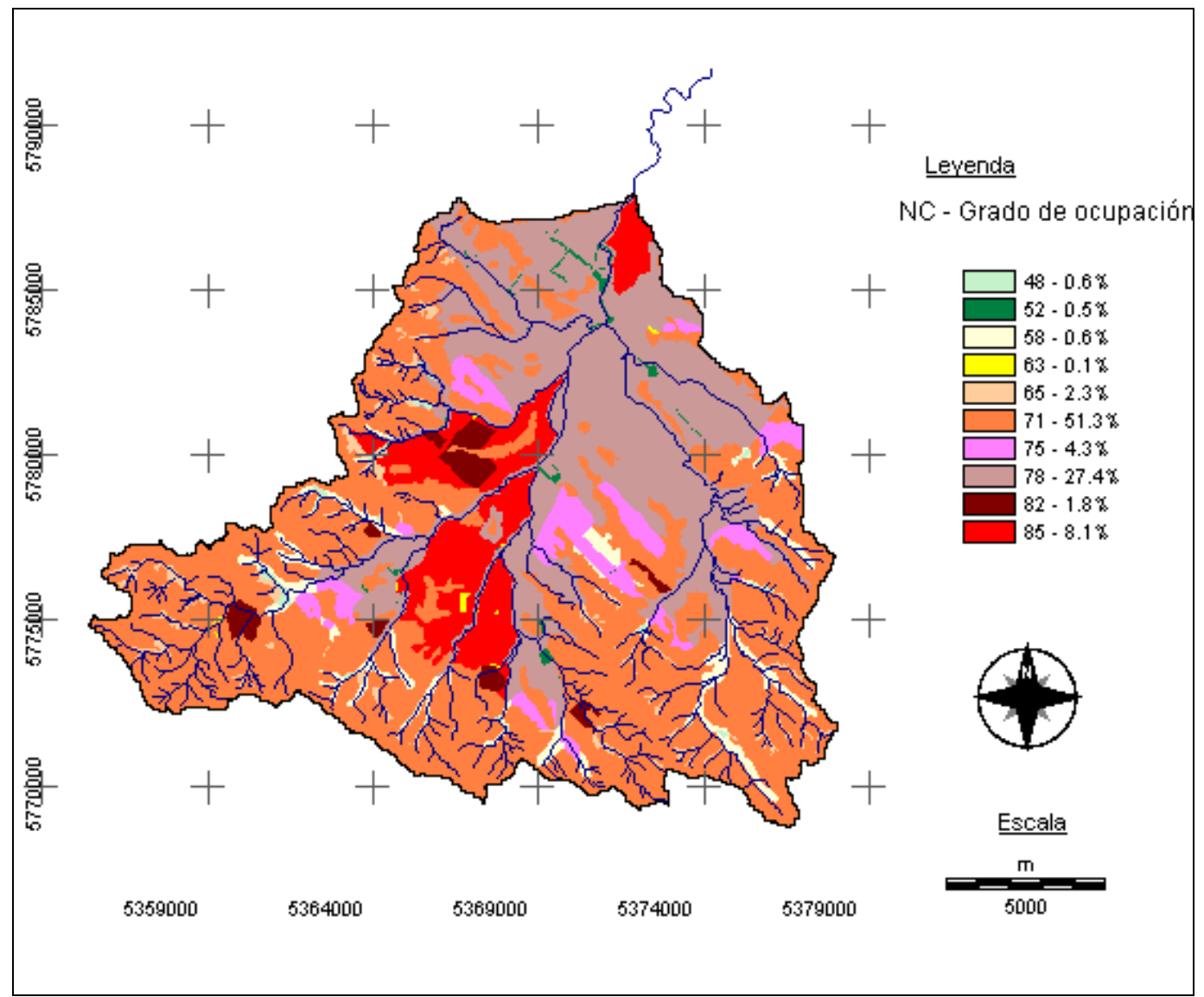

Figura 18: Mapa de número de curva

El Gráfico 25 expresa el grado de ocupación de $\mathrm{NC}$ a nivel subcuenca. En concordancia con lo sucedido a nivel de cuenca, se destacan los valores $71 \mathrm{y} 78$, con un claro predominio de 71 en las subcuencas altas y de 78 en las subcuencas bajas. Las subcuencas 3 y 7 poseen más del 35\% de su superficie con un NC de 85 . 


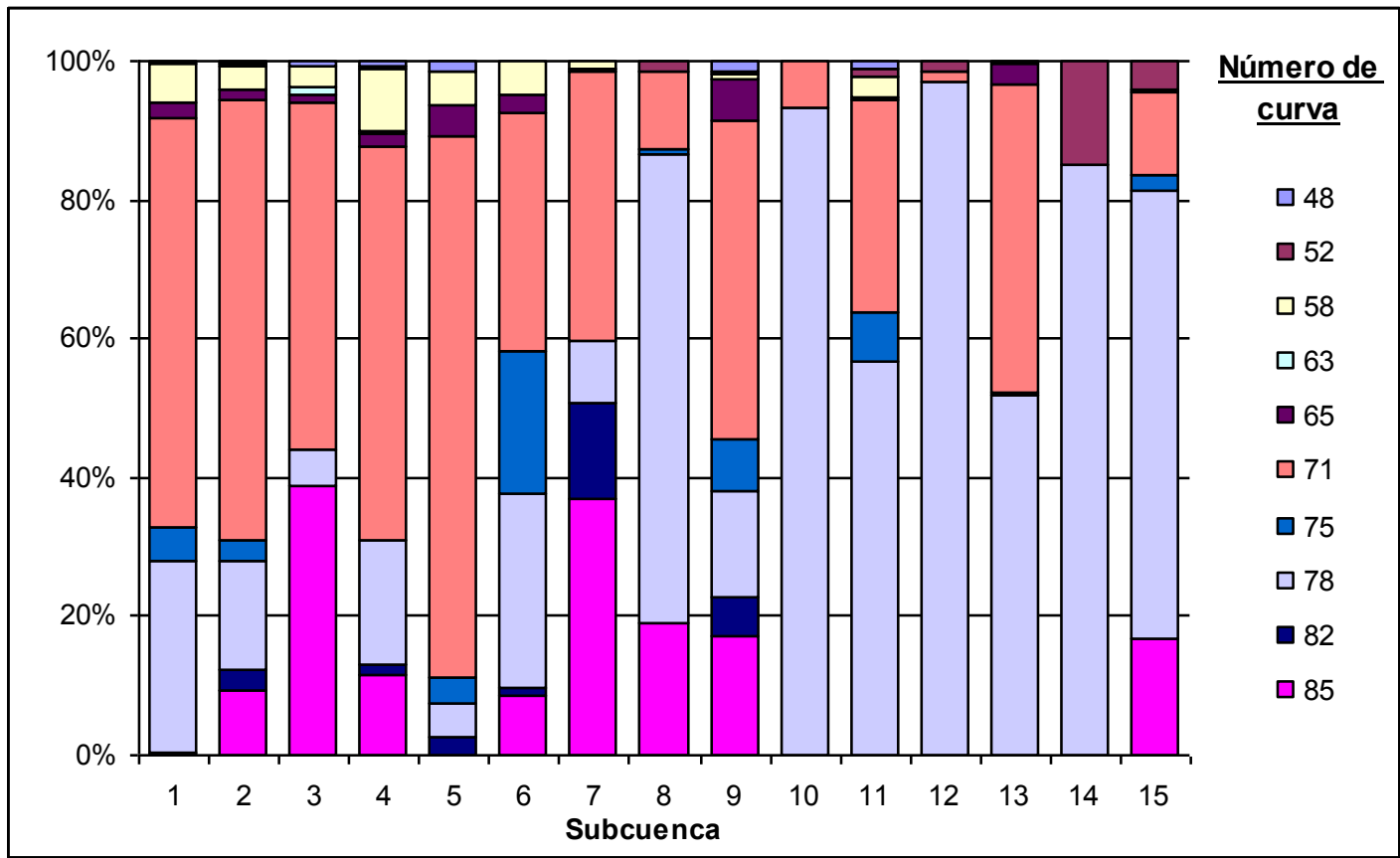

Gráfico 25: Grado de ocupación de números de curva a nivel subcuenca.

\section{Modelos hidrológicos. Elaboración de parámetros requeridos.}

\subsection{Modelo Lthia.}

El empleo de Lthia requirió la parametrización de variables hidrológicas para la modelización de la lámina de escorrentía. Los parámetros necesarios se expresan mediante modelos de distribución geoespacial y valores tabulares. A continuación se exponen los valores asignados para cada parámetro.

\subsubsection{Codificación del mapa de suelos.}

Se modificó la base de datos del mapa de suelos, creando los campos Rcls_hsg, asignando los grupos hidrológicos para cada complejo de suelos según la Tabla 14. Luego del primer procesamiento con Lthia se creó y asignó de manera automática el campo Code con sus respectivos valores (Tabla 15). 
Tabla 15: Valores asignados al mapa de suelos

\begin{tabular}{|c|c|c|}
\hline $\begin{array}{c}\text { Complejo } \\
\text { de suelos }\end{array}$ & $\begin{array}{c}\text { Valor asignado al } \\
\text { campo "Rcls_hs" }\end{array}$ & $\begin{array}{c}\text { Valor asignado } \\
\text { al campo } \\
\text { "Code" }\end{array}$ \\
\hline AoPoG & B & 2 \\
\hline EG2 & B & 2 \\
\hline Ph2 & C & 3 \\
\hline Ph5 & C & 3 \\
\hline TA6 & B & 2 \\
\hline R & C & 3 \\
\hline R1 & C & 3 \\
\hline RG1 & C & 3 \\
\hline TA10 & B & 2 \\
\hline TA12 & B & 2 \\
\hline TA 59 & B & 2 \\
\hline
\end{tabular}

\subsubsection{Codificación del mapa de vegetación y usos del suelo.}

La Tabla 16, expone los nombres de código asignados a las categorías del mapa de vegetación y usos del suelo requeridas por Lthia. El código numérico se generó automáticamente.

Tabla 16: Valores asignados al mapa de vegetación y usos del suelo

\begin{tabular}{|c|c|c|}
\hline $\begin{array}{c}\text { Categoría de vegetación y usos } \\
\text { del suelo }\end{array}$ & $\begin{array}{c}\text { Nombre del código } \\
\text { Rcls_hsg }\end{array}$ & Código \\
\hline Prados permanentes & Grass/Pasture & 6000 \\
\hline $\begin{array}{c}\text { Matorral, mezcla matorral y } \\
\text { maleza cubierta }>75 \%\end{array}$ & LD residental & 5000 \\
\hline Bosques B & Forestal & 7000 \\
\hline Cultivo alineados C B & Commercial & 2000 \\
\hline Cultivos alineados R B & Agricultural & 3000 \\
\hline
\end{tabular}

\subsubsection{Adaptación de los valores de NC del archivo CN Table.}

Se adaptaron los valores de $\mathrm{NC}$ a las condiciones locales. Los nuevos valores asignados a cada combinación suelo-vegetación se presentan el la Tabla 17.

Tabla 17: Valores asignados al archivo CN Table.

\begin{tabular}{|c|c|c|c|c|c|c|c|c|c|}
\hline \multirow{2}{*}{ Nombre del código LThia } & \multirow{2}{*}{ Código } & \multicolumn{4}{|c|}{ NC original } & \multicolumn{4}{|c|}{ NC adaptado } \\
\cline { 3 - 10 } & & A & B & C & D & A & B & C & D \\
\hline Grass/pasture & 6000 & 39 & 61 & 74 & 80 & 30 & 58 & 71 & 78 \\
\hline Ld residental & 5000 & 54 & 70 & 80 & 85 & 30 & 48 & 65 & 73 \\
\hline Forestal & 7000 & 30 & 55 & 70 & 77 & 26 & 52 & 63 & 69 \\
\hline Commercial & 2000 & 89 & 92 & 94 & 95 & 65 & 75 & 82 & 86 \\
\hline Agricultural & 3000 & 64 & 75 & 82 & 85 & 67 & 78 & 85 & 89 \\
\hline
\end{tabular}




\subsection{Modelo Hec Hms.}

\subsubsection{Modelo de Cuenca.}

La Figura 19 representa el diagrama de flujo de los elementos hidrológicos comprendidos en el Modelo de cuenca de Hec Hms.

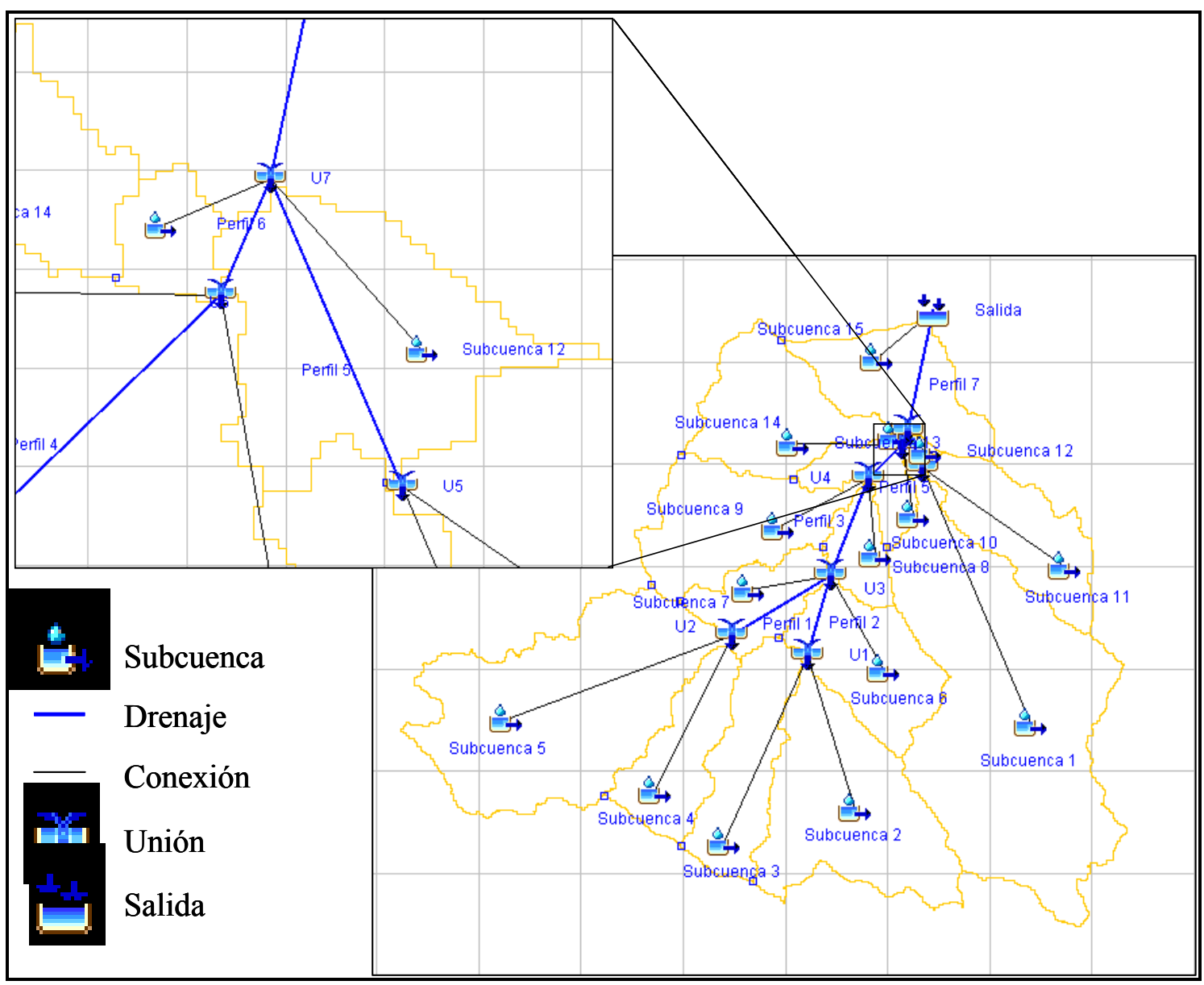

Figura 19: Diagrama de flujo de los elementos hidrológicos del Modelo de cuenca de Hec Hms.

La Tabla 18 describe las características paramétricas de las subcuencas que conforman el Modelo de cuenca. Cada subcuenca, luego de una precipitación eroga un caudal que es recibido por otro elemento, este sentido de flujo se representa a través de la conexión hacia el elemento que lo recibe. Por ejemplo la Subcuenca 1 se conecta a la unión U5.

El área total y los valores de $\mathrm{NC}$, determinan el volumen total de escorrentía producida luego de una precipitación. Se establecieron los NC ponderados para cada subcuenca, los valores calculados variaron entre un mínimo de 71 y un máximo de 78 con valores de Io entre 20.7 y $14.3 \mathrm{~mm}$ respectivamente. Se calculó el tiempo de retardo (Tlag) de cada subcuenca, cuyos valores fueron muy variables vinculados principalmente a la longitud de la mayor trayectoria del flujo. 
Tabla 18: Parámetros de subcuencas para el modelo de cuenca de Hec Hms.

\begin{tabular}{|c|c|c|c|c|c|}
\hline \multirow{2}{*}{ Subcuenca } & \multirow{2}{*}{ Conexión } & \multirow{2}{*}{$\begin{array}{c}\text { Area } \\
\mathbf{2}\end{array}$} & \multicolumn{2}{|c|}{$\begin{array}{c}\text { Método de pérdidas } \\
\text { (NC SCS) }\end{array}$} & \multirow{2}{*}{$\begin{array}{c}\text { Método de } \\
\text { transformación } \\
\text { (Tlag. } \text { (min) }^{\text {) }}\end{array}$} \\
\cline { 4 - 5 } & & & $\mathbf{N C}$ & $\mathbf{I o}_{(\mathbf{m m})}$ & 595.6 \\
\hline 1 & $\mathrm{U} 5$ & 58.05 & 72 & 19.8 & 273.7 \\
\hline 2 & $\mathrm{U} 1$ & 27.54 & 73 & 18.8 & 218.1 \\
\hline 3 & $\mathrm{U} 1$ & 14.23 & 76 & 16.0 & 245.4 \\
\hline 4 & $\mathrm{U} 2$ & 11.74 & 72 & 19.8 & 339.8 \\
\hline 5 & $\mathrm{U} 2$ & 41.42 & 71 & 20.7 & 212.2 \\
\hline 6 & $\mathrm{U} 3$ & 14.92 & 74 & 17.8 & 226.1 \\
\hline 7 & $\mathrm{U} 3$ & 8.23 & 78 & 14.3 & 241.0 \\
\hline 8 & $\mathrm{U} 4$ & 5.41 & 78 & 14.3 & 236.3 \\
\hline 9 & $\mathrm{U} 4$ & 18.09 & 74 & 17.8 & 145.3 \\
\hline 10 & $\mathrm{U} 6$ & 5.81 & 78 & 14.3 & 241.9 \\
\hline 11 & $\mathrm{U} 5$ & 13.92 & 74 & 17.8 & 133.6 \\
\hline 12 & $\mathrm{U} 7$ & 0.83 & 78 & 14.3 & 264.1 \\
\hline 13 & $\mathrm{U} 6$ & 16.39 & 74 & 17.8 & 58.2 \\
\hline 14 & $\mathrm{U} 7$ & 0.15 & 74 & 17.8 & 383.8 \\
\hline 15 & Salida & 14.6 & 77 & 15.2 & \\
\hline
\end{tabular}

Las uniones son elementos que recogen escorrentía de dos elementos que emiten hacia un mismo punto, cada unión combina dos hidrogramas y lo eroga hacia otro elemento. La Tabla 19 expone el sentido de flujo (conexión) de cada unión del Modelo de cuenca.

Tabla 19: Conexiones de las uniones (U) del Modelo de cuenca

\begin{tabular}{|c|c|}
\hline $\begin{array}{c}\text { Nombre del } \\
\text { elemento }\end{array}$ & Conexión \\
\hline U2 & Perfil 1 \\
\hline U1 & Perfil 2 \\
\hline U3 & Perfil 3 \\
\hline U4 & Perfil 4 \\
\hline U5 & Perfil 5 \\
\hline U6 & Perfil 6 \\
\hline U7 & Perfil 7 \\
\hline
\end{tabular}

Las características de los cauces para trasladar los hidrogramas se exponen en la Tabla 20. La conexión representa el elemento hacia el cual fluye el caudal que circula por el cauce. Se determinaron los valores del largo total de cada cauce, su pendiente media y los valores de Manning. 
Tabla 20: Características de los cauces del Modelo de cuenca.

\begin{tabular}{|c|c|c|c|c|c|c|}
\multirow{2}{*}{$\begin{array}{c}\text { Nombre del } \\
\text { elemento }\end{array}$} & Conexión & \multirow{2}{*}{$\begin{array}{c}\text { Largo } \\
(\mathbf{m})\end{array}$} & $\begin{array}{c}\text { Pendiente } \\
(\mathbf{m} / \mathbf{m})\end{array}$ & \multicolumn{3}{|c|}{ Número de Manning } \\
\cline { 5 - 7 } & & & & $\begin{array}{c}\text { Planicie } \\
\text { izquierda }\end{array}$ & $\begin{array}{c}\text { Planicie } \\
\text { derecha }\end{array}$ \\
\hline Perfil 1 & U3 & 4275 & 0.0055 & 0.046 & 0.045 & 0.04 \\
\hline Perfil 2 & U3 & 3041 & 0.0046 & 0.236 & 0.035 & 0.035 \\
\hline Perfil 3 & U4 & 3467 & 0.0035 & 0.109 & 0.045 & 0.035 \\
\hline Perfil 4 & U6 & 1583 & 0.0027 & 0.066 & 0.05 & 0.075 \\
\hline Perfil 5 & U7 & 1223 & 0.0021 & 0.091 & 0.07 & 0.06 \\
\hline Perfil 6 & U7 & 452 & 0.0029 & 0.038 & 0.035 & 0.033 \\
\hline Perfil 7 & Salida & 4671 & 0.0023 & 0.1771 & 0.04 & 0.04 \\
\hline
\end{tabular}

La Tabla 21 contiene los datos de ubicación con coordenadas Gauss Kruger y geográficas donde fueron relevados los datos que caracterizan la sección y Números de Manning de cada uno de los cauces del Modelo de cuenca. Su ubicación en la cuenca se observa en la Figura 20.

Tabla 21: Coordenadas Gauss Kruger y geográficas de ubicación de los perfiles transversales.

\begin{tabular}{|c|c|c|c|c|}
\hline \multirow{2}{*}{ Gerfiles } & \multicolumn{2}{|c|}{ Gauss Kruger $(\mathbf{m})$} & \multicolumn{2}{c|}{ Geográficas } \\
\cline { 2 - 5 } & $\mathbf{x}$ & $\mathbf{y}$ & longitud & latitud \\
\hline 1 & 5369337.58 & 5779389.21 & $61^{\circ} 29^{\prime} 24.552^{\prime \prime} \mathrm{W}$ & $38^{\circ} 7^{\prime} 35.015^{\prime \prime} \mathrm{S}$ \\
\hline 2 & 5369765.17 & 5779060.62 & $61^{\circ} 29^{\prime} 7.218^{\prime \prime} \mathrm{W}$ & $38^{\circ} 7^{\prime} 45.89^{\prime \prime} \mathrm{S}$ \\
\hline 3 & 5370730.18 & 5782257.22 & $61^{\circ} 28^{\prime} 25.525^{\prime \prime} \mathrm{W}$ & $38^{\circ} 6^{\prime} 2.749^{\prime \prime} \mathrm{S}$ \\
\hline 4 & 5371437.96 & 5783672.71 & $61^{\circ} 27^{\prime} 55.568^{\prime \prime} \mathrm{W}$ & $38^{\circ} 5^{\prime} 17.219^{\prime \prime} \mathrm{S}$ \\
\hline 5 & 5372224.39 & 5783820.00 & $61^{\circ} 27^{\prime} 23.212^{\prime \prime} \mathrm{W}$ & $38^{\circ} 5^{\prime} 12.845^{\prime \prime} \mathrm{S}$ \\
\hline 6 & 5371898.62 & 5783920.81 & $61^{\circ} 27^{\prime} 36.511^{\prime \prime} \mathrm{W}$ & $38^{\circ} 5^{\prime} 9.41^{\prime \prime} \mathrm{S}$ \\
\hline 7 & 5372328.2 & 5786990.98 & $61^{\circ} 27^{\prime} 16.916^{\prime \prime} \mathrm{W}$ & $38^{\circ} 330.086^{\prime \prime} \mathrm{S}$ \\
\hline
\end{tabular}




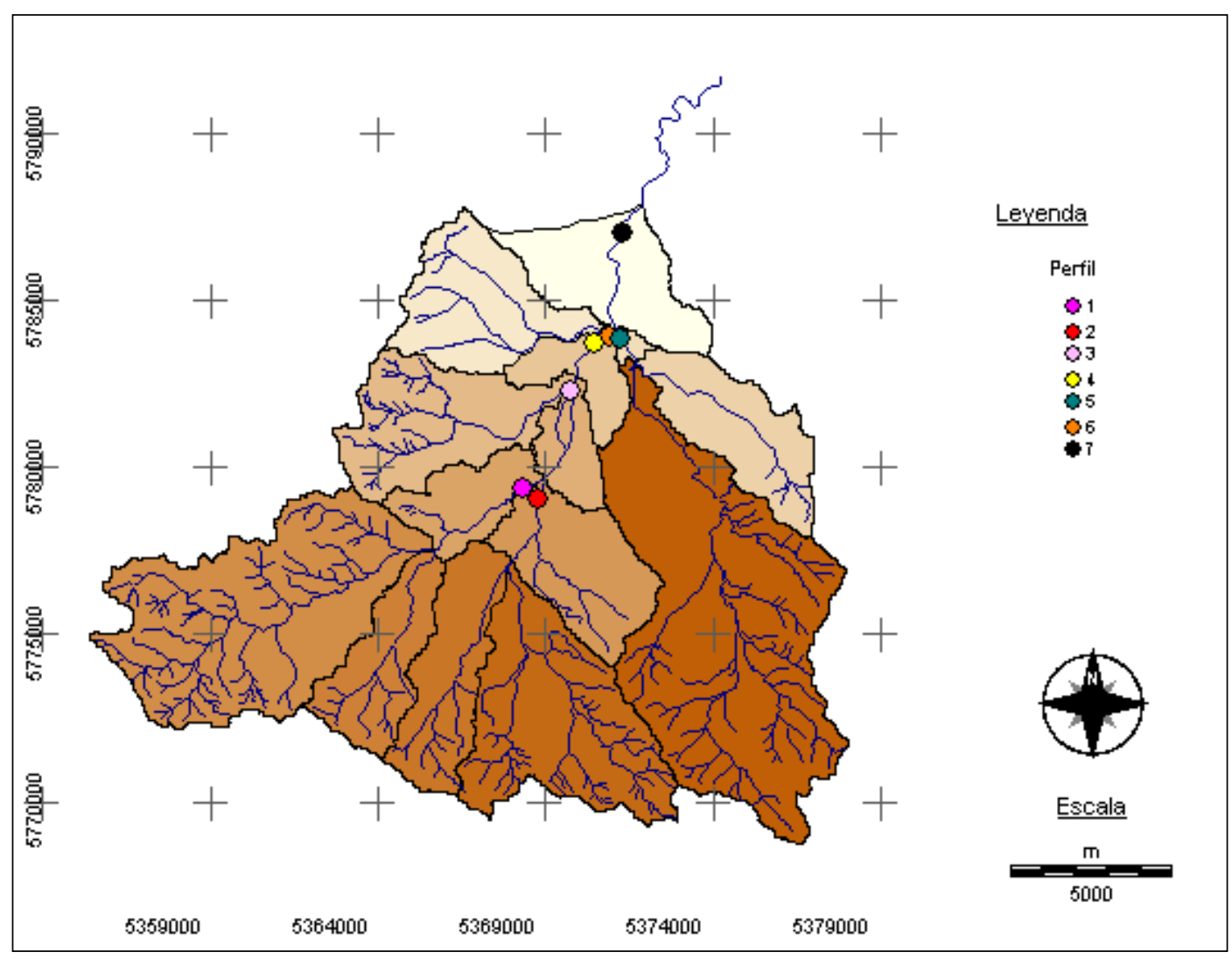

Figura 20: Ubicación de los perfiles transversales en la cuenca.

Las Figuras 21 a 27 representan las secciones transversales de cada uno de los perfiles relevados. El área azul es la sección de agua presente en el momento de realizar las mediciones. La tabla anexa corresponde a los valores del coeficiente de Manning y los factores de corrección para el curso y sus márgenes.

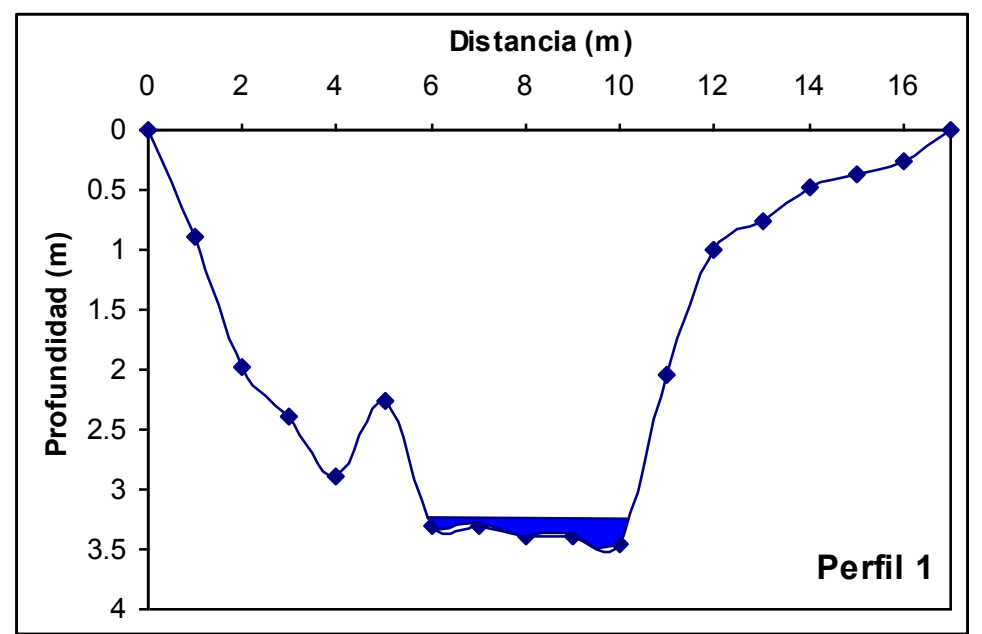

\begin{tabular}{|c|c|c|}
\hline \multicolumn{3}{|c|}{ Rugosidad $\left(\mathrm{n}^{\circ}\right.$ de Manning } \\
\hline & argen izquierdo & 0.045 \\
\hline \multirow{7}{*}{ 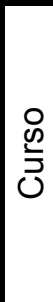 } & Valor base & 0.04 \\
\hline & irregularidad & 0.001 \\
\hline & Var. Del cauce & 0.003 \\
\hline & Obstrucciones & 0 \\
\hline & vegetacion & 0.002 \\
\hline & sinuosidad & 1 \\
\hline & Valor comp. & 0.046 \\
\hline \multicolumn{2}{|c|}{ Margen derecho } & 0.04 \\
\hline
\end{tabular}

Figura 21: Sección transversal y valores del coeficiente de Manning y factores de corrección del perfil 1. 


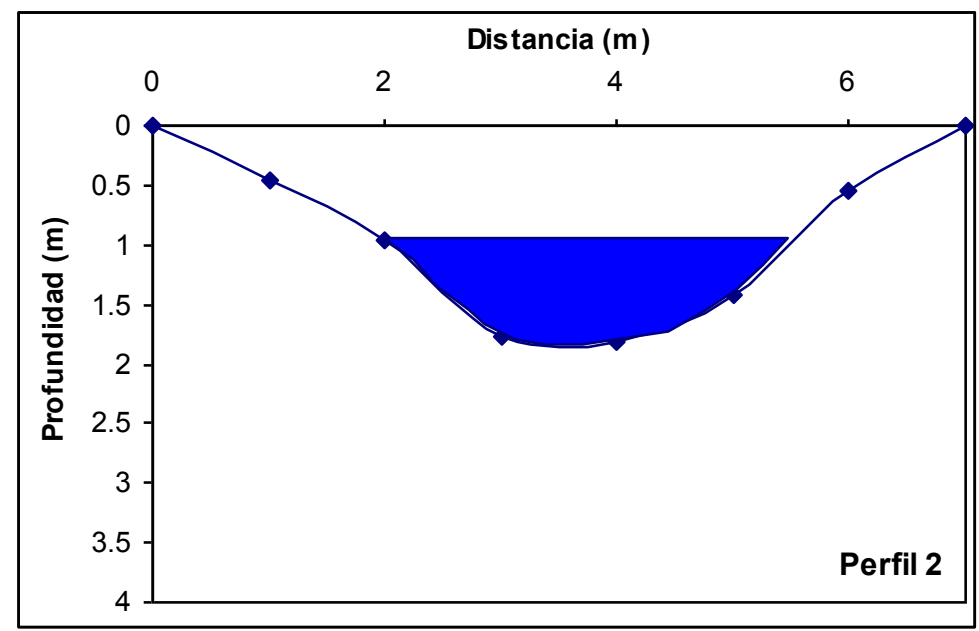

\begin{tabular}{|c|c|c|}
\hline \multicolumn{3}{|c|}{ Rugosidad $\left(\mathrm{n}^{\circ}\right.$ de Manning $)$} \\
\hline \multicolumn{2}{|c|}{ Margen izquierdo } & 0.035 \\
\hline \multirow{4}{*}{$\circlearrowleft$ Valor base } & 0.1 \\
\cline { 2 - 3 } & irregularidad & 0.006 \\
\cline { 2 - 3 } & Var. Del cauce & 0.01 \\
\cline { 2 - 3 } & Obstrucciones & 0.05 \\
\cline { 2 - 3 } & vegetacion & 0.07 \\
\cline { 2 - 3 } & sinuosidad & 1 \\
\cline { 2 - 3 } & Valor comp. & 0.236 \\
\hline \multicolumn{2}{|c|}{ Margen derecho } & 0.035 \\
\hline
\end{tabular}

Figura 22: Sección transversal y valores del coeficiente de Manning y factores de corrección del perfil 2.

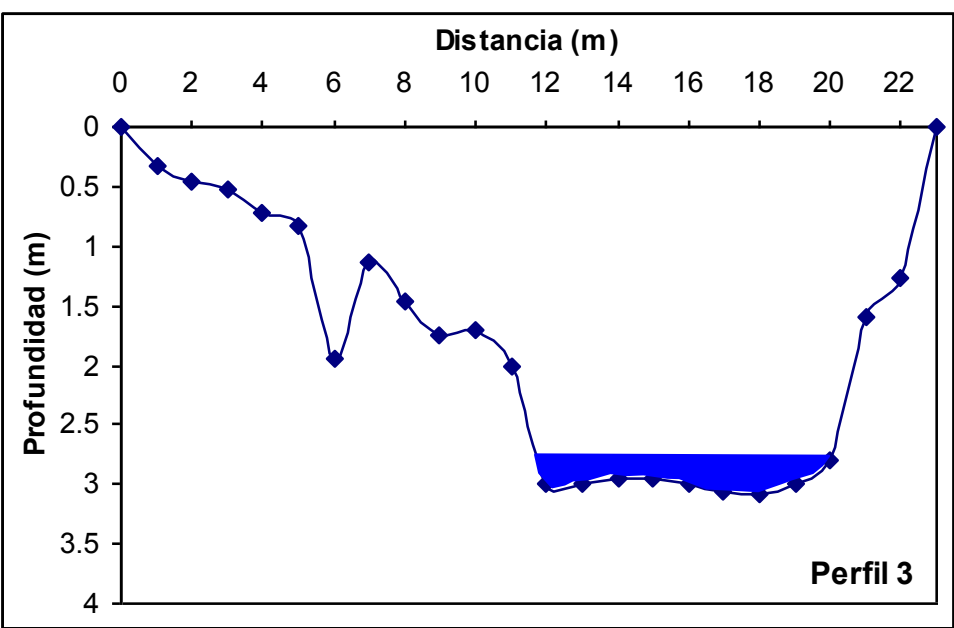

\begin{tabular}{|c|c|c|}
\hline & $\rho^{\circ} \mathrm{de}$ & \\
\hline & rgen izquierdo & 0.045 \\
\hline & Valor base & 0.04 \\
\hline & irregularidad & 0.006 \\
\hline & Var. Del cauce & 0.003 \\
\hline & Obstrucciones & 0.01 \\
\hline & vegetacion & 0.05 \\
\hline & sinuosidad & 1 \\
\hline & Valor comp. & 0.109 \\
\hline & & \\
\hline
\end{tabular}

Figura 23: Sección transversal y valores del coeficiente de Manning y factores de corrección del perfil 3

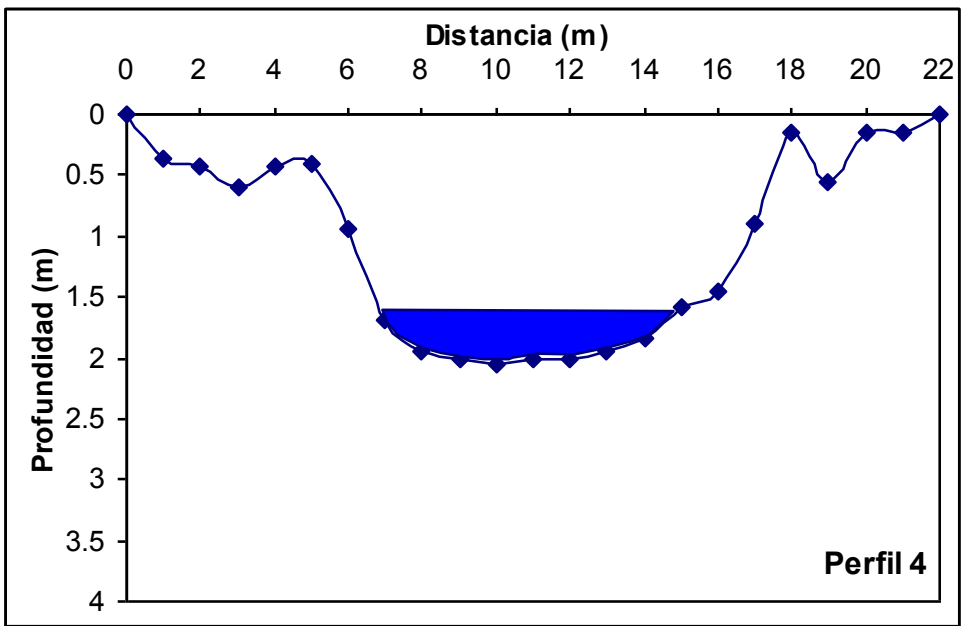

\begin{tabular}{|c|c|c|}
\hline \multicolumn{3}{|c|}{ Rugosidad ( $\mathrm{n}^{\circ}$ de Manning) } \\
\hline \multicolumn{2}{|c|}{ Margen izquierdo } & 0.05 \\
\hline \multirow{4}{*}{$\stackrel{\text { Valor base }}{0}$} & 0.04 \\
\cline { 2 - 3 } & irregularidad & 0.001 \\
\cline { 2 - 3 } & Var. Del cauce & 0.005 \\
\cline { 2 - 3 } & Obstrucciones & 0.01 \\
\cline { 2 - 3 } & vegetacion & 0.01 \\
\cline { 2 - 3 } & sinuosidad & 1 \\
\cline { 2 - 3 } & Valor comp. & 0.066 \\
\hline \multicolumn{2}{|c|}{ Margen derecho } & 0.075 \\
\hline
\end{tabular}

Figura 24: Sección transversal y valores del coeficiente de Manning y factores de corrección del perfil 4. 


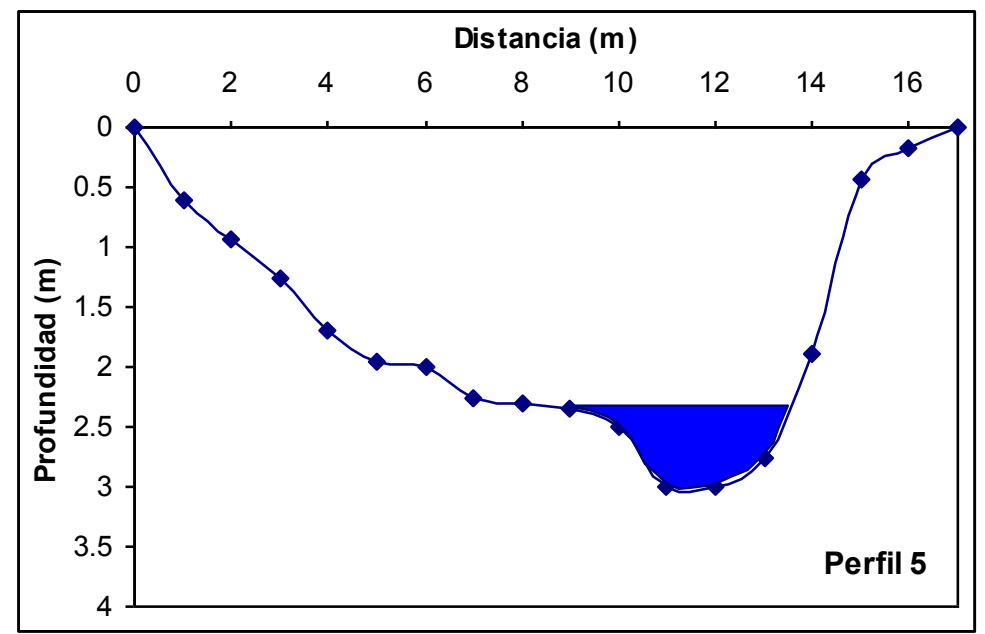

\begin{tabular}{|c|c|c|}
\hline \multicolumn{3}{|c|}{ Rugosidad ( $\mathrm{n}^{\circ}$ de Manning) } \\
\hline \multicolumn{1}{|c|}{ Margen izquierdo } & 0.07 \\
\hline & Valor base & 0.048 \\
\cline { 2 - 3 } & irregularidad & 0.003 \\
\cline { 2 - 3 }$\lesssim$ & Var. Del cauce & 0 \\
\cline { 2 - 3 } & Obstrucciones & 0.03 \\
\cline { 2 - 3 } & vegetacion & 0.01 \\
\cline { 2 - 3 } & sinuosidad & 1 \\
\cline { 2 - 3 } & Valor comp. & 0.091 \\
\hline Margen derecho & 0.06 \\
\hline
\end{tabular}

Figura 25: Sección transversal y valores del coeficiente de Manning y factores de corrección del perfil 5.

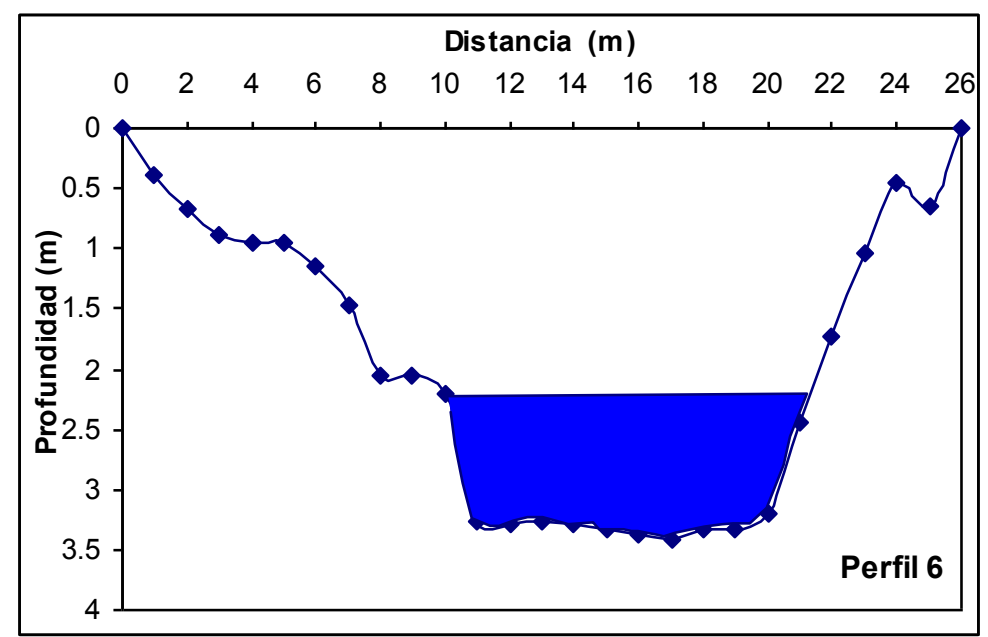

\begin{tabular}{|c|c|c|}
\hline \multicolumn{3}{|c|}{ Rugosidad $\left(\mathrm{n}^{\circ}\right.$ de Manning) } \\
\hline \multicolumn{2}{|c|}{ Margen izquierdo } & 0.035 \\
\hline \multirow{4}{*}{$\circ$} & Valor base & 0.035 \\
\cline { 2 - 3 } & irregularidad & 0.001 \\
\cline { 2 - 3 } & Var. Del cauce & 0 \\
\cline { 2 - 3 } & Obstrucciones & 0.001 \\
\cline { 2 - 3 } & vegetacion & 0.001 \\
\cline { 2 - 3 } & sinuosidad & 1 \\
\cline { 2 - 3 } & Valor comp. & 0.038 \\
\hline \multicolumn{2}{|c|}{ Margen derecho } & 0.033 \\
\hline
\end{tabular}

Figura 26: Sección transversal y valores del coeficiente de Manning y factores de corrección del perfil 6.

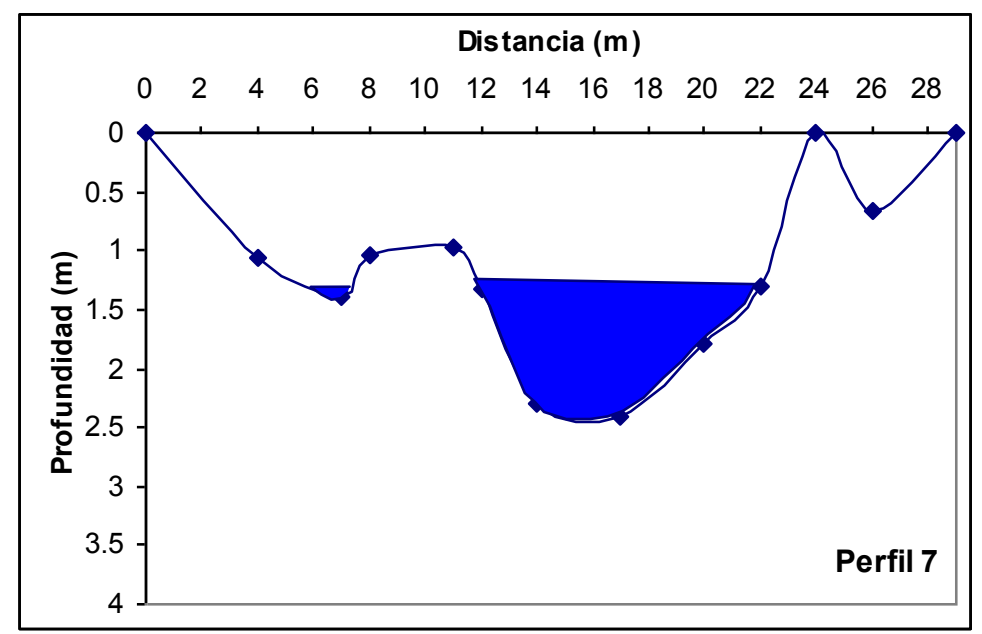

\begin{tabular}{|c|c|c|}
\hline \multicolumn{3}{|c|}{ Rugosidad $\left(\mathrm{n}^{\circ}\right.$ de Manning } \\
\hline \multicolumn{2}{|c|}{ Margen izquierdo } & 0.04 \\
\hline \multirow{4}{*}{$\diamond$} & Valor base & 0.07 \\
\cline { 2 - 3 } & irregularidad & 0.008 \\
\cline { 2 - 3 } & Var. Del cauce & 0.001 \\
& Obstrucciones & 0.025 \\
\cline { 2 - 3 } & vegetacion & 0.05 \\
\cline { 2 - 3 } & sinuosidad & 1.15 \\
\cline { 2 - 3 } & Valor comp. & 0.1771 \\
\hline \multicolumn{2}{|c|}{ Margen derecho } & 0.04 \\
\hline
\end{tabular}

Figura 27: Sección transversal y valores del coeficiente de Manning y factores de corrección del perfil 7. 


\subsubsection{Modelo Meteorológico.}

Se crearon tres modelos meteorológicos, para las tormentas seleccionadas. El Gráfico 26 presenta los hietogramas creados a partir de las curvas de masa de lluvia de la Tabla 12. Se asignó la misma fecha y hora de inicio a todos los modelos meteorológicos (01 de Enero de 2000), para homogeneizar criterios de evaluación y comparación. El fin corresponde a la hora de finalización de cada tormenta.
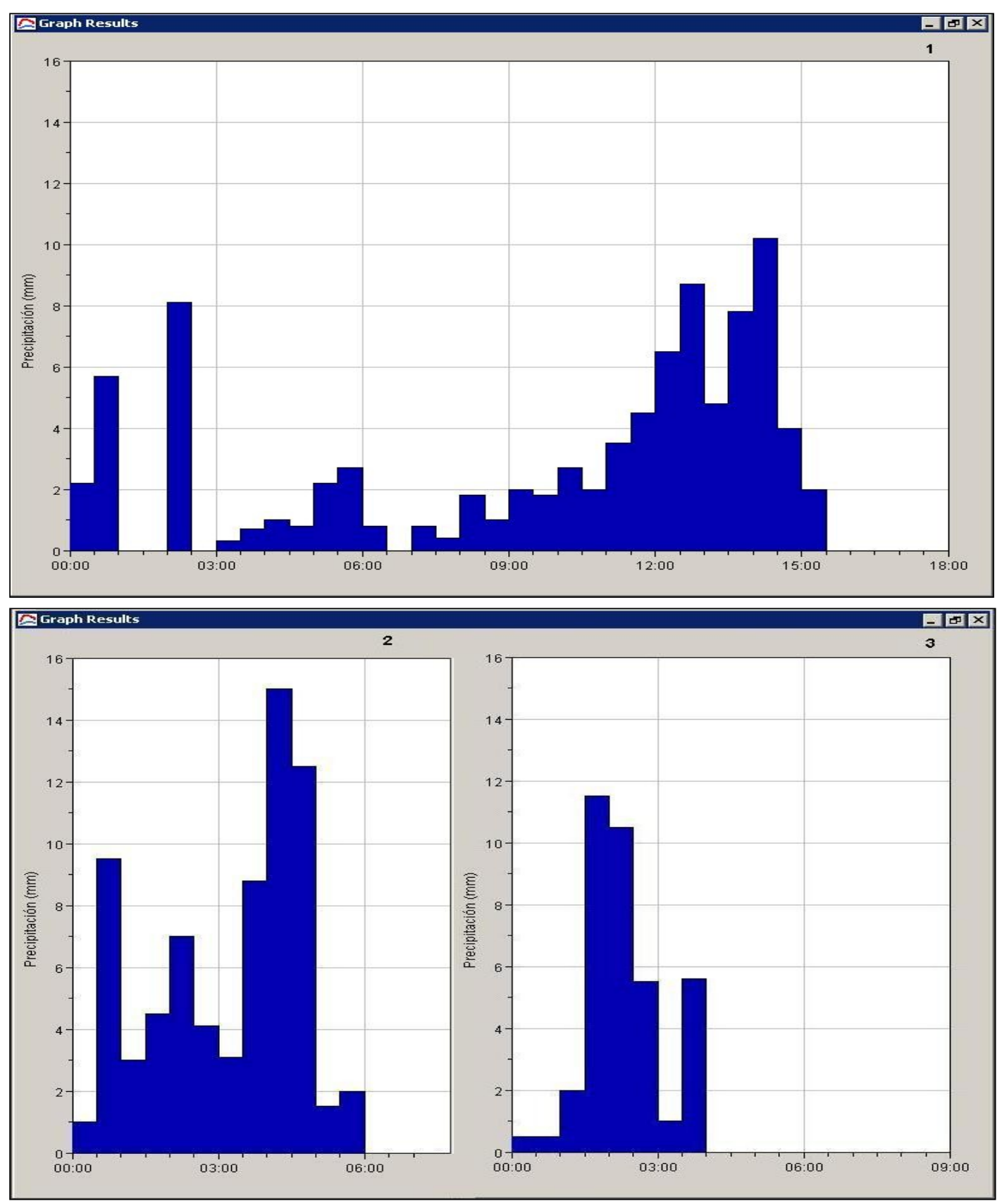

Gráfico 26: Hietogramas del modelo meteorológico. 1) TR 5.9 años; 2) TR 2.3 años; 3) TR 1 año. 


\subsubsection{Especificaciones de Control.}

Las especificaciones de control fueron las mismas para las tres modelizaciones, el comienzo corresponde con la fecha y hora de los modelos meteorológicos, la finalización del cómputo asignada fue tres días después, realizando los cálculos cada 30 minutos.

\subsection{Zonificación de la escorrentía superficial.}

Los resultados generados por Lthia para las tres tormentas seleccionadas se presentan en las Figuras 28, 29 y 30, utilizando una misma escala de colores para su representación.

Para una tormenta con TR 5.9 años solo el 1.1\% de la cuenca genera láminas de escorrentía menores a $10 \mathrm{~mm}$, el $6 \%$ de la superficie presenta láminas correspondiente al rango entre 10 y $20 \mathrm{~mm}$, el rango entre 20 y $30 \mathrm{~mm}$ de lámina de escorrentía representa la mayor superficie con un $51.3 \%$, teniendo el área restante una lámina mayor a $30 \mathrm{~mm}$ (41.6\%). De esta manera el $92.9 \%$ de la cuenca posee láminas de escorrentía altas a torrenciales (Figura 28).

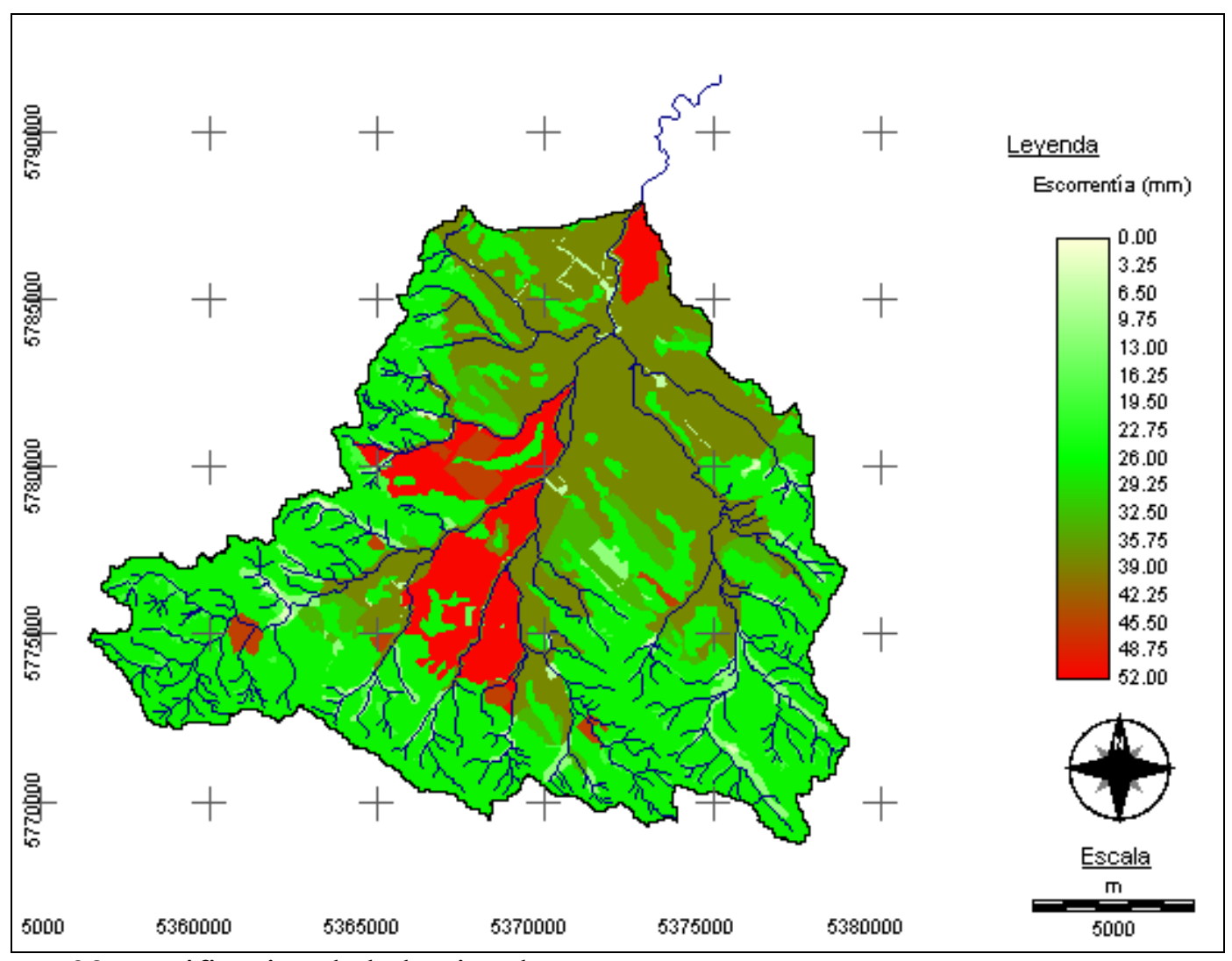

Figura 28: Zonificación de la lámina de escorrentía para una tormenta con TR 5.9 años.

En el caso de una tormenta con TR 2.3 años el 4.8\% de la cuenca genera láminas de escorrentía menores a $10 \mathrm{~mm}$, el rango entre 10 y $20 \mathrm{~mm}$ representa láminas de escorrentía medias, ocupando la mayor superficie correspondiente al 53.6\%. El rango 
entre 20 y $30 \mathrm{~mm}$ de lámina de escorrentía representa un $31.7 \%$ del área de la cuenca, teniendo el 9.9\% restante láminas mayores a 30mm (Figura 29).

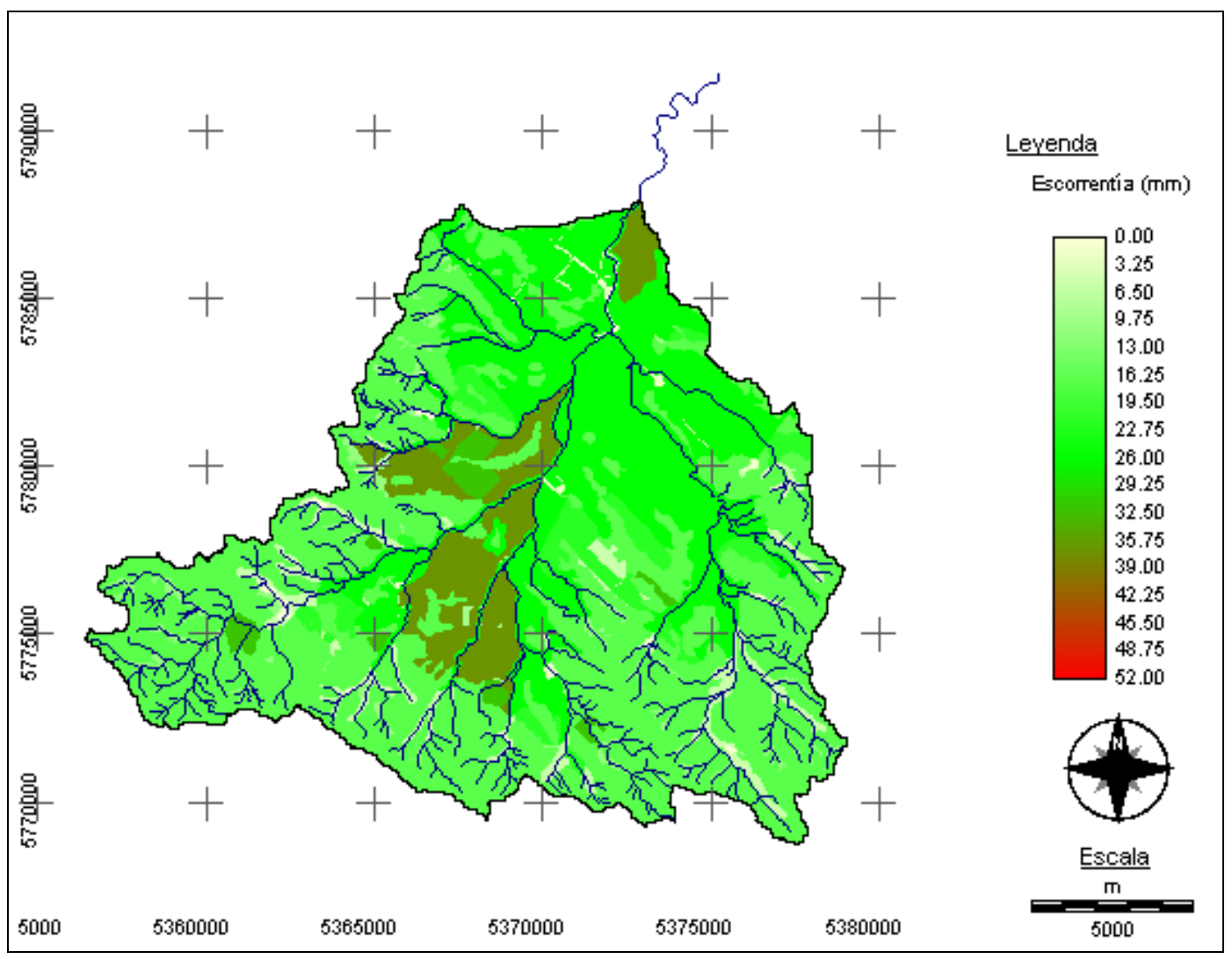

Figura 29: Zonificación de la lámina de escorrentía para una tormenta con TR 2.3 años.

Una tormenta con TR 1 año el 91.9\% de la cuenca genera láminas de escorrentía leves, menores a $10 \mathrm{~mm}$, el rango entre 10 y $20 \mathrm{~mm}$ representa láminas de escorrentía medias, ocupando la superficie restante de la cuenca con un $8.1 \%$ (Figura 30). 


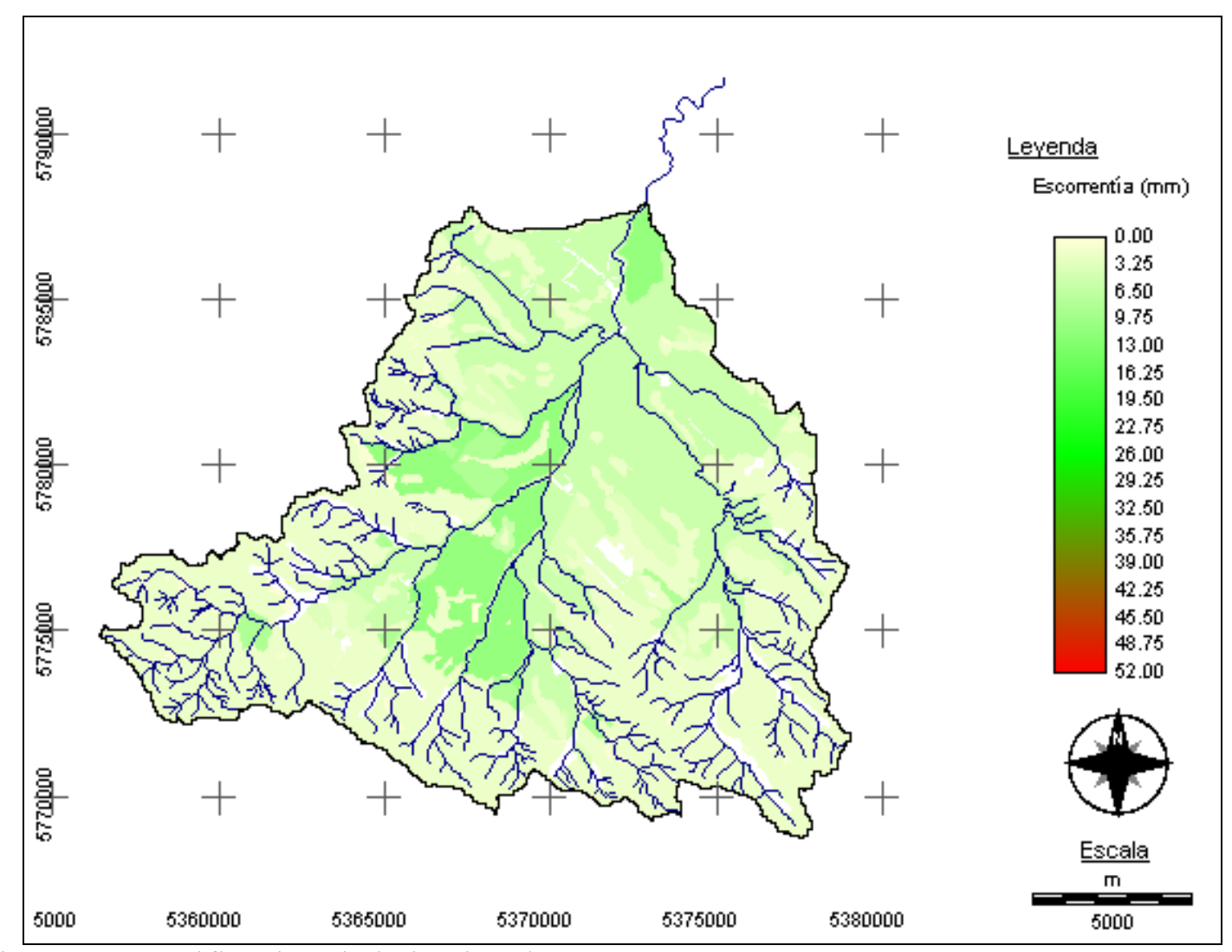

Figura 30: Zonificación de la lámina de escorrentía para una tormenta con TR 1 año.

A modo de síntesis se presenta en la Tabla 22 que expresa la lámina de escorrentía calculada por Lthia para cada una de las tormentas según el NC zonificado en la Figura 18.

Tabla 22: Lámina de escorrentía generada por cada tormenta según el NC.

\begin{tabular}{|c|c|c|c|}
\cline { 2 - 4 } \multicolumn{1}{c|}{} & \multicolumn{3}{c|}{ Lámina de escorrentía (mm) } \\
\hline NC & TR 5.9 años & TR 2.3 años & TR 1 año \\
\hline 48 & 3.73 & 0.98 & 0.00 \\
\hline 52 & 6.41 & 2.42 & 0.00 \\
\hline 58 & 11.54 & 5.65 & 0.00 \\
\hline 63 & 16.80 & 9.29 & 0.33 \\
\hline 65 & 19.15 & 10.98 & 0.63 \\
\hline 71 & 27.08 & 16.94 & 2.20 \\
\hline 75 & 33.13 & 21.70 & 3.84 \\
\hline 78 & 38.10 & 25.72 & 5.45 \\
\hline 82 & 41.36 & 31.75 & 8.18 \\
\hline 85 & 51.30 & 36.83 & 10.78 \\
\hline
\end{tabular}




\subsection{Generación de hidrogramas.}

A partir de la modelización hidrológica con Hec Hms se obtuvieron los hidrogramas de salida a nivel de cuenca y subcuencas. La Figura 31 representa el hidrograma a la salida de la cuenca para una precipitación con TR 5.9 años, cuyo volumen total de escorrentía fue de $7772800 \mathrm{~m}^{3}$ con un caudal pico de $229.9 \mathrm{~m}^{3} / \mathrm{s}$ a las 19:00 hs (Tp) representando una lámina total equivalente de $30.93 \mathrm{~mm}$.

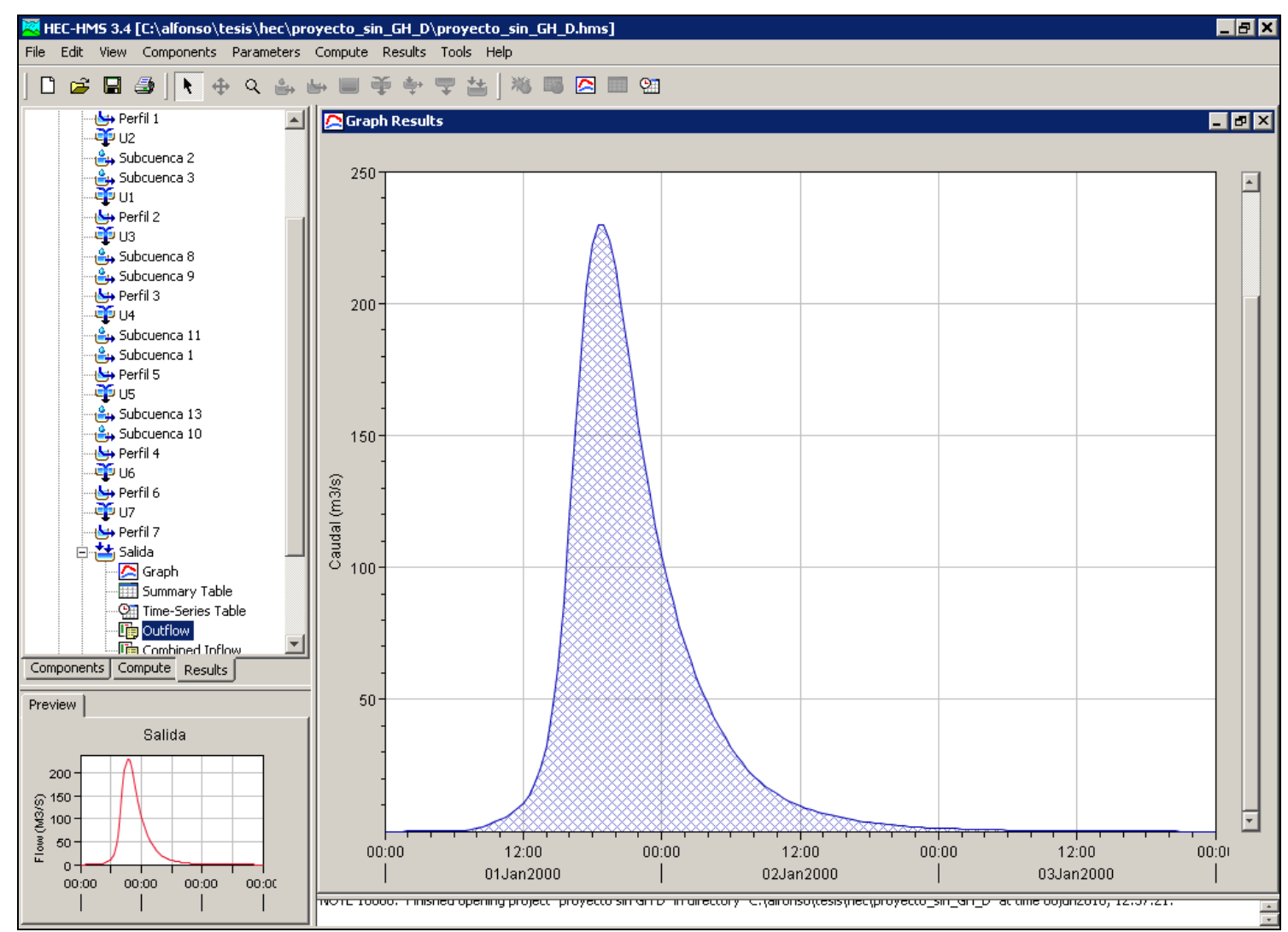

Figura 31: Hidrograma a la salida de la cuenca para una tormenta con TR 5.9 años.

En la Tabla 23 se presentan los valores característicos de los hidrogramas de cada subcuenca.

Tabla 23: Valores característicos de caudal pico (Qp), tiempo al pico (Tp) y lámina de escorrentía (E) de los hidrogramas de cada subcuenca.

\begin{tabular}{|c|c|c|c|c|c|c|c|c|c|c|c|c|c|c|c|}
\hline Subcuenca & $\mathbf{1}$ & $\mathbf{2}$ & $\mathbf{3}$ & $\mathbf{4}$ & $\mathbf{5}$ & $\mathbf{6}$ & $\mathbf{7}$ & $\mathbf{8}$ & $\mathbf{9}$ & $\mathbf{1 0}$ & $\mathbf{1 1}$ & $\mathbf{1 2}$ & $\mathbf{1 3}$ & $\mathbf{1 4}$ & $\mathbf{1 5}$ \\
\hline $\mathrm{Qp}\left(\mathrm{m}^{3} / \mathrm{s}\right)$ & 32.6 & 31.0 & 21.1 & 13.7 & 36.0 & 20.9 & 12.9 & 8.1 & 24.6 & 11.7 & 17.9 & 1.8 & 19.8 & 0.4 & 14.9 \\
\hline $\mathrm{Tp}(\mathrm{hs})$ & $23: 00$ & $18: 00$ & $17: 00$ & $17: 30$ & $19: 00$ & $17: 00$ & $17: 30$ & $17: 30$ & $17: 30$ & $16: 00$ & $17: 30$ & $16: 00$ & $18: 00$ & $15: 00$ & $19: 30$ \\
\hline $\mathrm{E}(\mathrm{mm})$ & 28.51 & 30.02 & 34.7828 .51 & 27.11 & 31.60 & 38.13 & 38.13 & 33.16 & 38.13 & 31.6 & 38.13 & 31.60 & 31.6036 .39 \\
\hline
\end{tabular}


El hidrograma a la salida de la cuenca para una precipitación con TR 2.3 años se observa en la Figura 32, el volumen total de escorrentía fue de $5026400 \mathrm{~m}^{3}$ representando una lámina total equivalente de $20.00 \mathrm{~mm}$, el caudal pico fue de 163.3 $\mathrm{m}^{3} / \mathrm{s}$ a las 09:30 hs (Tp).

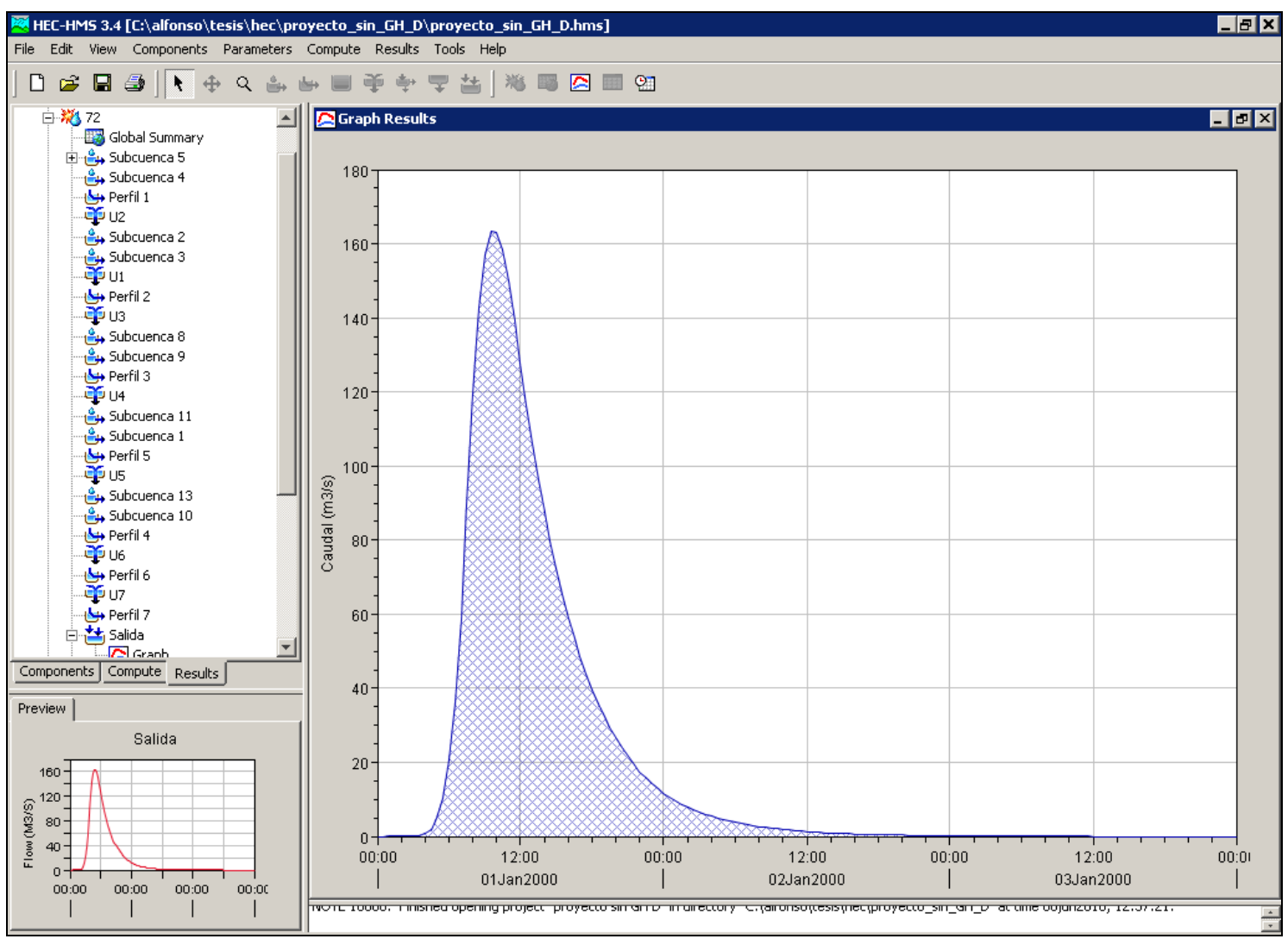

Figura 32: Hidrograma a la salida de la cuenca para una tormenta con TR 2.3 años.

Los valores característicos de los hidrogramas de cada subcuenca se presentan en la Tabla 24.

Tabla 24: Valores característicos de caudal pico (Qp), tiempo al pico (Tp) y lámina de escorrentía (E) de los hidrogramas de cada subcuenca.

\begin{tabular}{|c|c|c|c|c|c|c|c|c|c|c|c|c|c|c|c|}
\hline Subcuenca & $\mathbf{1}$ & $\mathbf{2}$ & $\mathbf{3}$ & $\mathbf{4}$ & $\mathbf{5}$ & $\mathbf{6}$ & $\mathbf{7}$ & $\mathbf{8}$ & $\mathbf{9}$ & $\mathbf{1 0}$ & $\mathbf{1 1}$ & $\mathbf{1 2}$ & $\mathbf{1 3}$ & $\mathbf{1 4}$ & $\mathbf{1 5}$ \\
\hline $\mathrm{Qp}\left(\mathrm{m}^{3} / \mathrm{s}\right)$ & 21.2 & 22.1 & 16.5 & 9.7 & 24.2 & 15.8 & 10.3 & 6.4 & 18.5 & 10.1 & 13.2 & 1.5 & 14.4 & 0.4 & 10.8 \\
\hline $\mathrm{Tp}(\mathrm{hs})$ & $14: 30$ & $09: 00$ & $08: 0008: 30$ & $10: 00$ & $08: 00$ & $08: 00$ & $08: 30$ & $08: 30$ & $07: 0008: 30$ & $06: 30$ & $09: 00$ & $05: 30$ & $10: 30$ \\
\hline $\mathrm{E}(\mathrm{mm})$ & 18.05 & 19.23 & 23.02 & 18.05 & 16.97 & 20.48 & 25.74 & 25.74 & 21.72 & 25.7420 .48 & 25.74 & 20.48 & 20.4824 .32 \\
\hline
\end{tabular}

La Figura 33 expresa el hidrogramas a la salida de la cuenca obtenido con Hec Hms para una precipitación con TR 1 año. El volumen total de escorrentía fue de $830500 \mathrm{~m}^{3}$ representando una lámina total equivalente de $3.30 \mathrm{~mm}$, el caudal pico fue de $27,0 \mathrm{~m}^{3} / \mathrm{s} \mathrm{a}$ las 09:30 hs (Tp). 


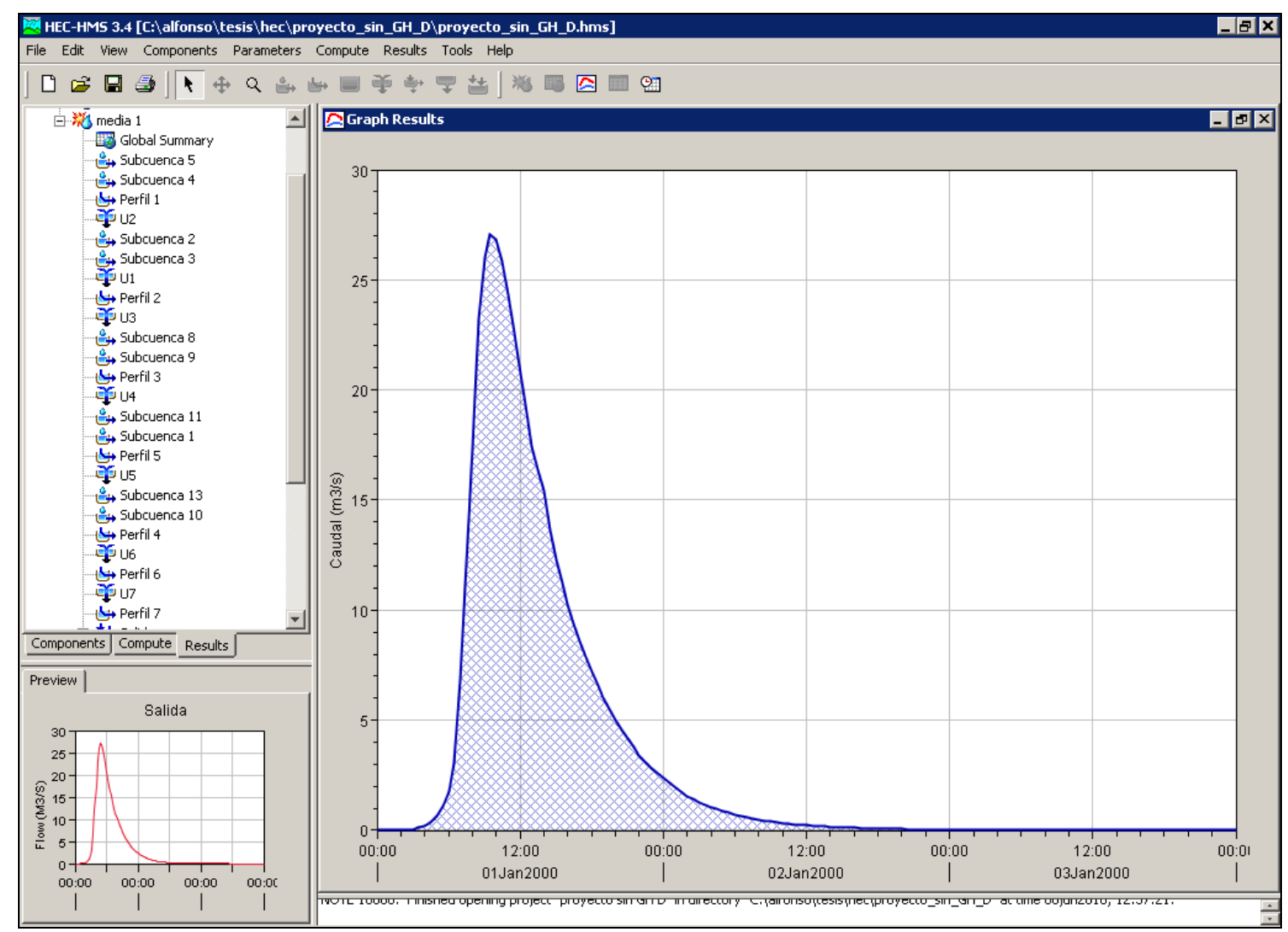

Figura 33: Hidrograma a la salida de la cuenca para una tormenta con TR 1 año.

La Tabla 25 presenta los valores característicos de los hidrogramas a la salida de cada subcuenca.

Tabla 25: Valores característicos de caudal pico (Qp), tiempo al pico (Tp) y lámina de escorrentía (E) de los hidrogramas de cada subcuenca.

\begin{tabular}{|c|c|c|c|c|c|c|c|c|c|c|c|c|c|c|c|}
\hline Subcuenca & $\mathbf{1}$ & $\mathbf{2}$ & $\mathbf{3}$ & $\mathbf{4}$ & $\mathbf{5}$ & $\mathbf{6}$ & $\mathbf{7}$ & $\mathbf{8}$ & $\mathbf{9}$ & $\mathbf{1 0}$ & $\mathbf{1 1}$ & $\mathbf{1 2}$ & $\mathbf{1 3}$ & $\mathbf{1 4}$ & $\mathbf{1 5}$ \\
\hline $\mathrm{Qp}\left(\mathrm{m}^{3} / \mathrm{s}\right)$ & 3.0 & 3.5 & 3.2 & 1.4 & 3.2 & 2.7 & 2.2 & 1.4 & 3.4 & 2.3 & 2.2 & 0.3 & 2.4 & 0.1 & 2.2 \\
\hline $\mathrm{Tp}(\mathrm{hs})$ & $13: 00$ & $08: 0007: 00$ & $07: 30$ & $09: 00$ & $07: 00$ & $07: 00$ & $07: 00$ & $07: 00$ & $05: 30$ & $07: 00$ & $05: 30$ & $07: 30$ & $04: 3009: 30$ \\
\hline $\mathrm{E}(\mathrm{mm})$ & 2.58 & 2.98 & 4.39 & 2.58 & 2.24 & 3.43 & 5.50 & 5.50 & 3.89 & 5.50 & 3.43 & 5.50 & 3.43 & 3.43 & 4.91 \\
\hline
\end{tabular}

\section{Medidas de restauración agro-hidrológica.}

\subsection{Caracterización de las propuestas.}

La metodología empleada para la asignación de nuevos usos del suelo se basó en una combinación multicriterio utilizando tres variables espaciales: grupo hidrológico, rangos de pendiente y vegetación y usos del suelo actual.

Esta combinación representa el potencial de escurrimiento, donde, mayores pendientes, suelos de textura más fina o con limitaciones a la infiltración y vegetaciones poco densas poseen escurrimientos potenciales altos. Sobre esta base se creó una tabla 
de triple entrada (Tabla 26) estableciendo medidas de restauración agro-hidrológicas diferentes para cada combinación. La vegetación y uso del suelo actual descripta en Apartado 2.3, se utilizó con doble propósito, por un lado, respetar los límites de producción agrícola, proponiendo métodos de labranza conservacionista sin cambiar el tipo de cobertura en aquellos casos que las pendientes no sean excesivas y por otro, determinar áreas con coberturas que favorecen la intercepción, como ser bosques y pajonales serranos a fin de mantenerlas. Las propuestas intentan conservar la biodiversidad natural del ambiente, preservando el pastizal serrano con la mayor superficie posible, sólo se plantea su reemplazo en aquellos casos donde las altas pendientes y los tipos de suelos generan condiciones de escurrimiento excesivamente altas. Sobre la base de los criterios citados, las medidas de restauración propuestas se describen a continuación:

En áreas con altas pendientes, donde el ganado bovino tiene acceso limitado, y potenciales de escurrimiento alto, se propone la implantación de especies forestales formando bosques protectores, es decir, masas forestales con el fin único de favorecer la intercepción de la lluvia y disminuir el escurrimiento superficial. En suelos destinados a algún tipo de cultivo, las medidas propuestas fueron dos: En pendientes suaves o moderadas, las labores realizadas deben practicarse siguiendo las curvas de nivel (cultivo a nivel), cuando las pendientes sean mayores, se implementa el uso de terrazas para realizar el cultivo de dichas áreas.

Tabla 26: Usos propuestos en función de Pendiente, G.H, y Vegetación y uso del suelo actual. Referencias: P.P: Prados permanentes; M.C $>75 \%$ : Matorral, mezcla matorral y maleza con cubierta $>75 \%$; B.B: Bosques B; C.C.B: Cultivo alineados CB; C.R.B: Cultivos alineados RB; C.T: Cultivos en terraza.

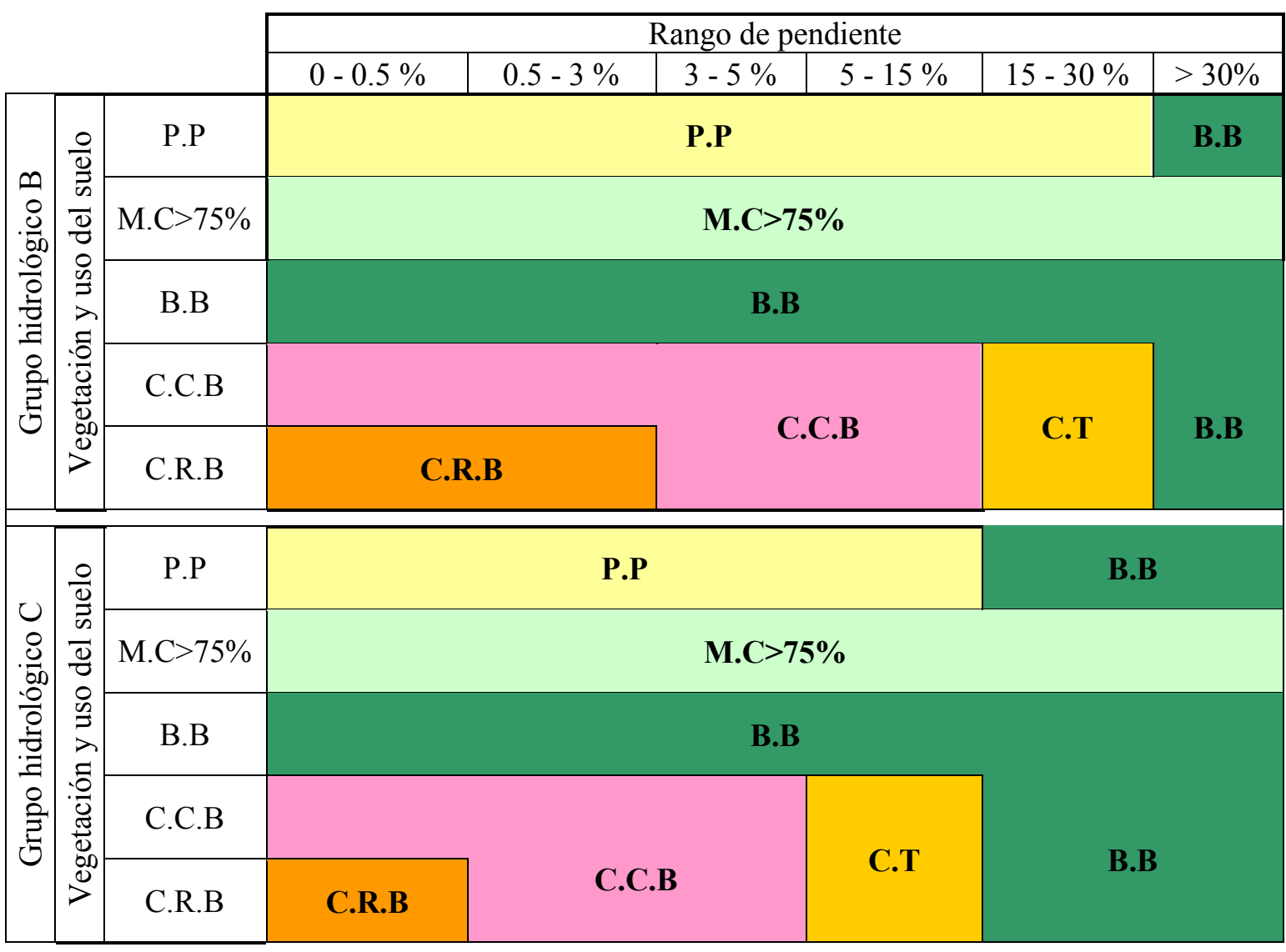




\subsection{Cartografía.}

\subsubsection{Mapa de vegetación y usos del suelo propuesto.}

La Figura 34 representa el mapa de vegetación y usos del suelo asignados según la Tabla 26. El nuevo escenario propuesto modificó la ocupación territorial.

- Los prados permanentes siguen constituyendo la categoría de mayor importancia, a pesar de haber disminuido su ocupación, pasando de un 54\% para la condición actual a un $45 \%$ para la situación propuesta.

- Los Cultivos alineados bajo labranza convencional o siembra directa en buenas condiciones hidrológicas, constituían el 36\% de la cuenca, la nueva situación restringe este uso al $15 \%$ desplazado por Cultivos alineados bajo labranza conservacionista, esta categoría representaba solo el $6 \%$ de la cuenca, adquiriendo un valor de $25 \%$ para la condición restaurada.

- Los Bosques en buenas condiciones representan el 1\% de la cobertura presente en la cuenca, la nueva situación propone aumentar su superficie hasta alcanzar un $10 \%$ del área total de la cuenca.

- Por otro lado la propuesta plantea la utilización de cultivo en terrazas, la cual no se encuentra presente en la actualidad, abarcando una superficie relativamente pequeña con un $2 \%$ de ocupación.

- El Matorral, mezcla matorral y maleza cubierta $>75 \%$ no varió respecto de la situación actual, ocupando el 3\% del área total de la cuenca.

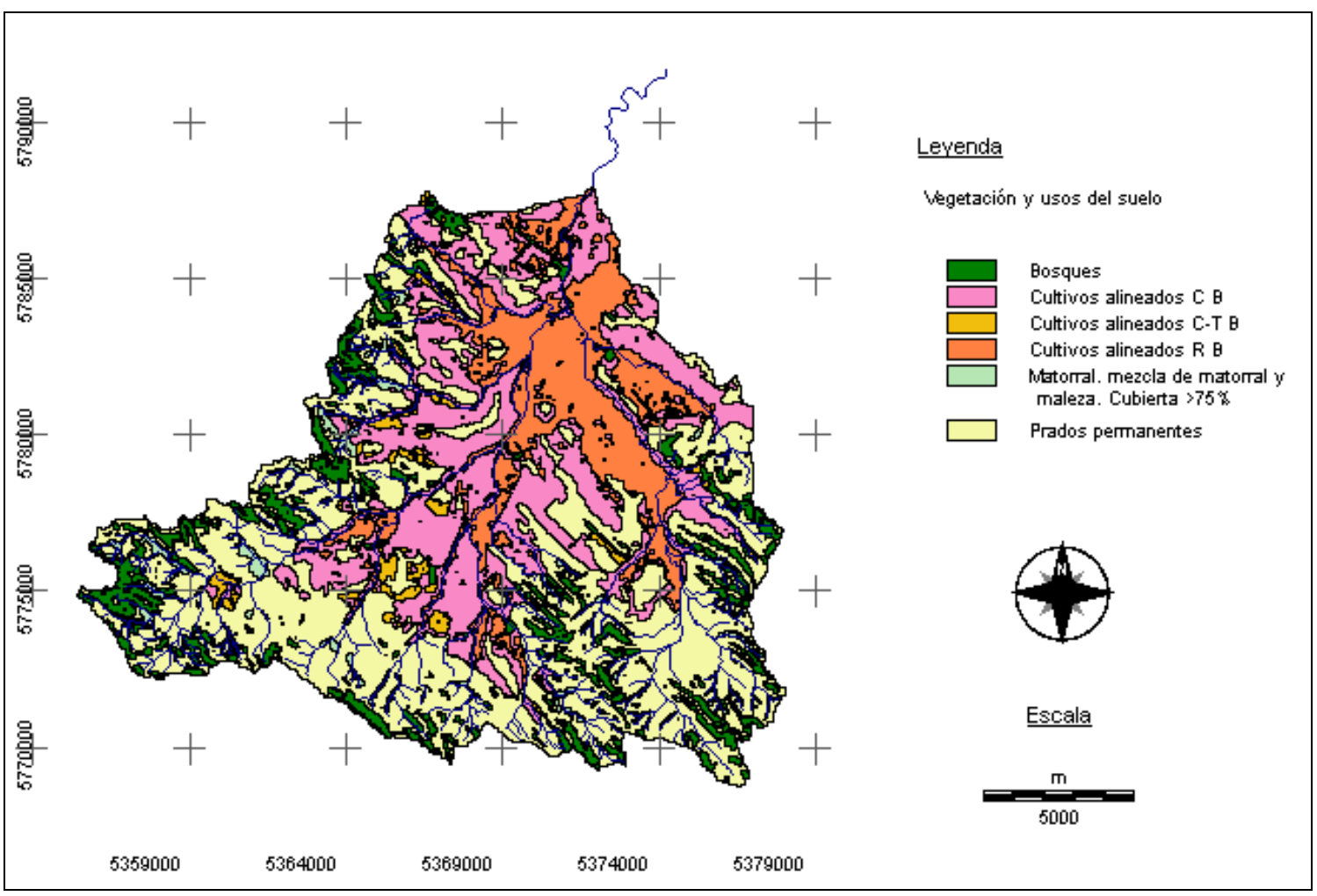

Figura 34: Mapa de vegetación y usos del suelo propuesto. 
Los cambios citados, se presentan en el Gráfico 27, exponiendo la superficie total cubierta por cada una de las categorías para la condición actual y la condición restaurada propuesta.

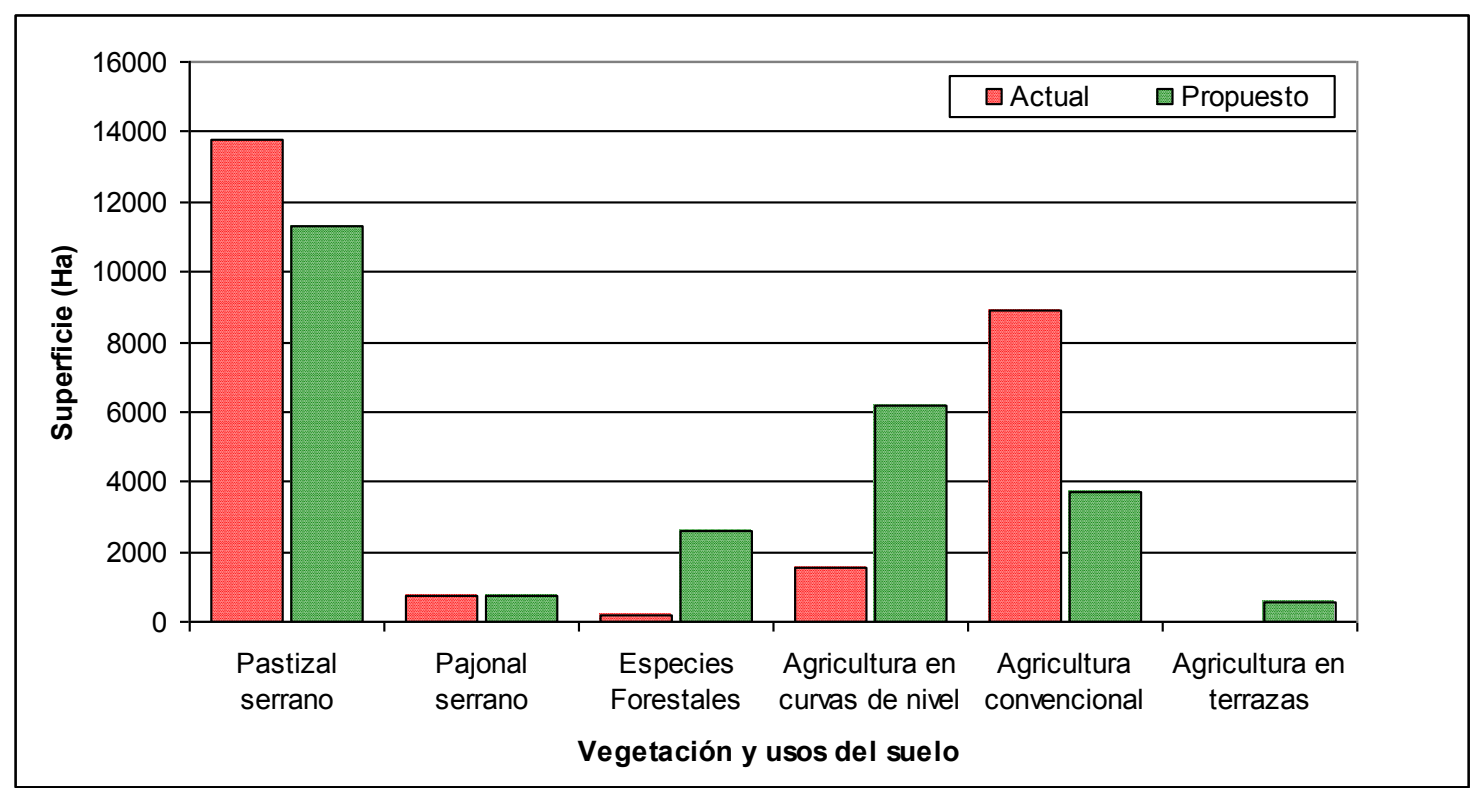

Gráfico 27: Superficie total cubierta según uso y vegetación del suelo para la condición actual y restaurada.

La Figura 35 muestra la distribución de los cambios en la vegetación y usos del suelo luego de aplicar las medidas propuestas. Se asignaron nuevos usos a 7812 ha de la cuenca.

- Se cambiaron 2454.5 ha de Pastizal serrano y 0.9 ha provenientes de Agricultura Convencional a Especies forestales.

- Se propuso el uso de Agricultura en terrazas a 151.6 ha que se encontraban destinadas a Agricultura en curvas de nivel.

- Se redujo la superficie de la Agricultura convencional convirtiendo 4793.8 ha en Agricultura en curvas de nivel.

- Se asignaron un total de 411.4 ha destinadas a Agricultura en terrazas con un uso actual de Agricultura convencional. 


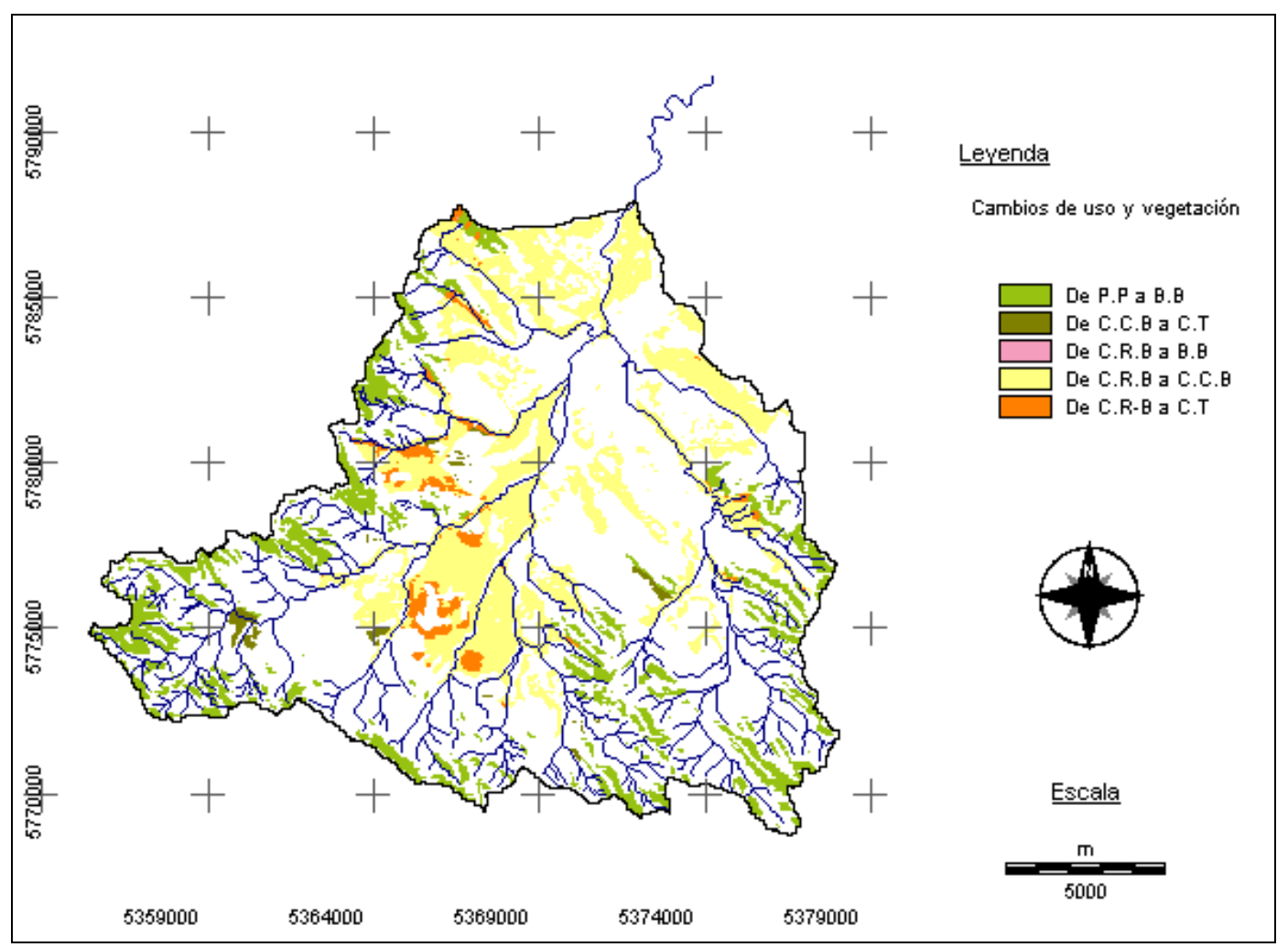

Figura 35: Distribución de los cambios en la vegetación y usos por la asignación de medidas de restauración agro-hidrológica.

Los valores netos de ganancia-pérdida de superficie para cada uno de los usos se presentan en el Gráfico 28, caracterizando la cartografía de la Figura 35.

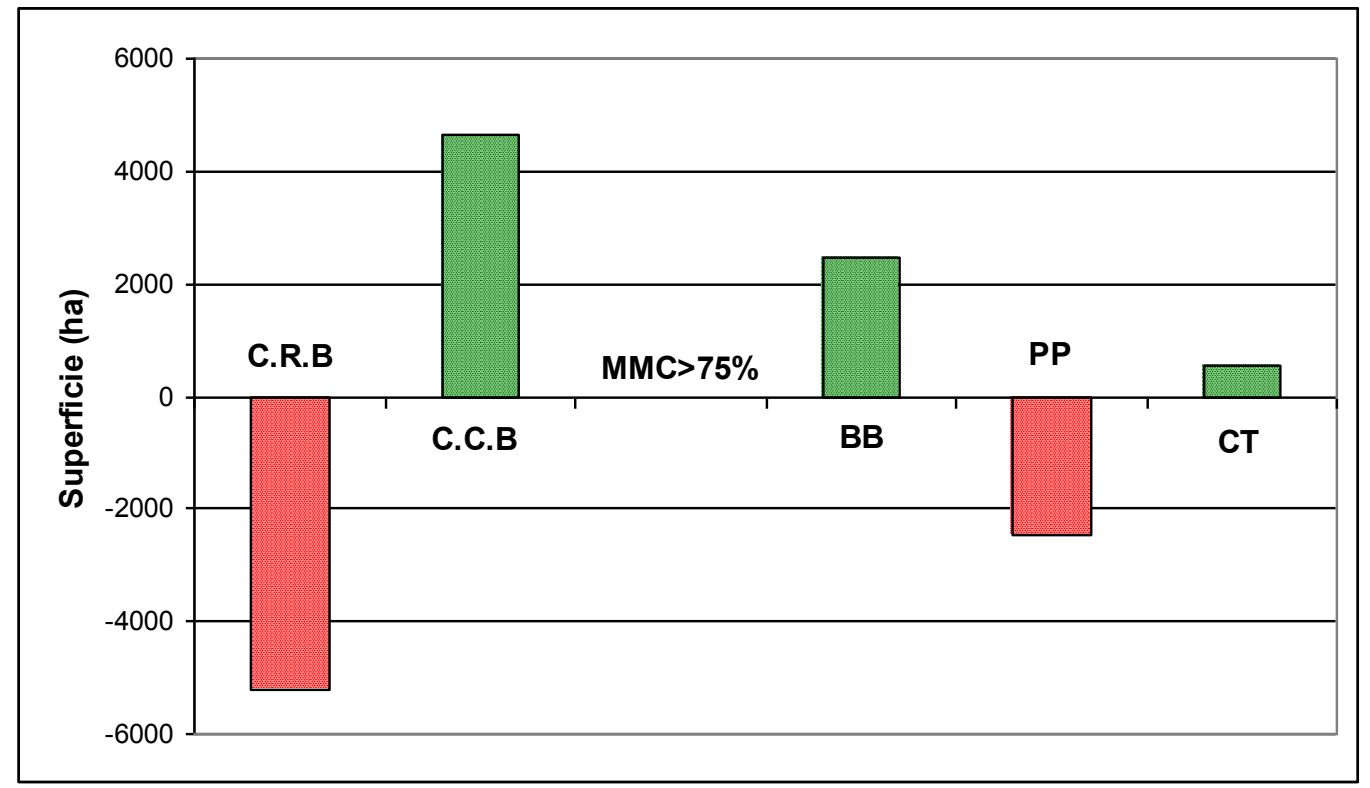

Gráfico 28: Valores de ganancia-pérdida de superficie por cambio de usos del suelo.

El Gráfico 29 expone la ocupación porcentual de la vegetación y usos del suelo para la condición restaurada por subcuenca. Los porcentajes de superficie en cada subcuenca son variables, la preponderancia de los Cultivos alineados RB en las subcuencas 10 y 12 
se debe fundamentalmente a las bajas pendientes presentes en ellas, del mismo modo puede apreciarse que los prados permanentes constituyen una categoría de gran importancia en aquellas subcuencas que poseen pendientes pronunciadas. Por otro lado es de destacar la presencia de Cultivos alineados $\mathrm{CB}$ en todas las subcuencas al igual que Bosques B exceptuando la subcuenca10.

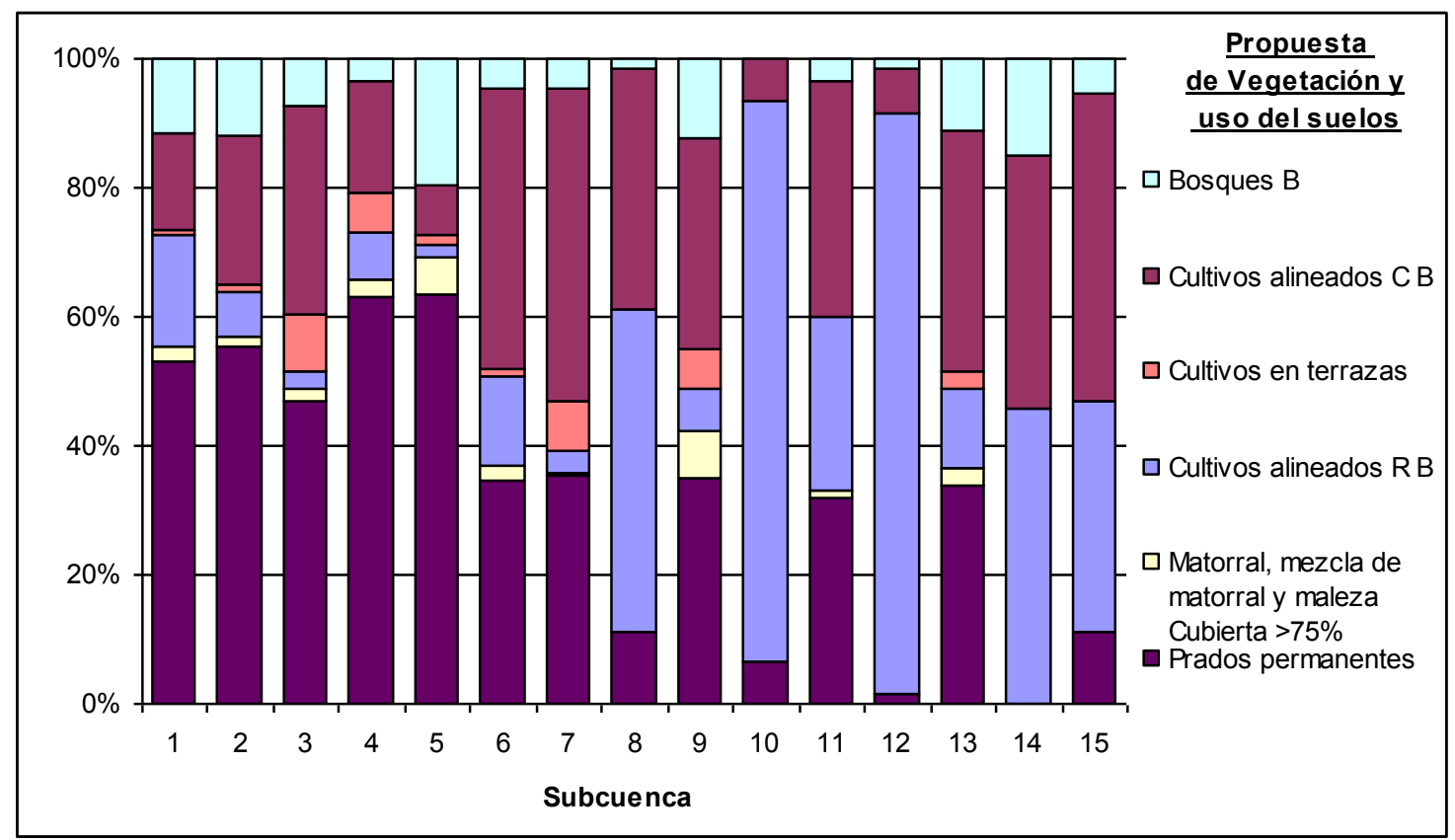

Gráfico 29: Ocupación porcentual de la vegetación y usos del suelo para la condición restaurada por subcuenca.

\subsubsection{Mapa de Número de curva propuesto.}

El mapa de número de curva de la cuenca para la condición restaurada (Figura 36) fue obtenido automáticamente a través del procesamiento de los mapas de Suelos y de Vegetación y usos del suelo propuesto con el modelo Lthia. Los NC obtenidos no difieren en valor con respecto a la condición actual, el cambio obtenido radica en su distribución espacial y el grado de ocupación territorial. 


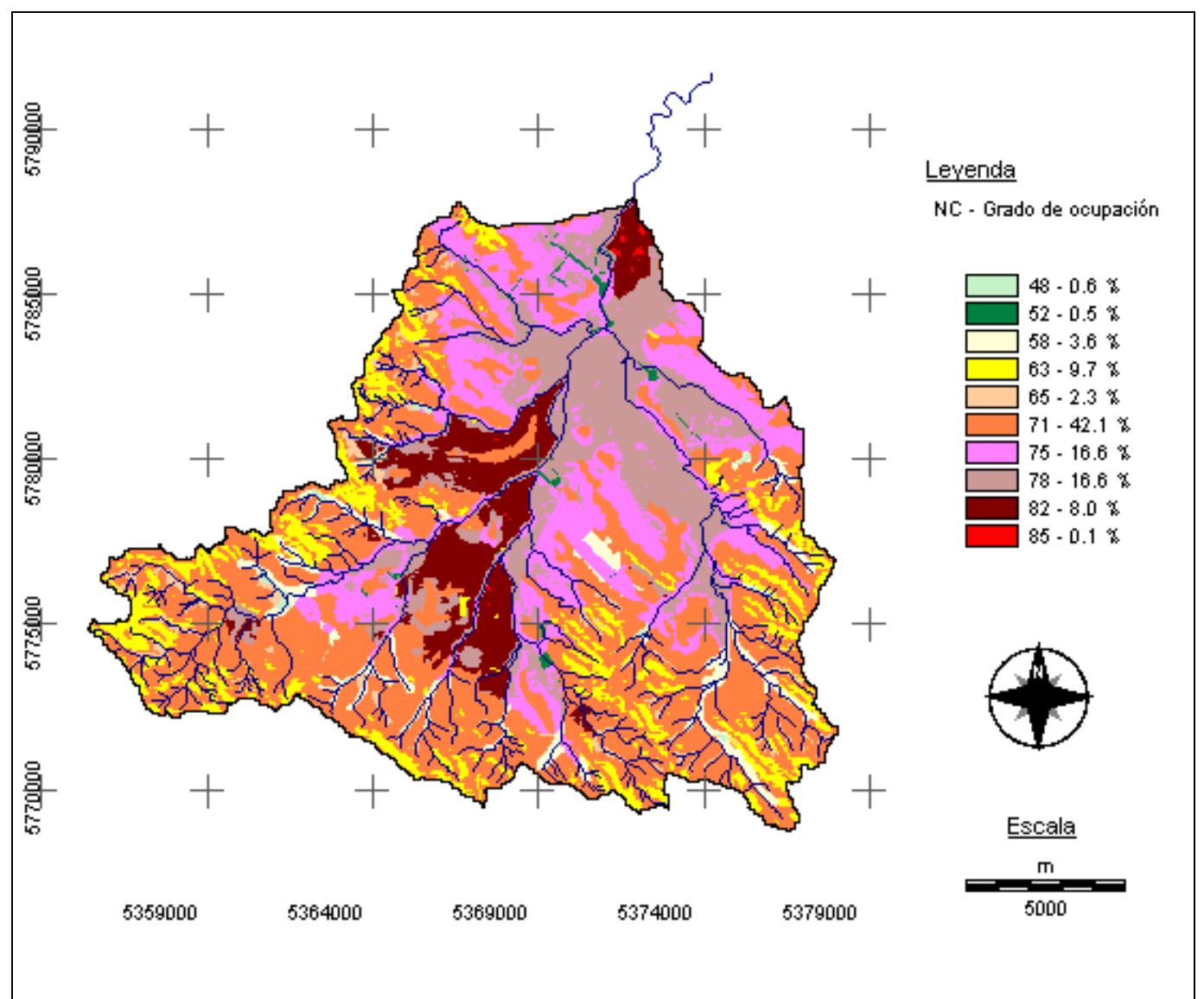

Figura 36: Mapa de número de curva para la condición restaurada.

La ocupación territorial de los NC según la condición actual y restaurada se presenta en el Grafico 30. La mayor ocupación en ambos casos corresponde al NC 71, aunque en la condición restaurada su superficie es menor, se redujo de $8.1 \%$ al $0.1 \%$ el valor 85 y se aumento un $12.6 \%$ la superficie cubierta con NC bajos (58 y 63), manteniéndose constante los NC 48, 52 y 65. 


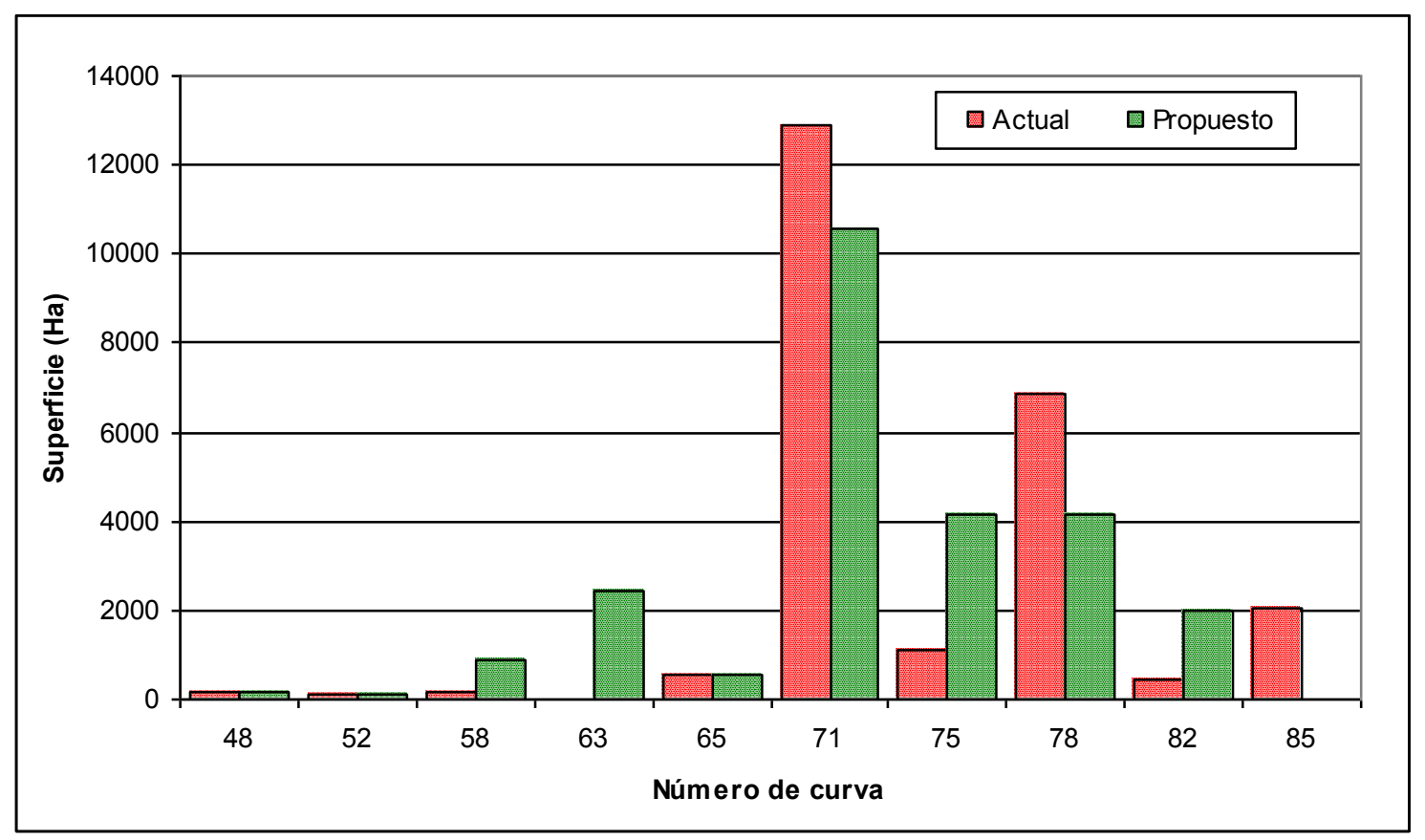

Grafico 30: Ocupación territorial de los NC según condición actual y restaurada.

El grado de ocupación porcentual de la superficie a nivel subcuenca se presenta en el Gráfico 31. La subcuencas 1 a 5 poseen un claro predominio del NC 71, mientras que en las subcuencas 10 y 12 predomina el valor 78. Las subcuencas restantes presentan una variada distribución de valores de NC.

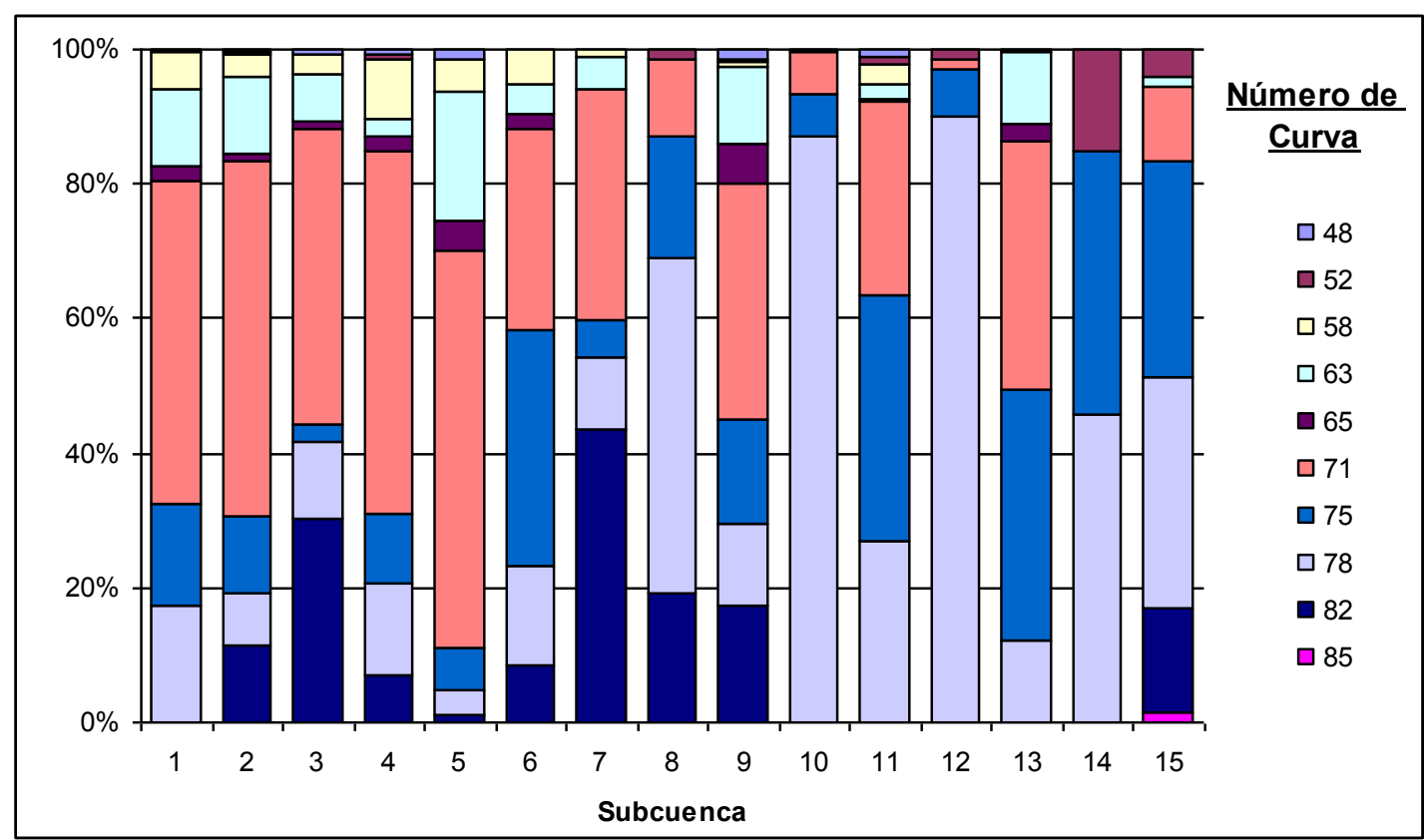

Gráfico 31: Ocupación porcentual por subcuenca de los valores de NC para la condición restaurada. 


\subsection{Elaboración de parámetros requeridos por los modelos.}

\subsubsection{Modelo Lthia.}

5.3.1.1 Codificación del mapa de vegetación y usos del suelo.

Se adaptó la Tabla 16 para la condición restaurada incluyendo la categoría correspondiente al cultivo en terrazas (Tabla 27)

Tabla 27: Categoría adicionada correspondiente al cultivo en terrazas.

\begin{tabular}{|c|c|c|}
\hline $\begin{array}{c}\text { Categoría de vegetación y usos } \\
\text { del suelo }\end{array}$ & $\begin{array}{c}\text { Nombre del código } \\
\text { Lthia }\end{array}$ & Código \\
\hline Cultivos alineados C-T B & HD Residential & 4000 \\
\hline
\end{tabular}

5.3.1.3. Adaptación de los valores de NC del archivo CN Table.

Se adaptaron los valores de NC a las condiciones propuestas de restauración. Los nuevos valores asignados a cada combinación suelo-cultivo en terrazas se presentan el la Tabla 28.

Tabla 28: Valores adicionados al archivo CN Table para la condición restaurada.

\begin{tabular}{|c|c|c|c|c|c|c|c|c|c|}
\hline \multirow{2}{*}{ Nombre del código LThia } & \multirow{2}{*}{ Código } & \multicolumn{4}{|c|}{ NC original } & \multicolumn{4}{|c|}{ NC adaptado } \\
\cline { 3 - 9 } & & A & B & C & D & A & B & C & D \\
\hline HD Residential & 4000 & 77 & 85 & 90 & 92 & 62 & 71 & 78 & 81 \\
\hline
\end{tabular}




\subsubsection{Modelo Hec Hms.}

El cambio en la distribución espacial de los NC, debida a las propuestas realizadas, modifican los valores ponderados de NC por subcuenca. Lo cual se traduce en cambios de las abstracciones iniciales (Io) y de los tiempos de retraso para cada una de ellas. La Tabla 29 expone los valores obtenidos para estas tres variables.

Tabla 29: Valores de NC ponderado, abstracciones iniciales y tiempo de retraso por subcuenca.

\begin{tabular}{|c|c|c|c|}
\hline \multirow{2}{*}{ Subcuenca } & \multicolumn{2}{|c|}{$\begin{array}{c}\text { Método de pérdidas } \\
\text { (NC SCS) }\end{array}$} & $\begin{array}{c}\text { Método de } \\
\text { transformación } \\
\text { (Tlag. } \text { (min) }^{\text {) }}\end{array}$ \\
\cline { 2 - 3 } & NC & $\mathbf{I o}_{\mathbf{m m} \text { ) }}$ & 612.1 \\
\hline 1 & 71 & 20.7 & 281.4 \\
\hline 2 & 72 & 19.8 & 231.0 \\
\hline 3 & 74 & 17.8 & 252.2 \\
\hline 4 & 71 & 20.7 & 358.7 \\
\hline 5 & 69 & 22.8 & 218.3 \\
\hline 6 & 73 & 18.8 & 239.9 \\
\hline 7 & 76 & 16.0 & 248.3 \\
\hline 8 & 77 & 15.2 & 250.0 \\
\hline 9 & 73 & 18.8 & 149.7 \\
\hline 10 & 77 & 15.2 & 248.8 \\
\hline 11 & 73 & 18.8 & 137.7 \\
\hline 12 & 77 & 15.2 & 279.3 \\
\hline 13 & 72 & 19.8 & 59.9 \\
\hline 14 & 73 & 18.8 & 395.3 \\
\hline 15 & 76 & 16.0 & \\
\hline
\end{tabular}

\subsection{Zonificación de la escorrentía superficial.}

Las Figuras 36, 37, y 38 presentan los resultados generados por Lthia para las tres tormentas seleccionadas según la condición restaurada, utilizando una misma escala de colores para su representación.

Para una tormenta con TR 5.9 años solo el 1.1\% de la cuenca genera láminas de escorrentía menores a $10 \mathrm{~mm}$ sin tener variaciones respecto a la condición actual, el $15.6 \%$ de la superficie presenta láminas correspondiente al rango entre 10 y $20 \mathrm{~mm}$ representando un aumento del $9.6 \%$ de la superficie, las láminas de escorrentía altas y torrenciales descendieron, el rango entre 20 y $30 \mathrm{~mm}$ representa el $42.1 \%$, teniendo el área restante una lámina mayor a $30 \mathrm{~mm}(41.3 \%)$. De esta manera el $83.3 \%$ de la cuenca posee láminas de escorrentía altas a torrenciales frente al $92.9 \%$ para la condición actual (Figura 37). 


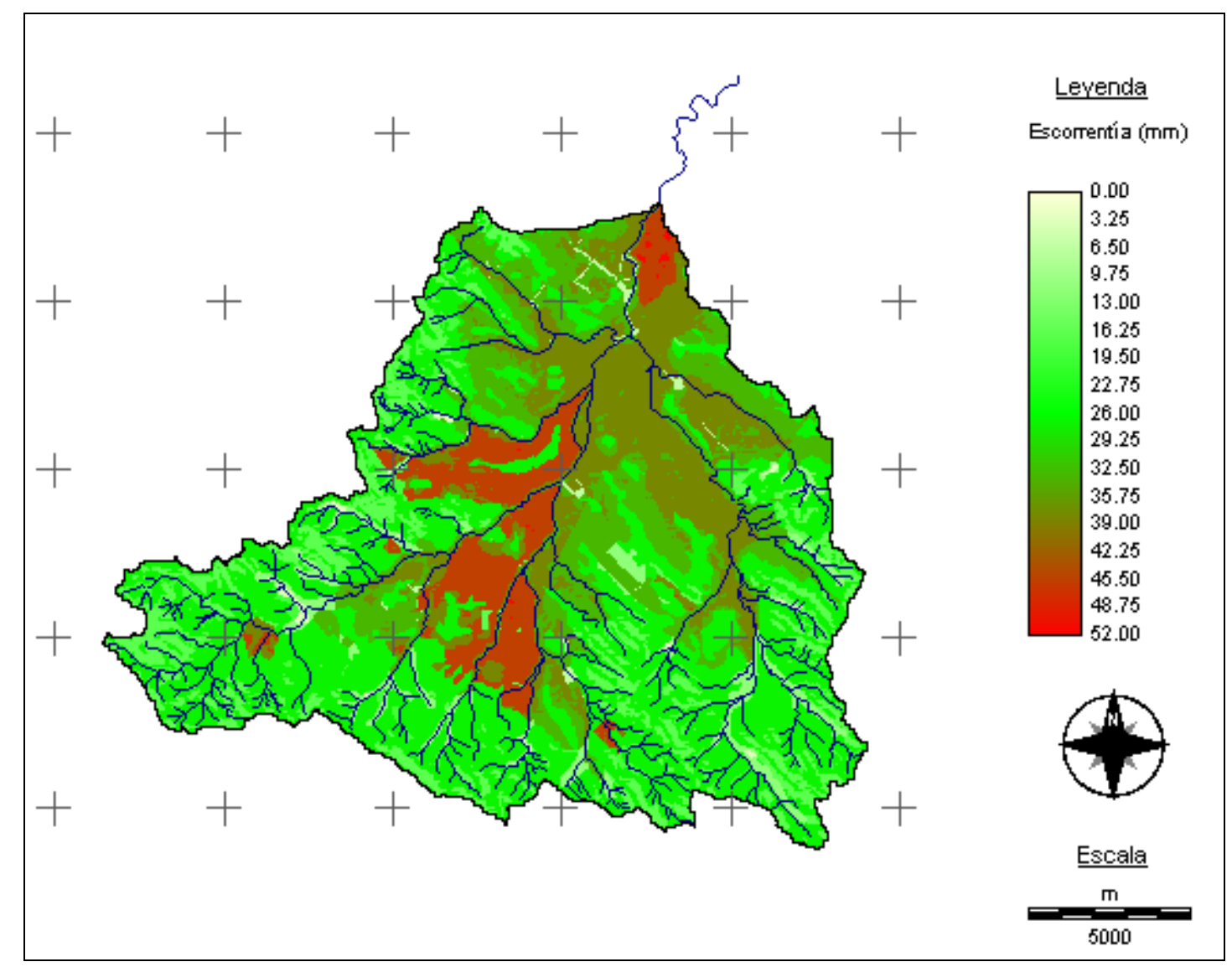

Figura 37: Zonificación de la lámina de escorrentía para una tormenta con TR 5.9 años.

En el caso de una tormenta con TR 2.3 años se determinó un aumento de láminas de escorrentía menores a $10 \mathrm{~mm}$ con un $14.4 \%$ de la cuenca frente al $4.8 \%$ en la condición actual, el rango entre 10 y $20 \mathrm{~mm}$ tuvo cambios respecto de la condición actual pasando de un $53.6 \%$ a un $44.4 \%$ de la superficie para la condición restaurada. El rango entre 20 y $30 \mathrm{~mm}$ de lámina de escorrentía aumentó un $1.5 \%$ pasando a representar un $33.2 \%$ del área de la cuenca, teniendo láminas mayores a $30 \mathrm{~mm}$ el $8.1 \%$ restante frente al $9.9 \%$ determinado para la condición actual (Figura 38). 


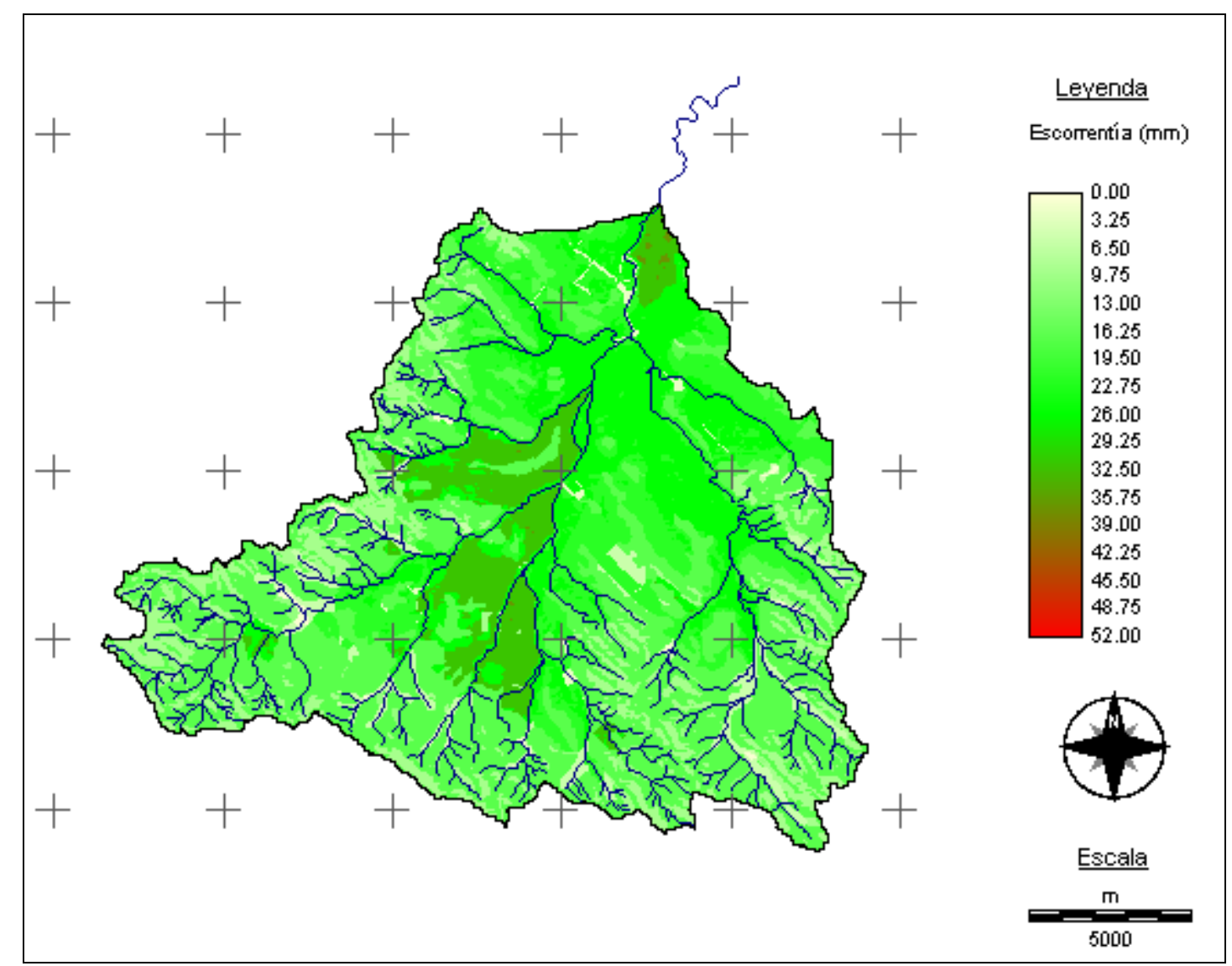

Figura 38: Zonificación de la lámina de escorrentía para una tormenta con TR 2.3 años.

Una tormenta con TR 1 año el $99.9 \%$ de la cuenca genera láminas de escorrentía leves, menores a $10 \mathrm{~mm}$, implicando un aumento del $8 \%$ de superficie respecto la condición actual. El rango entre 10 y $20 \mathrm{~mm}$ representa láminas de escorrentía medias, ocupando la superficie restante de la cuenca con un $0.1 \%$ (Figura 39). 


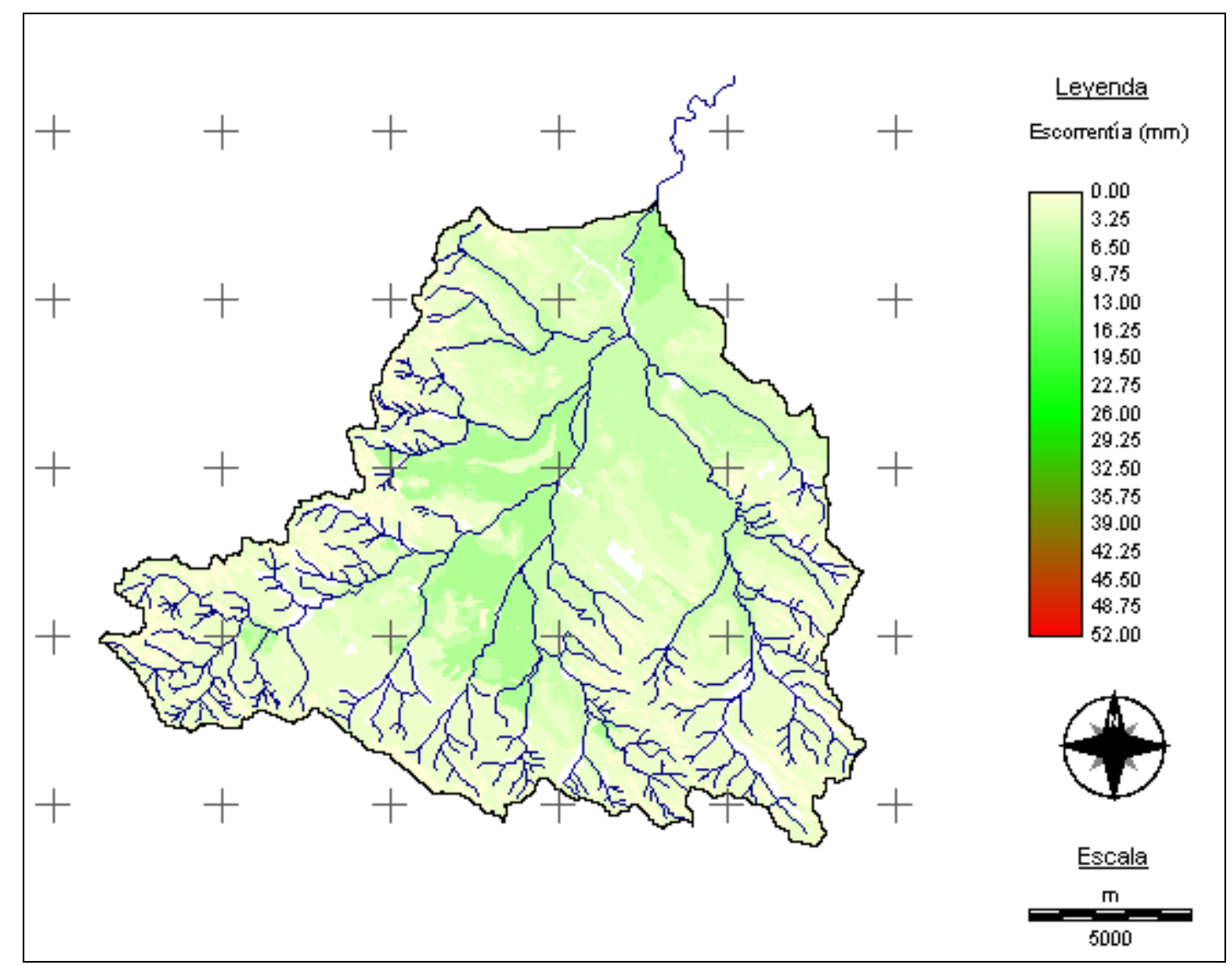

Figura 39: Zonificación de la lámina de escorrentía para una tormenta con TR 1 año.

\subsection{Generación de hidrogramas.}

Una vez obtenidos los parámetros necesarios, se realizó la modelización en Hec Hms para los tres modelos meteorológicos en la condición restaurada.

Los resultados obtenidos para una precipitación con TR 5.9 años se visualizan en la Figura 40. El volumen total de escorrentía fue de $7252200 \mathrm{~m}^{3}$, equivalentes a una lámina de $28.86 \mathrm{~mm}$. El máximo a la salida de la cuenca fue de $210.1 \mathrm{~m}^{3} / \mathrm{s}$ ocurridos a las 19:00 hs. 


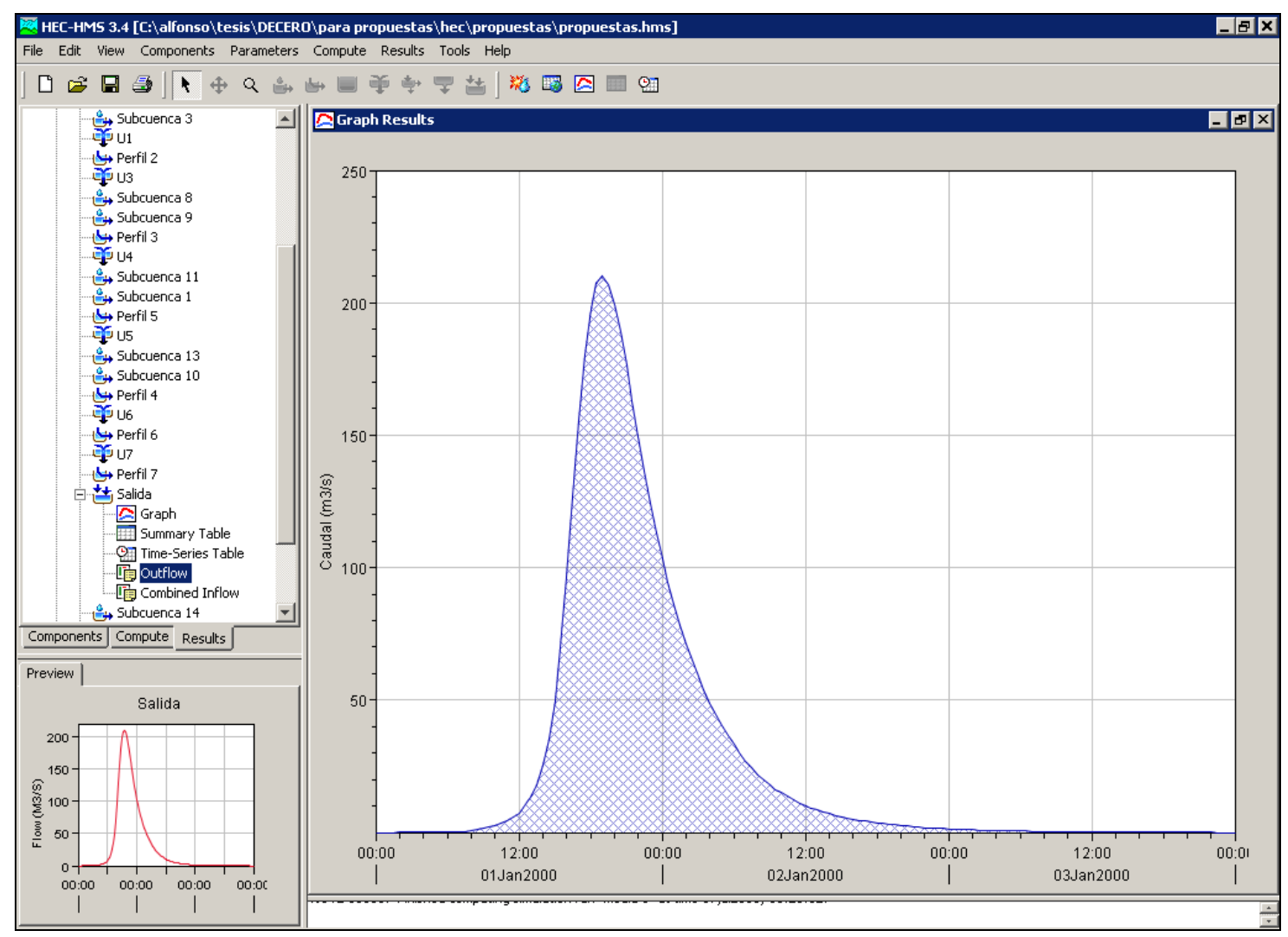

Figura 40: Hidrograma a la salida de la cuenca para una tormenta con TR 5.9 años.

Los resultados obtenidos para los valores característicos de los hidrogramas a la salida de cada subcuenca se presentan en la Tabla 30.

Tabla 30: Valores característicos de los hidrogramas de cada subcuenca: Caudal pico (Qp), tiempo al pico (Tp) y lámina de escorrentía (E).

\begin{tabular}{|c|c|c|c|c|c|c|c|c|c|c|c|c|c|c|c|}
\hline $\begin{array}{c}\text { Subcuenc } \\
\text { a }\end{array}$ & 1 & 2 & 3 & 4 & 5 & 6 & 7 & 8 & 9 & 10 & 11 & 12 & 13 & 14 & 15 \\
\hline & 30.3 & 29.0 & 18.9 & 12.8 & 31.3 & 19.6 & 11.5 & 7.7 & 21.7 & 11.1 & 16.8 & 1.7 & 17.4 & 0.4 & 14.0 \\
\hline & & & & & & & & & & & $7: 3$ & $16: 0$ & $18: 0$ & $15: 0$ & $20: 0$ \\
\hline & 0 & 0 & 0 & & 0 & 0 & ( & & & & & & & 0 & 0 \\
\hline & & 28.5 & 31.6 & 27.1 & 24.3 & 30.0 & 34.7 & 36.3 & 30.0 & 36.3 & 30.0 & 36.3 & 28.5 & 30.0 & 34.7 \\
\hline & .1 & 1 & 0 & 1 & 0 & 2 & 8 & 9 & 2 & 9 & 2 & 9 & 1 & 2 & \\
\hline
\end{tabular}

La Figura 41 representa el hidrograma de salida de la cuenca correspondiente a una precipitación con TR 2.3 años, para la cual se obtuvo un volumen total de escorrentía de $4614600 \mathrm{~m}^{3}$, cuyo hidrograma alcanzo un caudal pico de $145.2 \mathrm{~m}^{3} / \mathrm{s}$ a las 10:00 hs. La lámina de escorrentía total obtenida fue de $18.36 \mathrm{~mm}$. 


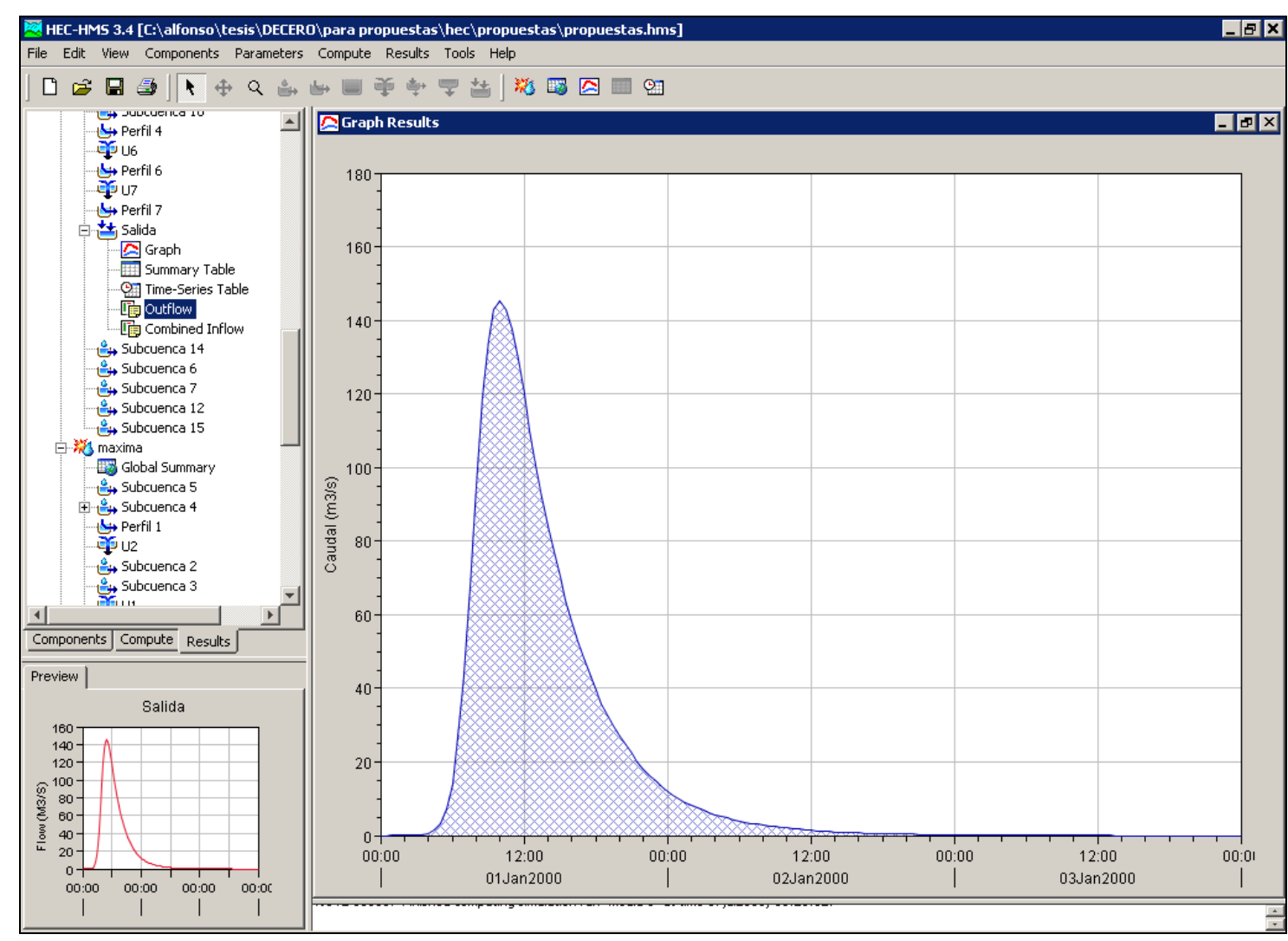

Figura 41: Hidrograma a la salida de la cuenca para una tormenta con TR 2.3 años.

Los resultados obtenidos de los valores característicos de los hidrogramas a nivel de subcuenca se presentan en la Tabla 31.

Tabla 31: Valores característicos de los hidrogramas de cada subcuenca: Caudal pico (Qp), tiempo al pico (Tp) y lámina de escorrentía (E).

\begin{tabular}{|c|c|c|c|c|c|c|c|c|c|c|c|c|c|c|c|}
\hline $\begin{array}{c}\text { Subcuenc } \\
\mathrm{a} \\
\end{array}$ & 1 & 2 & 3 & 4 & 5 & 6 & 7 & 8 & 9 & 10 & 11 & 12 & 13 & 14 & 15 \\
\hline $\mathrm{Qp}\left(\mathrm{m}^{3} / \mathrm{s}\right)$ & & 20.3 & 14.0 & 9.0 & 20.2 & 14.6 & 8.8 & 5.9 & 15.7 & 9.5 & 12.2 & 1.4 & 12.2 & 0.4 & 10 \\
\hline & & & & 08 & & & & & & & & 06 & & 05: & 11: \\
\hline & 0 & 0 & 0 & 0 & ( & 0 & 0 & ( & $(1$ & & & & & 0 & 0 \\
\hline & 16.97 & 18.0 & 20.4 & 16.9 & 14.8 & 19.2 & 23.0 & 24.3 & 19.2 & 24.3 & 19.2 & 24.3 & 18.0 & 19.2 & 23.0 \\
\hline & & & 8 & 7 & 2 & 3 & 2 & 2 & 3 & 2 & 3 & 2 & & 3 & 2 \\
\hline
\end{tabular}

Para una tormenta con TR 1 año (Figura 42) se obtuvieron valores de $686600 \mathrm{~m}^{3}$ para el volumen total de escorrentía, correspondiente a una lámina de $2.73 \mathrm{~mm}$. El caudal pico del hidrograma fue de $21.4 \mathrm{~m}^{3} / \mathrm{s}$ ocurridos a las 10:00 hs. 


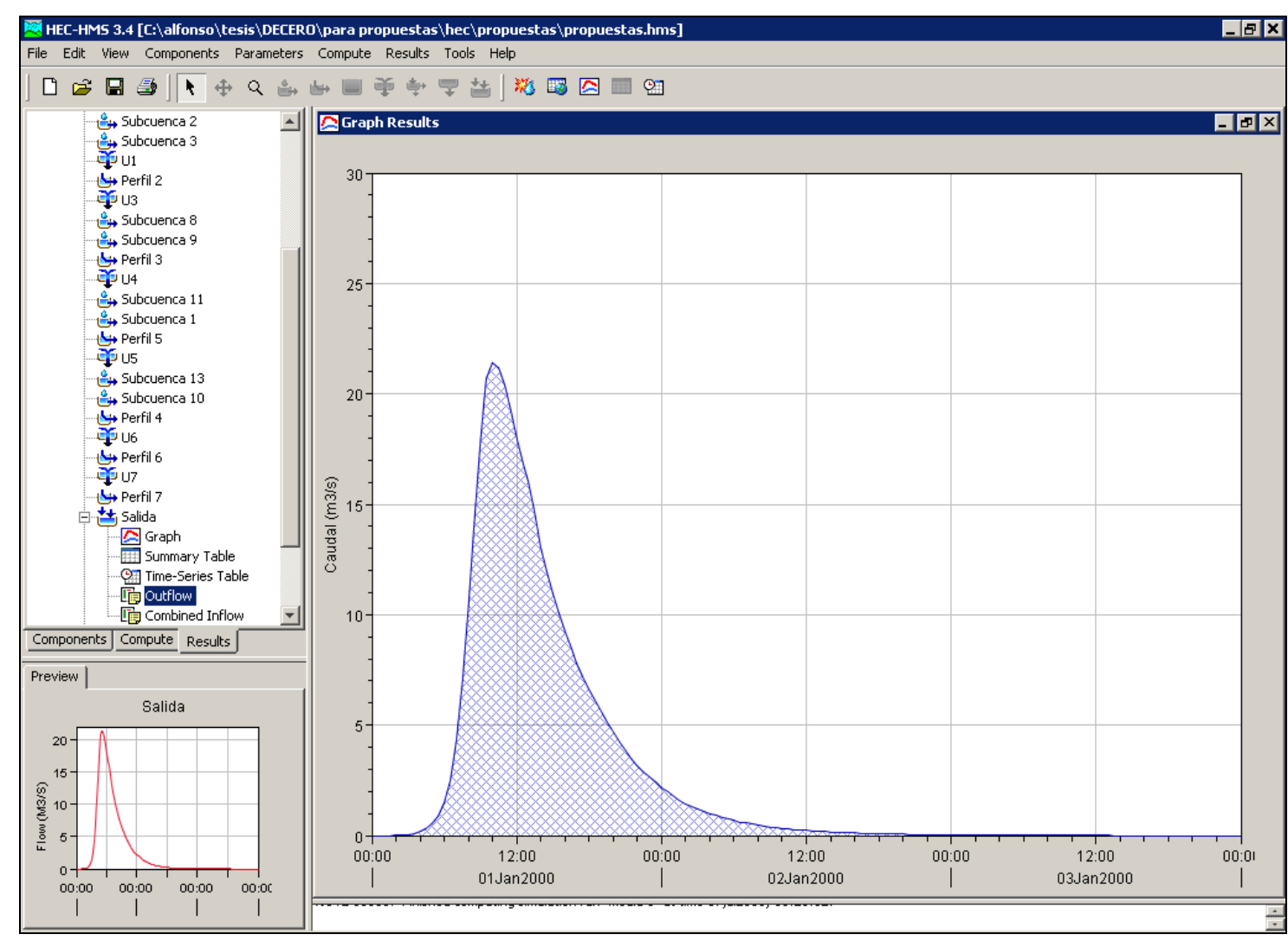

Figura 42: Hidrograma a la salida de la cuenca para una tormenta con TR 1 año.

La Tabla 32 expresa los resultados de los valores característicos de los hidrogramas obtenidos a nivel subcuenca.

Tabla 32: Valores característicos de los hidrogramas de cada subcuenca: Caudal pico (Qp), tiempo al pico (Tp) y lámina de escorrentía (E).

\begin{tabular}{|c|c|c|c|c|c|c|c|c|c|c|c|c|c|c|c|}
\hline $\begin{array}{c}\text { Subcuenc } \\
\mathbf{a}\end{array}$ & $\mathbf{1}$ & $\mathbf{2}$ & $\mathbf{3}$ & $\mathbf{4}$ & $\mathbf{5}$ & $\mathbf{6}$ & $\mathbf{7}$ & $\mathbf{8}$ & $\mathbf{9}$ & $\mathbf{1 0}$ & $\mathbf{1 1}$ & $\mathbf{1 2}$ & $\mathbf{1 3}$ & $\mathbf{1 4}$ & $\mathbf{1 5}$ \\
\hline $\mathrm{Qp}\left(\mathrm{m}^{3} / \mathrm{s}\right)$ & 2.6 & 2.9 & 2.4 & 1.2 & 2.2 & 2.3 & 1.7 & 1.2 & 2.5 & 2.0 & 1.9 & 0.3 & 1.8 & 0.1 & 1.9 \\
\hline $\mathrm{Tp}(\mathrm{hs})$ & $13: 3$ & $08: 0$ & $07: 0$ & $07: 3$ & $09: 3$ & $07: 0$ & $07: 0$ & $07: 3$ & $07: 3$ & $05: 3$ & $07: 3$ & $05: 3$ & $08: 0$ & $04: 3$ & $09: 3$ \\
& 0 & 0 & 0 & 0 & 0 & 0 & 0 & 0 & 0 & 0 & 0 & 0 & 0 & 0 & 0 \\
\hline $\mathrm{E}(\mathrm{mm})$ & 2.24 & 2.58 & 3.43 & 2.24 & 1.59 & 2.98 & 4.39 & 4.91 & 2.98 & 4.91 & 2.98 & 4.91 & 2.58 & 2.98 & 4.39 \\
\hline
\end{tabular}


6. Análisis comparativo de la respuesta del escurrimiento superficial de la condición actual y restaurada.

La comparación de la zonificación del escurrimiento se realizó a través de obtención de un mapa que representa las diferencias porcentuales entre lámina escurrida en la condición actual y la condición propuesta para cada una de las tormentas seleccionadas. A continuación se describen las diferencias porcentuales para cada cambio de uso del suelo, a través de una escala cuantitativa de colores, indicando con rojo las áreas de mayor variación porcentual y en color blanco las áreas sin cambios.

El cambio Agricultura Convencional a Especies forestales representa una superficie poco significativa de la cuenca, se prescindió en el presente análisis.

La Figura 43 exhibe la distribución espacial de las diferencias porcentuales obtenidas para una tormenta con TR 5.9 años.

- Las áreas con uso asignado a Bosques protectores provenientes de Pastizal serrano tuvieron la mayor diferencia porcentual, con una reducción del $37.9 \%$ de lámina escurrida.

- El cambio de cultivos bajo labranza convencional a labranza en terrazas fue del $25.7 \%$.

- Se redujo un $15.9 \%$ la lámina de escorrentía debido al cambio cultivo en curvas de nivel a labranza en terrazas.

- Por último el cambio labranza convencional a labranza en curvas de nivel obtuvo un $11.6 \%$ de diferencia.

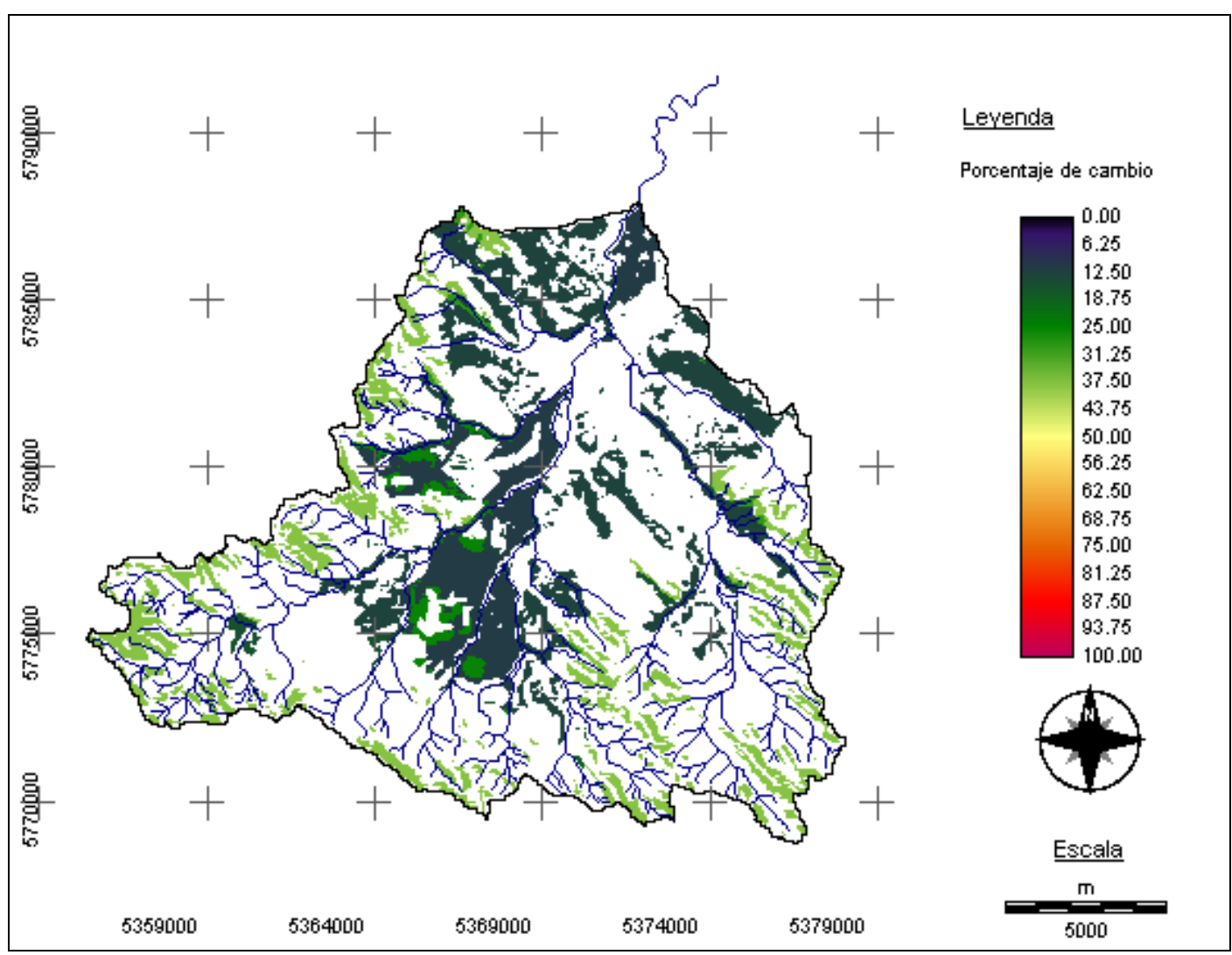

Figura 43: Zonificación de diferencias porcentuales de lámina de escorrentía para una tormenta con TR 5.9 años. 
La Figura 44 muestra la distribución espacial de las diferencias porcentuales para una tormenta con TR 2.3 años.

- Las áreas con uso asignado a Bosques protectores provenientes de Pastizal serrano tuvieron una reducción del $45.1 \%$ de lámina escurrida.

- El cultivo realizado en terrazas provenientes de cultivos bajo labranza convencional fue del $30.2 \%$.

- La lámina de escorrentía se redujo un $19 \%$ debido al cambio de cultivo en curvas de nivel a labranza en terrazas.

- El cambio labranza convencional a labranza en curvas de nivel obtuvo un $15.6 \%$ de diferencia.

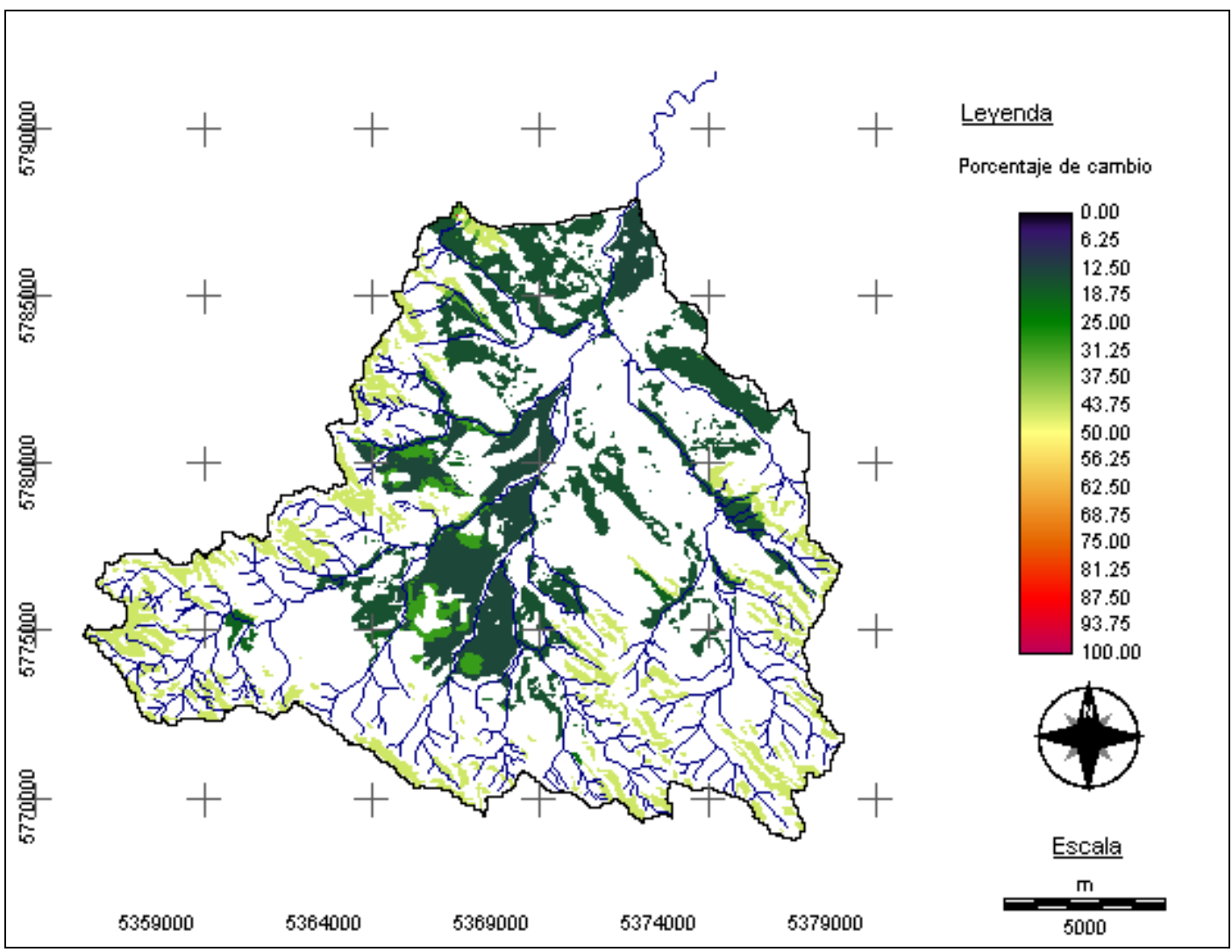

Figura 44: Zonificación de diferencias porcentuales de lámina de escorrentía para una tormenta con TR 2.3 años.

Para una tormenta con TR 1 años la distribución espacial de las diferencias porcentuales se muestra en la Figura 45.

- Los Bosques protectores provenientes de Pastizal serrano tuvieron la mayor diferencia porcentual, reduciendo su lámina un $85.1 \%$.

- Se redujo un $49.5 \%$ la lámina escurrida debido al cambio de cultivos bajo labranza convencional a labranza en terrazas.

- El cambio cultivo en curvas de nivel a labranza en terrazas redujo un $33.4 \%$ la lámina de escorrentía.

- La labranza en curvas de nivel provenientes de labranza convencional obtuvo un $24.1 \%$ de diferencia. 


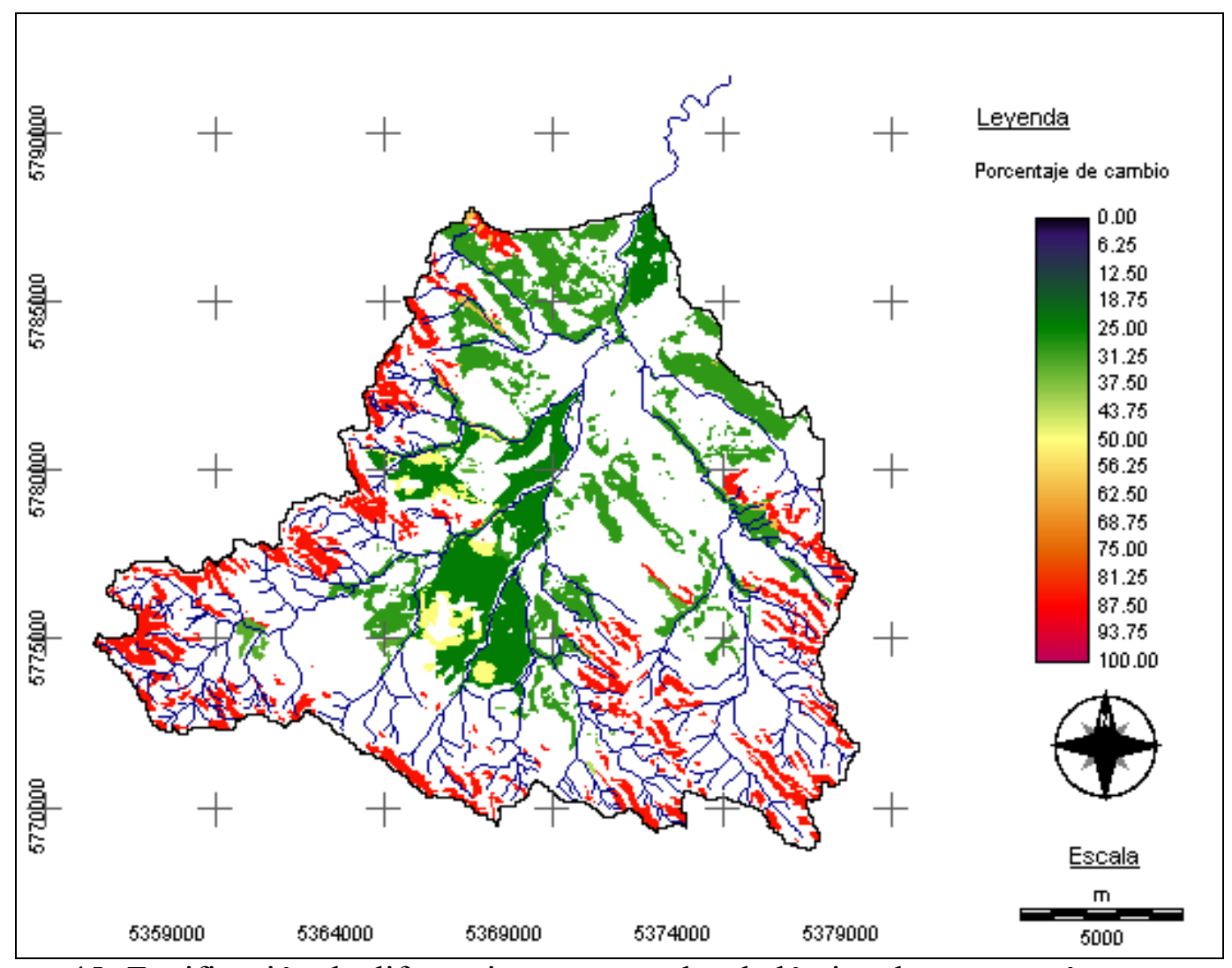

Figura 45: Zonificación de diferencias porcentuales de lámina de escorrentía para una tormenta con TR 1 año.

Los valores de diferencias porcentuales de lámina escurrida obtenidos por el cambio de uso del suelo para cada tormenta se observan en el Gráfico 32.

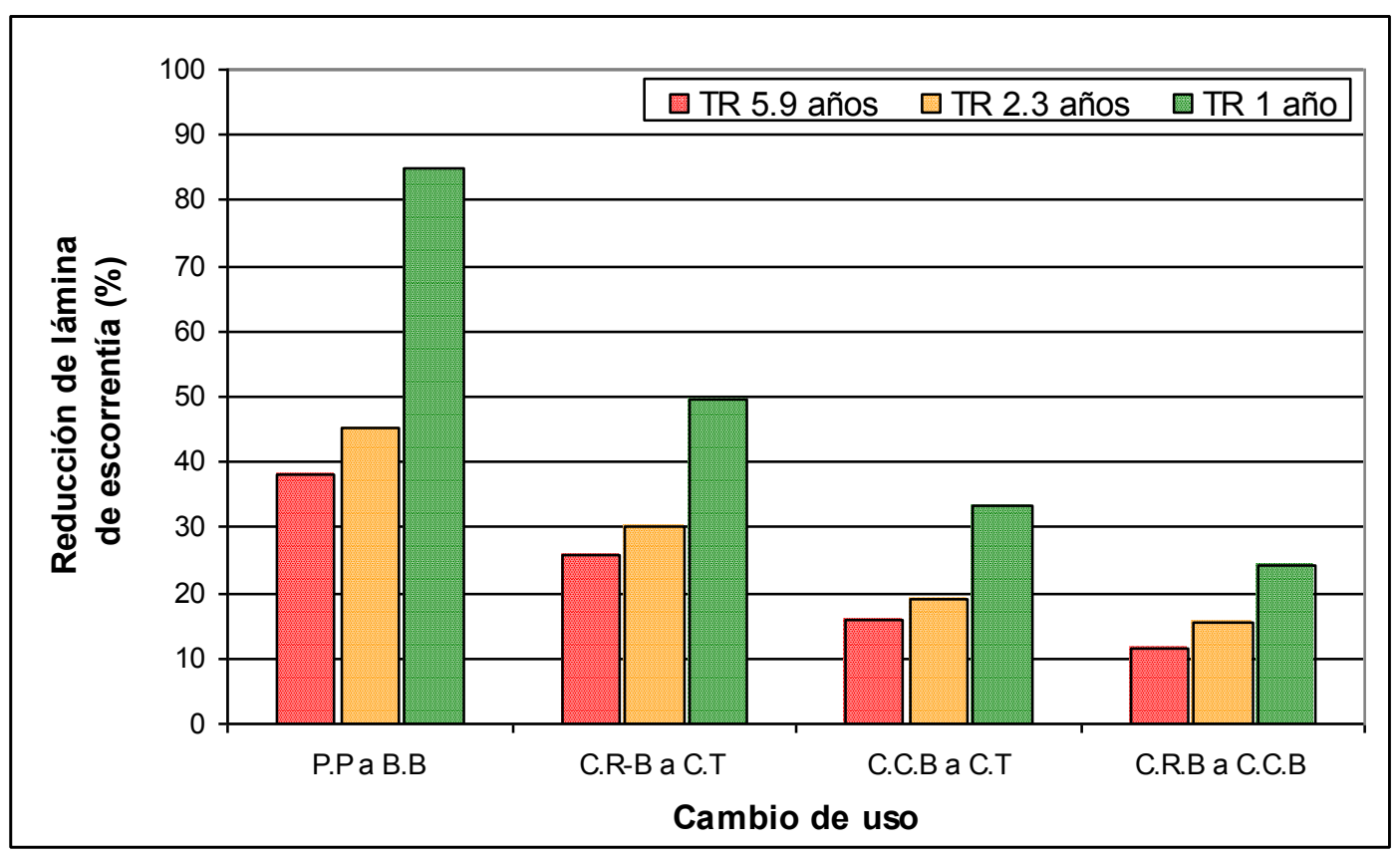

Gráfico 32: Reducción porcentual de la lámina de escorrentía según cambio de uso para las tres tormentas seleccionadas. 
Las mayores diferencias se presentan en el cambio de pastizal serrano a Bosques protectores, siendo el que posee menor diferencia el cultivo en curvas de nivel proveniente de cultivo bajo labranza convencional. Comparando las tres precipitaciones, puede visualizarse que a menor lámina precipitada, mayor es la reducción porcentual para cada uno de los cambios de uso del suelo.

El análisis comparativo de los valores característicos de los hidrogramas a la salida de la cuenca, expresa un similar comportamiento para las tres precipitaciones que el indicado a nivel de cambio de uso del suelo, siendo mayor la reducción a medida que la lámina de precipitación disminuye.

En el Grafico 33 se detallan las variaciones porcentuales del caudal líquido de la cuenca para cada una de las tormentas estudiadas. Las medidas de restauración agrohidrológicas propuestas generaron una disminución del caudal pico y de lámina de escorrentía, la primera obtuvo una reducción entre un 8.6 y $20.7 \%$, la segunda presentó una disminución entre 6.7 y $17.3 \%$.

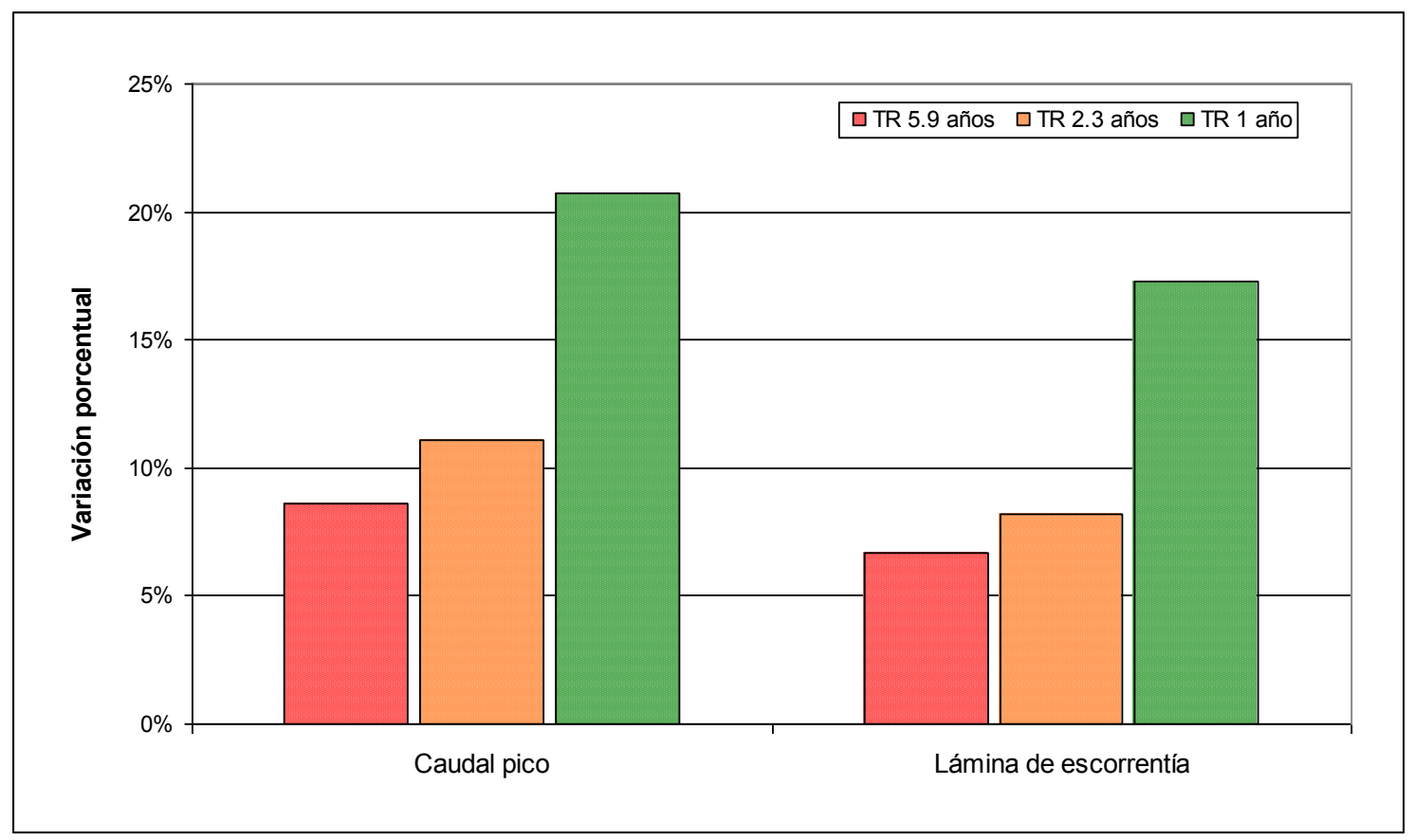

Gráfico 33: Variación porcentuales de caudal líquido en la salida de la cuenca para las tres tormentas estudiadas.

Se generó un análisis comparativo de la variación del volumen total de escorrentía para cada una de las subcuencas (Gráfico 34). La magnitud del cambio depende del tipo de medida asignada, del área total restaurada agro-hidrologicamente y del TR de la tormenta. El mayor cambio en volumen de escorrentía se produjo en la subcuenca 5 con valores de 10.4 y $28.8 \%$ para las tormentas con TR 5.9 años y 1 año respectivamente. La subcuenca 15 fue la que presentó los menores cambios. 


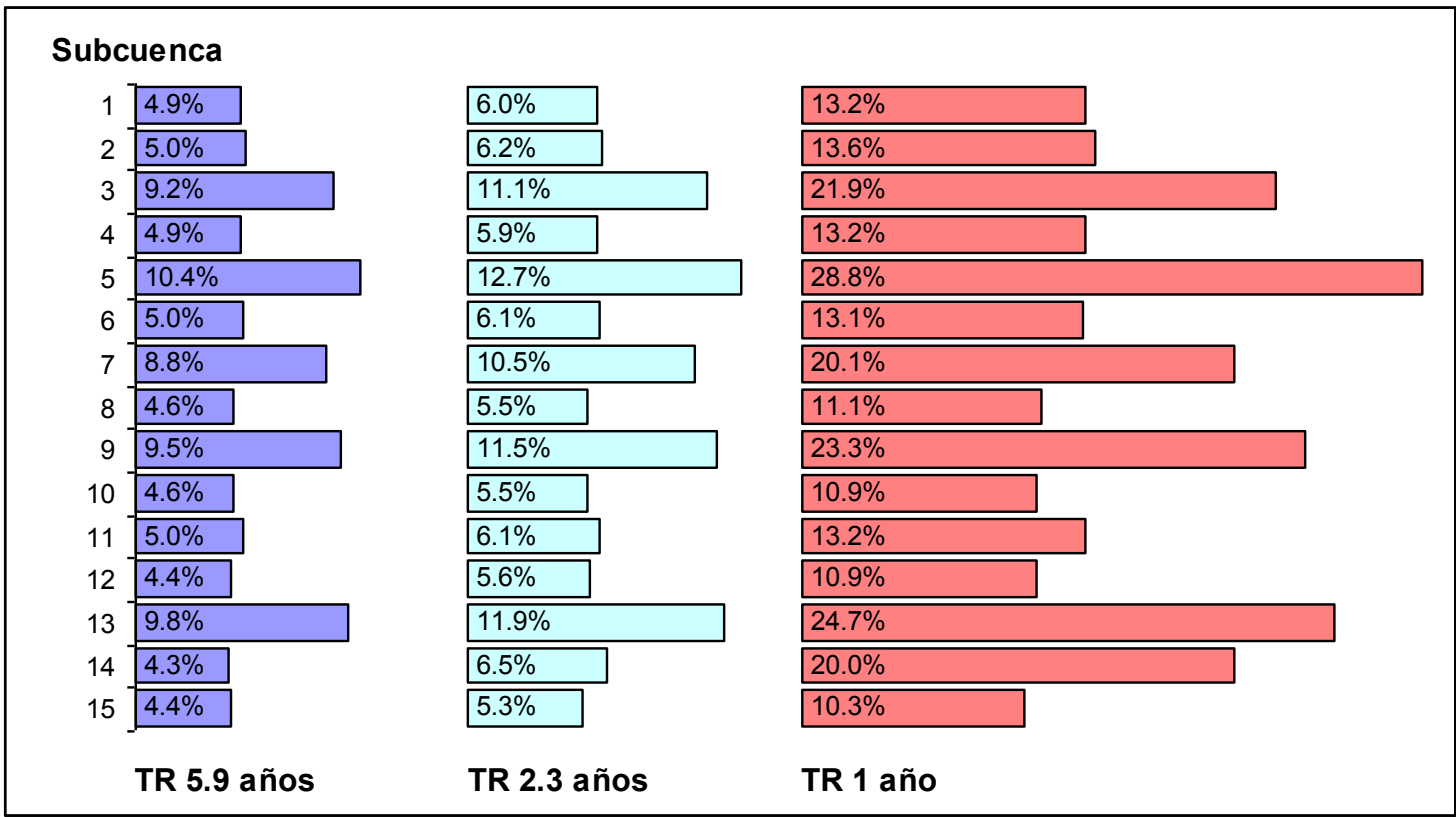

Gráfico 34: Variación del volumen total de escorrentía por subcuenca.

\section{Elementos básicos para la de la transferencia de resultados de la restauración agro-hidrológica sobre el escurrimiento superficial en la Sierra de Pillahuinco.}

La transferencia de los resultados obtenidos se basa en la creación de espacio de intercambio de información y articulación de grupos e instituciones (Robirosa, et al, 1989), es decir, un grupo interdisciplinario conformado por los actores públicos y privados que permita divulgar, mejorar, ejecutar y monitorear el plan propuesto. Dentro de los actores privados se encuentran los propietarios y/o arrendatarios de los predios como así también los profesionales y técnicos, asociaciones de productores y cooperativas rurales que llevan adelante las explotaciones agropecuarias. Los actores públicos están representados por autoridades municipales y provinciales.

La conformación de un grupo de estas características permite que todos los actores participen en los procesos de gestión para el desarrollo sustentable, recoge las opiniones de los actores y las compara, con lo que se evita perder tiempo y recursos en estudios detallados, permite exponer las ideas de distintos usuarios y habitantes del área con las ideas de los técnicos (Dourojeanni, 2000). Al disponer de una propuesta de restauración agro-hidrológica permite que todos los actores participen en la ejecución de las estrategias. En consecuencia se genera un método de trabajo que sirve para formular estrategias, y propicia la articulación, armonización y seguimiento a través del monitoreo de las etapas propuestas por los mismos gestores.

La Tabla 33 ofrece un panorama general para la presentación de las propuestas de restauración agro-hidrológica de la cuenca Serrana del Arroyo Pillahuinco Grande, detallando el efecto potencial de su implementación, la temporalidad del mismo, los actores involucrados y sus beneficiarios. 
Tabla 33: Panorama general de las propuestas de restauración agro-hidrológica de la cuenca Serrana del Arroyo Pillahuinco Grande.

\begin{tabular}{|c|c|c|c|c|}
\hline Propuesta & Efecto potencial & $\begin{array}{l}\text { Temporalidad } \\
\text { del efecto. }\end{array}$ & Actores & Beneficiarios \\
\hline $\begin{array}{l}\text { Bosques } \\
\text { protectores }\end{array}$ & $\begin{array}{c}\sqrt{ } \sqrt{\text { Disminución del }} \\
\text { escurrimiento. } \\
\sqrt{ } \quad \text { Regulación del } \\
\text { caudal de avenida. } \\
\sqrt{ } \quad \text { Control de las } \\
\text { pérdidas de suelo. } \\
\sqrt{ } \text { Aumento del } \\
\text { valor escénico. } \\
\sqrt{ } \text { Reducción del } \\
\text { riesgo de } \\
\text { inundación. } \\
\sqrt{ } \quad \text { Generación de } \\
\text { áreas de recreación. } \\
\sqrt{ } \text { Nuevos usos } \\
\text { potenciales } \\
\text { (Agroturismo, } \\
\text { fuente de leña, } \\
\text { postes, otros) }\end{array}$ & $\begin{array}{c}\text { Mediano y } \\
\text { Largo Plazo. }\end{array}$ & $\begin{array}{l}\text { Propietarios y/o } \\
\text { arrendatarios de } \\
\text { los predios. } \\
\text { Profesionales y } \\
\text { técnicos. } \\
\text { Asociaciones de } \\
\text { productores. } \\
\text { Cooperativas } \\
\text { rurales. } \\
\text { Autoridades } \\
\text { municipales y } \\
\text { provinciales. }\end{array}$ & $\begin{array}{l}\text { Propietarios y/o } \\
\text { arrendatarios. } \\
\text { Sector urbano. } \\
\text { Gobierno. } \\
\text { Empresas } \\
\text { privadas. } \\
\text { Poblaciones } \\
\text { vecinas y de la } \\
\text { región. }\end{array}$ \\
\hline $\begin{array}{l}\text { Curvas de } \\
\text { nivel }\end{array}$ & $\begin{array}{l}\sqrt{ } \quad \text { Disminución del } \\
\text { escurrimiento. } \\
\sqrt{ } \quad \text { Regulación del } \\
\text { caudal de avenida. } \\
\sqrt{ } \text { Aumento de la } \\
\text { infiltración en el } \\
\text { suelo. } \\
\sqrt{ } \text { Control de las } \\
\text { pérdidas de suelo. } \\
\sqrt{ } \text { Reducción del } \\
\text { riesgo de } \\
\text { inundación. } \\
\sqrt{ } \text { Control de surcos, } \\
\text { regueros y } \\
\text { cárcavas. }\end{array}$ & $\begin{array}{l}\text { Corto, Mediano } \\
\text { y Largo Plazo. }\end{array}$ & $\begin{array}{l}\text { Propietarios y/o } \\
\text { arrendatarios de } \\
\text { los predios. } \\
\text { Profesionales y } \\
\text { técnicos. } \\
\text { Asociaciones de } \\
\text { productores. } \\
\text { Cooperativas } \\
\text { rurales. } \\
\text { Autoridades } \\
\text { municipales y } \\
\text { provinciales. }\end{array}$ & $\begin{array}{l}\text { Propietarios y/o } \\
\text { arrendatarios. } \\
\text { Sector urbano. } \\
\text { Gobierno. } \\
\text { Empresas } \\
\text { privadas. }\end{array}$ \\
\hline $\begin{array}{c}\text { Cultivo en } \\
\text { terrazas }\end{array}$ & 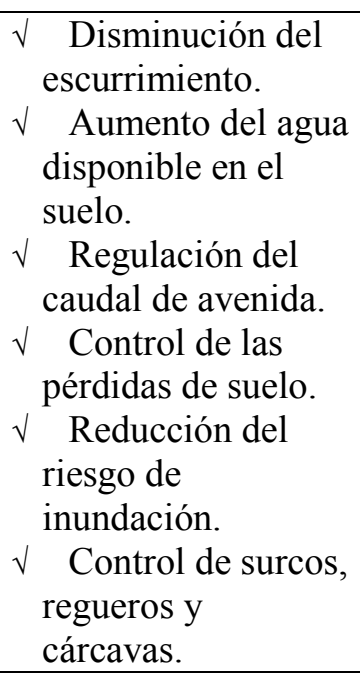 & $\begin{array}{l}\text { Corto, Mediano } \\
\text { y Largo Plazo. }\end{array}$ & $\begin{array}{l}\text { Propietarios y/o } \\
\text { arrendatarios de } \\
\text { los predios. } \\
\text { Profesionales y } \\
\text { técnicos. } \\
\text { Asociaciones de } \\
\text { productores. } \\
\text { Cooperativas } \\
\text { rurales. } \\
\text { Autoridades } \\
\text { municipales y } \\
\text { provinciales }\end{array}$ & $\begin{array}{l}\text { Propietarios y/o } \\
\text { arrendatarios. } \\
\text { Sector urbano. } \\
\text { Gobierno. } \\
\text { Empresas } \\
\text { privadas. }\end{array}$ \\
\hline
\end{tabular}




\section{CONCLUSIONES}

La realización de la presente tesis permitió establecer el posible efecto sobre el escurrimiento superficial de las medidas de restauración agro-hidrológica propuestas, para la cuenca serrana del Arroyo Pillahuinco Grande.

La recopilación y el procesamiento de antecedentes en la cuenca, la toma de datos a campo y el uso de imágenes satelitales permitieron elaborar una base de datos cartográfica temática digital caracterizando ambientalmente el área.

La base de datos cartográfica digital organiza y aglomera información mejorando el procesamiento de la misma, su empleo disminuye los tiempos de parametrización de variables hidrológicas, constituyendo una potente herramienta en la toma de decisiones.

Los modelos Lthia y Hec Hms permitieron establecer el funcionamiento hidrológico de la cuenca y sus subcuencas, obteniendo la zonificación espacial de la lámina de escorrentía, los hidrogramas caudales pico y volumen total de escorrentía para la condición actual y para las medidas propuestas, ante diferentes eventos de precipitación.

La utilización de SIG permitió establecer medidas de restauración agro-hidrológica haciendo una evaluación multicriterio de las condiciones presentes en la cuenca, proponiendo medidas coherentes con el tipo de producción actual que tiendan a disminuir la escorrentía superficial.

La comparación de los hidrogramas para la condición actual y restaurada ante los diferentes eventos de precipitación demuestra una marcada influencia de la morfometría sobre los volúmenes escurridos y los caudales picos. Una mayor disminución de los valores de lámina escurrida podría lograrse solo convirtiendo el pastizal serrano en bosques protectores, lo que trae aparejado, por un lado, una reducción del área con producción ganadera a niveles que pueden no poseer sustentabilidad económica y por otro, la disminución de la biodiversidad natural del ambiente.

La disminución de los caudales que circulan por el cauce pueden ser reducidos mediante una serie de obras estructurales transversales, aunque su utilización no cambia el volumen total de escurrimiento y trae necesariamente aparejado el mantenimiento de los mismos por colmatación con sedimentos. 
La modelización expuesta, parte de un modelo meteorológico homogéneo en toda la cuenca, es decir toda la precipitación ocurre al mismo tiempo con igual intensidad. Una mejor aproximación a la realidad implica la instalación de una red pluviométrica que permita un tratamiento adecuado de los datos.

Por otro lado el modelo de transformación precipitación-escorrentía se basa en valores de número de curva correspondientes a datos generados por el S.C.S y pueden ser ajustados in situ, estableciendo parcelas de escurrimiento para cada uno de los complejos suelo-vegetación presentes en la cuenca. El hidrograma podría ser mejorado estableciendo aforadores al cierre de cada subcuenca y relacionando los caudales medidos a los valores de lámina precipitada recogidos en la red pluviométrica. 
Con todo mi amor a mi Señora Vanesa y a mi hija Agustina.

\section{AGRADECIMIENTOS}

A mi Directora Fernanda, por su colaboración y sobre todo su insistencia.

A mi CoDirector Eduardo por su apoyo.

A mis Compañeros Sebastián, Gabriela e Isabel por hacer más agradable y llevadero el desarrollo de esta tesis. 


\section{BIBLIOGRAFÍA}

- Abbate, P.E. 2004. AGROCLIMA. Estación Experimental Agropecuaria Balcarce. Instituto Nacional de Tecnología Agropecuaria (INTA). Balcarce, Buenos Aires.

- AICET-RCD. 2008. Cartas de suelos de la Cuenca Ao. Pillahuincó Grande.

- Ameghino, F.1884. Las secas y las inundaciones en la provincia de Buenos Aires. Capitulo 2. Ed. Secretaria de política Ambiental. 19 Pp.

- Cabrera, Á. L. 1994. Regiones fitogeográficas argentinas. En Parodi, L. R. Enciclopedia Argentina de Agricultura y Jardinería, Fascículo 1. Acme. 85 Pp.

- Casaza, A. J. 2003. Informe nacional: La situación del manejo de cuencas en la república Argentina. Oficina Regional de la FAO para América Latina y el Caribe. Preparación del III Congreso Latinoamericano de Manejo de Cuencas. Pp 28.

- Centro de Información Meteorológica del Servicio Meteorológico Nacional, Comando Regiones Aéreas de la Fuerza Aérea Argentina. 2005. Información pluviográfica de la Estación Meteorológica en Coronel Pringles, Provincia de Buenos Aires. Expediente de tramitación No 99.833.

- Chow. 1982. Hidráulica de los canales abiertos. Ed Diana. Mexico. Pp 584.

- Chow, Maidment y Mays. 1994. Hidrología Aplicada. Ed. Mc Graw Hill Interamericana S.A., Bogotá, 2000. Pp 584.

- Di Luzio, M., Srinivasan, R., Arnold, J.G y Neitsch, S.L . 2002. Arcview interface for Swat2000.User's guide. $351 \mathrm{Pp}$.

- Dourojeanni, A. 2000. Procedimientos de gestión para el desarrollo sustentable. Contribución para mejorar la toma de decisiones conducentes al desarrollo sostenible en la región. Dir.Div.Rec. Naturales e Infraestructura. Serie, Manual 10, de la División de Recursos Naturales e Infraestructura. Santiago de Chile. Pp 372.

- Eastman, J.R. 2006. Idrisi Andes. Guide to Gis and Image processing. Clark Labs. Clark University. USA. Pp 327.

- $\quad$ Engel, B, Harbor, J, Muthukrishnan,S, Pandey,S, Kyoung, J.L, Theller,L. 2005. LTHIA NPS. User Manual. Purdue University, United States Environmental Protection Agency. 46 Pp.

- FAO/RLAC. 1989. FAO-Oficina Regional para América Latina y el Caribe. Informe de los cursos subregionales para ejecutivos de extensión rural. Venezuela. Pp 42.

- Farr, T. G., et al. (2007), The Shuttle Radar Topography Mission, Rev. Geophys., 45, RG2004, doi:10.1029/2005RG000183. Pág. 21- 22.

- Frangi, J y O. Bottino. 1994. Comunidades vegetales de la Sierra de la Ventana, Provincia de Buenos Aires, Argentina. Pág. 93-133.

- García Nájera, 1962. Principios de hidráulica torrencial. Ed. Min. Agric. Madrid. Pp. 350

- Gaspari, F. J. 2002. Ordenamiento territorial en cuencas serranas. Aplicación de Sistemas de Información Geográfica (S.I.G.). Ediciones Cooperativas. Pp 116.

- Gaspari, F. J. y A.M. Rodríguez Vagaría. 2006 Zonificación ambiental de la cuenca del arroyo Pillahuinco Grande. XI Reunión Argentina de Agrometeorología. Facultad de Ciencias Agrarias y Forestales. U.N.L.P. La Plata. 2006. 
- Gaspari, F.J. y G.E. Senisterra. 2006 Zonificación del número de la curva $(\mathrm{CN})$ en la Cuenca del Arroyo Pillahuinco Grande. Coronel Pringles. Tercer congreso de la ciencia cartográfica. 26 al 29 junio de 2006. Buenos Aires. Argentina.

- Gaspari, F.J, Senisterra, G.E, Delgado M.I, Rodríguez Vagaría, A.M y S.I Besteiro 2009. Manual de manejo integral de cuencas hidrográficas. Ed Gaspari. La Plata. Pp 321.

- Gaspari F.J, Senisterra G.E, Rodríguez Vagaría, A.M, Delgado, M.I y I. Odhe Cornely. 2007. Ordenamiento rural y aprovechamiento sostenido del recurso hídrico de la cuenca del arroyo Pillahuinco, Provincia de Buenos Aires, República Argentina. ISBN 978-987-05-2988-0. Versión digital.

- Gesch, D.B., Verdin, K.L., y Greenlee, S.K., 1999, New land surface digital elevation model covers the earth: Eos, Transactions, American Geophysical Union, v. 80, no. 6, Pág. 69-70.

- Gobierno de la Provincia de Buenos Aires. 1982. Decreto Ley 9867/82. Ley de fomento de la conservación de suelos.

http://www.gob.gba.gov.ar/legislacion/legislacion/l-9867.html

- Henaos, J. 1988. Introducción al manejo de cuencas hidrográficas. Universidad Santo Tomás. Centro de Enseñanza descolarizada, Bogotá. Pp 399.

- Langbein, W. B., 1947, Topographic characteristics of drainage basins. U.S. Geol. Survey Water SupplyPap. 968-C, Pág. 125-157.

- López Cadenas de Llano y Mintegui Aguirre. 1987. Hidrologia de superficie. Tomo 1. Editorial Fundación Salazar. ETSI Montes. Madrid, España. Pp 224.

- López Cadenas de Llano. 1998. Restauración hidrológico forestal de cuencas y control de la erosión. Ed. TRAGSA. Madrid. Pp 945.

- Mathew Cushing. USGS. 2008. Desarrollo de Mapas de Relieve. Hidrografía y Derivados para Suramérica. Papel Concepto. Editorial Corporación Andina de Fomento (CAF) U.S. Geological Survey (USGS). Pp 20. http://geosur.caf.com/upload/pubs/GeoSUR_Papel_Concepto_SRTM.pdf

- Miliarium Aureum, 2004. Anejo de Pluviometría e Hidrología. Pp 4. http://www.miliarium.com/Proyectos/Carreteras/Anejos/04/AN04a.asp

- Mintegui Aguirre y López Unzú, 1990. La ordenación agrohidrológica en la planificación. Ed. Servicio Central de Publicaciones del Gobierno Vasco. Pp.308.

- Mintegui Aguirre, J. A. y J. C. Robredo Sánchez, 1994. Caracterización de las cuencas hidrográficas, objeto de restauración hidrológico-forestal, mediante modelos hidrológicos. Ingeniería del Agua. Vol. 1 Num. 2. Pp 114.

- NASA. 2005. Shuttle Radar Topography Mission: Instruments. http://www2.jpl.nasa.gov/srtm/instr.htm.

- Racca, J. M. G. 2007. Análisis hipsométrico, frecuencia altimétrica y pendientes medias a partir de modelos digitales del terreno. Boletín del Instituto de Fisiografía y Geología 77(1-2). Pág. 31-38

- Robirosa, M; Caldarelli, G; La Palma, A. 1989. Turbulencia y Planificación social. Ediciones UNICEF- SIGLO XXI, Buenos Aires. Pp 142.

- Rodriguez, E., Morris, C. S. y J. E. Belz. 2006. A Global Assessment of the SRTM Performance: Photogrammetric Engineering and Remote Sensing, v. 72, no. 3, Pág. 249 - 260.

- Spinelli Zinni, F.1970. Estudio de situación del Partido de Coronel Pringles. Tomo III. Pp 92.

- Strahler, A. N. 1952. Hypsometric (area-altitude) analisys of erosional topography. Geol. Soc. Amer. Bull. (63). 1117 - 1142. 
- Strahler, A. N. 1957. Quantitative analysis of watershed geomorphology. Transactions Am. Geophys. Union, 38 (6). Pág. 913 - 925.

- Thornthwaite, C. W. 1948. An Approach toward a Rational Classification of Climate. Geographical Review, Vol. 38, No. 1 (Jan., 1948), Pág. 55-94

- Urdaneta, C.A. 2003. Zonas de vida de venezuela y sistemas de clasificación agroecológico- climático. Universidad Nacional Experimental Sur del Lago. Venezuela. Pp 23.

www.unesur.edu.ve/download/UNIDAD_III_climatologia.pdf

- US Army Corps of Engineering Center. 2000. Hydrologic Modeling System HECHMS. User Manual Version 2. Trad. Del Ingles por M. Auza. Pp 186. Davis CA.

- US Army Corps of Engineering Center. 2006. Hydrologic Modeling System HECHMS. User Manual. 


\section{ANEXO 1: TABLAS}

Tabla 1: Tipo de clima y símbolo en función del índice hídrico. Modificado de Urdaneta C.A.

\begin{tabular}{|c|c|c|}
\hline Símbolo & Tipo de clima & Índice hídrico \\
\hline A & Superhúmedo & Mayor de 100 \\
\hline B4 & Muy húmedo & 80 a 100 \\
\hline B3 & Húmedo & 60 a 80 \\
\hline B2 & Moderadamente húmedo & 40 a 60 \\
\hline B1 & Ligeramente húmedo & 20 a 40 \\
\hline C2 & Subhúmedo húmedo & 0 a 20 \\
\hline C1 & Subhúmedo seco & 0 a -20 \\
\hline D & Semiárido o seco & -20 a -40 \\
\hline E & Árido & -40 a -60 \\
\hline
\end{tabular}

Tabla 2: símbolo y deficiencia de humedad en función del índice de aridez. Modificado de Urdaneta C.A.

\begin{tabular}{|c|c|}
\hline Climas húmedos* & $\begin{array}{c}\text { Índice de } \\
\text { aridez }\end{array}$ \\
\hline $\mathrm{r}=$ nula o pequeña deficiencia de agua & 0 a 16,7 \\
\hline $\mathrm{S}=$ moderada deficiencia en verano & 16.7 a 33.3 \\
\hline $\mathrm{w}=$ moderada deficiencia en invierno & 16.7 a 33.3 \\
\hline $\mathrm{s} 2=$ gran deficiencia en verano & Más de 33.3 \\
\hline $\mathrm{w} 2=$ gran deficiencia en invierno & Más de 33.3 \\
\hline
\end{tabular}

*Los términos verano e invierno se refieren a las estaciones astronómicas de cada hemisferio

Tabla 3: símbolo y exceso de humedad en función del índice de humedad. Modificado de Urdaneta C.A.

\begin{tabular}{|c|c|}
\hline Climas secos & $\begin{array}{c}\text { Índice de } \\
\text { humedad }\end{array}$ \\
\hline $\mathrm{d}=$ nulo o pequeño exceso de agua & 0 a 10 \\
\hline $\mathrm{s}=$ moderado exceso en verano & 10 a 20 \\
\hline $\mathrm{w}=$ moderado exceso en invierno & 10 a 20 \\
\hline $\mathrm{s} 2=$ gran exceso en verano & Más de 20 \\
\hline $\mathrm{w} 2=$ gran exceso en invierno & Más de 20 \\
\hline
\end{tabular}




\section{ANEXO 1: TABLAS (continuación)}

Tabla 4: símbolo y región térmica en función de la evapotranspiración potencial. Modificado de Urdaneta, C.A.

\begin{tabular}{|c|c|c|}
\hline Símbolo & Región térmica & ETP \\
\hline $\mathrm{A}^{\prime}$ & Megatérmica o cálida & 1140 y más \\
\hline $\mathrm{B}^{\prime} 4$ & Mesotérmica semi- cálida & 997 a 1140 \\
\hline $\mathrm{B}^{\prime} 3$ & Mesotérmica templada-cálida & 855 a 997 \\
\hline $\mathrm{B}^{\prime} 2$ & Mesotérmica templada fría & 712 a 855 \\
\hline $\mathrm{B}^{\prime} 1$ & Mesotérmica semi- fría & 570 a 712 \\
\hline $\mathrm{C}^{\prime} 2$ & Microtérmica fría moderada & 427 a 570 \\
\hline $\mathrm{C}^{\prime} 1$ & Microtérmica fría acentuada & 285 a 427 \\
\hline $\mathrm{D}^{\prime}$ & Tundra & 142 a 285 \\
\hline $\mathrm{E}^{\prime}$ & Helado o glacial & Menos de 142 \\
\hline
\end{tabular}

Tabla 5: Símbolo correspondiente a la concentración de la eficiencia térmica en verano. Modificado de Urdaneta C.A.

\begin{tabular}{|c|c|}
\hline Tipo de Clima & \%Verano/Año \\
\hline $\mathrm{a}^{\prime}$ & Menos de $48.0 \%$ \\
\hline $\mathrm{b}^{\prime} 4$ & 48.0 a $51.9 \%$ \\
\hline $\mathrm{b}^{\prime} 3$ & 51.9 a $56.3 \%$ \\
\hline $\mathrm{b}^{\prime} 2$ & $56.3 \mathrm{a} 61.6 \%$ \\
\hline $\mathrm{b}^{\prime} 1$ & $61.6 \mathrm{a} 68.0 \%$ \\
\hline $\mathrm{c}^{\prime} 2$ & 68.0 a $76.3 \%$ \\
\hline $\mathrm{c}^{\prime} 1$ & 76.3 a 88.0 \\
\hline $\mathrm{d}^{\prime}$ & Más de $88.0 \%$ \\
\hline
\end{tabular}


ANEXO 1: TABLAS (continuación)

Tabla 6: Valores de cuantiles superiores de la distribución del estadístico D teórico de Kolmogorov-Smirnov. Adaptado de Canavos (1988).

\begin{tabular}{|c|c|c|c|c|c|}
\hline \multirow{2}{*}{$N$} & \multicolumn{5}{|c|}{$1-\alpha$} \\
\hline & 0.8 & 0.85 & 0.9 & 0.95 & 0.99 \\
\hline 1 & 0.9 & 0.925 & 0.95 & 0.975 & 0.995 \\
\hline 2 & 0.684 & 0.726 & 0.776 & 0.842 & 0.929 \\
\hline 3 & 0.565 & 0.597 & 0.642 & 0.708 & 0.828 \\
\hline 4 & 0.494 & 0.525 & 0.564 & 0.624 & 0.733 \\
\hline 5 & 0.446 & 0.474 & 0.51 & 0.565 & 0.669 \\
\hline 6 & 0.41 & 0.436 & 0.47 & 0.521 & 0.618 \\
\hline 7 & 0.381 & 0.405 & 438 & 0.486 & 0.577 \\
\hline 8 & 0.358 & 0.381 & 0.411 & 0.457 & 0.543 \\
\hline 9 & 0.339 & 0.36 & 0.388 & 0.432 & 0.514 \\
\hline 10 & 0.322 & 0.342 & 0.368 & 0.41 & 0.49 \\
\hline & & & & & \\
\hline 11 & 0.307 & 0.326 & 0.352 & 0.391 & 0.468 \\
\hline 12 & 0.295 & 0.313 & 0.338 & 0.375 & 0.45 \\
\hline 13 & 0.284 & 0.302 & 0.325 & 0.361 & 0.433 \\
\hline 14 & 0.274 & 0.292 & 0.314 & 0.349 & 0.418 \\
\hline 15 & 0.266 & 0.283 & 0.304 & 0.338 & 0.404 \\
\hline 16 & 0.258 & 0.274 & 0.295 & 0.328 & 0.392 \\
\hline 17 & 0.25 & 0.266 & 0.286 & 0.318 & 0.381 \\
\hline 18 & 0.244 & 0.259 & 0.278 & 0.309 & 0.371 \\
\hline 19 & 0.237 & 0.252 & 0.272 & 0.301 & 0.363 \\
\hline 20 & 0.231 & 0.246 & 0.264 & 0.294 & 0.356 \\
\hline 25 & 0.21 & 0.22 & 0.24 & 0.27 & 0.32 \\
\hline 30 & 0.19 & 0.2 & 0.22 & 0.24 & 0.29 \\
\hline 35 & 0.18 & 0.19 & 0.21 & 0.23 & 0.27 \\
\hline$n>50$ & $\frac{1.07}{\sqrt{n}}$ & $\frac{1.14}{\sqrt{n}}$ & $\frac{1.22}{\sqrt{n}}$ & $\frac{1.36}{\sqrt{n}}$ & $\frac{1.63}{\sqrt{n}}$ \\
\hline
\end{tabular}


ANEXO 1: TABLAS (continuación)

Tabla 7. Valores de Manning para canales rectos y uniformes.

\begin{tabular}{|c|c|c|c|}
\hline \multirow{2}{*}{ Tipo de cauce y descripción } & \multicolumn{3}{|c|}{ Valor de n } \\
\hline & Mínimo & Normal & Máximo \\
\hline \multicolumn{4}{|l|}{ A. Conductos cerrados que fluyen parcialmente llenos } \\
\hline \multicolumn{4}{|l|}{ A1) Metal } \\
\hline a) Latón liso & 0.009 & 0.01 & 0.013 \\
\hline \multicolumn{4}{|l|}{ b) Acero } \\
\hline Estriado y soldado & 0.01 & 0.012 & 0.014 \\
\hline Ribeteado y en espiral & 0.013 & 0.016 & 0.017 \\
\hline \multicolumn{4}{|l|}{ c) Hierro fundido } \\
\hline * Recubierto & 0.01 & 0.013 & 0.014 \\
\hline * No recubierto & 0.011 & 0.014 & 0.016 \\
\hline \multicolumn{4}{|l|}{ d) Hierro forjado } \\
\hline * Negro & 0.012 & 0.014 & 0.015 \\
\hline * Galvanizado & 0.013 & 0.016 & 0.017 \\
\hline \multicolumn{4}{|l|}{ e) Metal corrugado } \\
\hline * Subdrenaje & 0.017 & 0.019 & 0.021 \\
\hline * Drenaje de aguas lluvias & 0.021 & 0.024 & 0.03 \\
\hline \multicolumn{4}{|l|}{ A2) No metal } \\
\hline a) Lucita & 0.008 & 0.009 & 0.01 \\
\hline b) Vidrio & 0.009 & 0.01 & 0.013 \\
\hline \multicolumn{4}{|l|}{ c) Cemento } \\
\hline * Superficie pulida & 0.01 & 0.011 & 0.013 \\
\hline * Mortero & 0.011 & 0.013 & 0.015 \\
\hline \multicolumn{4}{|l|}{ d) Concreto } \\
\hline * Alcantarilla, recta y libre de basuras. & 0.01 & 0.011 & 0.013 \\
\hline * Alcantarilla con curvas, conexiones y algo de basuras. & 0.011 & 0.013 & 0.014 \\
\hline * Bien terminado. & 0.011 & 0.012 & 0.014 \\
\hline $\begin{array}{l}\text { * Alcantarillado de aguas residuales, con pozos de inspección, } \\
\text { entradas, etc., recto. }\end{array}$ & 0.013 & 0.015 & 0.017 \\
\hline * Sin pulir, formaleta y encofrado metálico. & 0.012 & 0.013 & 0.014 \\
\hline * Sin pulir, formaleta y encofrado en madera lisa. & 0.012 & 0.014 & 0.016 \\
\hline * Sin pulir, formaleta o encofrado en madera rugosa. & 0.015 & 0.017 & 0.02 \\
\hline \multicolumn{4}{|l|}{ e) Madera } \\
\hline * Machihembrada & 0.01 & 0.012 & \\
\hline * Laminada, tratada & 0.015 & 0.017 & \\
\hline \multicolumn{4}{|l|}{ f) Arcilla } \\
\hline * Canaleta común de baldosas. & 0.011 & 0.013 & 0.017 \\
\hline * Alcantarilla vitrificada. & 0.011 & 0.014 & 0.017 \\
\hline * Alcantarilla vitrificada con pozos de inspección, entradas, etc. & 0.013 & 0.015 & 0.017 \\
\hline
\end{tabular}


ANEXO 1: TABLAS (continuación)

Tabla 7. Valores de Manning para canales rectos y uniformes (Continuación).

\begin{tabular}{|c|c|c|c|}
\hline \multirow{3}{*}{\begin{tabular}{|l} 
Tipo de cauce y descripción \\
* Subdrenaje vitrificado con juntas abiertas.
\end{tabular}} & \multicolumn{3}{|c|}{ Valor de $n$} \\
\hline & \multirow{2}{*}{$\begin{array}{c}\text { Mínimo } \\
0.014\end{array}$} & \multicolumn{2}{|c|}{ Normal|Máximo } \\
\hline & & 0.016 & 0.018 \\
\hline \multicolumn{4}{|l|}{ g) Mampostería en ladrillo } \\
\hline Barnizada o lacada & 0.011 & 0.013 & 0.015 \\
\hline $\begin{array}{l}\text { h) Alcantarillados sanitarios recubiertos con limos y babas de } \\
\text { aguas residuales, con curvas y conexiones. }\end{array}$ & 0.012 & 0.013 & 0.016 \\
\hline i) Alcantarillado con batea pavimentada, fondo liso. & 0.016 & 0.019 & 0.02 \\
\hline j) Mampostería de piedra, cementada. & 0.018 & 0.025 & 0.03 \\
\hline \multicolumn{4}{|l|}{ B) Canales revestidos o desarmables } \\
\hline \multicolumn{4}{|l|}{ B1) Metal } \\
\hline \multicolumn{4}{|l|}{ a) Superficie lisa de acero } \\
\hline Sin pintar & 0.011 & 0.012 & 0.014 \\
\hline Pintada & 0.012 & 0.013 & 0.017 \\
\hline b) Corrugado & 0.021 & 0.025 & 0.03 \\
\hline \multicolumn{4}{|l|}{ B2) No metal } \\
\hline \multicolumn{4}{|l|}{ a) Cemento } \\
\hline Superficie pulida & 0.01 & 0.011 & 0.013 \\
\hline Mortero & 0.011 & 0.013 & 0.015 \\
\hline \multicolumn{4}{|l|}{ b) Madera } \\
\hline Cepillada, sin tratar. & 0.01 & 0.012 & 0.014 \\
\hline Cepillada, creosotada & 0.011 & 0.012 & 0.015 \\
\hline Sin cepillar & 0.011 & 0.013 & 0.015 \\
\hline Láminas con listones. & 0.012 & 0.015 & 0.018 \\
\hline Forrada con papel impermeabilizante & 0.01 & 0.014 & 0.017 \\
\hline \multicolumn{4}{|l|}{ c) Concreto } \\
\hline Terminado con llana metálica (palustre) & 0.011 & 0.013 & 0.015 \\
\hline Terminado con llana de madera & 0.013 & 0.015 & 0.016 \\
\hline Pulido, con gravas en el fondo & 0.015 & 0.017 & 0.02 \\
\hline Sin pulir. & 0.014 & 0.017 & 0.02 \\
\hline Lanzado, sección buena & 0.016 & 0.019 & 0.023 \\
\hline Lanzado, sección ondulada & 0.018 & 0.022 & 0.025 \\
\hline Sobre roca bien excavada & 0.017 & 0.02 & \\
\hline Sobre roca irregularmente excavada & 0.022 & 0.027 & \\
\hline \multicolumn{4}{|l|}{$\begin{array}{l}\text { d) Fondo de concreto terminado con llana de madera y con lados } \\
\text { de: }\end{array}$} \\
\hline Piedra labrada, en mortero. & 0.015 & 0.017 & 0.02 \\
\hline Piedra sin seleccionar, sobre mortero & 0.017 & 0.02 & 0.024 \\
\hline Mampostería de piedra cementada, recubierta & 0.016 & 0.02 & 0.024 \\
\hline Mampostería de piedra cementada & 0.02 & 0.025 & 0.03 \\
\hline
\end{tabular}


ANEXO 1: TABLAS (continuación)

Tabla 7. Valores de Manning para canales rectos y uniformes (Continuación).

\begin{tabular}{|c|c|c|c|}
\hline \multirow{2}{*}{ Tipo de cauce y descripción } & \multicolumn{3}{|c|}{ Valor de $n$} \\
\hline & Mínimo & Normal & Máximo \\
\hline Piedra suelta o riprap & 0.029 & 0.03 & 0.035 \\
\hline \multicolumn{4}{|l|}{ e) Fondo de gravas con lados de: } \\
\hline Concreto encofrado & 0.017 & 0.02 & 0.025 \\
\hline Piedra sin seleccionar, sobre mortero. & 0.02 & 0.023 & 0.026 \\
\hline Piedra suelta o riprap & 0.023 & 0.033 & 0.036 \\
\hline \multicolumn{4}{|l|}{ f) Ladrillo } \\
\hline * Barnizado o lacado & 0.011 & 0.013 & 0.015 \\
\hline * En mortero de cemento & 0.012 & 0.015 & 0.018 \\
\hline \multicolumn{4}{|l|}{ g) Mampostería } \\
\hline * Piedra partida cementada & 0.017 & 0.025 & 0.03 \\
\hline * Piedra suelta o riprap & 0.023 & 0.032 & 0.035 \\
\hline h) Bloques de piedra labrados & 0.013 & 0.015 & 0.017 \\
\hline \multicolumn{4}{|l|}{ i) Asfalto } \\
\hline * Liso & 0.013 & 0.013 & \\
\hline * Rugoso & 0.016 & 0.016 & \\
\hline j) Revestimiento vegetal & 0.03 & $\ldots$ & 0.5 \\
\hline \multicolumn{4}{|l|}{ C. Excavado o dragado } \\
\hline \multicolumn{4}{|l|}{ a) En tierra, recto y uniforme } \\
\hline * Limpio, recientemente terminado & 0.016 & 0.018 & 0.02 \\
\hline * Limpio, después de exposición a la intemperie. & 0.018 & 0.022 & 0.025 \\
\hline * Con gravas, sección uniforme, limpio. & 0.022 & 0.025 & 0.03 \\
\hline * Con pastos cortos, algunas malezas. & 0.022 & 0.027 & 0.033 \\
\hline \multicolumn{4}{|l|}{ b) En tierra, serpenteante y lento } \\
\hline * Sin vegetación. & 0.023 & 0.025 & 0.03 \\
\hline * Pastos, algunas malezas. & 0.025 & 0.03 & 0.033 \\
\hline * Malezas densas o plantas acuáticas en canales profundos. & 0.03 & 0.035 & 0.04 \\
\hline * Fondo en tierra con lados en piedra. & 0.028 & 0.03 & 0.035 \\
\hline * Fondo pedregoso y bancas con maleza. & 0.025 & 0.035 & 0.04 \\
\hline * Fondo en cantos rodados y lados limpios. & 0.03 & 0.04 & 0.05 \\
\hline \multicolumn{4}{|l|}{ c) Excavado con pala o dragado } \\
\hline * Si vegetación. & 0.025 & 0.028 & 0.033 \\
\hline * Matorrales ligeros en las bancas. & 0.035 & 0.05 & 0.06 \\
\hline \multicolumn{4}{|l|}{ d) Cortes en roca } \\
\hline * Lisos y uniformes. & 0.025 & 0.035 & 0.04 \\
\hline * Afilados e irregulares. & 0.035 & 0.04 & 0.05 \\
\hline e) Canales sin mantenimiento, malezas y matorrales sin co & & & \\
\hline
\end{tabular}


ANEXO 1: TABLAS (continuación)

Tabla 7. Valores de Manning para canales rectos y uniformes (Continuación).

\begin{tabular}{|c|c|c|c|}
\hline \multirow{2}{*}{ Tipo de cauce y descripción } & \multicolumn{3}{|c|}{ Valor de n } \\
\hline & Mínimo & Normal & Máximo \\
\hline * Malezas densas, tan altas como la profundidad del flujo. & 0.05 & 0.08 & 0.12 \\
\hline * Fondo limpio, matorrales en los lados. & 0.04 & 0.05 & 0.08 \\
\hline * Igual, nivel máximo del flujo. & 0.045 & 0.07 & 0.11 \\
\hline * Matorrales densos, nivel alto & 0.08 & 0.1 & 0.14 \\
\hline $\begin{array}{l}\text { D. Cauces naturales menores (ancho superior a nivel de crecida } \\
\text { menor que } 30 \mathrm{~m} \text { ) }\end{array}$ & & & \\
\hline D1) Cauces en planicie & & & \\
\hline 1) Limpio, recto, nivel lleno, sin fallas o pozos & & & \\
\hline Profundos & 0.025 & 0.03 & 0.033 \\
\hline 2) Igual que arriba pero más piedras y pastos & 0.03 & 0.035 & 0.04 \\
\hline 3) Limpio, curvado, algunos pozos y bancos & 0.033 & 0.04 & 0.045 \\
\hline 4) Igual que arriba pero algunos pastos y piedras & 0.035 & 0.045 & 0.05 \\
\hline 5) Igual que arriba, niveles más bajos, pendiente y & & & \\
\hline secciones más inefectivas & 0.04 & 0.048 & 0.055 \\
\hline 6) Igual que 4, pero más piedras & 0.045 & 0.05 & 0.06 \\
\hline 7) Tramos sucios, con pastos y pozos profundos & 0.05 & 0.07 & 0.08 \\
\hline $\begin{array}{l}\text { 8) Tramos con muchos pastos, pozos profundos o recorridos de la } \\
\text { crecida con mucha madera o arbustos bajos }\end{array}$ & 0.075 & 0.1 & 0.15 \\
\hline $\begin{array}{l}\text { D2) Cauces de montaña, sin vegetación en el canal, laderas con } \\
\text { pendientes usualmente pronunciadas, árboles y arbustos a lo largo de } \\
\text { las laderas y sumergidos para niveles altos }\end{array}$ & & & \\
\hline 1) Fondo: grava, canto rodado y algunas rocas & 0.03 & 0.04 & 0.05 \\
\hline 2) Fondo: canto rodado y algunas rocas & 0.04 & 0.05 & 0.07 \\
\hline E) Cauces con planicie crecida & & & \\
\hline 1) Pastos, sin arbustos & & & \\
\hline * Pastos cortos & 0.025 & 0.03 & 0.035 \\
\hline * Pastos altos & 0.03 & 0.035 & 0.05 \\
\hline 2) Áreas cultivadas & & & \\
\hline * Sin cultivo & 0.02 & 0.03 & 0.04 \\
\hline * Cultivos maduros alineados & 0.025 & 0.035 & 0.045 \\
\hline * Campo de cultivos maduros & 0.03 & 0.04 & 0.05 \\
\hline 3) Arbustos & & & \\
\hline * Arbustos escasos, muchos pastos & 0.035 & 0.05 & 0.07 \\
\hline * Pequeños arbustos y árboles, en invierno & 0.035 & 0.05 & 0.06 \\
\hline * Pequeños arbustos y árboles, en verano & 0.04 & 0.06 & 0.08 \\
\hline * Arbustos medianos a densos, en invierno & 0.045 & 0.07 & 0.11 \\
\hline * Arbustos medianos a densos, en verano & 0.07 & 0.1 & 0.16 \\
\hline
\end{tabular}




\section{ANEXO 1: TABLAS (continuación)}

Tabla 7. Valores de Manning para canales rectos y uniformes (Continuación).

4) Arboles

\begin{tabular}{|l|l|l|l|l|}
\hline * Sauces densos, en verano, y rectos & 0.11 & 0.15 & 0.2 \\
\hline * Tierra clara con ramas, sin brotes & 0.03 & 0.04 & 0.05 \\
\hline * Igual que arriba pero con gran crecimiento de brotes & 0.05 & 0.06 & 0.08 \\
\hline $\begin{array}{l}\text { * Grupos grandes de madera, algunos árboles caídos, poco crecimiento inferior y y } \\
\text { nivel de la inundación por debajo de las ramas }\end{array}$ & 0.08 & 0.1 & 0.12 \\
\hline * Igual que arriba, pero con el nivel de inundación alcanzando las ramas & 0.1 & 0.12 & 0.16 \\
\hline
\end{tabular}




\section{ANEXO 1: TABLAS (continuación)}

Tabla 8: Valores adicionales para el cálculo del coeficiente compuesto de Manning.

\begin{tabular}{|c|c|c|c|c|}
\hline Efecto & Factor & Condición & Valor & Comentario \\
\hline \multirow{4}{*}{$\begin{array}{l}\text { Irregularidad en la } \\
\text { sección recta }\end{array}$} & \multirow{4}{*}{$\mathrm{n}_{1}$} & Suave & 0 & Canal muy liso \\
\hline & & Pequeña & $0.001-0.005$ & Bancas algo erodadas \\
\hline & & Moderada & $0.006-0.010$ & Lecho y bancas rugosas \\
\hline & & Fuerte & $0.011-0.020$ & Bancas muy irregulares \\
\hline \multirow{3}{*}{ Variaciones en el cauce } & \multirow{3}{*}{$\mathrm{n}_{2}$} & Gradual & 0 & Cambios graduales \\
\hline & & $\begin{array}{c}\text { Alternado } \\
\text { ocasionalmente }\end{array}$ & $0.001-0.005$ & $\begin{array}{l}\text { Cambios ocasionales de } \\
\text { secciones pequeñas a } \\
\text { grandes }\end{array}$ \\
\hline & & $\begin{array}{c}\text { Alternando } \\
\text { frecuentemente }\end{array}$ & $0.010-0.015$ & $\begin{array}{l}\text { Cambios frecuentes en la } \\
\text { forma de la sección recta }\end{array}$ \\
\hline \multirow{4}{*}{ Obstrucciones } & \multirow{4}{*}{$\mathrm{n}_{3}$} & Despreciables & $0-0.004$ & $\begin{array}{l}\text { Obstrucción menor que el } \\
5 \% \text { de la sección recta }\end{array}$ \\
\hline & & Pocas & $0.005-0.015$ & $\begin{array}{l}\text { Obstrucción entre el } 5 \% \text { y } \\
\text { el } 15 \% \text { de la sección recta }\end{array}$ \\
\hline & & Algunas & $0.020-0.030$ & $\begin{array}{l}\text { Obstrucción entre el } 15 \% \\
\text { y el } 50 \% \text { de la sección }\end{array}$ \\
\hline & & Muchas & $0.040-0.060$ & $\begin{array}{l}\text { Obstrucción mayor que el } \\
50 \%\end{array}$ \\
\hline \multirow{4}{*}{ Vegetación } & \multirow{4}{*}{$\mathrm{n}_{4}$} & Poca & $0.002-0.010$ & $\begin{array}{l}\text { Profundidad del flujo } \\
\text { mayor que } 2 \text { veces la } \\
\text { altura de la vegetación }\end{array}$ \\
\hline & & Mucha & $0.010-0.025$ & $\begin{array}{l}\text { Profundidad del flujo } \\
\text { mayor que la altura de } \\
\text { vegetación }\end{array}$ \\
\hline & & Bastante & $0.025-0.050$ & $\begin{array}{l}\text { Profundidad del flujo } \\
\text { menor que la altura de } \\
\text { vegetación }\end{array}$ \\
\hline & & Excesiva & $0.050-0.100$ & $\begin{array}{l}\text { Profundidad del flujo } \\
\text { menor que } 0.5 \text { la altura de } \\
\text { la vegetación }\end{array}$ \\
\hline \multirow{3}{*}{ Sinuosidad } & \multirow{3}{*}{$\mathrm{n}_{5}$} & Pequeña & 1 & Sinuosidad $<1.2$ \\
\hline & & Media & 1.15 & $1.2<$ sinuosidad $<1.5$ \\
\hline & & Fuerte & 1.3 & Sinuosidad $>1.5$ \\
\hline
\end{tabular}


ANEXO 1: TABLAS (continuación)

Tabla 9: Valores de número de curva en condiciones normales de humedad antecedente. Adaptado de Mintegui Aguirre \& López Unzu (1990)

\begin{tabular}{|c|c|c|c|c|}
\hline \multirow{2}{*}{ Vegetación y uso del suelo } & \multicolumn{4}{|c|}{ Grupo hidrológico } \\
\hline & $\mathbf{A}$ & B & $\mathbf{C}$ & D \\
\hline Barbecho & 77 & 86 & 91 & 94 \\
\hline Cultivos alineados R P & 72 & 81 & 88 & 91 \\
\hline Cultivos alineados R B & 67 & 78 & 85 & 89 \\
\hline Cultivos alineados C P & 70 & 79 & 84 & 88 \\
\hline Cultivos alineados C B & 65 & 75 & 82 & 86 \\
\hline Cultivos alineados C-T P & 66 & 74 & 80 & 82 \\
\hline Cultivos alineados C-T B & 62 & 71 & 78 & 81 \\
\hline Cultivos no alineados o surcos pequeños R P & 65 & 76 & 84 & 88 \\
\hline Cultivos no alineados o surcos pequeños R B & 63 & 75 & 83 & 87 \\
\hline Cultivos no alineados o surcos pequeños C P & 63 & 74 & 82 & 85 \\
\hline Cultivos no alineados o surcos pequeños C B & 61 & 73 & 81 & 84 \\
\hline Cultivos no alineados o surcos pequeños C-T P & 61 & 72 & 79 & 82 \\
\hline Cultivos no alineados o surcos pequeños C-T B & 59 & 70 & 78 & 81 \\
\hline Cultivos densos leguminosas R P & 66 & 77 & 84 & 88 \\
\hline Cultivos densos leguminosas R B & 58 & 72 & 81 & 85 \\
\hline Cultivos densos leguminosas C P & 64 & 75 & 83 & 85 \\
\hline Cultivos densos leguminosas C B & 55 & 69 & 78 & 83 \\
\hline Cultivos densos leguminosas C-T P & 63 & 73 & 80 & 83 \\
\hline Cultivos densos leguminosas C-T B & 51 & 67 & 76 & 80 \\
\hline Matorral, mezcla matorral y maleza Cubierta $50 \%$ & 48 & 67 & 77 & 83 \\
\hline Matorral, mezcla matorral y maleza Cubierta $50-75 \%$ & 35 & 56 & 70 & 77 \\
\hline Matorral, mezcla matorral y maleza Cubierta $>75 \%$ & 30 & 48 & 65 & 73 \\
\hline Montes con pastos $\mathrm{P}$ & 45 & 66 & 77 & 83 \\
\hline Montes con pastos $\mathrm{M}$ & 36 & 60 & 73 & 79 \\
\hline Montes con pastos B & 25 & 55 & 70 & 77 \\
\hline Bosques MP & 56 & 75 & 86 & 91 \\
\hline Bosques P & 46 & 68 & 78 & 84 \\
\hline Bosques M & 36 & 60 & 70 & 76 \\
\hline Bosques B & 26 & 52 & 63 & 69 \\
\hline Bosques MB & 15 & 44 & 54 & 61 \\
\hline Prados permanentes & 30 & 58 & 71 & 78 \\
\hline Pastizal P & 68 & 79 & 86 & 89 \\
\hline Pastizal M & 49 & 69 & 79 & 84 \\
\hline Pastizal B & 39 & 61 & 74 & 80 \\
\hline Pastizal C P & 47 & 67 & 81 & 88 \\
\hline Pastizal C M & 25 & 59 & 75 & 83 \\
\hline Pastizal C B & 6 & 35 & 70 & 79 \\
\hline Residencial baja densidad & 54 & 70 & 80 & 85 \\
\hline Residencial alta densidad & 77 & 85 & 90 & 92 \\
\hline Superficies impermeables & 98 & 98 & 98 & 98 \\
\hline Espejos de agua & 0 & 0 & 0 & 0 \\
\hline
\end{tabular}

Referencias

$R$ Laboreo sin prácticas de conservación; C Curvas de nivel; C-T Curvas de nivel y Terrazas abiertas; MP Condición de infiltración muy pobres; $P$ Condición de infiltración pobres; $M$ Condición de infiltración mala; B Condición de infiltración buena; MB Condición de infiltración muy buena. 